\title{
Análise sismoestratigráfica das bacias de Barreirinhas e do Ceará como ferramenta para estudos paleoceanográficos no Cenozoico na Margem Equatorial Brasileira
}

Tese apresentada ao Instituto Oceanográfico da Universidade de São Paulo, como parte dos requisitos para obtenção do título de Doutor em Ciências, Programa de Oceanografia, área de Oceanografia Geológica.

Orientador: Prof. Dr. Luigi Jovane

São Paulo 


Alves, Daniel Pavani Vicente
Análise sismoestratigráfica das bacias de Barreirinhas e do Ceará como
ferramenta para estudos paleoceanográficos no Cenozoico na Margem Equato-
rial Brasileira / Daniel Pavani Vicente Alves. - São Paulo, 2018.
xvii, 116f.
Tese (doutorado) - Universidade de São Paulo. Instituto Oceanográfico. Pro-
grama de Pós-Graduação em Oceanografia Geológica.
Título em inglês: Seismic stratigraphic analysis of the Barreirinhas and Ce-
ara Basins as a tool to paleoceanographic studies on the Cenozoic of the Brazilian
Equatorial Margin.
1. Margem Equatorial Brasileira. 2. Paleoceanografia. 3. Paleoclimatologia.
4. Sismoestratigrafia. I. Luigi Jovane. II. Título.


Universidade de São Paulo

Instituto Oceanográfico

\title{
Análise sismoestratigráfica das bacias de Barreirinhas e do Ceará como ferramenta para estudos paleoceanográficos no Cenozoico na Margem Equatorial Brasileira
}

\author{
Daniel Pavani Vicente Alves
}

Tese apresentada ao Instituto Oceanográfico da Universidade de São Paulo, como parte dos requisitos para obtenção do título de Doutor em Ciências, Programa de

Oceanografia, área de Oceanografia Geológica.

Versão corrigida

Julgada em:

Conceito

$\operatorname{Prof}(a) \cdot \operatorname{Dr}(a)$.

Conceito

$\operatorname{Prof}(a) . \operatorname{Dr}(a)$.

Conceito

$\operatorname{Prof(a).~Dr(a).~}$

Conceito

Prof(a). Dr(a).

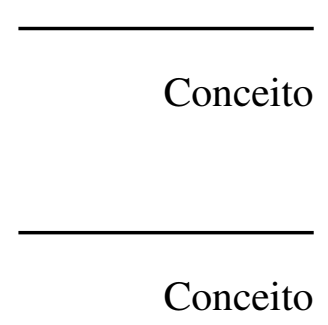

Prof(a). Dr(a).

Conceito 


\section{Conteúdo}

Agradecimentos $\quad$ xi

Resumo xii

$\begin{array}{ll}\text { Abstract } & \text { xiii }\end{array}$

1 Introdução 1

2 Hipótese científica $\quad 5$

3 Objetivos 6

4 Área de estudo $\quad 7$

4.1 Condições climáticas e oceanográficas atuais . . . . . . . . . . 8

$4.1 .1 \quad$ Rio Parnaíba . . . . . . . . . . . . . . . . . 11

4.1.2 Zona de Convergência Intertropical - ZCIT . . . . . . . . . . . 12

4.2 Evolução da MEB . . . . . . . . . . . . . . . . . . . . . . . . . . . 13

4.3 Bacias sedimentares . . . . . . . . . . . . . . 15

4.4 Variações relativas do nível do mar, subsidência e aporte sedimentar . . . 21 
5 Material e método 2

5.1 Considerações iniciais . . . . . . . . . . . . . . 26

5.2 Dados sísmicos e de poços . . . . . . . . . . . . . . . . 27

5.3 Aquisição e processamento . . . . . . . . . . . . . . . . . 34

5.3 .1 Edição e demultiplexação . . . . . . . . . . . . . . . . . 34

5.3.2 Compensação por espalhamento geométrico . . . . . . . . . . 35

5.3.3 Deconvolução para remoção da assinatura da fonte . . . . . . . . 35

5.3.4 Deconvolução de fase mínima . . . . . . . . . . . . . . 35

5.3.5 Agrupamento em famílias CDP . . . . . . . . . . 35

5.3.6 Determinação de velocidades de empilhamento . . . . . . . . . 36

5.3.7 Migração pré-empilhamento . . . . . . . . . . . . 36

5.3 .8 Empilhamento . . . . . . . . . . . . . . 37

5.3.9 Deconvolução pós-empilhamento . . . . . . . . . . . . . 37

5.3 .10 Migração . . . . . . . . . . . . . . . . . . . . 37

5.3.11 Filtros de banda . . . . . . . . . . . . . . . . . 37

5.3.12 Equalização de traços e ganho de sinal . . . . . . . . . . . . . 38

5.4 Amarração sísmica $x$ poço $\ldots \ldots \ldots \ldots$. . . . . . . . . . 38

5.4.1 Registro de densidade e velocidade do som . . . . . . . . . . 38

5.4.2 Extração da wavelet original e cálculo do traço sísmico sintético 39

5.5 Correlação entre os sismogramas sintético e original . . . . . . . . . . . . 40

5.6 Litologia e conversão tempo $x$ profundidade . . . . . . . . . . . . . 41

5.7 Análise dos perfis . . . . . . . . . . . . . . . . 45

5.8 Pós-processamento dos perfis sísmicos . . . . . . . . . . . . . . . . . . . 47

5.9 Cálculo de espessuras e taxas de sedimentação . . . . . . . . . . . . . . 49 
6.1 Sismofácies em detalhes nas seções sísmicas . . . . . . . . . . . . . . . 60

6.1 .1 Cânions .......................... 60

6.1.2 Bacias menores separadas por altos ............ 61

6.1.3 Espessuras influenciadas por montes submarinos . . . . . . . 61

6.1.4 Estruturas internas identificadas na sísmica . . . . . . . . . . . 62

6.2 Conversão tempo $x$ profundidade $\ldots \ldots \ldots \ldots$. . . . . . . 65

6.3 Horizonte $\mathrm{H} 1 \ldots \ldots \ldots \ldots 6$

6.4 Horizonte $\mathrm{H} 2 \ldots \ldots \ldots \ldots$. . . . . . . . . . . . . . 67

6.5 Horizonte $\mathrm{H} 3 \ldots \ldots \ldots \ldots$. . . . . . . . . . . . . . . 68

6.6 Horizonte $\mathrm{H} 4 \ldots \ldots \ldots$. . . . . . . . . . . . . . . . 69

6.7 Horizonte H5 . . . . . . . . . . . . . . . 70

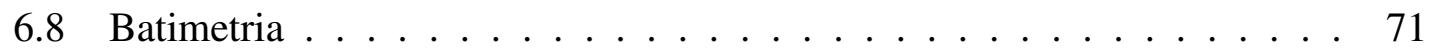

6.9 Unidade Cronoestratigráfica 1 - Paleoceno . . . . . . . . . . . . . . 72

6.10 Unidade Cronoestratigráfica 2 - Eoceno . . . . . . . . . . . . . . 72

6.11 Unidade Cronoestratigráfica 3 - Oligoceno/Mioceno . . . . . . . . . . 73

6.12 Unidade Cronoestratigráfica 4 - Mioceno Inferior/Médio . . . . . . . . 73

6.13 Unidade Cronoestratigráfica 5 - Mioceno Médio até presente . . . . . . . 74

6.14 Divisão em fases . . . . . . . . . . . . . . . . . . 76

6.15 Espessuras do Paleógeno e do Neógeno . . . . . . . . . . . . . 78

6.16 Taxas de sedimentação para o Paleógeno e Neógeno . . . . . . . . . . . . 81 
7 Discussão

7.1 Sedimentação . . . . . . . . . . . . . . . . . . . . . . 84

7.1.1 Sedimentação no Paleógeno . . . . . . . . . . . . . . . 84

7.1.2 Sedimentação no Neógeno . . . . . . . . . . . . . . 85

7.2 Paleocirculação . . . . . . . . . . . . . . . . . 86

7.2.1 O papel da Cordilheira Norte Brasileira . . . . . . . . . . . . 90

7.3 Paleoclima, paleoceanografia e taxas de sedimentação . . . . . . . . . . 92

7.3.1 Paleoclima e sedimentação no Paleógeno . . . . . . . . . . . 93

7.3.2 Paleoclima e sedimentação no Neógeno e Quaternário . . . . . . 95

8 Conclusões $\quad 99$

$\begin{array}{ll}\text { Referências } & 103\end{array}$

$\begin{array}{lr}\text { Apêndices } & 115\end{array}$ 


\section{Lista de Figuras}

1 Paleomapa da MEB . . . . . . . . . . . . . . . . . 4

2 Área de estudo . . . . . . . . . . . . . . . 7

3 Correntes no Atlântico Sul . . . . . . . . . . . . . . . . . 9

4 Bacia do Rio Parnaíba . . . . . . . . . . . . . . 11

5 Carta estratigráfica da Bacia Potiguar . . . . . . . . . . . . . . . . 16

6 Carta estratigráfica da Bacia do Ceará . . . . . . . . . . . . . . . 18

7 Carta estratigráfica da Bacia de Barreirinhas . . . . . . . . . . . . 20

8 Fatores de influência no volume de água . . . . . . . . . . . . . . . . 22

9 Curva de variação do nível relativo do mar . . . . . . . . . . . . . . . . . 24

10 Mapa das linhas sísmicas obtidas . . . . . . . . . . . . . . . . . . . 29

11 Registro do poço MAS-35 . . . . . . . . . . . . . 31

12 Registro do poço CES-112 . . . . . . . . . . . . . . . . 32

13 Cronoestratigrafia do poço CES-112 . . . . . . . . . . . 33

14 Extração da wavelet do dado sísmico . . . . . . . . . . . . . . . . . . 39

15 Painel de amarração sísmica x poço . . . . . . . . . . . . . . . 40

16 Correlação de picos para amarração . . . . . . . . . . . . . . . . 41

17 Trecho do perfil composto do poço CES-112 . . . . . . . . . . . . . . 42

18 Trecho do perfil composto do poço CES-112, indicando amostras de VSP 42

19 Diferença de processamentos pós-empilhamento . . . . . . . . . . . 45 
20 Tipos de terminações de refletores . . . . . . . . . . . . . . . 46

21 Exemplo de pós-processamentos aplicados aos dados sísmicos . . . . . . 48

22 Exemplo do uso da janela fantasma . . . . . . . . . . . . . . . . . . . 49

23 Poço CES-112 sobre linha sísmica . . . . . . . . . . . . . . 53

24 Carta estratigráfica da Bacia do Ceará com horizontes sísmicos interpretados 54

25 Seção sísmica da linha LEPLAC-501 . . . . . . . . . . . . . . . . 56

26 Seção sísmica da linha 0231-MUNDAU-16A.0231-1158.MIG-FIN.7 . . . 57

27 Seção sísmica da linha LEPLAC-502 . . . . . . . . . . . . . . . 58

28 Seção sísmica da linha LEPLAC-513 . . . . . . . . . . . . . . . . . . . 58

29 Mapa de posições dos horizontes mapeados . . . . . . . . . . . . . . 59

30 Detalhe da presença de canais da plataforma continental . . . . . . . . 60

31 Detalhe de bacias menores na Bacia do Ceará . . . . . . . . . . . . . 62

32 Diferenças de espessuras influenciadas por montes submarinos . . . . . 63

33 Terminações em onlap dos horizontes H3, H4 e H5 na Bacia de Barreirinhas 64

34 Seção sísmica completa da Linha LEPLAC-502 . . . . . . . . . . . . . . 64

35 Mapa de espessuras do horizonte $\mathrm{H} 1 \ldots \ldots 66$

36 Mapa de espessuras do horizonte $\mathrm{H} 2 \ldots \ldots$. . . . . . . . . . 67

37 Mapa de espessuras do horizonte $\mathrm{H} 3 \ldots \ldots$. . . . . . . . . . . . 68

38 Mapa de espessuras do horizonte H4 . . . . . . . . . . . . . . . . . . 69

39 Mapa de espessuras do horizonte H5 . . . . . . . . . . . . . 70 
40 Mapa batimétrico das bacias do Ceará e Barrerinhas . . . . . . . . . . . . 71

41 Sismofácies das unidades cronoestratigráficas . . . . . . . . . . . 75

42 Carta estratigráfica da Bacia do Ceará com horizontes sísmicos interpretados 77

43 Mapa de espessuras do Paleógeno . . . . . . . . . . . . . . . . . . . 79

44 Mapa de espessuras do Neógeno e Quaternário . . . . . . . . . . . . . 79

45 Mapa de espessuras do Cenozoico . . . . . . . . . . . . . . . 80

46 Taxas de sedimentação para o Paleógeno . . . . . . . . . . . . . . . . . 81

47 Taxas de sedimentação para o Neógeno . . . . . . . . . . . . . . 82

48 Principais correntes atuando na MEB atualmente . . . . . . . . . . . 87

49 Paleocirculação no Oceano Atlântico . . . . . . . . . . . . . . . . . . . . 89

50 Circulação na costa brasileira, na isóbata de 1900 metros . . . . . . . . . 91

51 Evolução climática ao longo do Cenozoico . . . . . . . . . . . . . . . . 93

52 Seção sísmica da linha ANP 0073-NORDESTE-5A-SEGMENTO 0073-

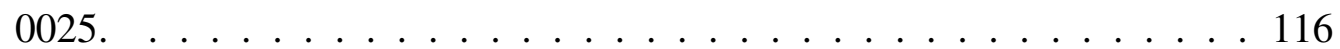

53 Seção sísmica da linha ANP 0073-NORDESTE-5A-SEGMENTO 00730025, interpretada. . . . . . . . . . . . . . . 117

54 Seção sísmica da linha ANP 0073-NORDESTE-5A SEGMENTO-0073-

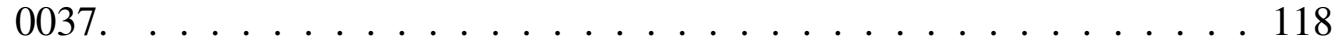

55 Seção sísmica da linha ANP 0073-NORDESTE-5A-SEGMENTO 00730037, interpretada. . . . . . . . . . . . . . . . 119

56 Seção sísmica da linha ANP R0003-GRAND-NORTH 02220479 FIN11. 120 
57 Seção sísmica da linha ANP R0003-GRAND-NORTH 02220479 FIN11, interpretada. . . . . . . . . . . . . . . . 121

58 Seção sísmica da linha ANP R0003-GRAND-NORTH 02220489 FIN12. 122

59 Seção sísmica da linha ANP R0003-GRAND-NORTH 02220489 FIN12, interpretada. . . . . . . . . . . . . . . . . 123

60 Seção sísmica da linha ANP 0231-MUNDAU 16A 02311106 MI FIN6. . 124

61 Seção sísmica da linha ANP 0231-MUNDAU 16A 02311106 MIG FIN6, interpretada. . . . . . . . . . . . . . . . . 125

62 Seção sísmica da linha ANP 0231-MUNDAU 16A 02311158 MIG FIN7. 126

63 Seção sísmica da linha ANP 0231-MUNDAU 16A 02311158 MIG FIN7, interpretada. . . . . . . . . . . . . . . . . . 127

64 Seção sísmica da linha ANP 0231-MUNDAU 16A 0231 1170 MIG FIN8. 128

65 Seção sísmica da linha ANP 0231-MUNDAU 16A 02311170 MIG FIN8, interpretada. . . . . . . . . . . . . . . . . . . . . 129

66 Seção sísmica da linha ANP 0239-BARREIRINHAS-6A 02390240 MIG FIN1. . . . . . . . . . . . . . . . . . 130

67 Seção sísmica da linha ANP 0239-BARREIRINHAS-6A 02390240 MIG FIN1, interpretada. . . . . . . . . . . . . . . . . . 131

68 Seção sísmica da linha ANP 0239-BARREIRINHAS-6A 02390243 MIG

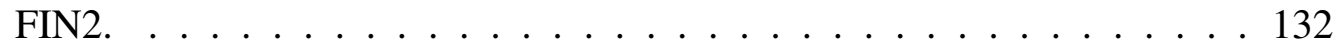

69 Seção sísmica da linha ANP 0239-BARREIRINHAS-6A 02390243 MIG FIN2, interpretada. . . . . . . . . . . . . . . . . 133

70 Seção sísmica da linha ANP R0003-GRAND-NORTH 02390207 MIG FIN9. . . . . . . . . . . . . . . . . . . . . 134 
71 Seção sísmica da linha ANP R0003-GRAND-NORTH 02390207 MIG

FIN9, interpretada. . . . . . . . . . . . . . . . . 135

72 Seção sísmica da linha LEPLAC 1501. . . . . . . . . . . . . . . . 136

73 Seção sísmica da linha LEPLAC 1 501, interpretada. . . . . . . . . . . . 137

74 Seção sísmica da linha LEPLAC $1502 \ldots$. . . . . . . . . . . . . . . 138

75 Seção sísmica da linha LEPLAC 1 502, interpretada. . . . . . . . . . . . 139

76 Seção sísmica da linha LEPLAC 1503. . . . . . . . . . . . . . . . . 140

77 Seção sísmica da linha LEPLAC 1 503, interpretada. . . . . . . . . . . . 141

78 Seção sísmica da linha LEPLAC 1504 . . . . . . . . . . . . . . . . . . 142

79 Seção sísmica da linha LEPLAC 1 504, interpretada. . . . . . . . . . . . 143

80 Seção sísmica da linha LEPLAC 1513. . . . . . . . . . . . . . . . . . 144

81 Seção sísmica da linha LEPLAC 1 513, interpretada. . . . . . . . . . . 145

82 Seção sísmica da linha LEPLAC 1505. . . . . . . . . . . . . . . . . 146

83 Seção sísmica da linha LEPLAC 1 505, interpretada. . . . . . . . . . . . 147

84 Seção sísmica da linha LEPLAC 1506. . . . . . . . . . . . . . . . . 148

85 Seção sísmica da linha LEPLAC 1 506, interpretada. . . . . . . . . . . . . 149

86 Seção sísmica da linha LEPLAC 1507 . . . . . . . . . . . . . . . 150

87 Seção sísmica da linha LEPLAC 1 507, interpretada. . . . . . . . . . . . 151

88 Seção sísmica da linha LEPLAC 1508. . . . . . . . . . . . . . . . . . 152

89 Seção sísmica da linha LEPLAC 1 508, interpretada. . . . . . . . . . . 153 


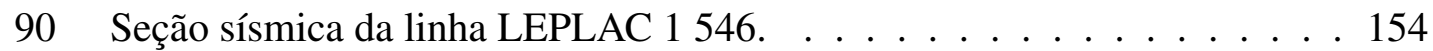

91 Seção sísmica da linha LEPLAC 1 546, interpretada. . . . . . . . . . . 155

92 Seção sísmica da linha LEPLAC 1548 . . . . . . . . . . . . . . . . . . 156

93 Seção sísmica da linha LEPLAC 1 548, interpretada. . . . . . . . . . . . 157

94 Seção sísmica da linha LEPLAC 1549 . . . . . . . . . . . . . . . . . 158

95 Seção sísmica da linha LEPLAC 1 549, interpretada. . . . . . . . . . . . 159

96 Seção sísmica da linha LEPLAC 1550 . . . . . . . . . . . . . . . . . 160

97 Seção sísmica da linha LEPLAC 1 550, interpretada. . . . . . . . . . . . . 161

98 Seção sísmica da linha LEPLAC 2 S8-SEQ-192 . . . . . . . . . . . . . . 162

99 Seção sísmica da linha LEPLAC 2 S8-SEQ-192, interpretada. . . . . . . 163

\section{Lista de Tabelas}

1 Relação das linhas sísmicas e dados de poços obtidos junto à ANP e à DHN, indicando seu nome, comprimento e bacia a que pertence. . . . . . 30

2 Parâmetros de aquisição utilizados durante os levantamentos do LEPLAC. 34

3 Relação dos valores de tempo obtidos pela ferramenta VSP no poço CES-

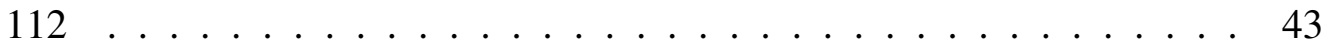

4 Valores de duração (em milhões de anos) utilizados para o cálculo das taxas de sedimentação. . . . . . . . . . . . . . . . . . 50

5 Valores de velocidade de propagação do som aplicados para a conversão tempo x profundidades nos dados sísmicos, definidos para cada unidade cronoestratigráfica. . . . . . . . . . . . . . . 65 


\section{Agradecimentos}

Esta tese é fruto de quatro anos de trabalho, acompanhado de muitas e diversas coisas que marcaram talvez a época das maiores mudanças da minha vida adulta. Ele é resultado não apenas do meu trabalho e esforço, mas também de diversas pessoas envolvidas na minha vida pessoal, profissional e acadêmica. Sendo assim, não é justo nem razoável que eu deixe de agradecer a cada uma destas pessoas.

Em primeiro lugar, meu pai Jair e minha mãe Rosa, por todo o apoio desde os primeiros passos da minha educação. Por sempre se empenharem por mim e me darem condições de alcançar o que alcanço agora.

A meu orientador e amigo, Prof. Dr. Luigi Jovane, que me acolheu num momento de dúvidas, lá em 2013; que me entendeu quando desisti de fazer este doutorado fora do país; que entendeu minha falta de tempo em diversos momentos; e que sempre me motivou a fazer o melhor - que ele sabia que sou capaz.

A meu segundo orientador, Prof. Dr. Jorge Figueiredo, pelos inúmeros e gigantescos ensinamentos na área de sismoestratigrafia, sem os quais nada disso poderia ter dado certo.

À minha esposa, Luciana, por me ajudar a ler, revisar e melhorar textos, figuras e mapas, além de apoiar muito mais do que se pode imaginar as minhas muitas horas de trabalhos nas madrugadas e finais de semana para que este trabalho viesse à tona.

Aos amigos do laboratório que, ainda que eu tenha passado boa parte do tempo distante, sempre proporcionaram ótimas conversas, campos e reuniões. Em especial, ao Max e ao Gabriel, meus bons amigos.

Aos amigos da SALT, pela compreensão e apoio durante estes 4 anos.

Aos amigos da vida, pelas horas de descontração, pelas cervejas, pelas conversas, pelas tretas, pelos casamentos, pelas festas e bloquinhos de Carnaval.

Finalmente, à CAPES, pelo apoio financeiro e ao Instituto Oceanográfico da Universidade de São Paulo pelo apoio educacional.

Enfim, obrigado a todos! 


\section{Resumo}

A Margem Equatorial Brasileira (MEB) é uma área de extrema importância para os estudos paleoceanográficos e paleoclimáticos do Atlântico Equatorial, mas que ainda possui um vasto campo para pesquisa. Este trabalho visa aprimorar a compreensão desta importante região, fornecendo uma interpretação paleoceanográfica para a evolução sedimentar das Bacias do Ceará e de Barreirinhas no Cenozoico, a partir de uma análise sismoestratigráfica. Foram analisadas linhas de sísmica multicanal e informações de poços de exploração petrolífera para a construção de um modelo de evolução deposicional para as duas bacias. Este modelo foi criado a partir da análise dos registros sísmicos e de técnicas de sismoestratigrafia e mapeamento de horizontes. Como resultados, identificaram-se cinco marcadores cronoestratigráficos e definiram-se duas fases distintas: (1) o Paleógeno e (2) o Neógeno + Quaternário. Durante o Paleógeno, a sedimentação passa a ter maior influência oceânica, com a sedimentação de desenvolvendo em um clima quente e úmido, e ainda controlada por uma circulação de superfície e de fundo ainda muito restritas. Durante o Neógeno e Quaternário, a Corrente Norte do Brasil (CNB) e a Corrente de Contorno Oeste Profunda passaram a atuar efetivamente na MEB, remobilizando os sedimentos e erodindo os depósitos de águas profundas. Durante este período, foi também possível identificar o efeito das variações climáticas no aporte sedimentar nas bacias e na circulação, principalmente com enfraquecimento da CNB e da Célula de Revolvimento Meridional do Atlântico.

Palavras-chave: Margem Equatorial Brasileira, paleoceanografia, paleoclimatologia, sismoestratigrafia 


\section{Abstract}

The Brazilian Equatorial Margin (BEM) is an area of extreme importance for the paloceanography and paleoclimatology of the South Atlantic although still with a wide field for research. The scope of this work is improve the comprehension of this important region, with the paleoceanographic interpretation for the sedimentary evolution of the Ceará and Barreirinhas basins in the Cenozoic through a seismic stratigraphic approach. Multichannel seismic lines and bore hole geophysical data were analyzed to the construction of a depositional model for both basins. This model was created using seismic stratigraphy and horizon mapping techniques. As results, five chronostratigraphical markers were identified and two distinct phases defined: (1) Paleogene and (2) Neogene + Quaternary. During the Paleogene, the sedimentation became more controlled by marine influence, developing in a time of warm and humid climate and surface and bottom currents still incipient. During the Neogene and Quaternary, the North Brazil Current (NBC) and the Deep Western Boundary Current became more important in the sediment transport, erosion and rework in the BEM. During this period, it was also possible to identify the climatic changes effect on the sediment supply for both basins, and also the paleocirculation variations, especially with the weakening of the NBC and the Atlantic Meridional Overturning Circulation.

Keywords: Brazilian Equatorial Margin, paleoceanography, paleoclimatology, sismoestratigraphy 


\section{Introdução}

As bacias sedimentares da Margem Equatorial Brasileira (MEB) não apenas acumularam sedimentos desde sua formação a partir do Eocretáceo, mas também foram palco de processos tectônicos que transformaram os depósitos sedimentares. Posicionadas há pelo menos 100 milhões de anos em uma região de clima equatorial, as bacias sedimentares de Barreirinhas e do Ceará registraram em seus conteúdos litológicos os resultados das variações climáticas de toda a era Cenozóica sob esta condição equatorial.

Reconstruções das variações paleoclimáticas e paleoceanográficas do Paleógeno e Neógeno se tornaram cada vez mais importantes e precisas durante as últimas décadas e passaram ser usadas como analogias para auxiliar na predição dos efeitos climáticos e ambientais do atual processo de aquecimento global. Exemplos desse uso é a reconstrução paleoceanográfica do Neotetis no Eoceno/Oligoceno em relação às fases tectônicas feitas por Jovane et al. (2009) e também as reconstruções dos ciclos de carbono descritas por Zachos et al. (2008). Avanços nestes estudos foram favorecidos principalmente pela exploração das seções sedimentares depositadas em águas profundas e ultra-profundas por meio de perfurações de poços executadas pelo IODP - International Ocean Drilling Program, responsável pela obtenção de testemunhos sedimentares para estudos acadêmicos em todos os oceanos.

A evolução dos estudos não se deve apenas às amostragens diretas de rochas recuperadas em poços do IODP, mas também à aquisição de dados indiretos, principalmente da indústria do petróleo, entre os quais destaca-se a aquisição sísmica de reflexão em bacias sedimentares de margens continentais.

As pesquisas na margem continental do norte e nordeste brasileiro começaram na década de 1960, com sondagens e levantamentos geofísicos ligados à indústria do petróleo, sobretudo com interesse em sua estratigrafia. No entanto, as características estruturais da crosta Pré-Cambriana e as distensões Neocomianas ainda permanecem incertas (Castro et al., 2012). Além disso, os levantamentos sísmicos e os poços de exploração na MEB realizados pela Petrobras (ou empresas concessionárias) concentram-se principalmente na plataforma continental. 
No Brasil, além da indústria do petróleo, a Marinha do Brasil também trabalha na aquisição de dados geofísicos da margem continental. Dada a pouca quantidade de dados e informações sobre estas regiões, há algumas décadas, após a assinatura e ratificação da Convenção das Nações Unidas sobre o Direito do Mar (CNUDM), nos anos 1980 e 1990, a Marinha, por meio da Diretoria de Hidrografia e Navegação (DHN), passou a realizar levantamentos geofísicos mais completos em toda a plataforma continental brasileira (projeto LEPLAC), com linhas sísmicas extensas, atingindo até mesmo as proximidades da dorsal meso-oceânica (Souza, 1999).

O acesso a estas informações é fundamental para os estudos sismoestratigráficos, dado o alto custo de se adquirir dados deste tipo na academia. Toda a sísmica feita em território brasileiro (continental ou marinho) com mais de 10 anos de adquirida é considerada pública e encontra-se disponível para pesquisa no banco de dados da Agência Nacional do Petróleo (ANP). Já os dados adquiridos pela marinha do Brasil encontram-se disponíveis para pesquisa acadêmica na Diretoria de Hidrografia e Navegação da Marinha do Brasil.

A sísmica de reflexão profunda é uma ferramenta que permite ao pesquisador identificar desde registros de eventos tectônicos até as variações no padrão deposicional nas bacias sedimentares. Por sua vez, a Estratigrafia de Sequências é uma ferramenta da Geologia para o estudo das sequências deposicionais em bacias sedimentares. Este tipo de análise começou a ser realizado em afloramentos, porém, a análise de dados geofísicos (notadamente perfis de gamma ray e sônico, que fornecem informações sobre as características litológicos das seções sedimentares atravessadas por poços), possibilitaram a correlação ou "amarração" entre poço e sísmica, o que culminou na Sismoestratigrafia. O uso da Estratigrafia de Sequências se mostra efetivo para o estudo da história sedimentar e, após interpretação, da possível história climática da MEB. Isto porque diversos locais da margem apresentam boa preservação da coluna sedimentar (Trosdtorf Junior et al., 2007), sendo possível traçar períodos bastante antigos da história deposicional das bacias.

Com este trabalho, pretende-se contribuir com os incipientes estudos paleoclimáticos e paleoceanográficos na MEB com a reconstrução da história oceanográfica da porção central da MEB (bacias de Barreirinhas e Ceará) no Cenozoico, por meio de sua análise sismoestratigráfica. As correntes de superfície e de fundo possuem papel essencial 
na distribuição de sedimentos nas duas bacias, assim como seu relevo. Espera-se entender o papel das correntes e das feições morfológicas, principalmente aquelas relacionadas à Cordilheira Norte Brasileira, na distribuição e acúmulo de sedimentos nas bacias do Ceará e Barreirinhas.

Variações climáticas geradas por oscilações térmicas na atmosfera e águas oceânicas, bem como na posição da Zona de Convergência Intertropical e na intensidade da Célula de Revolvimento Meridional do Atlântico também são analisadas, já que estas oscilações têm influência direta no regime de ventos da região e na atuação da Corrente Norte do Brasil.

A incipiência dos estudos paleoceanográficos do Cenozoico na região fica mais evidente quando comparados com os estudos de épocas mais recentes, com trabalhos sobre a evolução do clima na Margem Equatorial Brasileira, bem mais desenvolvidos e diversos para o Holoceno, como Colinvaux et al. (1996), Maslin e Burns (2000), Behling e da Costa (2001), Pessenda et al. (2001), Turcq et al. (2002), Chiessi et al. (2014), Zhang et al. (2011) e Zhang et al. (2015).

Uma das características mais importantes da MEB que lhe concede importância para a paleoceanografia é sua posição latitudinal ao longo do Cenozoico. A Figura 1 mostra a reconstrução da posição dos continentes no globo, ao longo dos últimos 100 milhões de anos, feitos com base no trabalho de Scotese e Golonka (1997). A posição relativamente constante da MEB desde o início do processo de abertura do Atlântico Equatorial possibilita que ela ofereça bons registros das variações paleoceanográficas e paleoclimáticas, já que, excluídas as variações latidunidais - como aquelas sofridas pelo continente Antártico em outros períodos, por exemplo - podemos supor que toda variação climática aferida nos registros sedimentares representam as condições reais da região Equatorial ao longo do tempo.

Diferente de trabalhos que utilizam dados de testemunhos (Wagner (2002); Santos et al. (2014); Nace et al. (2014); e Krauspenhar et al. (2014), entre outros), neste trabalho serão utilizados dados sísmicos que, apesar de indiretos, possibilitam uma cobertura muito mais ampla da área para estudos regionais. E, para amarrar os dados sísmicos, serão utilizadas informações de poços de exploração, com as quais dados sedimentares e estratigráficos serão relacionados com os dados acústicos. 

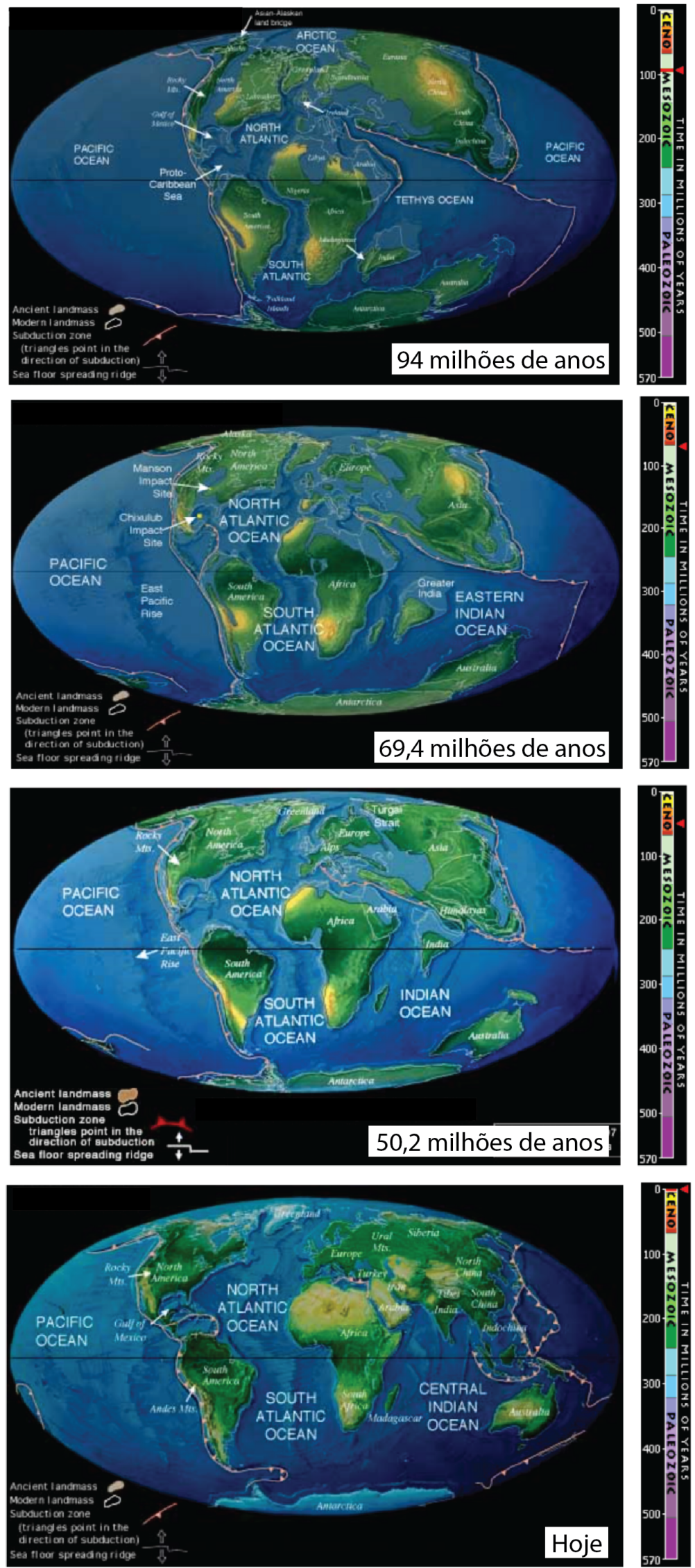

Figura 1: Paleomapa mostrando o posicionamento latitudinalmente quase constante da MEB nos últimos 100 milhões de anos. Imagens da USGS, baseadas no Projeto Paleomap (Scotese e Golonka, 1997). 


\section{Hipótese científica}

Antes do fechamento da passagem Central América Seaway (CAS, ou o Istmo do Panamá) e do estabelecimento da Célula de Revolvimento Meridional do Atlântico (AMOC, na sigla em inglês), a distribuição dos sedimentos na Margem Equatorial Brasileira (MEB) era controlada pela Água Superior do Pacífico, que os transportava para sudeste, rumo o Atlântico Sul.

A circulação de fundo no Atlântico Sul e Equatorial se estabeleceu apenas no Mioceno, quando o resfriamento do planeta permitiu a formação da Corrente de Contorno Oeste Profunda (CCOP), que passou a transportar a Água Profunda do Atlântico Norte (APAN) até o Atlântico Sul. Essa corrente profunda atuou no transporte sedimentar de fundo para sudeste, aprisionando os sedimentos junto aos montes submarinos da Cordilheira Norte Brasileira.

Desta forma, a hipótese deste trabalho é que a MEB dos últimos 66 milhões de anos pode ser dividida em dois momentos bastantes distintos:

1. Paleógeno: clima quente e úmido no continente, com características do Cretáceo, com relevante aporte sedimentar terrígeno. No oceano, ainda não havia circulação de fundo efetiva e a sedimentação se dava de forma mais espalhada pelas bacias, com os sedimentos sendo transportados para sudeste pela Água Superior do Pacífico.

2. Neógeno e Quaternário: clima mais frio, com diminuição gradual e global do nível do mar. A sedimentação passa a ocorrer mais próxima à plataforma e talude continentais, já que a circulação de fundo passa a ser mais eficiente com a CCOP, com o transporte de sedimentos de fundo para sudeste, aprisionando-os junto aos montes submarinos da Cordilheira Norte Brasileira. Há ainda o início da atuação da Corrente Norte do Brasil, levando a carga sedimentar em suspensão para noroeste, porém, com sua atuação fortemente influenciada pelas variações climáticas e de posição da Zona de Convergência Intertropical (ZCIT). 


\section{Objetivos}

O conhecimento das características oceanográficas da Margem Equatorial Brasileira fornece subsídio para estudos paleoclimáticos na região equatorial brasileira, tanto no continente quanto no oceano. Por conta de sua formação, as bacias sedimentares da MEB possuem diversas falhas e descontinuidades. Entretanto, as bacias do Ceará e de Barreirinhas fornecem colunas sedimentares espessas o suficiente para o desenvolvimento deste tipo de estudo. A Bacia de Barreirinhas, pela presença de formações carbonáticas em seu registro, fornece importantes informações sobre as variações na sedimentação e no clima da MEB.

Sendo assim, o objetivo principal deste trabalho é compreender a evolução e as variações paleoceanográficas nas Bacias do Ceará e de Barreirinhas, contribuindo para os incipientes estudos paleoclimáticos na região.

Este objetivo principal pode ser detalhado em objetivos específicos, definidos a seguir:

- Descrever a evolução sedimentar da fase pós-rifte das bacias de Barreirinhas e do Ceará, buscando um modelo da evolução deposicional que resultou em seu preenchimento.

- Compreender como a presença de montes submarinos e a Cordilheira Norte Brasileira contribuíram para o controle da sedimentação e para as mudanças nas características oceanográficas.

- Definir uma relação entre horizontes sísmicos e eventos climáticos e oceanográficos marcantes e as diferenças nas respostas das duas bacias sedimentares da área de estudo.

- Compreender e explicar o papel da circulação de superfície e de fundo na região equatorial brasileira na distribuição dos sedimentos terrígenos e no preenchimento das duas bacias. 


\section{4 Área de estudo}

A Margem Equatorial Brasileira (MEB) é uma margem transformante posicionada a latitudes praticamente constantes nos últimos 100 milhões de anos (Fig. 1). As duas bacias analisadas neste trabalho possuem colunas sedimentares com espessuras contínuas nas regiões de bacia profunda, sobre crosta oceânica, as quais podem conter registros de eventos climáticos desde o Neocretáceo (Trosdtorf Junior et al., 2007; Condé et al., 2007).

A MEB (Fig. 2) inclui os estados brasileiros mais próximos ao Equador, tendo início no estado do Rio Grande do Norte, a partir do Alto de Touros, estendendo-se até o estado do Amapá. Sua porção oriental (bacias de Potiguar e Ceará) teve origem no processo de estiramento crustal fortemente influenciado por movimentos laterais, que culminou com uma fase sin-transformante, entre o Albiano e Aptiano no Eocretáceo (Matos, 2000), no que se conhece como Província Borborema (Almeida et al., 1977).

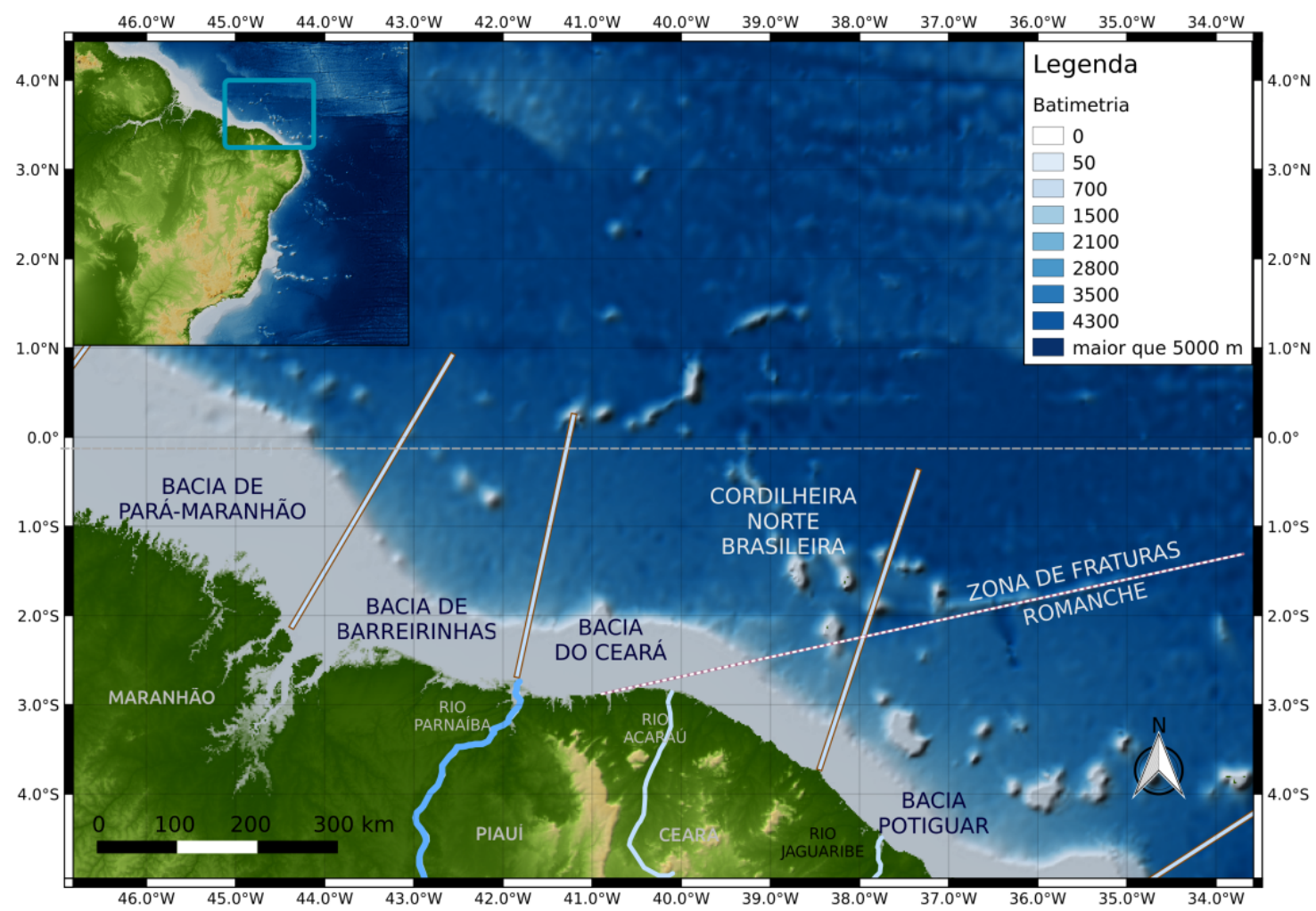

Figura 2: Margem Equatorial Brasileira, com destaque às bacias sedimentares de Pará-Maranhão, Barreirinhas, Ceará e Potiguar; destaque também à Zona de Fraturas Romanche e à Cordilheira Norte Brasileira. 
A área de estudo deste trabalho (Fig. 2) é composta por trechos da Bacia Potiguar, do Ceará e de Barreirinhas. As linhas sísmicas analisadas aqui estão distribuídas aproximadamente entre $34,5^{\circ}$ e $43,8^{\circ} \mathrm{W}$ e $4^{\circ} \mathrm{S}$ e $3^{\circ} \mathrm{N}$.

Uma das feições mais proeminentes do relevo da região é a Cordilheira Norte Brasileira (Hayes e Ewing, 1970; Houtz et al., 1977), que consiste numa série de montes submarinos, grosseiramente alinhados com os lineamentos das zonas de fraturas São Paulo e Romanche (Fig. 2). Além de influências na circulação de fundo (Dengler et al., 2004), esta cadeia de montanhas ainda parece ter atuado como anteparo aos sedimentos até o Mioceno Inferior (Martins e Coutinho, 1981).

\subsection{Condições climáticas e oceanográficas atuais}

Durante sua formação, a MEB passou por eventos tectônicos e oceanográficos que ajudaram a definir suas características atuais. As variações climáticas que ocorreram durante o Mesozoico e, principalmente, o Cenozoico, também contribuíram para o transporte e sedimentação na plataforma continental brasileira em formação.

Atualmente, a plataforma continental da MEB possui larguras que variam entre cerca de $30 \mathrm{~km}$ em Cabo de São Roque (RN), até mais de $300 \mathrm{~km}$ na foz do Rio Amazonas (Martins e Coutinho, 1981). A menor largura na porção leste da MEB é consequência da conformidade das bacias em relação a linha de costa e da ausência de grandes rios, o que implica no atual baixo aporte sedimentar terrígeno na região. Depois de chegar nos oceano, a maior parte dos sedimentos modernos são transportados até a porção oeste da MEB (Bacias de Pará-Maranhão e Foz do Amazonas) pela Corrente Norte do Brasil (CNB), que é a mais importante na região e que transporta sedimentos oriundos do aporte continental, sendo o principal contribuinte o Rio Parnaíba (Nace et al., 2014). A porção centro-leste da MEB (Bacias de Barreirinhas, Ceará e Potiguar) recebe o aporte sedimentar de rios de menor porte que são retrabalhados por ondas e ventos, formando praias e dunas, como os Lençóis Maranhenses.

A CNB faz parte do giro equatorial, juntamente com a Corrente Sul-Equatorial (CSE) e a Contra-corrente Norte-Equatorial (CCNE) (Fig. 3). A CNB não somente transporta sedimentos, mas é também responsável pelo transporte de calor entre o Atlântico 
Sul e o Atlântico Norte (Philander, 2001). A CNB se forma em $10^{\circ} \mathrm{S}$, ocupa os primeiros 1200 metros da coluna d'água e tem suas maiores velocidades entre as isóbatas de 100 e 200 metros (Silveira et al., 1994), cujos valores máximos podem chegar a $80 \mathrm{~cm} . \mathrm{s}^{-1}$ (Schott et al., 2005).

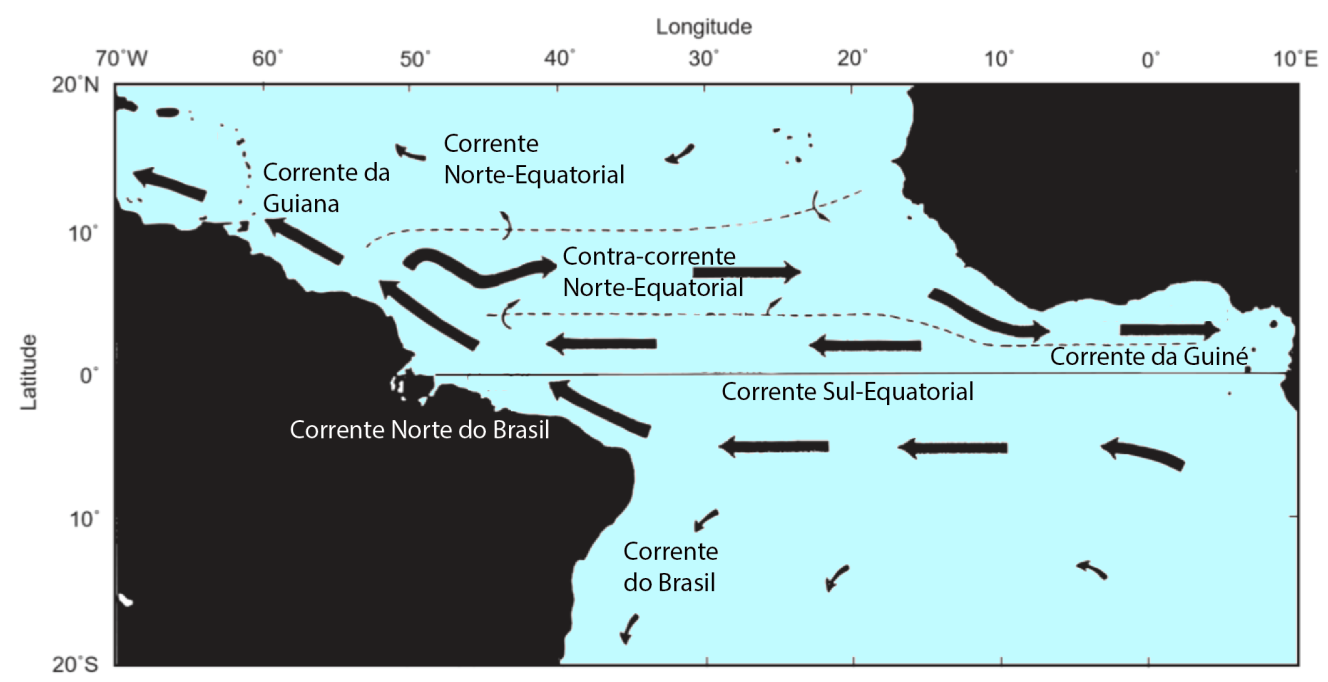

Figura 3: Correntes que formam o Giro Equatorial: Corrente Sul-Equatorial (CSE), Corrente da Guiné, Corrente Norte do Brasil (CNB), Contra-Corrente Norte-Equatorial (CCNE), Corrente Norte-Equatorial (CNE), Corrente da Guiana; e Corrente do Brasil (CB) (Philander, 2001).

A CNB possui variação sazonal em seu transporte total, que ocorre nos primeiros 800 metros da coluna d'água. Esta variação é diretamente relacionada com a variação da Zona de Convergência Intertropical (ZCIT) e dos ventos. Durante os meses de abril a maio, o transporte atinge seu mínimo, em torno de $13 \mathrm{~Sv}\left(1 \mathrm{~Sv}=10^{6} \mathrm{~m}^{3} . \mathrm{s}^{-1}\right)$, enquanto seu máximo ocorre entre julho e agosto, com cerca de 36 Sv (Johns et al., 1998). De acordo com Zhang et al. (2011), além dessa variação anual, a CNB também apresenta uma variação multidecadal, relacionada com variações da Célula de Revolvimento Meridional do Atlântico (mais conhecida por sua sigla em inglês, AMOC), influenciando no fluxo de calor do Atlântico Equatorial para o Atlântico Norte. Esses mesmos autores sugerem a possibilidade de utilização da variação da CNB como indicadora da variação da AMOC.

Após cruzar o Equador, a CNB segue para o norte, rumo ao Golfo do México, mas uma parte dela sofre retroflexão para leste. Esta retroflexão acontece entre $5^{\circ} \mathrm{N}$ e $8^{\circ} \mathrm{N}$, de forma sazonal (entre julho e dezembro), quando as camadas mais superficiais da CNB alimentam a CCNE (Johns et al., 1990).

Logo abaixo da CNB, em cerca de 800 metros, passa a atuar a Corrente de Contorno Oeste Profunda (CCOP), que leva a Água Profunda do Atlântico Norte (APAN) em 
direção ao sul e possui seu núcleo em torno de $4300 \mathrm{~m}$, com velocidades de até $35 \mathrm{~cm} . \mathrm{s}^{-1}$ (Johns et al., 1993, 1998).

O clima das regiões Norte e Nordeste do Brasil é bastante variado na direção E$\mathrm{W}$, tendo no extremo oeste o clima tropical úmido e no extremo leste o clima semi-árido nordestino. Uma das influências mais importantes no clima da região é sua localização junto à ZCIT, que proporciona condições de vento bastante particulares e variáveis ao longo do ano. Estes ventos influenciam diretamente os efeitos das correntes e marés nos processos sedimentares na MEB, criando ambientes de alta energia e grande mistura de águas (Vital et al., 2010b). A região Nordeste do Brasil ainda está sujeita a dois fenômenos atmosféricos sazonais que influenciam diretamente o regime de chuvas na região: a migração da ZCIT e o El Niño Oscilação Sul (ENOS) (Hastenrath e Merle, 1987; Chang et al., 1997; Chiessi et al., 2014; Zhang et al., 2015).

A ausência de grandes aportes fluviais nas Bacias de Barreirinhas possibilita a atual sedimentação carbonática nesta bacia. Atualmente, o ambiente deposicional das bacias Potiguar e do Ceará pode ser classificado como uma plataforma mista com sedimentação carbonática e siliciclástica (Vital et al., 2010b). Mais a norte, com atuação da descarga do Rio Amazonas, a sedimentação se torna predominantemente siliciclástica, na Bacia da Foz do Amazonas, enquanto na Bacia de Pará-Maranhão predomina a deposição carbonática.

Na região costeira, a sedimentação é controlada pelas correntes costeiras que, por conta do regime de ondas e de ventos, possuem direção preferencial para oeste (Gomes et al., 2016). Nas áreas mais profundas, a CNB atua de forma importante, com velocidade entre 30 e $40 \mathrm{~cm} . \mathrm{s}^{-1}$ (Knoppers et al., 1999). Além disso, as Cordilheiras Norte Brasileira e de Fernando de Noronha possuem um papel importante na sedimentação da MEB, sendo que a primeira atuou como barreira para os sedimentos até o Mioceno Inferior (Martins e Coutinho, 1981).

A maré predominante na costa norte brasileira é a semi-diurna, com amplitudes de mais de 6 metros no Pará, até cerca de 3,3 metros no Rio Grande do Norte o que, nessa última região, por exemplo, gera correntes de maré de cerca de $130 \mathrm{~cm} . \mathrm{s}^{-1}$ (Gomes et al., 2016). O transporte de sedimentos ao longo da costa do Rio Grande do Norte pode atingir valores próximos de $110 \mathrm{~m}^{3}$ por dia (Vital et al., 2006). 


\subsubsection{Rio Parnaíba}

O Rio Parnaíba (Fig. 4) é o principal rio que deságua na MEB nas proximidades das bacias de Barreirinhas e do Ceará, sendo assim o principal agente atual de aporte de terrígenos para as duas bacias sedimentares. Este rio possui cerca de $1400 \mathrm{~km} \mathrm{de}$ comprimento, sendo formado pela confluência dos rios Água Quente e Lontra do Piauí, na região do Parque Nacional das Nascentes do Parnaíba, na divisa dos estados de Piauí, Maranhão, Tocantins e Bahia.

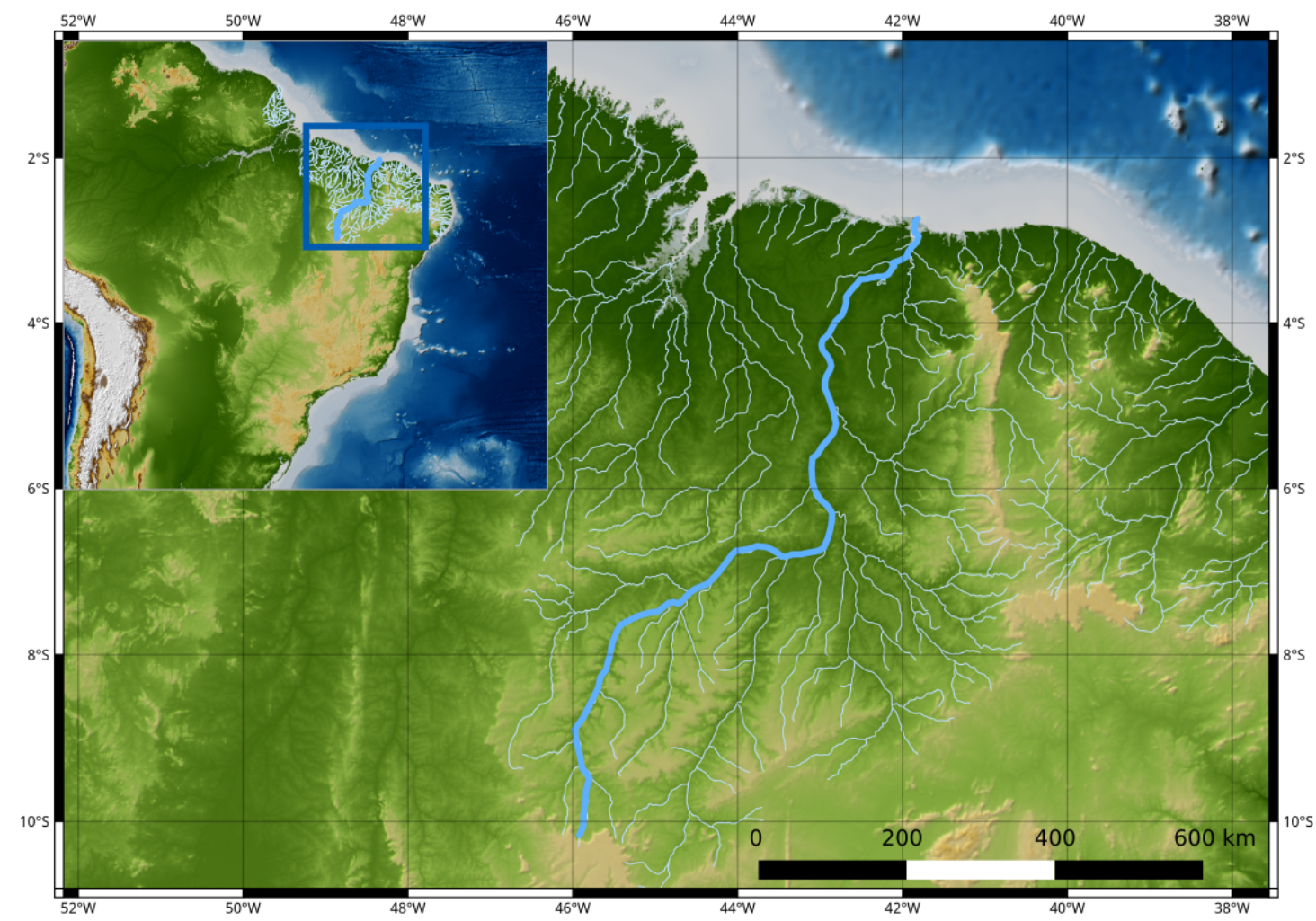

Figura 4: Bacia hidrográfica do Rio Parnaíba, que divide os estados de Maranhão e Piauí, e é o principal agente de aporte de material terrígeno para as Bacia de Barreirinhas e Ceará.

A bacia de drenagem do Rio Parnaíba engloba a totalidade do estado do Piauí e partes do Maranhão e Ceará, resultando em uma área de cerca de 344 mil km² (Aquino da Silva et al., 2015). Em sua foz, se forma o Delta do Parnaíba, em um ambiente dominado por ondas e com importante atuação da maré (Szczygielski et al., 2015).

A bacia hidrográfica se encontra em uma zona de transição entre o clima úmido amazônico e o semi-árido nordestino, sendo altamente influenciado pelo posicionamento da ZCIT e por fenômenos interanuais como o ENOS. Estes eventos tem influência direta no clima do Norte e Nordeste brasileiros e, consequentemente, no regime de chuvas, 
intemperismo, volume dos rios e aporte sedimentar para as bacias oceânicas. A quantidade de sedimentos em suspensão no Rio Parnaíba foi correlacionada com sucesso com a quantidade de chuvas na região, controlando as variações ocorridas na linha de costa de seu delta (Aquino da Silva et al., 2015).

\subsubsection{Zona de Convergência Intertropical - ZCIT}

A Zona de Convergência Intertropical é uma área na região equatorial em que ocorrem mínimos valores de pressão atmosférica, permitindo a convergências dos ventos de NE e de SE (Garreaud et al., 2009). Por esta razão, as precipitações associadas a esta zona de convergência são basicamente convectivas, com formações de profundas cumulus-nimbus. A migração da ZCIT ao longo do ano faz com que a área de atuação destas chuvas mude.

Quando não há a atuação marcante de eventos interanuais como o ENOS, a ZCIT muda de posição ao longo do ano, com um posição mais a sul $\left(2^{\circ} S\right)$ no verão austral, e mais a norte $\left(14^{\circ} \mathrm{N}\right)$ no inverno austral (Melo et al., 2009). Este deslocamento ocorre devido à variação da intensidade dos ventos atuantes no Equador. Durante o inverno boreal, os ventos de NE são mais intensos, deslocando a ZCIT mais para o sul; por outro lado, no inverno austral os ventos dominantes são os de SE, que deslocam a ZCIT mais para o norte (Rühlemann et al., 2001). Estes dois posicionamentos distintos são responsáveis por gerar maior quantidade de chuvas na região acima do Equador durante o inverno austral, deixando o clima mais seco no Brasil durante esta época. Por outro lado, durante o verão austral, o posicionamento mais a sul da ZCIT traz mais umidade e chuvas para o continente.

As variações da ZCIT são importantes para estudos climáticos não apenas atuais, mas também no passado. Seja por um deslocamento mais a norte ou mais a sul, seja por um tempo maior em um dos hemisférios, ou seja ainda por seu enfraquecimento, a variação na posição da ZCIT vem sendo estudada por diversos autores para a compreensão de sua atuação no paleoclima (Russell e Johnson, 2005; Armstrong e Allen, 2011; Zhang et al., 2015). Da mesma forma, a variação do aporte de sedimentos para as bacias da MEB possui relação direta com estas variações. 


\subsection{Evolução da MEB}

Apesar do processo de break up no Atlântico Sul ter se iniciado no Aptiano, no Atlântico Equatorial ele demorou um pouco mais, tendo início apenas no Albiano (Chang et al., 1988; Matos, 1992, 2000). A Margem Equatorial Brasileira faz parte do que Matos $(1987,1992)$ definiu como Sistema de Riftes do Nordeste Brasileiro. A proposta de evolução deste sistema, atualizada pelo mesmo autor anos depois (Matos, 2000), é que o processo de abertura do Atlântico Equatorial teve início com três estágios: pré, sin e pós-movimentos transformantes. Após os três estágios, seguiu-se o processo de ruptura da crosta continental, criação de crosta oceânica e início dos movimentos cisalhantes entre as placas sul-americana e africana. Este modelo tem como base o fato de que os processos distensivos convencionais não podem explicar a geometria e cinemática dos riftes das bacias da MEB (Matos, 2000).

Alguns grábens nos riftes de Cassiporé, Marajó e Potiguar apresentam falhas de borda com direções diferentes daquelas nas bacias de pull-apart da margem continental. Dessa forma, na MEB encontram-se seguimentos com falhas na direção E-W e outros com direção NW-SE. Nesta mesma direção, há zonas de cisalhamento que podem apresentar continuidade com alinhamentos encontrados no continente africano (Castro et al., 2012).

Os registros da tectônica da margem equatorial são bastante variados, apresentando desde falhas normais de rifte até falhas inversas na porção oeste da Bacia do Ceará, com cinturões de dobramentos associados às falhas de transcorrência envolvendo o embasamento. Na região, além da quebra do talude nas bacias da Foz do Amazonas, Pará-Maranhão e Barreirinhas, destaca-se também um notável cinturão de dobramentos associado à tectônica gravitacional (Zalán, 2005, 2011).

O norte da América do Sul foi afetado por intenso magmatismo durante o Jurássico e Triássico, relacionado com a abertura do Atlântico Norte e eventos ígneos tanto intrusivos quanto extrusivos aconteceram durante todo o Mesozoico e Cenozoico, tanto em áreas emersas quanto na plataforma continental (Almeida, 1967; Almeida et al., 2000). Com idades do Paleógeno, províncias magmáticas mais novas podem ser encontradas no Ceará e no Rio Grande do Norte, pertencentes ao evento Macau, que se estendeu até o 
Pleistoceno (Mizusaki et al., 2002; Condé et al., 2007). Nos poucos dados sísmicos disponíveis para a região, também há evidências de edifícios vulcânicos na base de montes submarinos, como no Platô do Ceará (Jovane et al., 2016).

Na área oceânica, por sua vez, a formação do arquipélago de Fernando de Noronha é um exemplo de formação ígnea mais recente (de 12 a 1,5 Ma). Em um conjunto de linhas sísmicas da Bacia de Pará-Maranhão, Azevedo (2016) identificou edifícios vulcânicos, falhas e dobramentos que associou à tectônica gravitacional. Rochas magmáticas cortam eventualmente as rochas sedimentares das bacias Potiguar e do Ceará e diques magmáticos estão presentes nos alinhamentos distensionais, ainda que se discuta se eles estiveram ativa ou passivamente envolvidos nos processos distensivos.

O preenchimento sedimentar da fase pós-rifte (drifte) das bacias da MEB está diretamente relacionado ao processo de abertura do Atlântico Equatorial. No Eocretáceo, nas margens em processo de ruptura, passaram a se desenvolver sistemas deposicionais lacustres e fluviais, preenchidos com sedimentos siliciclásticos e carbonáticos (Bonatti et al., 1996; Arai, 2014). Depois disso, no final do Eocretáceo (Neoaptiano e Eoalbiano) a região foi afetada pelos primeiros estágios do início do break up e ingressões marinhas, que levaram ao acúmulo dos primeiros evaporitos em algumas bacias, como na Bacia do Ceará (Cunha e Koutsoukos, 1998; Dingle, 1999). No Neocretáceo, folhelhos com alto teor de matéria orgânica foram depositados em um ambiente de mar alto, durante um período de oceanos anóxicos por todo o globo (Schlanger e Jenkins, 1976).

Em seu estágio final de abertura, a nova passagem gerada pelo Atlântico Equatorial provocou alterações significativas na distribuição e circulação de massas d'água, que produziram efeitos profundos no clima e nos ecossistemas. Com a nova abertura, deu-se início a uma circulação de fundo mais efetiva entre as regiões sul e equatorial a partir do Neocretáceo e início do Paleógeno (Weissert e Erba, 2004; Jenkyns, 2010), permitindo uma nova troca de massas d'água, e a mudança do Atlântico Sul de um estado mais anóxico e com grande sedimentação de material orgânico para um estado com uma circulação de fundo mais efetiva.

É importante destacar que a MEB propicia a preservação de importantes camadas sedimentares. Suas características únicas tornam possível estudar tanto as variações 
dos padrões tectono-estruturais e explicar a ocorrência de deformações recentes, quanto entender a evolução dos processos sedimentares.

\subsection{Bacias sedimentares}

A área de estudo deste trabalho compreende majoritariamente trechos das porções submersas das bacias sedimentares do Ceará e de Barreirinhas, além de uma área menor da Bacia Potiguar. Mesmo sendo vizinhas, as características dessas bacias são diferentes, tanto do ponto de vista tectônico quanto de cobertura sedimentar.

A Bacia Potiguar (Fig. 5) não é predominante na área de estudo deste trabalho, mas apenas seu setor extremo oeste. Esta bacia é limitada a leste pelo Alto de Touros e a oeste pelo Alto de Fortaleza, onde faz divisa com a Bacia do Ceará (Pessoa Neto et al., 2007). A bacia possui uma área de cerca de $48.000 \mathrm{~km}^{2}$, sendo aproximadamente 26.500 $\mathrm{km}^{2}$ em sua porção submersa.

A Bacia Potiguar foi formada durante os esforços extensionais no Neocomiano, relacionados à separação das placas sul-americana e africana (Mohriak, 2003). Seu registro estratigráfico indica a presença de três megassequências:

- Sinrifte: depositada durante o Neocomiano e caracterizada por sedimentos fluviais, deltaicos e lacustres das Formações Pendência e Pescada;

- Transicional: depositada durante o Andar Alagoas (Aptiano) e caracterizada por sedimentos flúvio-deltaicos e também com os primeiros indícios de ingressão marinha, com a Formação Alagamar; e

- Pós-rifte: depositada a partir do Albiano durante a fase de subsidência termal da bacia (drifte). Possui uma sedimentação transgressiva flúvio-marinha (Formações Açu, Ponta do Mel, Quebradas, Jandaíra e Ubarana) e outra regressiva, de caráter carbonático (Formações Ubarana, Tibau e Guamaré), ainda com presença de rochas vulcânicas da Formação Macau (Eoceno e Oligoceno). 


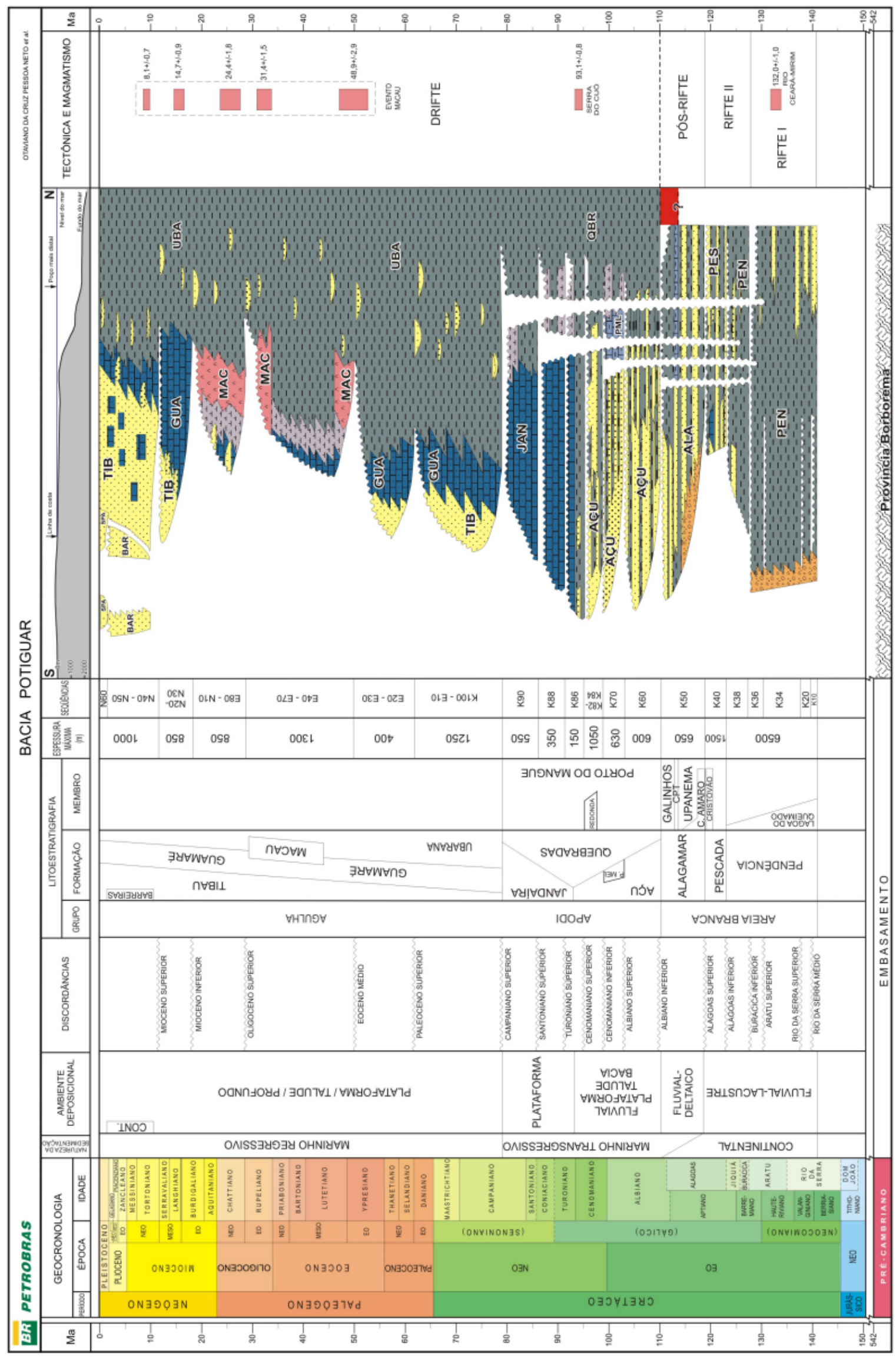

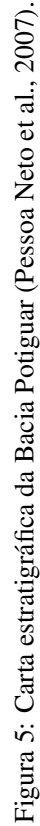


A Bacia do Ceará (Fig. 6) abrange uma área de aproximadamente 34.000 km², tendo seu limite a sudeste com a Bacia Potiguar no Alto de Fortaleza, a oeste com a Bacia de Barreirinhas no Alto de Tutóia, e a norte com o ramo sul da Zona de Fraturas Romanche (Condé et al., 2007).

A Bacia do Ceará é a mais complexa das três e, justamente por isso, foi dividida em 4 sub-bacias: Camocim, Acaraú, Icaraí e Mundaú. Enquanto as separações entre Acaraú-Icaraí e Icaraí-Mundaú foram definidas por falhas, e a sub-bacia de Camocim é separada das demais pelo Alto do Ceará (Morais Neto et al., 2003).

Por conta da maior concentração de estudos na sub-bacia de Mundaú, seu preenchimento é melhor conhecido e pode ser dividido em três megassequências (Beltrami et al., 1994; Mohriak, 2003):

- Sinrifte: sedimentos tipicamente continentais, como arenitos fluviais e folhelhos lacustres, que compõem a Formação Mundaú, com idades identificadas até o início do Aptiano;

- Transicional: de forma análoga ao apresentado na Bacia Potiguar, aqui também há sedimentos de origem continental e as primeiras ingressões marinhas, caracterizados pela Formação Paracuru (final do Aptiano e início do Albiano); e

- Pós-rifte: corresponde a toda a sedimentação marinha que ocorreu após a separação das placas sul-americana e africana (drifte), sendo representada pelas Formações Ubarana, Tibau e Guamaré. Também denominada marinha, esta fase pode ser dividida em um primeiro período transgressivo, até o Campaniano e, a partir daí, uma fase regressiva.

No Paleógeno, a sub-bacia de Mundaú registrou, além de fácies progradacionais, intensa atividade vulcânica - associadas ao Vulcanismo Macau (Morais Neto et al., 2003) - o que provocou desestabilização de taludes e bordas, gerando escorregamentos e fluxos gravitacionais que podem ser reconhecidos nas seções sísmicas da área. 


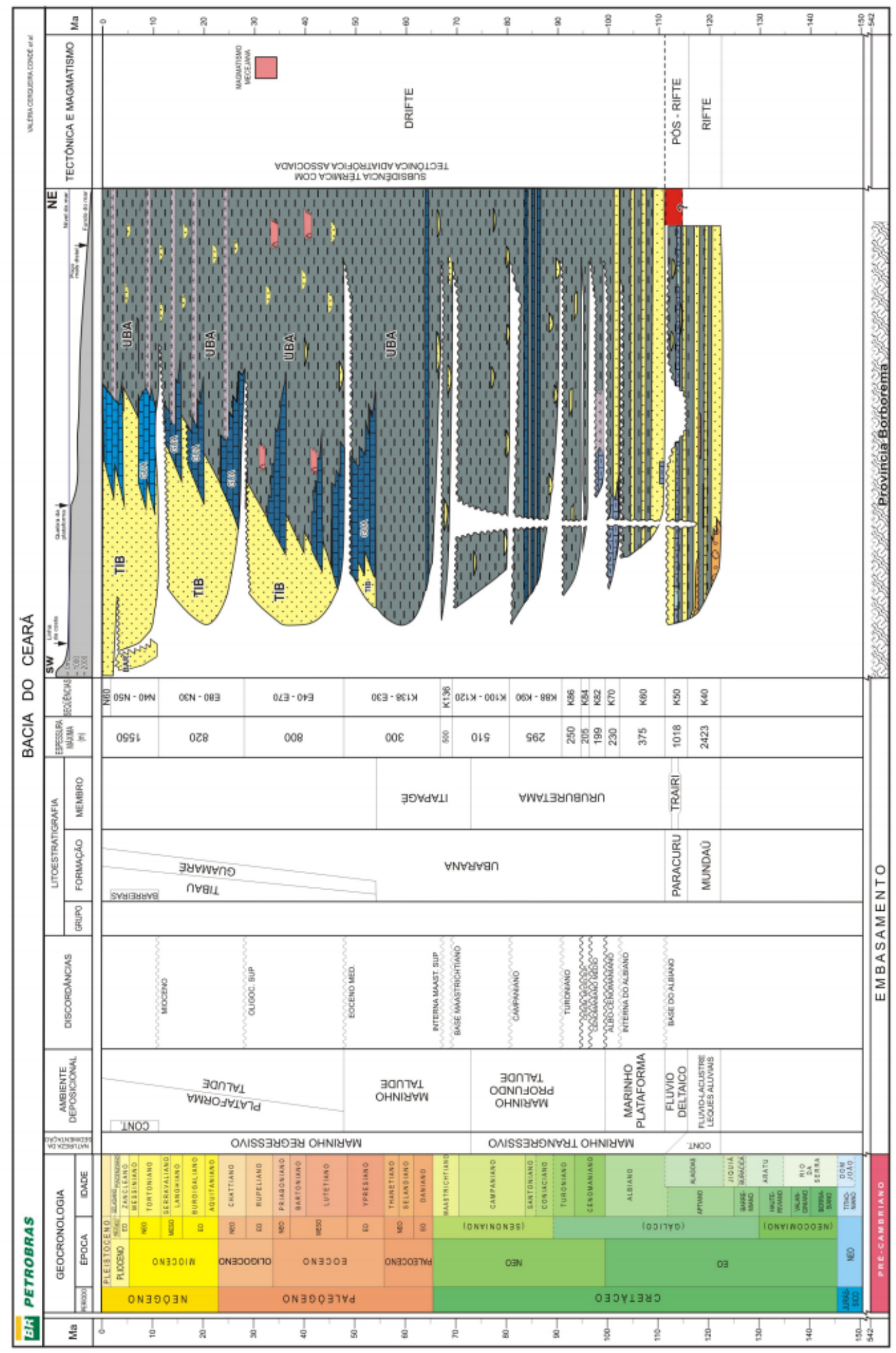

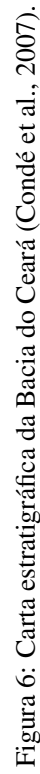


A Bacia de Barreirinhas (Fig. 7) está situada na porção mais a oeste da área de estudo, e compreende cerca de $46.000 \mathrm{~km}^{2}$, dos quais aproximadamente $37.500 \mathrm{~km}^{2}$ estão em sua porção submersa. A bacia é limitada a leste pelo Alto de Tutoia e a oeste pela plataforma da Ilha de Santana. Seu limite norte não é bem definido com relação à Bacia de Pará-Maranhão, sendo arbitrariamente considerado o meridiano de $44^{\circ} \mathrm{W}$ (Trosdtorf Junior et al., 2007).

O preenchimento sedimentar da Bacia de Barreirinhas é mais complexo. Em sua base, há sequências paleozoicas que foram mantidas nos grábens que se formaram inicialmente na bacia (Trosdtorf Junior et al., 2007). Sobre estas sequências pré-rifte, estão depositadas sequências sedimentares sin-rifte do Aptiano e Albiano. Finalmente, recobrindo estas duas fases, há a fase drifte, depositada a partir do Neo-Albiano. Trosdtorf Junior et al. (2007) destacam que uma particularidade da Bacia de Barreirinhas é a espessa seção drifte depositada sobre a crosta oceânica. Segundo os autores, esta seção pode atingir mais de $10 \mathrm{~km}$ de espessura em águas bastante profundas da bacia. A sequência pós-rifte (drifte) pode ainda ser dividida em três estágios bem definidos: (1) um período de sedimentação predominantemente carbonática; (2) um segundo período de sedimentação siliciclástica; e (3) o retorno de uma sedimentação predominantemente carbonática com a Formação Pirabas já durante o Mioceno. 


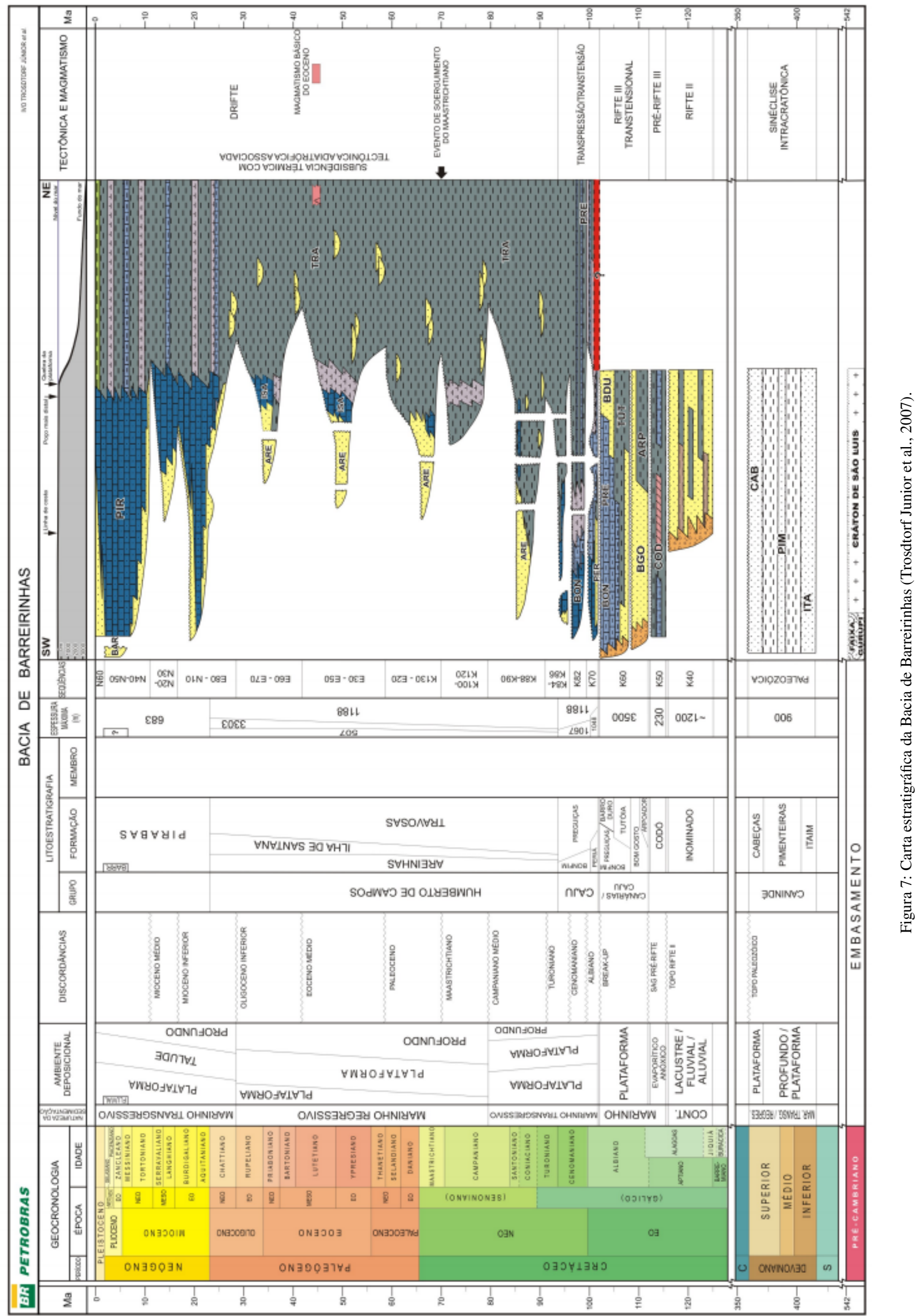




\subsection{Variações relativas do nível do mar, subsidência e aporte sedi- mentar}

Após a ruptura da crosta continental e o consequente início da abertura do Atlântico Equatorial, os processos sedimentares típicos de margem passiva começaram a ter início na MEB. Assim, a sedimentação passou a ser controlada pela relação entre as taxas de aporte sedimentar e de subsidência, além das variações eustáticas.

O aporte sedimentar continental é influenciado pela carga de sedimentos disponível no continente e que é carreada para as bacias sedimentares oceânicas por meio agentes de transporte, como os rios, o vento e as geleiras. Em bacias sedimentares marinhas, a sedimentação autóctone (pelágica e hemipelágica) também exerce papel fundamental na composição estratigráfica das bacias, como as plataformas carbonáticas.

A taxa de subsidência de uma bacia sedimentar está relacionada com o espaço de acomodação gerado nas bacias e, no processo de preenchimento sedimentar da MEB, com a subsidência termal da fase pós-rifte e isostática, ou seja, em resposta à carga de sedimentos que passou a ser depositada. Estudos sobre as taxas de subsidência especificamente nas bacias da MEB são incipientes, entretanto, durante a fase de sedimentação marinha pós-rifte, as taxas de subsidência termal e isostática não apresentaram variações importantes nas bacias Potiguar, do Ceará e de Barreirinhas (Condé et al., 2007; Pessoa Neto et al., 2007; Trosdtorf Junior et al., 2007).

Buscando compreender as transgressões marinhas do Mioceno, Rossetti et al. (2013) sugerem que o soerguimento da Cordilheira dos Andes poderia ter gerado um aumento na taxa de subsidência nas bacias marinhas brasileiras, assim como nas outras bacias ao redor da cordilheira. Os autores ainda relacionam fatores locais para estas transgressões, como tectônica intraplaca e eventos de resfriamento crustal na margem leste brasileira.

As variações eustáticas são decorrentes principalmente das variações de volume de água nos oceanos ou no volume disponível das bacias (Miller et al., 2005). Somadas a outras influências, esta variação de volume gera uma subida ou descida do nível relativo médio do mar (Fig. 8). Alguns fatores produzem subidas mais rápidas do nível relativo 
do mar, como a expansão térmica ou a inserção de águas subterrâneas ou de lagos. Entretanto, essas subidas são de menor amplitude quando comparadas àquelas provocadas por fatores como degelo, criação de crosta oceânica, sedimentação ou colisões continentais.

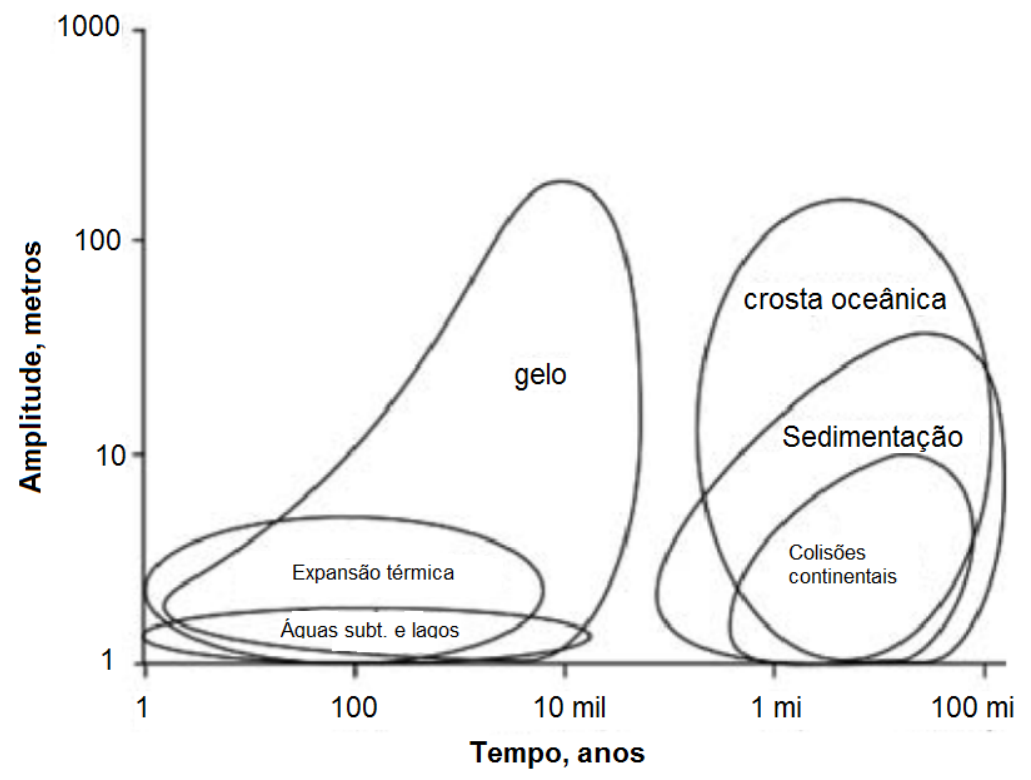

Figura 8: Diferentes fatores que podem influenciar no volume de água presente nos oceanos. Figura adaptada de Miller et al. (2005).

Diferentes fatores provocam alterações nos volumes das bacias em escalas, períodos e frequências distintas. Miller et al. (2005) organizaram estas causas, classificandoas de acordo com suas escalas de tempo e amplitude:

1. Longos períodos (10 a 100 milhões de anos): atribuídos principalmente à abertura dos oceanos;

2. Médios períodos (1 milhão de anos): dominados por variações no aporte sedimentar; e

3. Curtos períodos (10 a 100 mil anos): dominados por variações no volume de gelo e controlados por forçantes astronômicas.

Allen e Allen (1991) destacam que as variações do volume de água causadas pelo congelamento de águas marinhas e degelo de calotas tem seu efeito ampliado no nível relativo do mar. Considerando o degelo, por exemplo, o peso da massa adicional de água disponibilizada para os oceanos causa maior pressão sobre o leito marinho que, por 
isostasia, sofre subsidência, gerando um espaço ainda maior. O efeito contrário também ocorre quando há o congelamento de águas marinhas na formação das geleiras e calotas polares.

Pela complexidade de fatores e pouca quantidade de dados confiáveis, o estudo das curvas de variação do nível do mar é bastante complexo, e a construção de curvas "globais", ainda mais. Isto porque é praticamente impossível se considerar que eventos de máximos ou mínimos sejam síncronos no mundo todo (Allen e Allen, 1991). Mesmo assim, algumas das mais importantes curvas de variação do nível do mar são globais. Considerando-se os últimos 250 milhões de anos, as curvas publicadas por Vail et al. (1977), Haq et al. (1987; 1988), Kominz (1984), Kominz et al. (1998) e Van Sickel et al. (2004) estão entre as mais importantes.

Van Sickel et al. (2004) trabalharam com dados de testemunhos em Nova Jersey (da pernada 174AX do ODP - Ocean Drilling Program), e comparam seus resultados com as curvas de Kominz (1984) e Haq et al. (1987). Miller et al. (2005) apresentam uma curva compilada deste trabalho, juntamente com outras informações (Fig. 9).

O estudo das variações paloceanográficas do Paleógeno ao Neógeno e Quaternário na MEB na escala em que se propõe este trabalho não requer uma curva de variação do nível do mar de alta resolução. Esta análise regional é perfeitamente satisfeita com uma curva geral global, já que não existe uma curva local para a região equatorial do Brasil.

Alguns destaques sobre a curva eustática do Cenozoico são importantes: no Paleoceno, o continente Antártico já estava posicionado no polo sul, mas ainda não havia gelo formado sobre o continente. Após o Ótimo Climático do Eoceno Inferior (EECO, na sigla em inglês), a temperatura média global passou a diminuir, levando à formação das primeiras calotas polares na Antártica (Zachos et al., 2008), há cerca de 33 milhões de anos. Esta formação removeu um grande quantidade de água dos oceanos, gerando uma diminuição geral no volume de água disponível nas bacias oceânicas. Após o Ótimo Climático do Mioceno Médio, novas calotas polares começaram a se formar, desta vez, no Hemisfério Norte, causando uma nova diminuição no volume de água dos oceanos (Fig. 9). 


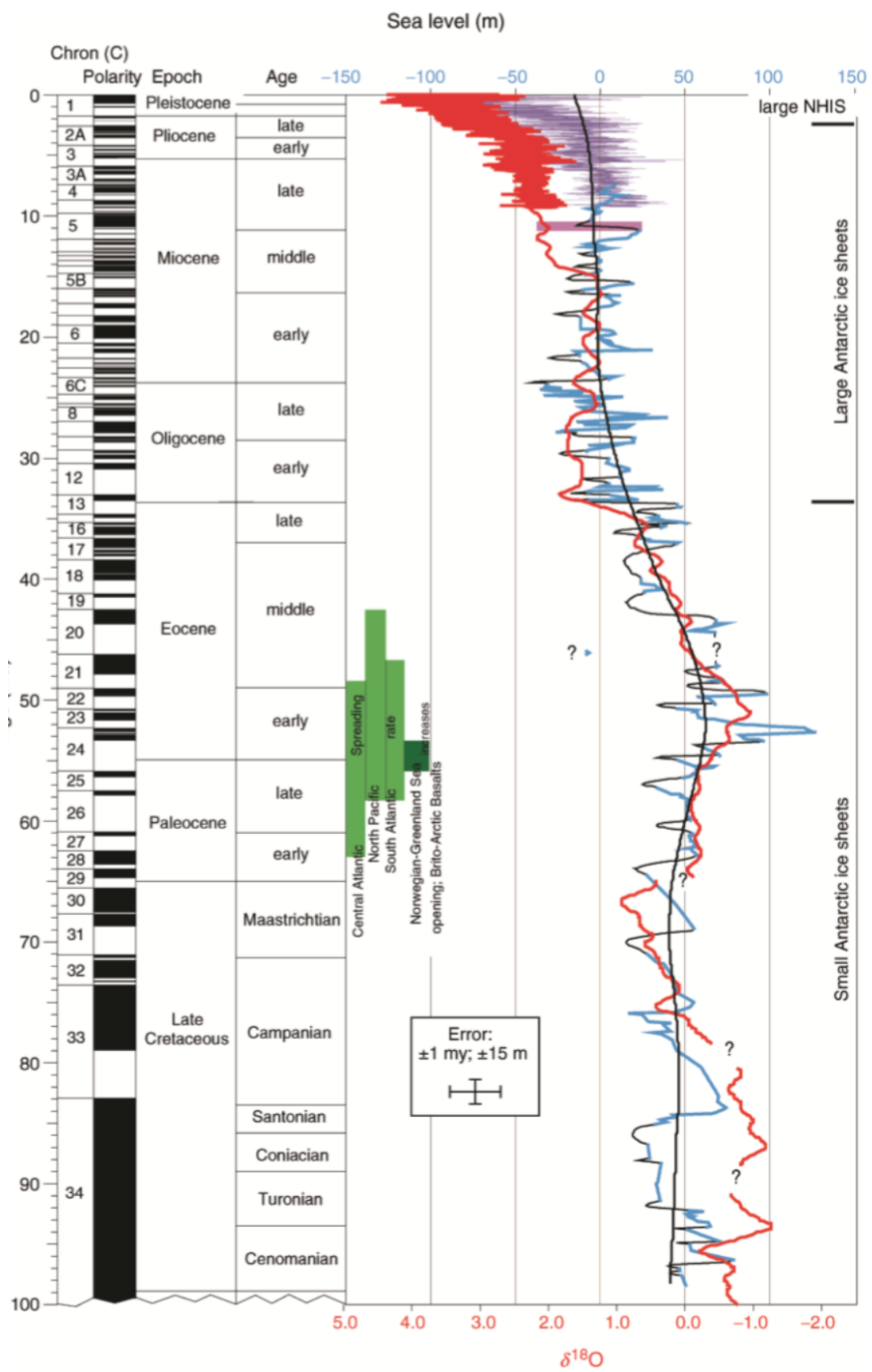

Figura 9: Curva de variação eustática (em azul claro, no painel à direita); em vermelho, valores de $\delta^{18} \mathrm{O}$ extraídos de foraminíferos bentônicos; as caixas verdes indicam períodos de abertura de oceanos; a linha preta representa a curva de conformidade de longo período para os dados de variação eustática. 
A relação entre o nível do mar e o clima é bastante estudada para períodos mais recentes, devido aos métodos de datação e proxies mais abundantes. Além disso, não se pode deixar de avaliar a relação entre as variações relativas do nível do mar, o aporte sedimentar e as taxas de subsidência. Entretanto, a escassez de trabalhos descrevendo as variações na subsidência da fase pós-rifte das bacias do Ceará e de Barreirinhas dificulta uma análise mais profunda desta relação. Sendo assim, as relações estudadas aqui são baseadas nas variações relativas do nível do mar e no aporte, inferido por meio das variações paleoclimáticas. 


\section{Material e método}

\subsection{Considerações iniciais}

Os estudos sismoestratigráficos foram iniciados pelos pesquisadores da empresa petrolífera Exxon, nos anos 1970 e 1980 (Naish e Kamp, 1997). Trabalhos como os de Payton et al. (1977) e Vail (1987) são clássicos para este ramo relativamente recente dos estudos geológicos.

A formação de uma sequência sedimentar está ligada primeiramente ao aporte sedimentar e ao espaço de acomodação. Este último termo se refere ao espaço disponível na bacia para receber os sedimentos e sua taxa de variação está ligada a dois importantes processos: as variações eustáticas e a taxa de subsidência da bacia.

A deposição de sedimentos é formada sob um mesmo conjunto de processos combinados à taxa de subsidência, ao aporte sedimentar e à posição do nível do mar - seja ela estável ou em processos regressivos ou transgressivos. As variações dos três efeitos determinarão como os sedimentos chegarão e de que forma serão depositados na bacia, sendo os três igualmente importantes.

Esta forma de deposição leva a outro conceito importante, o de fácies sedimentares ou litofácies. Cada fácies sedimentar está limitada cronoestratigraficamente, o quer dizer que terá um limite estratigráfico inferior e outro superior, podendo ser o embasamento, um limite deposicional (como um hiato) ou um limite erosivo. A sucessão de fácies sedimentares leva à formação de uma sequência sedimentar.

As sequências deposicionais são subdivididas em tratos de sistemas. De acordo com Posamentier (1988) e mais tarde revisto por Posamentier e Allen (1999), os tratos de sistemas relacionados à curva de variações relativas do nível do mar são três: Trato de Sistemas de Mar Alto (TSMA), Trato de Sistemas de Mar Baixo (TSMB) e Trato de Sistemas Transgressivos (TST).

Além da utilização dos conceitos delineados até aqui, o estudo sismoestratigráfico neste trabalho será feito com base nos princípios descritos por Vail et al. (1977). Um 
dos conceitos apresentados pelos autores foi a curva de onlap costeiro, definido como uma forma de derivar a curva de variação do nível relativo do mar a partir das posições do onlap na costa.

As posições do onlap fornecem informações a respeito da posição do nível relativo médio do mar. Enquanto seu avanço em direção ao continente está ligado a processos de transgressão marinha, a descida do nível do mar faz com que o onlap recue em direção ao centro da bacia. Assim, a sucessão destes eventos é ferramenta para se inferir a posição média do nível do mar ao longo do tempo.

\subsection{Dados sísmicos e de poços}

Os dados sísmicos utilizados neste trabalho foram provenientes de duas fontes: a Marinha do Brasil, por meio da Diretoria de Hidrografia e Navegação (DHN) e a Agência Nacional do Petróleo (ANP), por meio do Banco de Dados de Exploração e Produção (BDEP).

O Plano de Levantamento da Plataforma Continental (LEPLAC) foi criado pelo governo brasileiro para o estabelecimento dos limites jurídicos da plataforma continental brasileira. Para isso, diversos cruzeiros realizaram a aquisição de dados geofísicos desde a década de 1980, com a coleta de dados sísmicos, batimétricos, magnetométricos e gravimétricos. Esta iniciativa se deu a partir da assinatura da Convenção das Nações Unidas sobre o Direito do Mar (CNUDM), em 1982, em busca de melhor definir e regulamentar o uso dos espaços marítimos, como águas costeiras, plataforma, assoalho e subsolo oceânicos.

A CNUDM foi assinada pelo Brasil em 10 de dezembro de 1982 e ratificada em 22 de dezembro de 1988, introduzindo e consagrando conceitos como Mar Territorial, Zona Economicamente Exclusiva e Plataforma Continental (Souza, 1999). Foi definido então que os limites de mar territorial não seriam maiores que 200 milhas marítimas da linha de base de cada país. Entretanto, em seu Artigo 76, a CNUDM abre a possibilidade de prolongamento deste limite, caracterizando a Plataforma Continental Jurídica (PCJ) (Souza, 1999). O Artigo 76 define ainda os critérios pelos quais os países signatários 
podem requisitar este prolongamento, critérios estes envolvendo conceitos geológicos, geofísicos, geodésicos e hidrográficos. A partir de 1987, o LEPLAC se tornou também o programa do governo que passou a buscar o aumento da extensão da PCJ.

As linhas sísmicas utilizadas neste estudo são provenientes do Banco Nacional de Dados da DHN. Os dados foram coletados durante primeira e segunda fases do projeto LEPLAC e as linhas já se encontram no estado pós-empilhamento, com o processamento realizado por empresas da indústria do petróleo. Os dados foram cedidos pela DHN para a realização deste trabalho, e adquiridos em três cruzeiros a bordo do N.Oc. Almirante Câmara que, juntos, receberam o nome de LEPLAC EQUATORIAL:

- LEPLAC III: dados sísmicos, gravimétricos e magnetométricos adquiridos entre outubro e dezembro de 1988;

- LEPLAC V: dados sísmicos, gravimétricos e magnetométricos adquiridos entre agosto e outubro de 1989;

- LEPLAC VIII: dados sísmicos, gravimétricos, magnetométricos e batimétricos, adquiridos entre outubro e dezembro de 1990.

Além dos dados da DHN, fazem parte deste trabalho outros dois conjuntos de dados junto à Agência Nacional do Petróleo (ANP). Em estado bruto, o primeiro deles foi utilizado como base para o desenvolvimento e aprendizado de técnicas de processamento de sinais sísmicos, o que foi fundamental para que as linhas já processadas pudessem ser melhor compreendidas em termos de suas feições e possíveis artefatos gerados durante o processamento. As técnicas de processamento foram desenvolvidas no sistema Seismic Unix (SU), que é capaz de realizar todas as etapas de processamento de dados multicanal. Às linhas em estado bruto, foram aplicadas as seguintes etapas de processamento, para melhor compreender sua finalidade no desenvolvimento da seção sísmica final:

- Agrupamento de famílias de tiro e profundidade comum;

- Aplicação de filtros pré-empilhamento;

- Análise de velocidades e de frequências; 
- Diferentes tipos de deconvoluções (spike ou de remoção da assinatura da fonte);

- Migração e correção NMO;

- Empilhamento e geração da seção sísmica; e

- Processamento gráfico pós-empilhamento.

O segundo conjunto foi obtido já processado, no estado de pós-empilhamento, juntamente com informações de poços. Este segundo conjunto de dados serviu principalmente para a amarração sísmica x poço, para o posterior mapeamento dos horizontes. Ao todo, foram utilizadas 28 linhas sísmicas e 2 poços (Fig. 10 e Tabela 1).

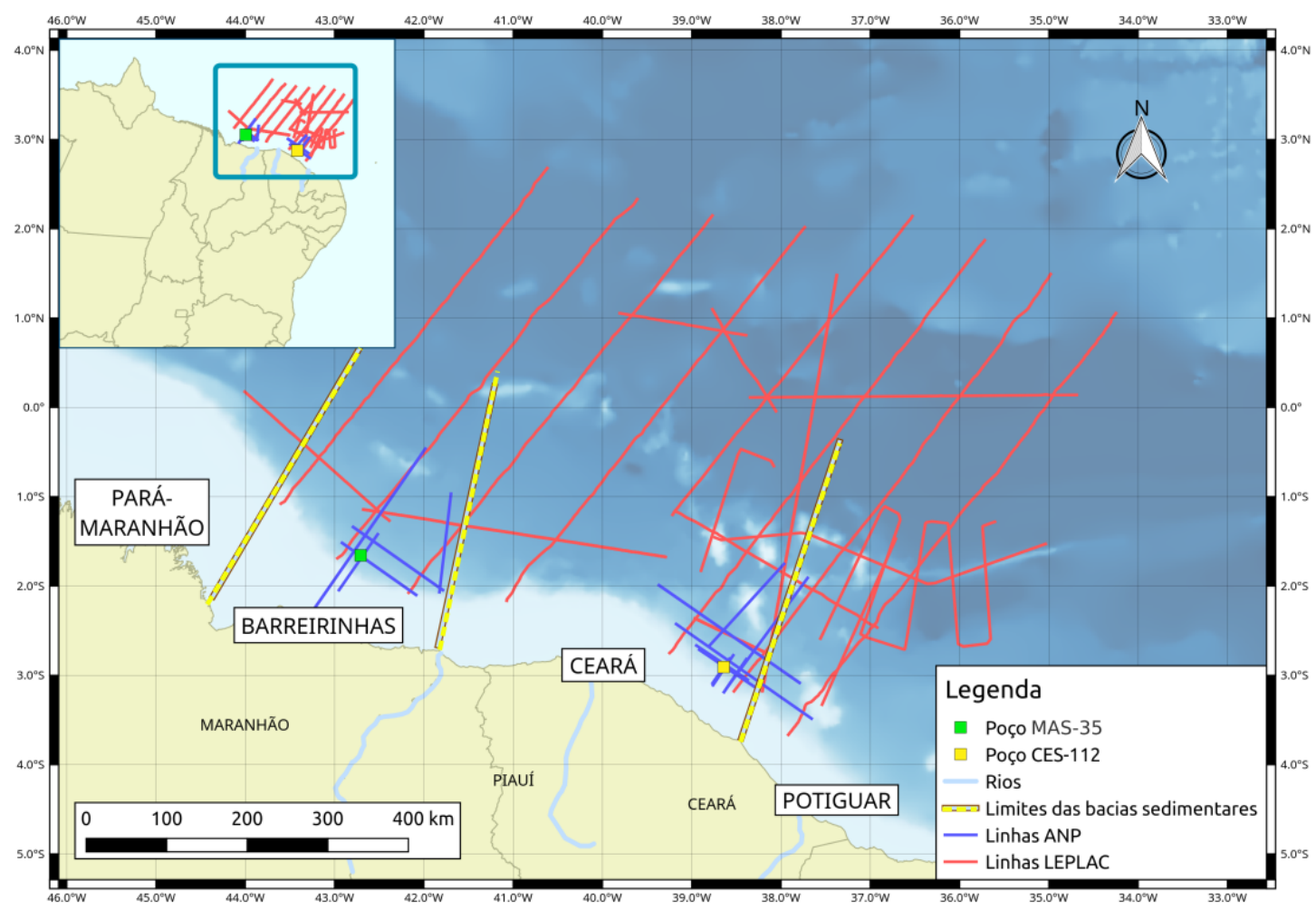

Figura 10: Linhas sísmicas obtidas junto à DHN (LEPLAC, em vermelho) e à ANP (em azul); os poços MAS-35 e CES-112 estão representados em verde e amarelo, respectivamente. 
Tabela 1: Relação das linhas sísmicas e dados de poços obtidos junto à ANP e à DHN, indicando seu nome, comprimento e bacia a que pertence.

\begin{tabular}{|c|c|c|c|}
\hline Fonte & Nome & $\begin{array}{c}\text { Comp. } \\
(\mathrm{km})\end{array}$ & Bacia \\
\hline \multirow{11}{*}{ ANP } & 0073-NORDESTE-5A.0073-0025 & 206 & Ceará/Potiguar \\
\hline & 0073-NORDESTE-5A.0073-0037 & 175 & Ceará/Potiguar \\
\hline & R0003-GRAND-NORTH.0222-0479-FIN11 & 36 & Ceará \\
\hline & R0003-GRAND-NORTH.0222-0489-FIN12 & 78 & Ceará \\
\hline & 0231-MUNDAU-16A.0231-1106.MIG-FIN.6 & 49 & Ceará \\
\hline & 0231-MUNDAU-16A.0231-1158.MIG-FIN.7 & 81 & Ceará \\
\hline & 0231-MUNDAU-16A.0231-1170.MIG-FIN.8 & 215 & Ceará/Potiguar \\
\hline & 0239-BARREIRINHAS-6A.0239-0240.MIG-FIN.1 & 113 & Barreirinhas \\
\hline & 0239-BARREIRINHAS-6A.0239-0243.MIG-FIN.2 & 137 & Ceará \\
\hline & R0003-GRAND-NORTH.0231-1103.MIG-FIN.11 & 45 & Barreirinhas \\
\hline & R0003-GRAND-NORTH.0239-0207.MIG-FIN.9 & 85 & Barreirinhas \\
\hline \multirow{14}{*}{ LEPLAC 1} & 501 & 700 & Potiguar \\
\hline & 502 & 655 & Potiguar/Ceará \\
\hline & 503 & 654 & Potiguar/Ceará \\
\hline & 504 & 472 & Ceará \\
\hline & 505 & 580 & Ceará \\
\hline & 506 & 604 & Ceará/Barreirinhas \\
\hline & 507 & 584 & Barreirinhas/Ceará \\
\hline & 508 & 523 & Barreirinhas \\
\hline & 513 & 293 & Potiguar/Ceará \\
\hline & 546 & 160 & Barreirinhas \\
\hline & 547 & 150 & Ceará \\
\hline & 548 & 415 & Potiguar/Ceará \\
\hline & 549 & 246 & Barreirinhas \\
\hline & 550 & 383 & Ceará/Barreirinhas \\
\hline \multirow{3}{*}{ LEPLAC 2} & B16-seq156 & 193 & Potiguar \\
\hline & S7-S8-seq191 & 97 & Ceará \\
\hline & S8-seq192 & 525 & Ceará \\
\hline \multirow{2}{*}{ ANP } & Poço 1-CES-0112 (CES-112) & - & Ceará \\
\hline & Poço 1-BRSA-729-MAS (MAS-35) & - & Barreirinhas \\
\hline
\end{tabular}


Os dois poços obtidos (Fig. 10) para este trabalho foram o 1-BRSA-729-MAS (MAS-35) e o 1-CES-0112 (CES-112). O poço MAS-35 (Fig. 11) está localizado na Bacia de Barreirinhas e o poço CES-112 (Fig. 12) na Bacia do Ceará, o que garante uma amarração para as duas bacias estudadas. Os dois poços foram escolhidos pelo conhecimento prévio da qualidade dos seus dados e das informações cronoestratigráficas, além de sua localização. Ambos estão posicionados no talude continental, o que garante maior proximidade com as linhas sísmicas obtidas para o projeto. Os dados dos dois poços são diferentes em qualidade sendo que os dados provenientes do MAS-35 são mais limitados, possuindo registros em apenas cerca de 200 metros. Já os dados do CES-112 são mais extensos, possuindo mais de 2000 metros de registros.
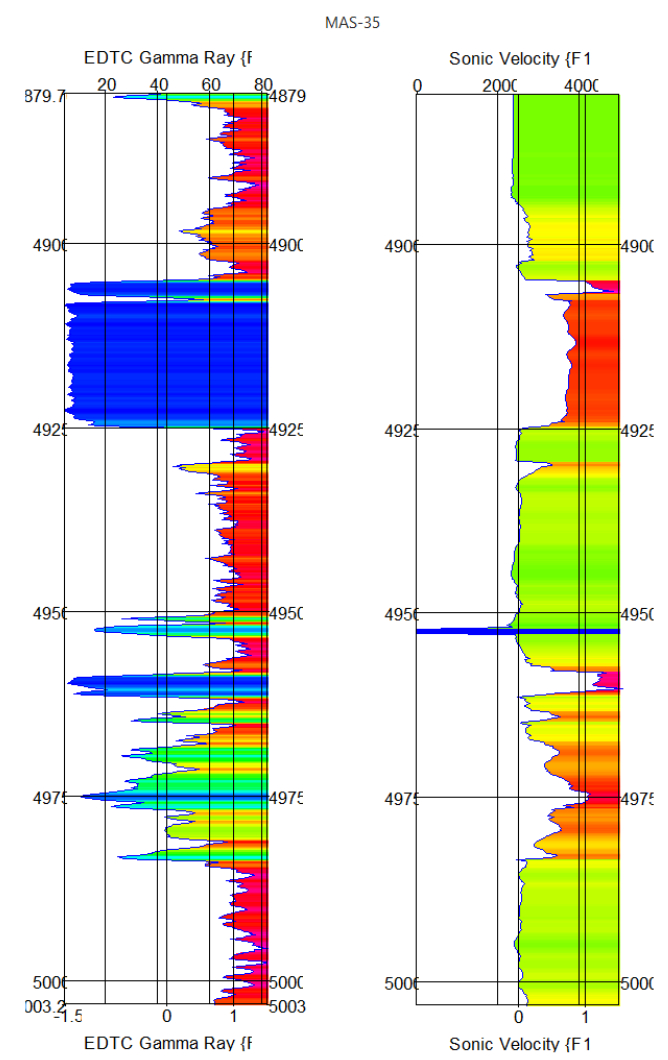

Figura 11: Exemplo dos registros de raios gama e velocidade de propagação do som ao longo do poço MAS-35.

Os dois poços obtidos encontram-se a mais de $50 \mathrm{~km}$ de distância das linhas do LEPLAC e, por esta razão, foram adquiridas linhas junto à ANP exclusivamente para a amarração sísmica-poço. Estas novas linhas estão posicionadas a distâncias menores que $1 \mathrm{~km}$, o que é aceitável para a amarração. 

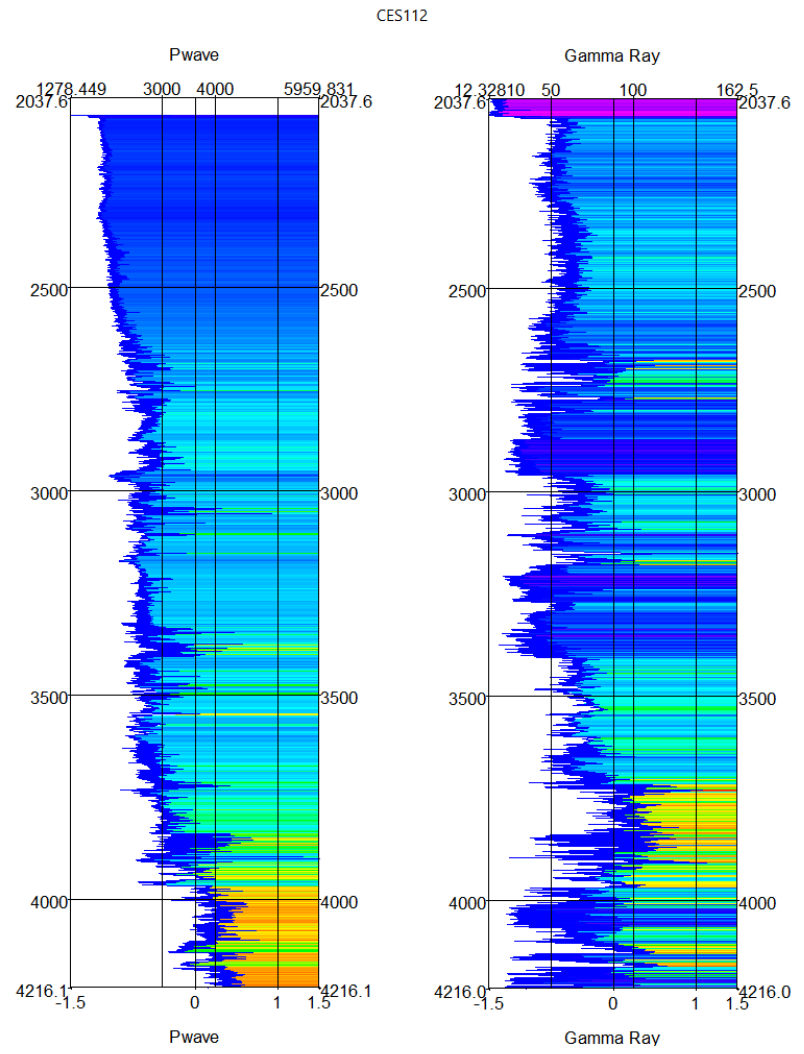

Figura 12: Exemplo dos dois registros presentes dos dados de raios gama e velocidade de propagação do som ao longo do poço CES-112.

Para ambos os poços foram adquiridas as curvas LAS/DLIS, utilizadas para a amarração com a sísmica. Além disso, na "Pasta Poço" foram adquiridos relatórios de perfuração, dados geoquímicos e os perfis compostos de ambos os poços, com informações sedimentológicas, cronoestratigráficas e valores de velocidade direta de propagação (checkshot). O poço CES-112 contém ainda informações cronoestratigráficas que servirão de base para a datação dos horizontes sísmicos interpretados (Fig. 13). 


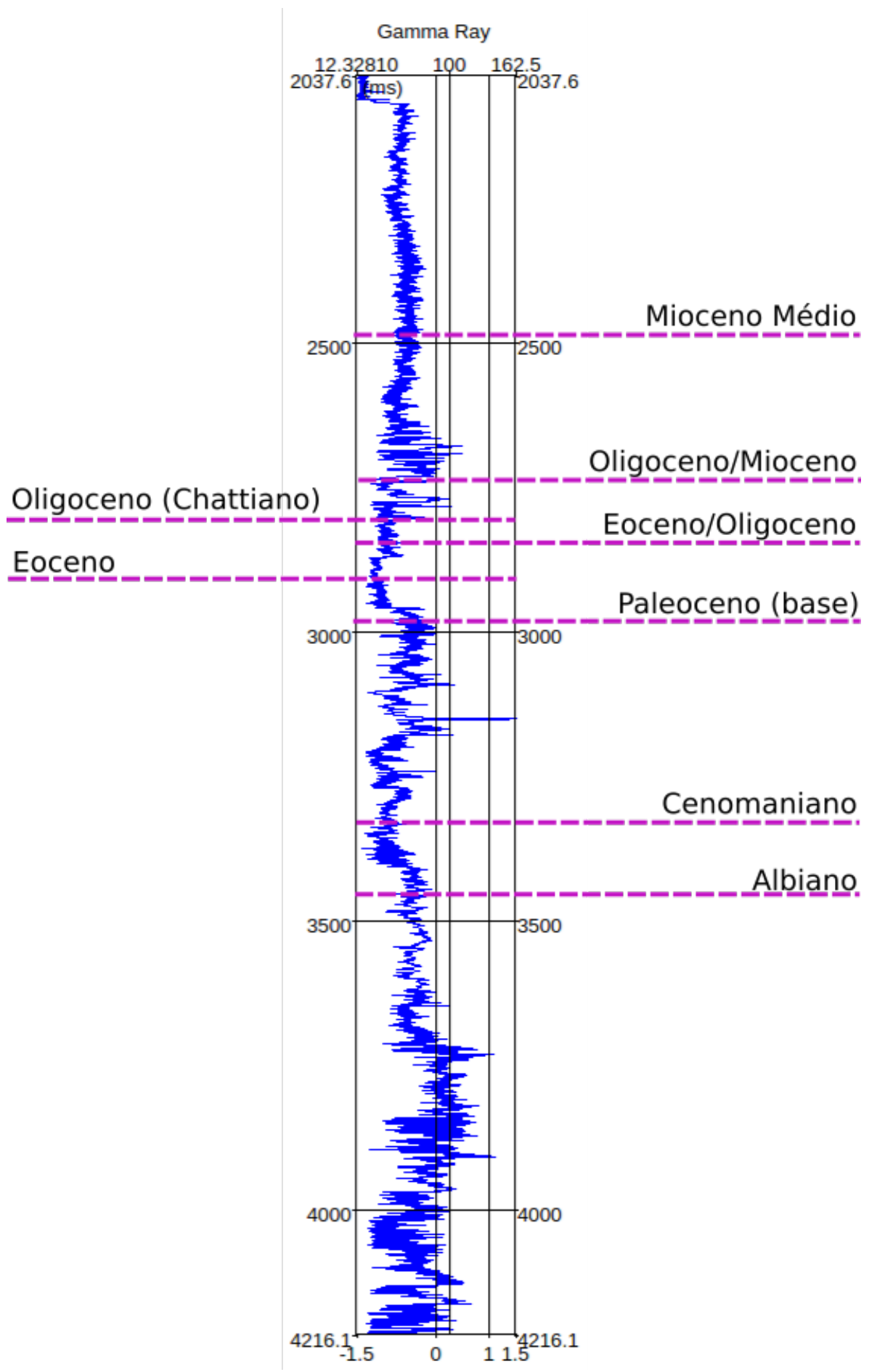

Figura 13: Informações cronoestratigráficas presentes no poço CES-112. 


\subsection{Aquisição e processamento}

A aquisição dos dados sísmicos do LEPLAC foi feita a bordo do Navio Oceanográfico Almirante Câmara, utilizando configurações específicas (Tabela 2). A seguir, os dados foram processados por duas empresas, a Themag Geosource Geofísica Ltda. (TGG) e a PETROBRAS. O fluxo de processamento de ambas foi bastante semelhante e aqui será descrito em detalhes aquele realizado pela PETROBRAS.

Tabela 2: Parâmetros de aquisição utilizados durante os levantamentos do LEPLAC.

\begin{tabular}{l|l} 
Fonte & Air gun \\
\hline Profundidade da fonte & 7 metros \\
\hline Intervalo de tiro & 50 metros \\
\hline Instrumento de registro & DFS-V \\
\hline Filtros/inclinação de corte & $8-90 \mathrm{~Hz} / 18-72 \mathrm{~dB} / \mathrm{oit}$ \\
\hline Intervalo de amostragem & $4 \mathrm{~ms}(250$ amostragens por segundo) \\
\hline Duração do registro & \\
LEPLAC III & 12 segundos \\
LEPLAC V & $12 / 13 / 15$ segundos \\
LEPLAC VIII & $10 / 12 / 14 / 16 / 18$ segundos \\
\hline Profundidade do cabo & 10 metros \\
\hline Intervalo dos grupos de hidrofones & 25 metros \\
\hline Número de canais & 96
\end{tabular}

\subsubsection{Edição e demultiplexação}

A aquisição dos dados sísmicos com sistema multicanal foi feita em fita magnética, ou seja, a cada instante são gravadas as informações referentes a cada um dos 96 canais utilizados. Na etapa de edição e demultiplexação, as informações foram organizadas e os dados gravados foram reordenados na sequencia dos grupos de hidrofones. Foi nesta etapa também que se eliminaram dados de canais com problemas e também dados de canais auxiliares. 


\subsubsection{Compensação por espalhamento geométrico}

Após a organização e ordenação dos dados, foi feita uma correção matemática para compensar a perde de energia do sinal sísmico decorrente do espalhamento da onda ao longo do percurso entre a fonte, refletor e receptor. A função para esta correção depende do espaço percorrido pela onda e é variável com o tempo.

\subsubsection{Deconvolução para remoção da assinatura da fonte}

Cada fonte sísmica possui um espectro de emissão característico para o pulso gerado, conhecido por assinatura sísmica. De acordo com Rosa et al. (1985), esta assinatura está relacionada ainda a outros fatores como o registrador, o hidrofone, os fantasmas da fonte e dos hidrofones, seus arranjos, o meio de propagação da onda e as características intrínsecas ao próprio pulso sísmico gerado. Durante o processamento, a PETROBRAS calculou o operador matemático utilizado para a deconvolução específica da fonte utilizada, processo pelo qual as frequências relacionadas à assinatura da fonte são eliminadas do sinal sísmico.

\subsubsection{Deconvolução de fase mínima}

A deconvolução de fase mínima é também conhecida como deconvolução spike, e é utilizada para a remoção de reflexões múltiplas de curto período (aquelas existentes entre duas reflexões primárias) e outros elementos que distorcem o sinal sísmico.

\subsubsection{Agrupamento em famílias CDP}

As famílias CDP (common depth point, ponto de profundidade comum, no inglês) são formadas pelos sinais provenientes de um mesmo ponto em profundidade, mas recebidos por hidrofones diferentes. O agrupamento CDP une estes dados provenientes dos mesmos pontos e, depois de feitas algumas correções, estes dados podem ser somados para que se aumente a razão sinal/ruído do levantamento. 


\subsubsection{Determinação de velocidades de empilhamento}

$\mathrm{Na}$ aquisição sísmica multicanal, o uso de diversos hidrofones aumenta a razão sinal/ruído justamente pela obtenção de dados em CDP. Entretanto, a distância entre os refletores faz com que cada hidrofone capte o sinal refletido em um mesmo ponto em tempos distintos. Em outras palavras, hidrofones mais próximos do ponto receberão o sinal refletido mais rapidamente que hidrofones mais distantes. Sendo assim, é necessário que se faça a análise de velocidades do meio de propagação para que se possa realizar a correção conhecida como normal move-out (NMO). De posse das velocidades de propagação, a correção NMO leva cada reflexão para sua posição correta no tempo.

A análise de velocidades é feita matematicamente, utilizando um ou mais conjuntos CDP e aplicando diversas velocidades arbitrárias para a correção NMO. Fatores que devem ser considerados durante a análise de velocidades são os intervalos de velocidade escolhidos para cada etapa e também o espaçamento entre os CDPs escolhidos. Observam-se os resultados e o melhor conjunto de velocidades é então escolhido para de fato realizar a correção NMO no conjunto inteiro dos dados.

Durante este procedimento, a experiência do técnico responsável pelo processamento é fundamental para que se escolham limites adequados de velocidades a serem testadas, além das famílias CDP suficientes para o estudo. Além disso, a experiência e capacidade do técnico também são fundamentais no momento de se realizar a correção NMO e definir quais conjuntos de velocidade corrigiram os dados da maneira mais correta.

\subsubsection{Migração pré-empilhamento}

Este processo visa corrigir o mergulho no tempo, ou dip move-out (DMO) como é melhor conhecido. Ao contrário da correção NMO, que corrige os atrasos do tempo decorrentes da distância entre hidrofones, a correção do DMO corrige o efeito da inclinação dos refletores, que pode gerar tempos maiores de retorno. 


\subsubsection{Empilhamento}

O empilhamento horizontal dos dados é feito com a soma de todos os traços pertencentes a uma mesma família CDP, após a correção NMO. Esta soma aumenta a razão sinal/ruído do dado sísmico.

\subsubsection{Deconvolução pós-empilhamento}

A deconvolução pós-empilhamento procura eliminar múltiplas internas e reverberações que possam ter surgido após os processamentos feitos até então.

\subsubsection{Migração}

A migração é uma das etapas mais importantes do processamento sendo responsável por levar cada reflexão ao ponto a que ela realmente pertence. Os pontos em subsuperfície refletem as ondas sísmicas a distâncias diferentes para cada hidrofone. Isso quer dizer que eles não estão localizados exatamente abaixo ou a uma distância média, por exemplo, o que aconteceria apenas na reflexão de uma camada perfeitamente plana e homogênea. Sendo assim, a migração dos dados busca posicionar os pontos de reflexão ao local que melhor se aproxima do real, bem como colapsar as difrações resultantes de ondas sísmicas de direções diferentes refletindo em um mesmo ponto.

\subsubsection{Filtros de banda}

Os filtros passa-banda (ou filtros de frequência) são utilizados para eliminar do sinal sísmico aquelas frequências que são definitivamente reconhecidas como ruído. Estas frequências podem ter sido captadas pelo próprio hidrofone durante a aquisição, quanto também ter sido inseridas no sinal sísmico durante as etapas prévias de processamento. A utilização de filtros de frequência aumenta consideravelmente a relação sinal/ruído dos dados sísmicos. 


\subsubsection{Equalização de traços e ganho de sinal}

Após todas etapas de processamento é possível que alguns traços da seção sísmica apresentem amplitudes maiores em relação aos demais traços. Assim, durante esta etapa, estas amplitudes são equalizadas. Finalmente, após gerada a seção sísmica, são aplicados valores de ganho em tempo, para que reflexões em tempos maiores (mais profundas) possam ter amplitudes semelhantes àquelas de tempos menores (mais rasas).

\subsection{Amarração sísmica $x$ poço}

A correlação dos dados de poço com a sísmica foi realizada por um processo conhecido como amarração. Neste procedimento, os dados geofísicos e geológicos extraídos diretamente do poço são correlacionados com os dados indiretamente adquiridos por meio das ondas sísmicas. Assim, concluída a amarração, os dados sísmicos adquirem uma correspondência geológica direta, podendo ser utilizados de forma confiável para a interpretação estratigráfica - ou cronoestratigráfica, quando se tem datações. Além disso, a amarração é essencial para a conversão dos dados de tempo para profundidade.

A amarração dos poços foi feita por meio do software OpendTect pela convolução entre a ondaleta (wavelet) do dado sísmico original e a curva de variação da impedância acústica calculada a partir dos dados de velocidade e densidade do poço. A seguir serão descritas e explicadas as etapas deste procedimento realizado apenas para o poço CES-112, já que o MAS-35 não apresentou registros longos o suficiente para o procedimento.

\subsubsection{Registro de densidade e velocidade do som}

Os dois registros (ou logs) necessários para a amarração são os de densidade e de velocidade de propagação da onda $P$. Os dois registros foram adquiridos por ferramentas específicas utilizadas no poço CES-112 e os dados foram adquiridos durante a descida das ferramentas ao longo do poço. 


\subsubsection{Extração da wavelet original e cálculo do traço sísmico sintético}

A ondaleta representativa do traço sísmico original foi extraída do registro sísmico da linha R0003-GRAND-NORTH.0222-479-FIN11, nas proximidades do poço CES-112. Esta ondaleta representa o perfil de amplitudes para o traço sísmico original (Fig. 14).
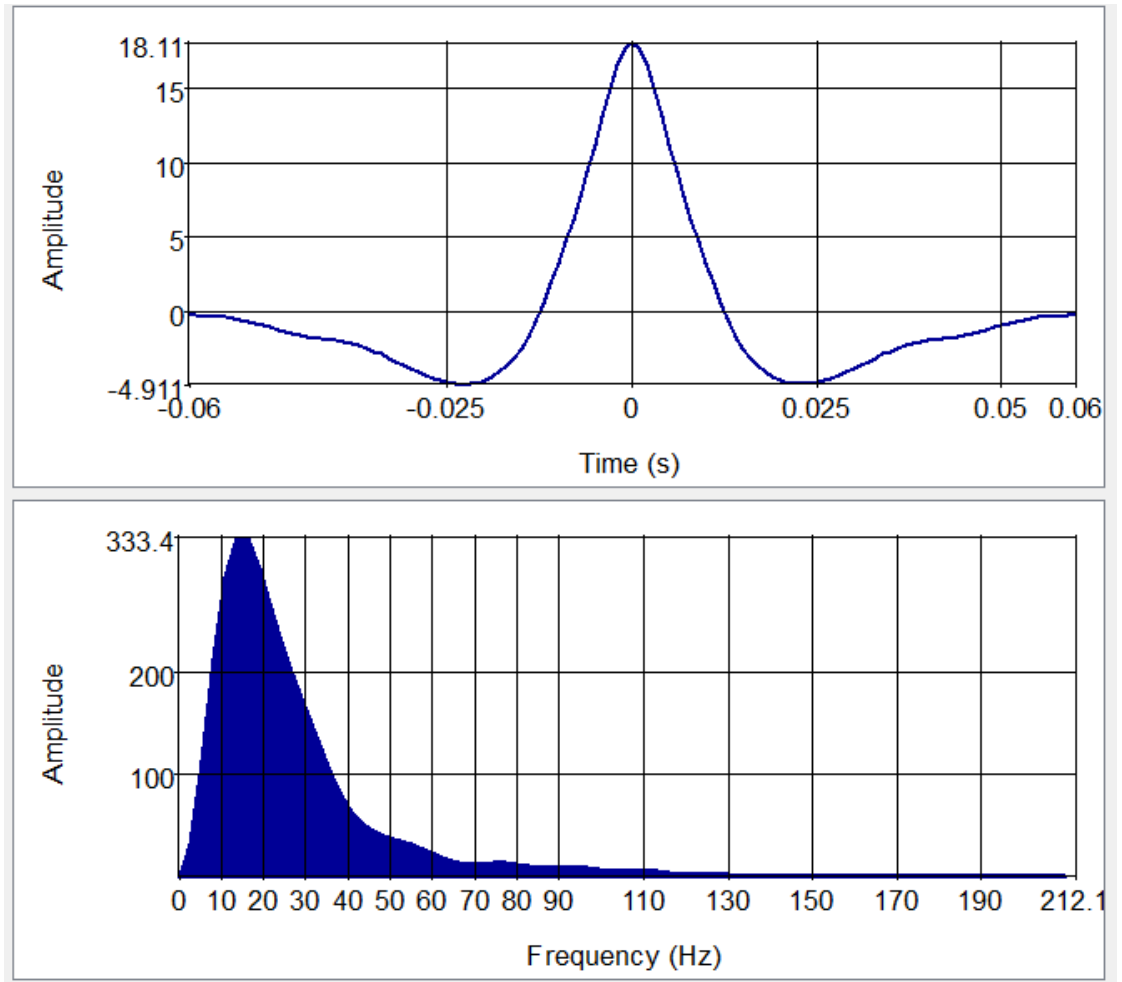

Figura 14: Perfil de amplitude (acima) e espectro de frequências (abaixo) da wavelet extraída da linha sísmica R0003-GRAND-NORTH.0222-479-FIN11 para a amarração com o poço CES-112.

O próximo passo foi o cálculo da perfil vertical de variação de impedância acústica, gerado indiretamente a partir dos dados de velocidade e densidade do poço. Esta curva foi calculada a partir da Equação 1:

$$
Z=V \cdot \rho
$$

Em que:

- $Z$ = Impedância acústica 
- $V=$ Velocidade de propagação da onda $\mathrm{P}$

- $\rho=$ Densidade

Para cada par de velocidade e densidade, foi calculado um valor de impedância acústica, dando origem a uma curva de variação da impedância acústica ao longo do poço.

Finalmente, a wavelet foi utilizada para o cálculo de um sismograma sintético, a partir da sua convolução com a curva de impedância acústica calculada a partir dos dados de densidade e velocidade de propagação da onda $P$, o que gerou um sismograma sintético.

\subsection{Correlação entre os sismogramas sintético e original}

A correlação entre os dados sintéticos obtidos por meio dos dados do poço e os dados sísmicos originais foi realizada também no software OpendTect. O painel de amarração (Fig. 15) possui, à esquerda, as curvas representando os registros de perfil sônico (vermelho) e densidade (azul), extraídos diretamente dos dados do poço. A partir da curva de impedância acústica, o software calculou os traços sísmicos sintéticos, no primeiro painel da direta (Fig. 15). Finalmente, estes traços sintéticos foram comparados com os traços sísmicos originais (último painel à direita).

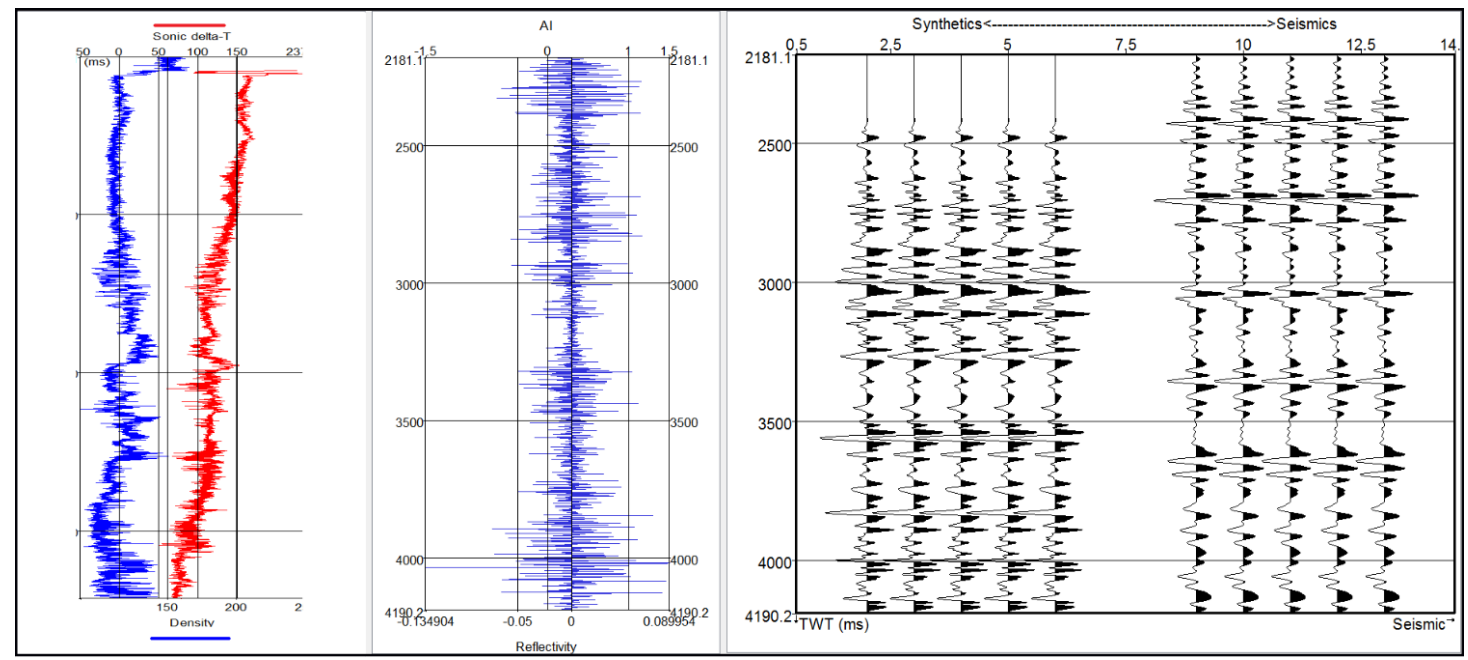

Figura 15: Painel de amarração poço $x$ sísmica do software OpendTect. À esquerda, os registros de densidade e velocidade do som, seguido curva de impedância acústica, calculada a partir dos dois registros. À direta, a ondas sintética e o dado sísmica original. 
Depois disso, foi realizada a correlação dos sismogramas sintético e original (Fig. 16). Esta correlação é feita pela interpretação dos picos e vales dos dois sismogramas, o sintético e o original. Feita a correlação de todos os picos e vales entre os dois sismogramas, foi criada e exportada uma tabela de correlação entre tempo, profundidade e velocidade do som, utilizada para a conversão profundidade x tempo dos dados sísmicos.

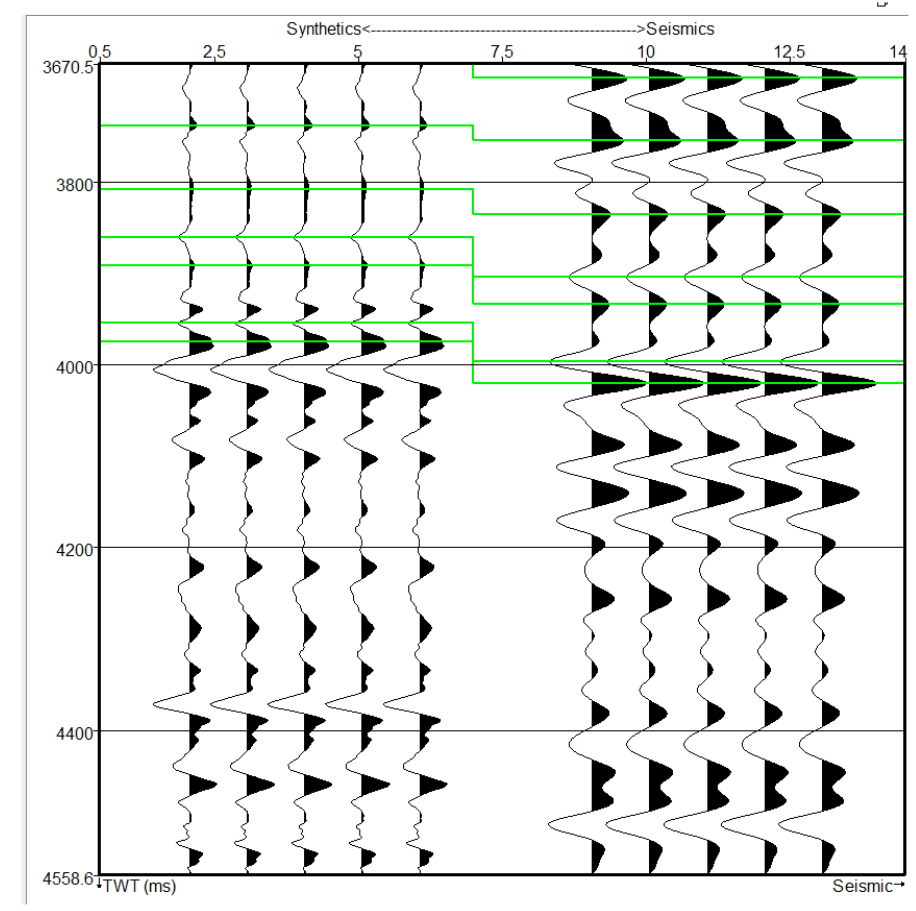

Figura 16: Correlação dos picos e vales dos perfis sintético (à esquerda) e original (à direita), feita para a amarração poço x sísmica.

\subsection{Litologia e conversão tempo $x$ profundidade}

Após a amarração sísmica-poço realizada via software, a correlação entre estes dados foi confirmada por meio da análise dos dados de litologia presentes no perfil composto do poço CES-112. Além dos registros geofísicos (densidade, velocidade etc.), o poço traz também informações litológicas, de indícios de hidrocarbonetos e cronoestratigrafia (Fig. 17).

Outra informação importante presente no perfil composto do poço são valores de tempo de trânsito e velocidade de propagação, adquiridas pelas ferramentas WST e VSP, respectivamente. A Figura 18 apresenta um outro trecho do perfil composto, em que se observam setas vermelhas indicando a profundidade de leitura da ferramenta, com os 


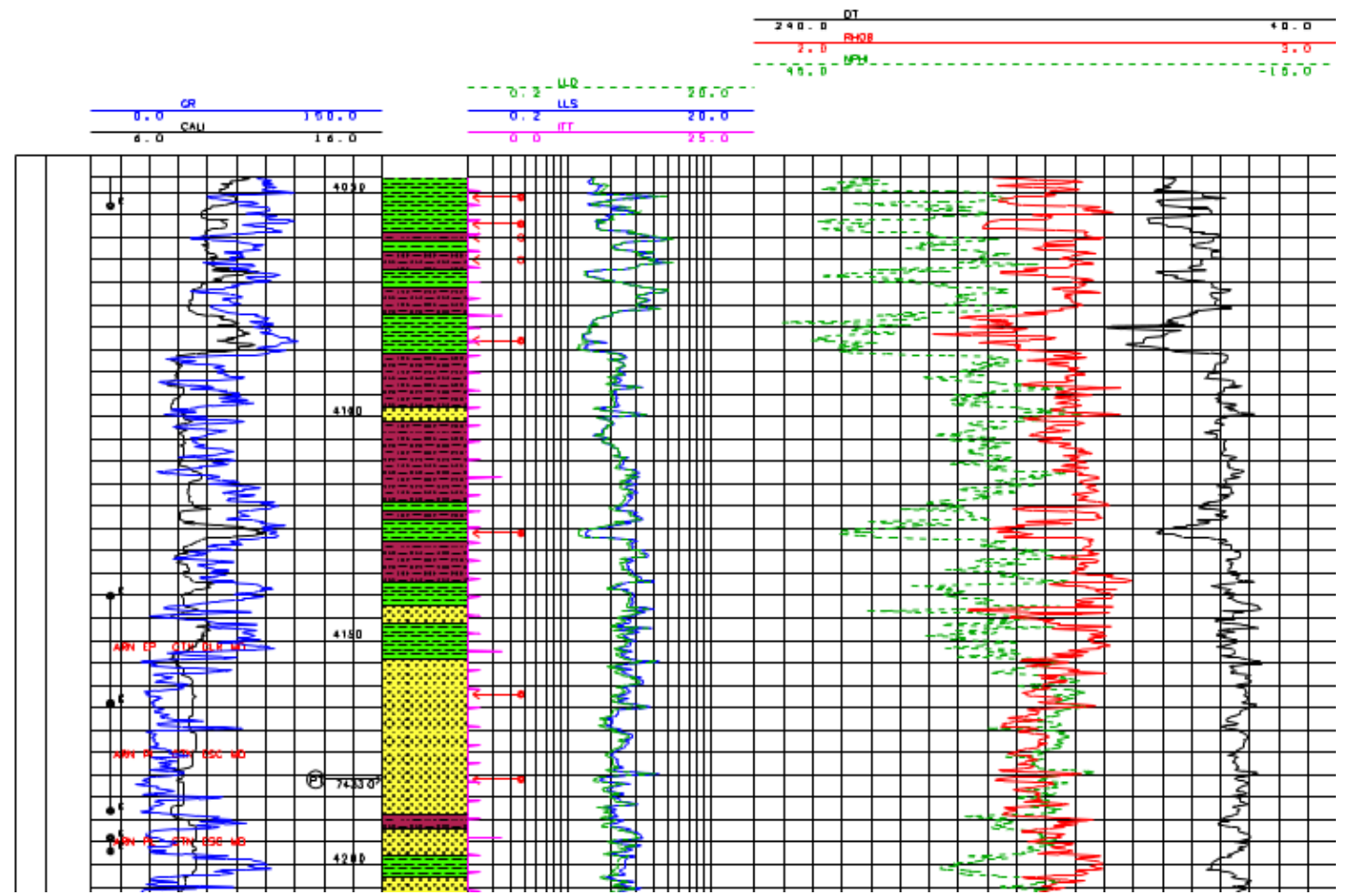

Figura 17: Trecho do perfil composto do poço CES-112, mostrando as curvas dos diferentes registros, além da litologia e profundidades de extração de calhas e testemunhos. Os registros, da esquerda para a direita: em azul, gamma-ray; em verde, azul e rosa, resistividade; em preto, tempo de trânsito; em vermelho, densidade; e, em verde, porosidade.

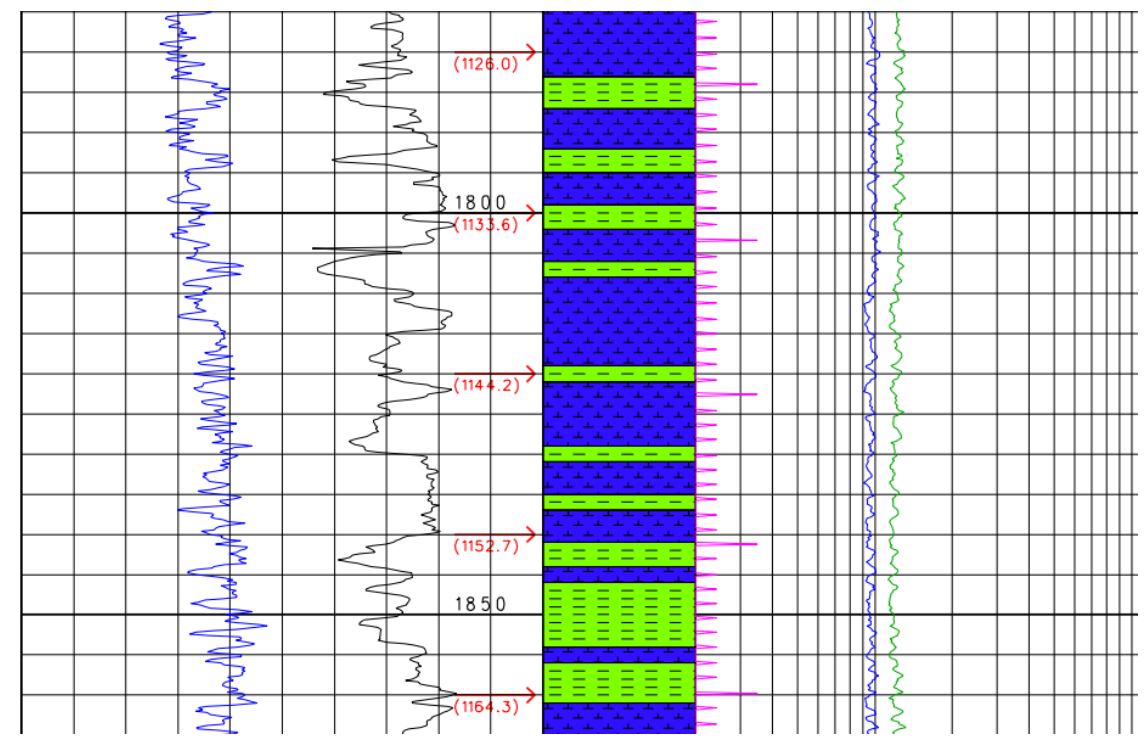

Figura 18: Trecho do perfil composto do poço CES-112 indicando, além dos demais registros, amostras de valores da ferramenta VSP, nas setas em vermelho. 
respectivos valores de tempo simples obtidos na aquisição, conhecidos por checkshot. A Tabela 3 mostra a relação de pares profundidade e tempo de trânsito medidos.

Tabela 3: Relação dos valores de tempo obtidos pela ferramenta VSP no poço CES-112

\begin{tabular}{|c|c|c|c|}
\hline Profundidade & Tempo & Profundidade & Tempo \\
\hline \hline 1670,0 & 1066,0 & 2020,0 & 1241,5 \\
1675,0 & 1068,0 & 2040,0 & 1250,2 \\
1685,0 & 1075,5 & 2060,0 & 1259,9 \\
1700,0 & 1083,0 & 2080,0 & 1269,4 \\
1720,0 & 1092,8 & 2100,0 & 1278,3 \\
1740,0 & 1103,7 & 2120,0 & 1287,3 \\
1760,0 & 1113,2 & 2140,0 & 1296,9 \\
1780,0 & 1126,0 & 2160,0 & 1305,5 \\
1800,0 & 1133,6 & 2180,0 & 1315,0 \\
1820,0 & 1144,2 & 2200,0 & 1322,9 \\
1840,0 & 1152,7 & 2220,0 & 1332,9 \\
1860,0 & 1164,3 & 2240,0 & 1340,2 \\
1880,0 & 1174,0 & 2260,0 & 1348,5 \\
1900,0 & 1183,4 & 2280,0 & 1357,0 \\
1920,0 & 1193,4 & 2300,0 & 1364,7 \\
1940,0 & 1203,4 & 2320,0 & 1372,6 \\
1960,0 & 1212,8 & 2340,0 & 1381,5 \\
1980,0 & 1221,2 & 2360,0 & 1390,0 \\
2000,0 & 1231,5 & 2380,0 & 1397,6 \\
\hline \hline
\end{tabular}

Utilizando estes valores, com suas respectivas profundidades de leitura, foram calculadas as velocidades para cada par. Estas velocidades foram utilizadas para refinamento do modelo de velocidades utilizado para a conversão de tempo $x$ profundidade.

De posse dos valores calculados no modelo de velocidades e da confirmação com os valores de checkshot, foi feita a conversão tempo $x$ profundidade. Esta conversão foi então cruzada com as informações cronoestratigráficas e de checkshot contidas no perfil composto do poço para garantir a qualidade da amarração. A conversão dos dados foi realizada a partir da Equação 2: 
Em que:

- $\Delta \mathrm{S}=$ Profundidade

- $V m=$ Velocidade média de propagação da onda sísmica

- $\Delta \mathrm{t}=$ Variação de tempo

As primeiras profundidades calculadas foram as do leito marinho. Para este cálculo, o valor utilizado para a velocidade de propagação na água foi de $1500,00 \mathrm{~m} \cdot \mathrm{s}^{-1}$. Para as unidades cronoestratigráficas (ou camadas sedimentares) subsequentes, foram sempre descontados os valores de tempo dos horizontes superiores. Como exemplo, para a camada posicionada imediatamente abaixo do leito marinho, o tempo de retorno do sinal sísmico considerado foi o tempo do refletor, subtraído do tempo de reflexão do leito marinho.

A partir destas informações, foram calculadas as velocidades médias intervalares para cada unidade cronoestratigráfica definida no trabalho (apresentadas mais adiante). As velocidades foram calculadas por média simples, com a remoção de eventuais pontos espúrios. As velocidades calculadas para cada unidade estão apresentadas na Seção 6.2.

Informações estratigráficas também estão presentes no perfil composto, como o topo do Membro Uruburetama, da Formação Ubarana (Fig. 6), identificado a 2992 metros de profundidade, e também o topo da Formação Mundaú, identificado a 3695 metros de profundidade. 


\subsection{Análise dos perfis}

A interpretação dos dados foi feita nos softwares OpendTect e GSEGYView, de acordo com os fundamentos da Estratigrafia de Sequências, e utilizando características como amplitude, fase e continuidade. Estas características foram ressaltadas com técnicas de pós-processamento que serão melhor descritas na Seção 5.8.

Uma vez que os dados sísmicos foram amarrados aos poços, os principais horizontes sísmicos puderam ser identificados baseados em sua profundidade no cruzamento com os poços. Para sua identificação utilizaram-se duas características: (1) a amplitude média e (2) sua fase. Com estas duas características dos horizontes foi possível traçar sua continuidade desde a posição do poço ao longo da linha sísmica. Quando se deparou com quaisquer dúvidas com relação à continuidade, ferramentas como níveis de aproximação (zoom), visualização em wiggle (em ondaletas) ou amplitude RMS (root mean square) ajudaram a resolve-las.

Enquanto a visualização por wiggle mostra a forma da onda sísmica, a visualização por amplitudes marca continuidades de amplitudes semelhantes, tornando mais fácil a identificação de refletores e horizontes. Além disso, é possível utilizar a visualização RMS - que calcula a raiz quadrada da média dos quadrados das amplitudes ao longo da onda (Chopra e Marfurt, 2007). Cada um destes processamentos e destas visualizações fornece subsídios diferentes para a interpretação (Fig. 19).
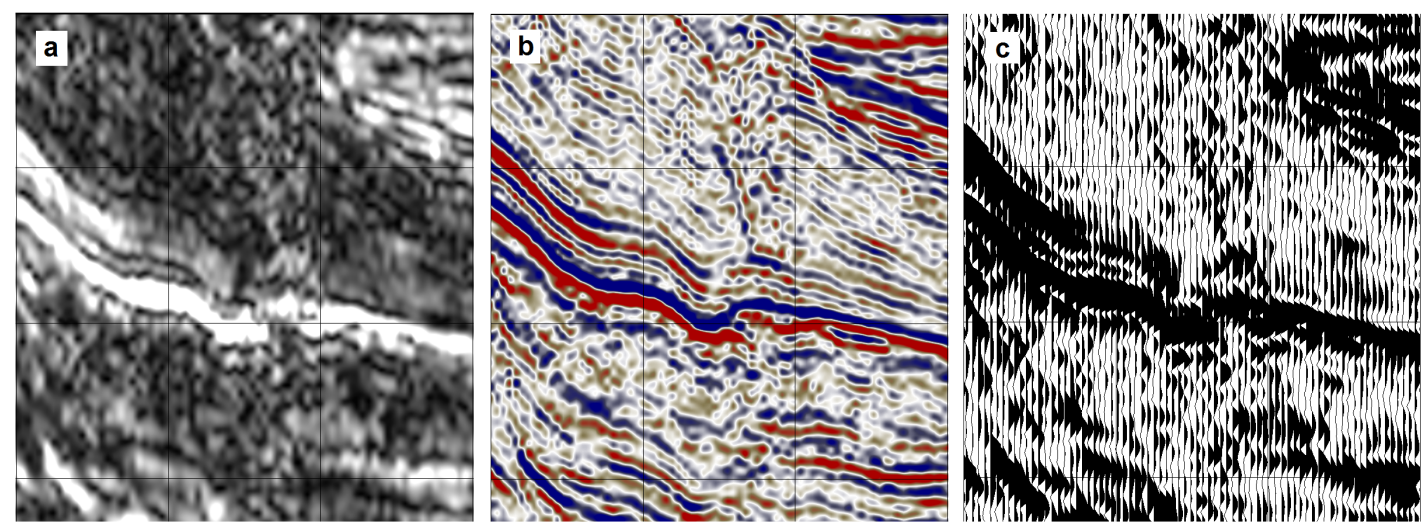

Figura 19: Diferentes processamentos de imagem para a visualização do dado sísmico: (a) amplitude RMS; (b) valores normais de amplitude com suas fases diferentes sendo representadas pelas cores azul e vermelho; e (c) visualização em wiggle.

Para a análise de horizontes sísmicos, foram consideradas suas terminações e superfícies, conforme descrito por Ribeiro (2001). Estruturas como as terminações em 
onlap, downlap, toplap e truncamentos erosivos (Fig. 20) são pontos chave da análise de perfis sísmicos.

Os tipos de terminação encontrados nos dados sísmicos fornecem informações a respeito dos possíveis processos deposicionais. Refletores com terminações em onlap e downlap estão relacionados com a sedimentação ligada a processos regressivos ou transgressivos. O avanço do downlap em direção ao centro da bacia sedimentar indica uma progradação da pilha sedimentar com possível descida do nível relativo médio do mar ou aumento do aporte sedimentar ou da subsidência da bacia. Um aumento no aporte sedimentar na bacia em períodos de nível do mar alto estável também pode ter este mesmo efeito representado pelo avanço do downlap. Por sua vez, o avanço do onlap em direção ao continente indica um processo transgressivo com o consequente afogamento da bacia sedimentar e a retrogradação da linha de costa. Esta migração do onlap em direção ao continente também pode estar relacionado à diminuição do aporte sedimentar, quando aliada a um recuo do downlap em períodos de nível do mar alto estável.

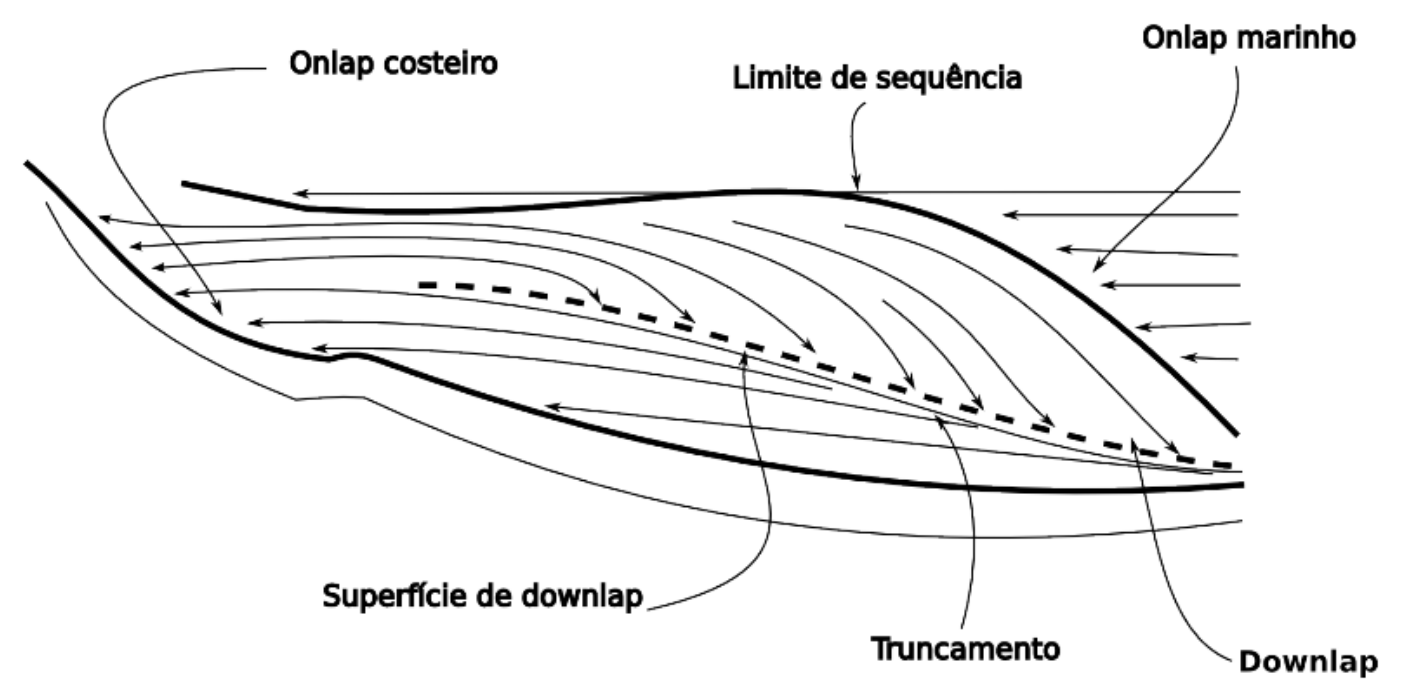

Figura 20: Terminações de refletores em um perfil sísmico (Alves, 2012), adaptado de (Mitchum et al., 1977).

As informações que podem ser obtidas com as terminações em onlap e downlap dos refletores estão geralmente relacionadas com subidas e descidas relativas do nível do mar - considerando-se variações no volume de água e no espaço de acomodação. Quando a velocidade da subida relativa do nível do mar é alta, é mais provável que os eventos erosivos predominem e os truncamentos erosivos se tornam importantes para a identificação destes eventos. 
Esta análise, bem como a correlação da interpretação com outros estudos na MEB ou em sua correlata africana, serve de base para a identificação de eventos climáticos importantes para a definição dos processos sedimentares atuantes durante a evolução do tempo geológico.

\subsection{Pós-processamento dos perfis sísmicos}

Os dados sísmicos deste projeto foram adquiridos em sua forma processada, com exceção de algumas linhas fornecidas em estado bruto. Por esta razão, as técnicas de processamento utilizadas se basearam no pós-processamento, ou processamento gráfico das seções sísmicas.

O pós-processamento foi realizado no software OpendTect, que possui ferramentas próprias para processamentos de dados pós-empilhamento, como amplitude RMS, similaridade e fase instantânea (Fig. 21).

O cálculo do atributo de fase instantânea foi utilizado para melhor mapear os horizontes sísmicos definidos. A fase instantânea permite mapear a continuidade dos refletores, ressaltando suas fases, sem levar em conta as amplitudes (Fig. 21B). Este tipo de processamento melhora a capacidade de mapeamento, já que um mesmo horizonte sísmico, salvo algumas exceções, possui a mesma fase.

A representação do atributo de amplitudes RMS ressalta as amplitudes mais altas (Fig. 21C), seja qual for sua fase, tendo sido muito útil para a identificação dos refletores principais em uma bacia, como o embasamento acústico.

Por sua vez, o atributo de similaridade destaca a descontinuidade de refletores sísmicos (Fig. 21D). A presença de falhas, dobramentos, paleocanais ou mesmo do embasamento acústico são mais facilmente percebidas com a utilização deste tipo de processamento. 

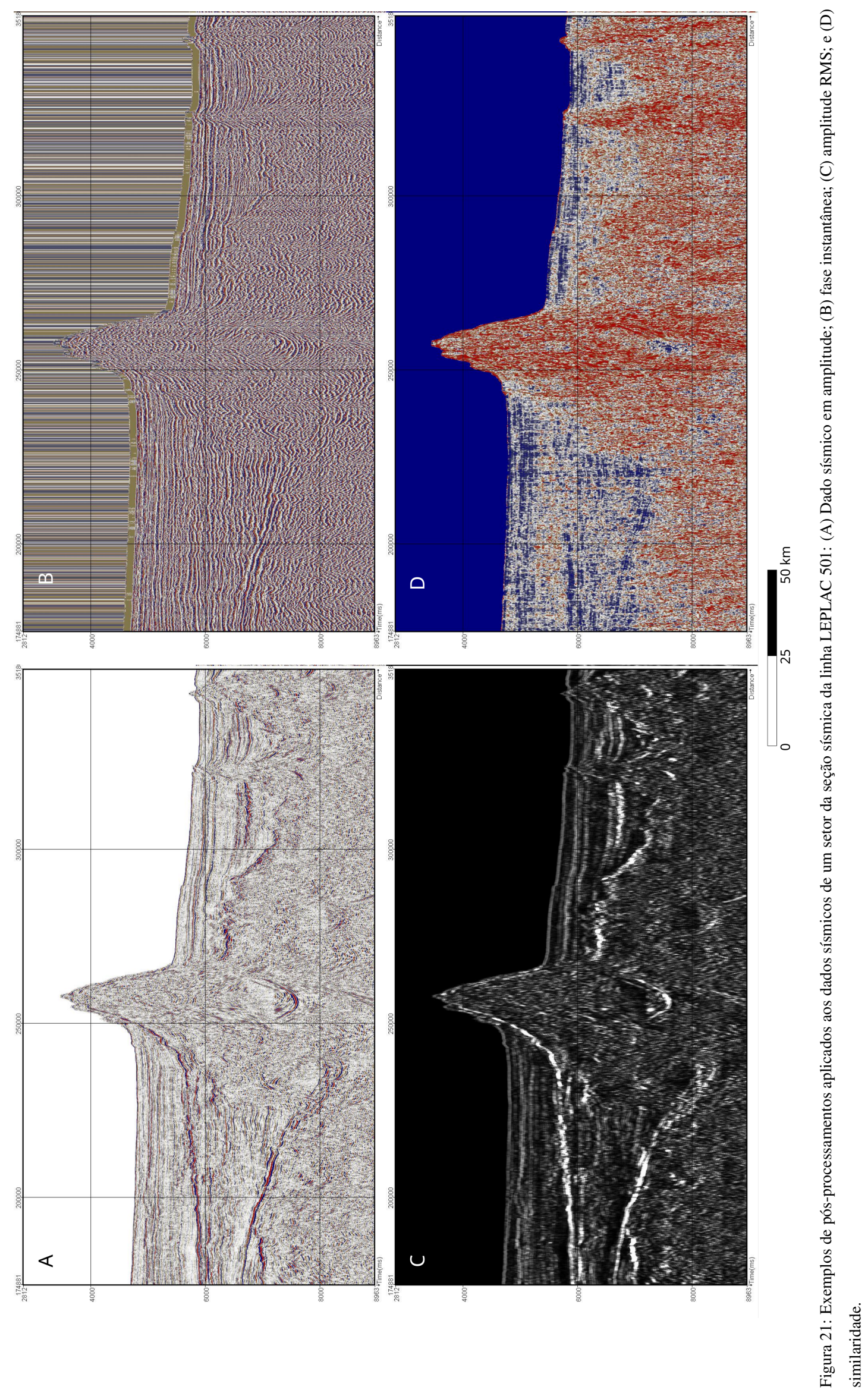
Finalmente, outra ferramenta utilizada durante a interpretação, para a transposição dos montes submarinos e a continuidade do mapeamento dos horizontes foi a janela fantasma (Fig. 22). Com esta ferramenta, foi possível levar o mapeamento feito pela continuidade dos horizontes de um lado para o outro dos montes submarinos. Sua utilização é bastante simples e consiste na transposição de uma "janela" de lado do obstáculo (neste caso, os montes submarinos) para o outro. Assim, é possível correlacionar mais facilmente um horizonte de um lado para ao outro, com base em sua fase, amplitude ou sismofácies.

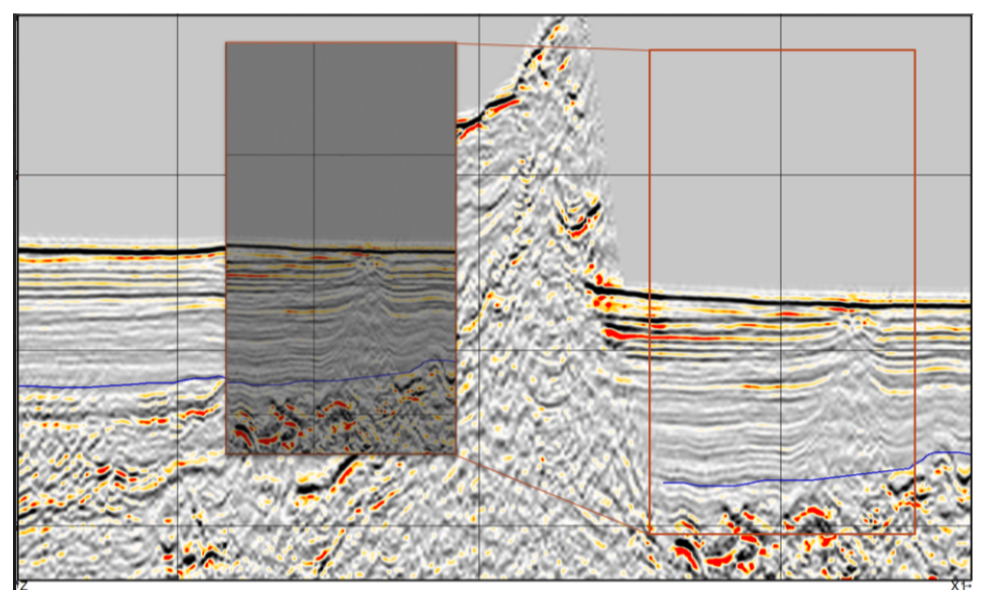

Figura 22: Exemplo da ferramenta conhecida como "janela fantasma", com a qual é possível levar a interpretação de um lado de uma barreira para o outro.

Todas estas técnicas de processamento foram utilizadas em grande parte das linhas sísmicas, tendo contribuído para a definição de horizontes, continuidade de mapeamento e transposição de obstáculos como montes submarinos.

\subsection{Cálculo de espessuras e taxas de sedimentação}

Os horizontes sísmicos identificados marcam os limites de cinco Unidades Cronoestratigráficas (UC) definidas neste trabalho. Estes horizontes foram exportados para arquivos de texto do tipo XYZ/ASCII, contendo informações de latitude, longitude e tempo. A partir do modelo de velocidades, os valores em tempo foram convertidos para profundidades em metros conforme descrito na Seção 5.6. A seguir, os dados foram interpolados no software Surfer 13.0 pelo método TIN (Rede Irregular de Triangulação) para a geração de superfícies para cada um dos horizontes. 
As espessuras de cada UC analisada foram calculadas com base na diferença entre as profundidades dos horizontes que os limitam no topo e na base. O cálculo das espessuras foi realizado no software QGIS 2.18.9, por meio da calculadora de rasters. Entrentanto, é fundamental que se destaque que as espessuras calculadas são relacionadas a superfícies erosivas. Isso quer dizer que os valores encontrados são apenas aproximados, já que não representam a totalidade da carga sedimentar depositada na região, uma vez que grande parte dos sedimentos foi removida.

Finalmente, com as espessuras e o tempo total de duração de cada período, foram calculadas as taxas de sedimentação aproximadas para cada um deles, também no software QGIS 2.18.9, utilizando a Equação 3:

$$
T S=\frac{\Delta S}{\Delta t}
$$

Em que,

- $\mathrm{TS}=$ Taxa de sedimentação

- $\Delta \mathrm{S}=$ Espessura do pacote sedimentar

- $\Delta \mathrm{t}=$ Tempo de duração do período considerado

As durações $(\Delta t)$ utilizadas para o Paleógeno e Neógeno + Quaternário utilizadas para os cálculos das taxas de sedimentação foram extraídas da Tabela Cronoestratigráfica Internacional (Cohen et al., 2017) (Tabela 4).

Tabela 4: Valores de duração (em milhões de anos) utilizados para o cálculo das taxas de sedimentação.

\begin{tabular}{c|c}
\hline \hline Período & Idade (milhões de anos) \\
\hline \hline P1 - Paleógeno & 42,97 \\
\hline P2 - Neógeno + Quaternário & 23,03 \\
\hline \hline
\end{tabular}


Cálculos de taxa de sedimentação a partir de dados sísmicos são realizados a partir da técnica conhecida por backstripping (Steckler e Watts, 1978). Este é um método quantitativo para a reconstrução da sequência deposicional em uma bacia (Van Sickel et al., 2004), no qual tanto os valores de subsidência quanto a compactação das camadas sedimentares (pelo peso das camadas superiores) é considerado. De maneira sintética, retira-se sucessivamente as camadas superiores, descompactando as camadas inferiores e, desta forma, chega-se a valores mais realistas das espessuras dos pacotes sedimentares e, consequentemente, das taxas de sedimentação. Como o escopo deste trabalho não envolve a técnica backstripping, os valores aqui apresentados são aproximações das taxas de sedimentação para cada um dos períodos, que não quantificam nem a erosão nem os processos de subsidência e de compactação das camadas sedimentares. 


\section{Resultados}

Com a integração dos dados sísmicos e do poço, foi possível atribuir profundidades e idades aos horizontes sísmicos interpretados ao longo das linhas sísmicas nas duas bacias sedimentares. A amarração do poço CES-112 à sísmica foi feita por meio da linha R0003-GRAND-NORTH.0222-0479-FIN11, localizada na Bacia do Ceará (Fig. 23).

Foram definidos 5 horizontes sísmicos os quais, após confirmação com a carta estratigráfica das bacias, foram definidos como marcadores cronoestratigráficos:

- H1: topo do Maastrichtiano, representado em azul-escuro nas seções sísmicas;

- H2: topo do Thanetiano, representado em roxo nas seções sísmicas;

- H3: base do Chattiano, representado em verde nas seções sísmicas;

- H4: topo do Aquitaniano, representado em laranja nas seções sísmicas; e

- H5: topo do Serravalliano, representado em amarelo nas seções sísmicas.

A posição destes horizontes sísmicos interpretados na carta estratigráfica da Bacia do Ceará (Condé et al., 2007) (Fig. 24), indica sua posição no tempo geológico, na sequência estratigráfica da bacia e com relação à curva de variação do nível relativo médio do mar de Miller et al. (2005). 


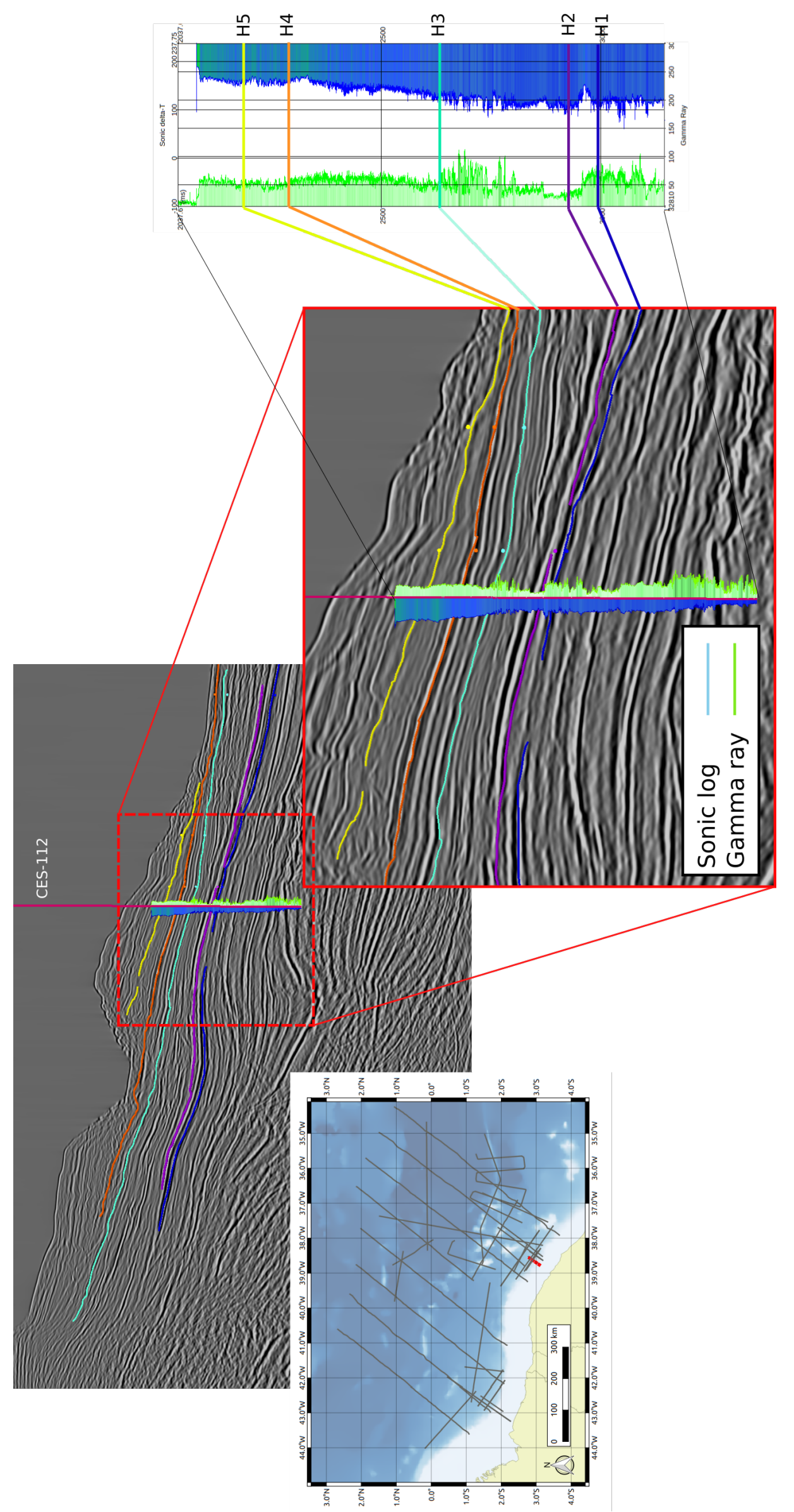

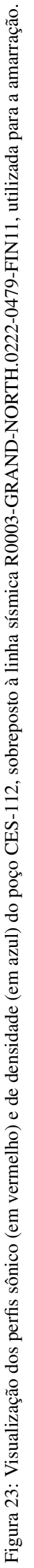




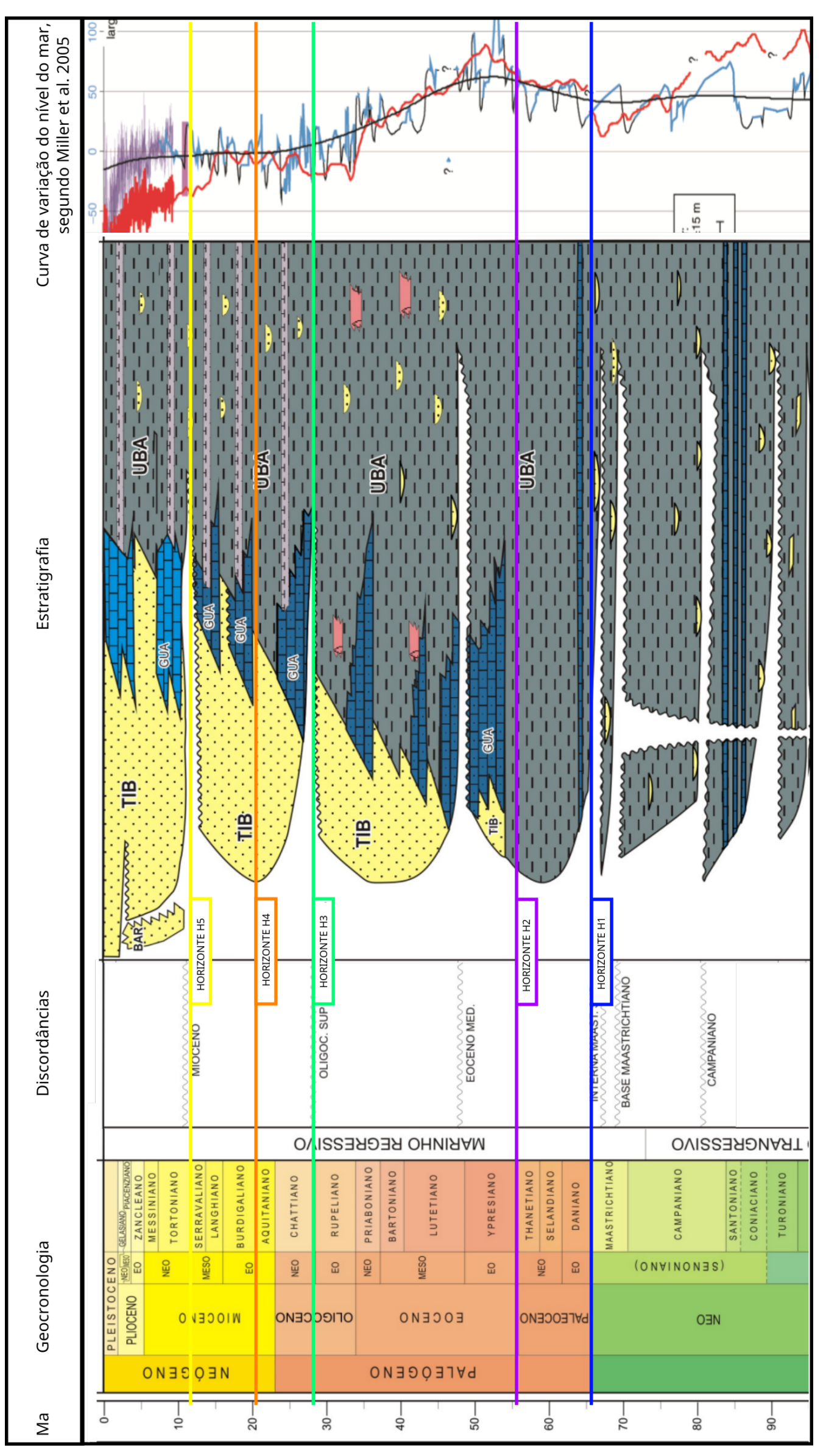

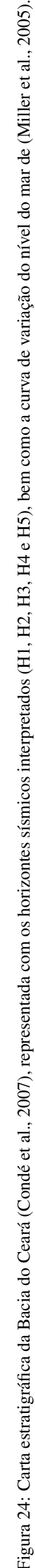


As camadas sedimentares entre cada par de horizontes sísmicos definiram cinco Unidades Cronoestratigráficas (UC), sendo elas:

- UC1: base em H1 e topo em H2, representando o Paleoceno;

- UC2: base em H2 e topo em H3, representando o Eoceno e Oligoceno Inferior;

- UC3: base em H3 e topo em H4, representando o Oligoceno e parte do Mioceno Inferior;

- UC4: base em H4 e topo em H5, representando o restante do Mioceno Inferior;

- UC5: base em H5 e topo no leito marinho, representando o Mioceno Médio até o presente.

De forma geral, todos os horizontes foram bem mapeados ao longo das duas bacias sedimentares, com exceção ao H2 - Topo do Thanetiano, que teve seu mapeamento limitado apenas a porção mais a leste da Bacia do Ceará. Esta limitação é decorrente das próprias características de reflexão e amplitude do refletor, de morfologia bastante descontínua. Por esta razão, foi impossível mapeá-lo para além de uma pequena área, conforme será descrito adiante.

Além dos cinco horizontes sísmicos interpretados e mapeados, foi ainda mapeada a primeira reflexão em todas as linhas, o que corresponde à batimetria da área. A batimetria foi definida para que houvesse uma superfície de topo da coluna sedimentar atuando como referência para os cálculos de espessura, além de fornecer informações adicionais sobre as características atuais da região.

Em um trecho de pouco mais de $580 \mathrm{~km}$ da seção sísmica da linha LEPLAC501 (Fig. 25), pode-se observar o Platô do Ceará e um segundo monte submarino, ligado à cadeira de montes da Zona de Fraturas Romanche (ZFR). Além disso, a figura ainda mostra os horizontes sísmicos mapeados em quase toda a extensão da seção sísmica. Esta linha é um exemplo de como foi feita a aquisição dos dados do LEPLAC, isto é, com linhas bastante longas, e passando sobre feições geológicas como estas. 
so

NE
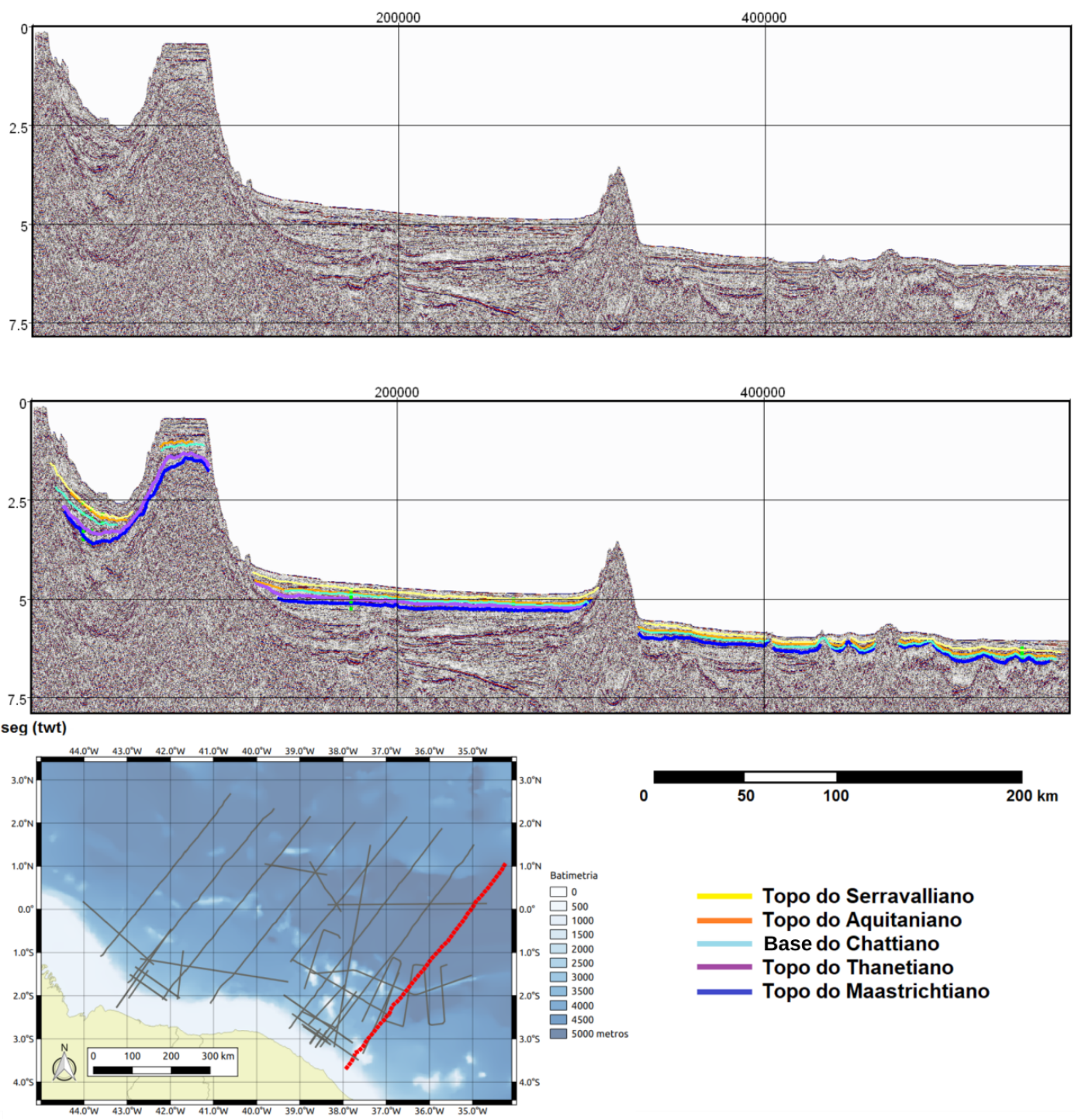

Figura 25: Seção sísmica da linha LEPLAC-501, passando pelo Platô do Ceará e um segundo monte submarino, ligado à ZFR. Exagero vertical de 40 vezes.

As linhas da ANP, por sua vez, são linhas sísmicas obtidas na indústria do petróleo, o que lhes dá características diferentes de comprimento, local de aquisição, profundidade de registro e processamento. A seção sísmica da linha 0231-MUNDAU-16A.02311158.MIG-FIN.7 (Fig. 26), que foi registrada na direção strike (paralela à linha de costa e à quebra da plataforma), torna evidentes os cânions presentes na plataforma continental da MEB (como descrito por Vital et al. (2010b), Vital et al. (2010a) e Almeida et al. (2015)).

Durante o mapeamento dos horizontes, foram encontradas algumas limitações relacionadas a características das linhas sísmicas, principalmente por sua localização sobre montes submarinos e pelo tipo de processamento realizado, que visava ressaltar as 
maiores profundidades.

NO
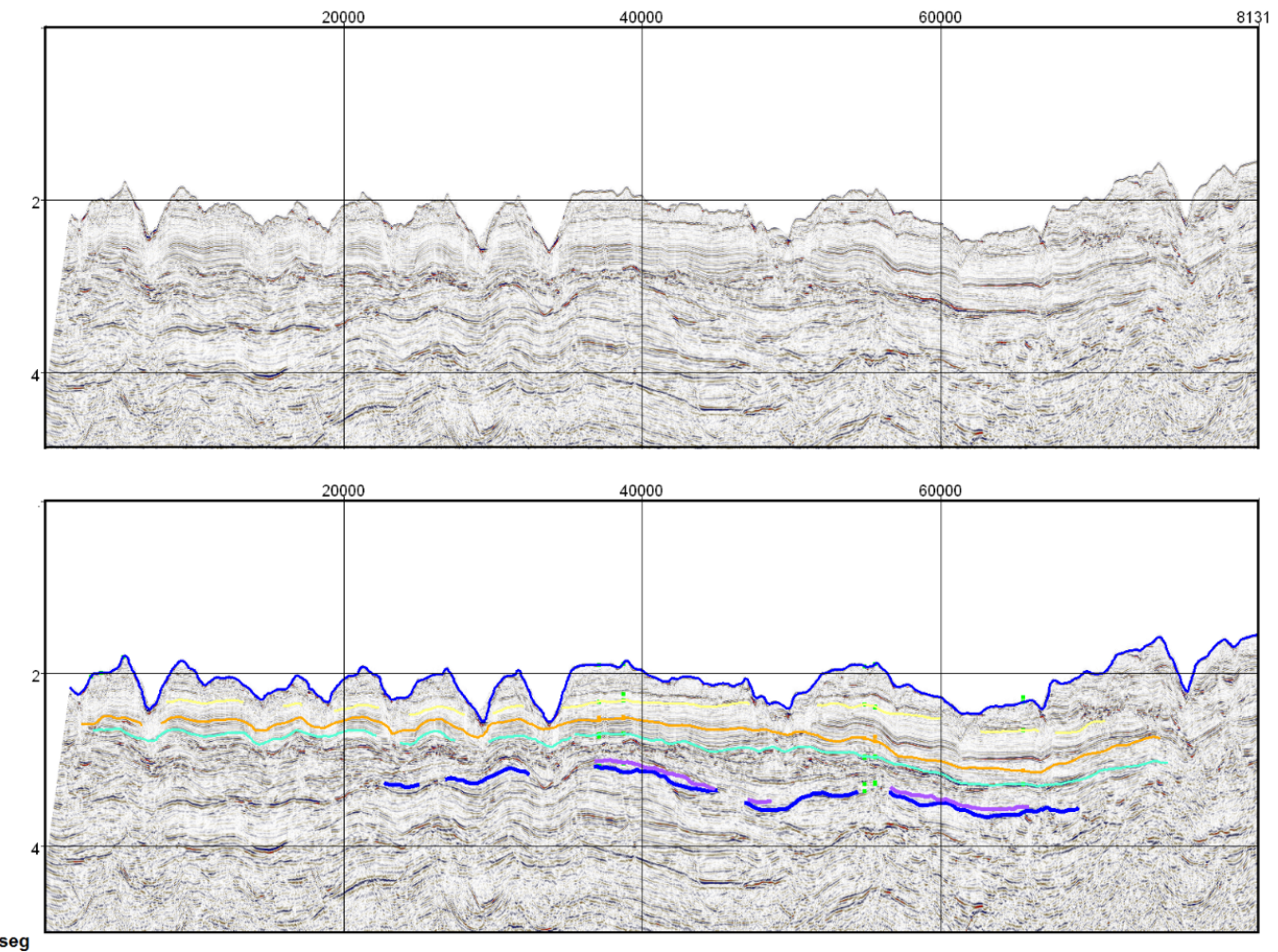

seg
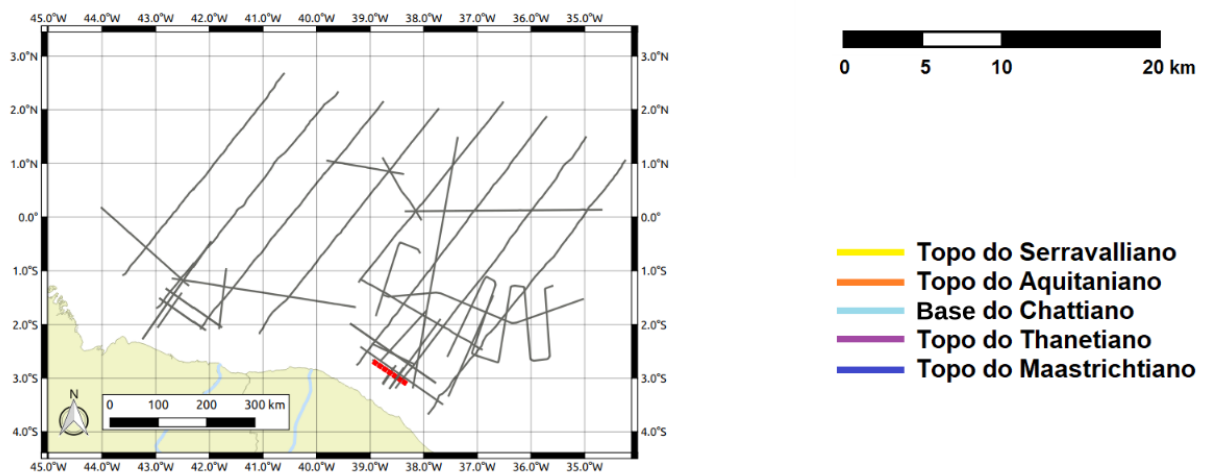

Topo do Aquitaniano

Base do Chattiano

Topo do Thanetiano

Topo do Maastrichtiano

Figura 26: Seção sísmica da linha 0231-MUNDAU-16A.0231-1158.MIG-FIN.7, na direção strike, isto é, paralela à linha de costa e transversal ao talude. Exagero vertical de 8 vezes.

Essas limitações são decorrentes do tipo de levantamento sísmico realizado para aquisição dos dados do LEPLAC. Em algumas linhas, como na LEPLAC - 502 (Fig. 27) existem interrupções na continuidade dos horizontes devido à presença de montes submarinos ou elevações do embasamento acústico. Essas interrupções foram vencidas com técnicas descritas anteriormente, porém, em alguns casos, elas não puderam ser ultrapassadas (Fig. 28). 


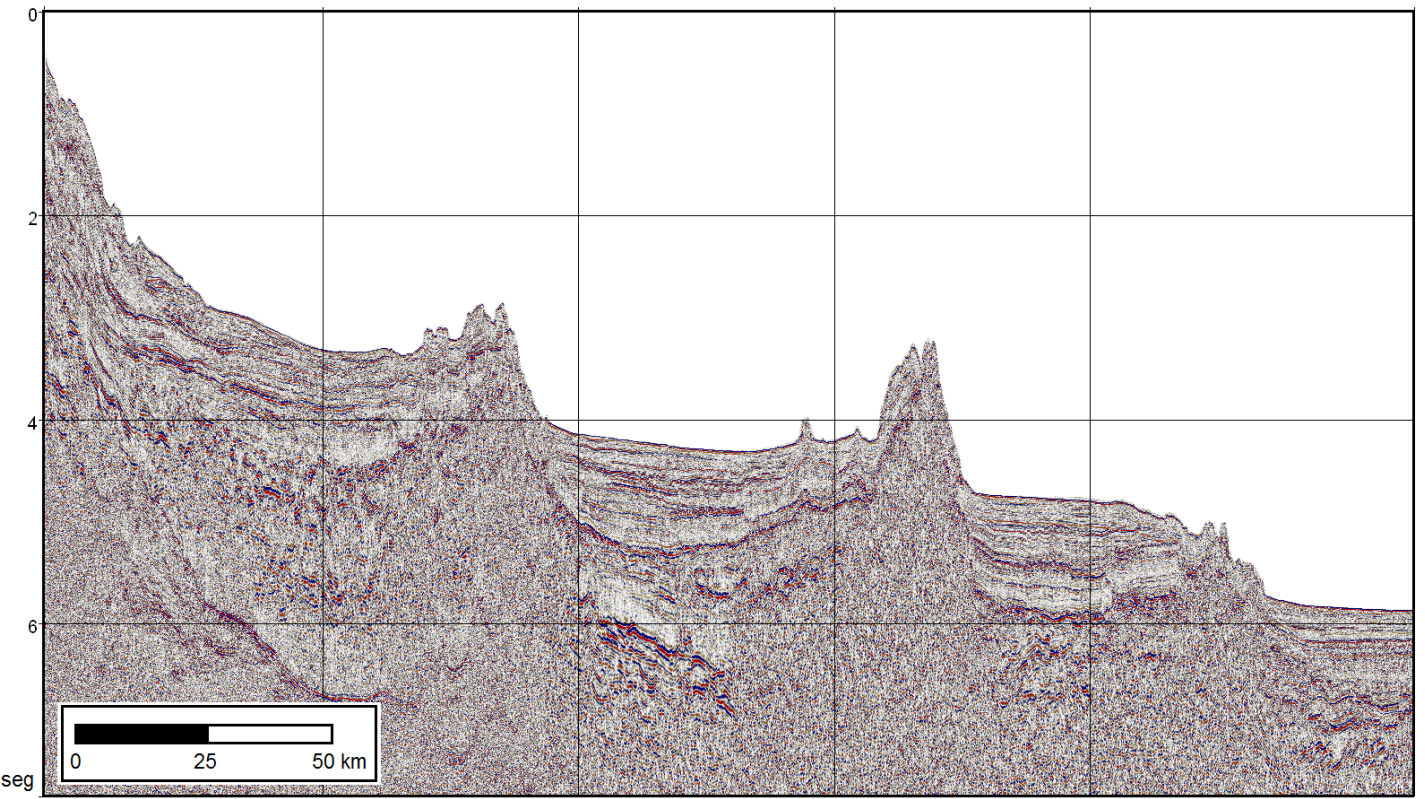

Figura 27: Seção sísmica de trecho da linha LEPLAC-502, que mostra a presença de pelo menos 3 elevações do embasamento e a consequente interrupção da continuidade dos horizontes. Exagero vertical de 27 vezes.

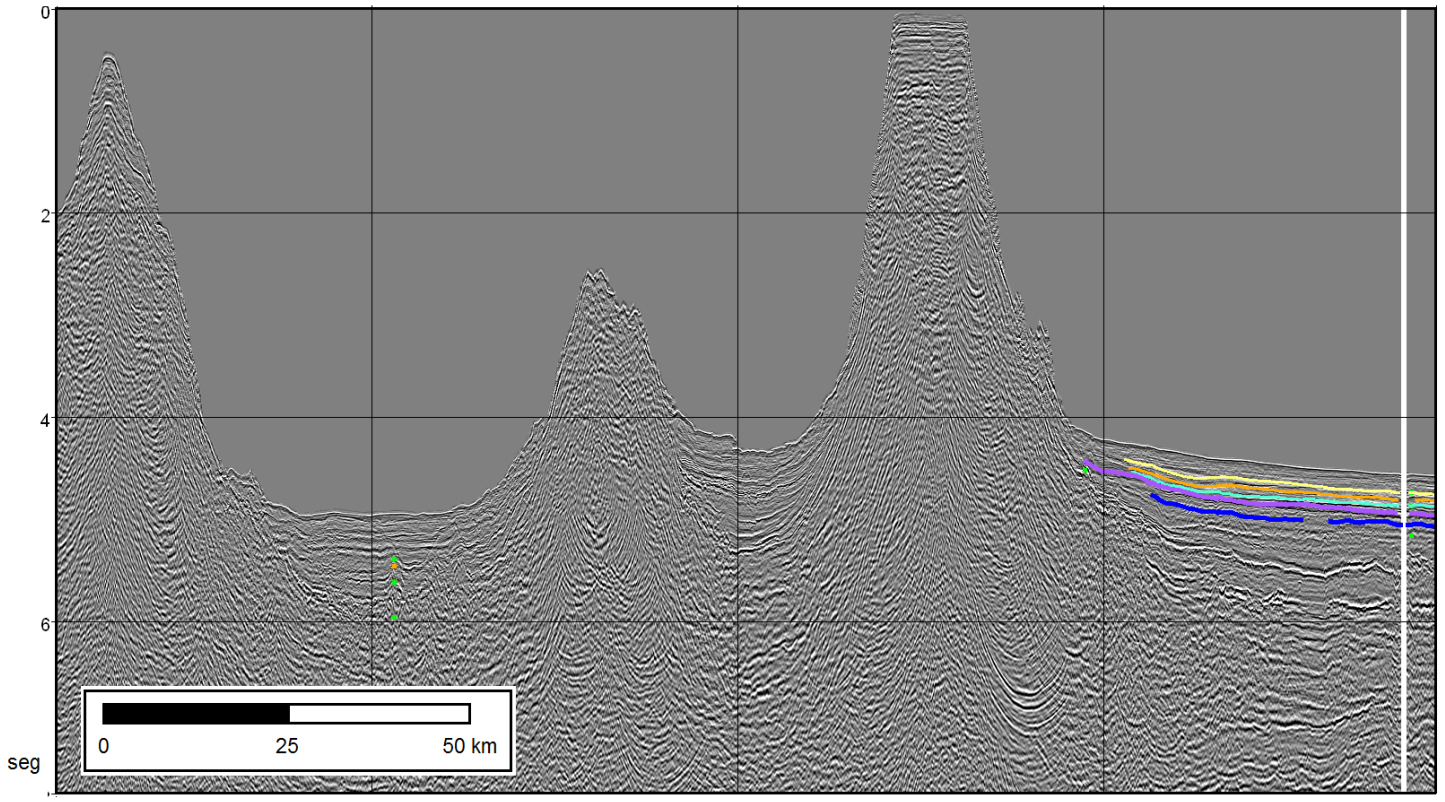

Figura 28: Seção sísmica de trecho da linha LEPLAC-513, mostrando a presença de 3 montes submarinos que os horizontes sísmicos interrompido. Exagero vertical de 17 vezes. 
A distribuição do mapeamento dos horizontes (Fig. 29) mostra que, com exceção ao horizonte $\mathrm{H} 2$ (em roxo), todos os demais foram mapeados de forma bastante ampla ao longo das duas bacias. Pelas características morfológicas já mencionadas de $\mathrm{H} 2$, seu mapeamento foi dificultado e, por este motivo, ao contrário dos demais horizontes - que foram interpolados para toda a área de estudo -, H2 foi interpolado apenas na região em que foi interpretado, isto é, na porção a sudeste da Bacia do Ceará.

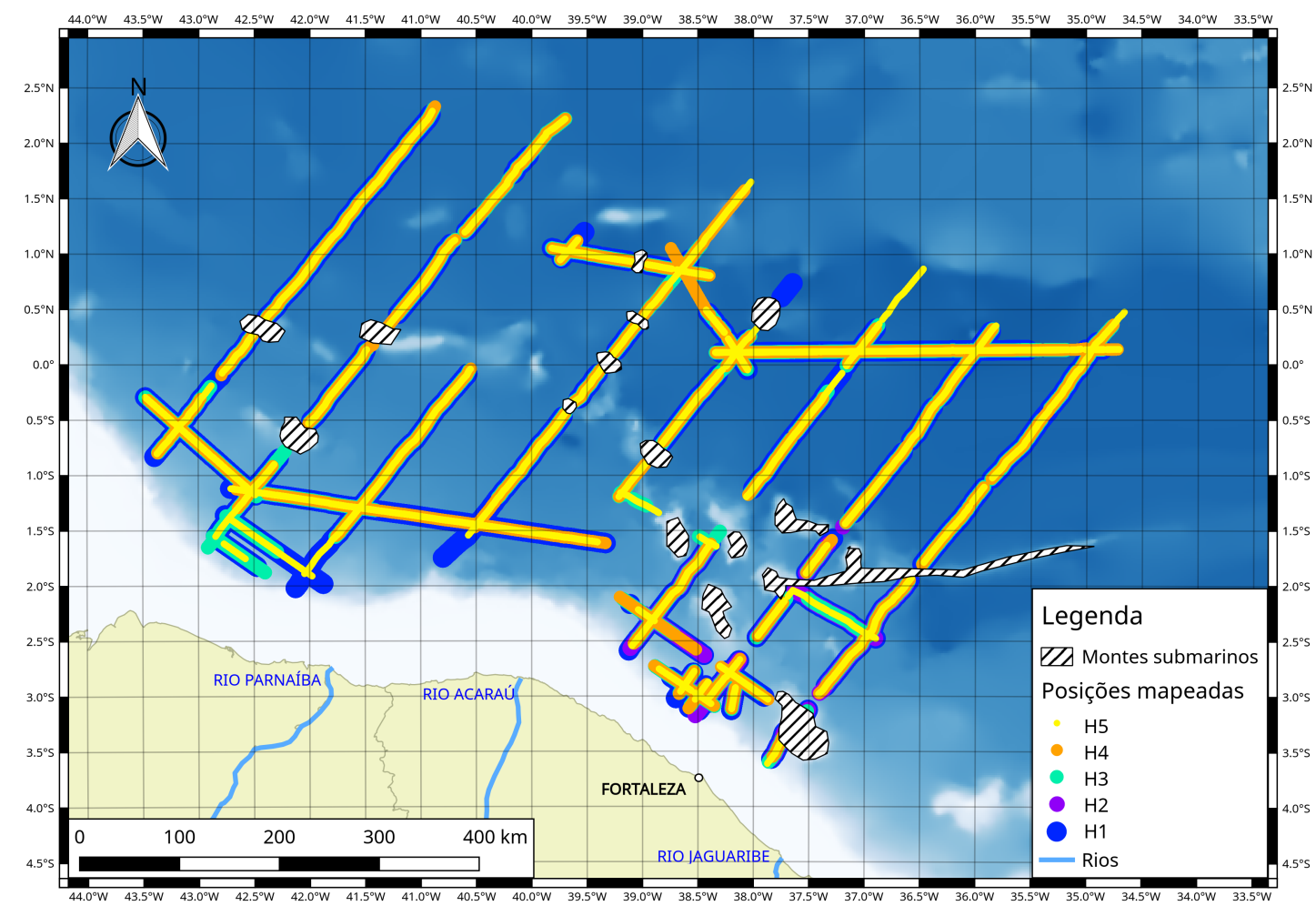

Figura 29: Mapa da região das bacias do Ceará e de Barreirinhas, com as posições mapeadas para cada um dos horizontes sísmicos interpretados. Coordenadas geográficas, Datum WGS84.

Durante a interpretação das seções sísmicas, foram encontradas feições de importância para o estudo sedimentar e oceanográfico da região, que serão melhor descritas a seguir. 


\subsection{Sismofácies em detalhes nas seções sísmicas}

\subsubsection{Cânions}

Conforme mencionado anteriormente na Figura 26, algumas das seções sísmicas obtidas na direção strike cruzam diversos cânions existentes no talude, que podem ser facilmente identificados nos registos sísmicos.

Em uma visão aproximada da porção superior da linha 0231-MUNDAU-16A 0231-1158.MIG-FIN.7 (Fig. 30, com visão geral da linha e sua localização na Fig. 63, nos Apêndices), podem ser observados detalhes destes cânions, como sua largura de cerca de 2,5 km, em alguns casos. Os canais em destaque cortam o horizonte H5 - Serravalliano, o que indica que a atuação destes canais erodiu o talude até camadas sedimentares de 11,63 milhões de anos de idade (Cohen et al., 2017).

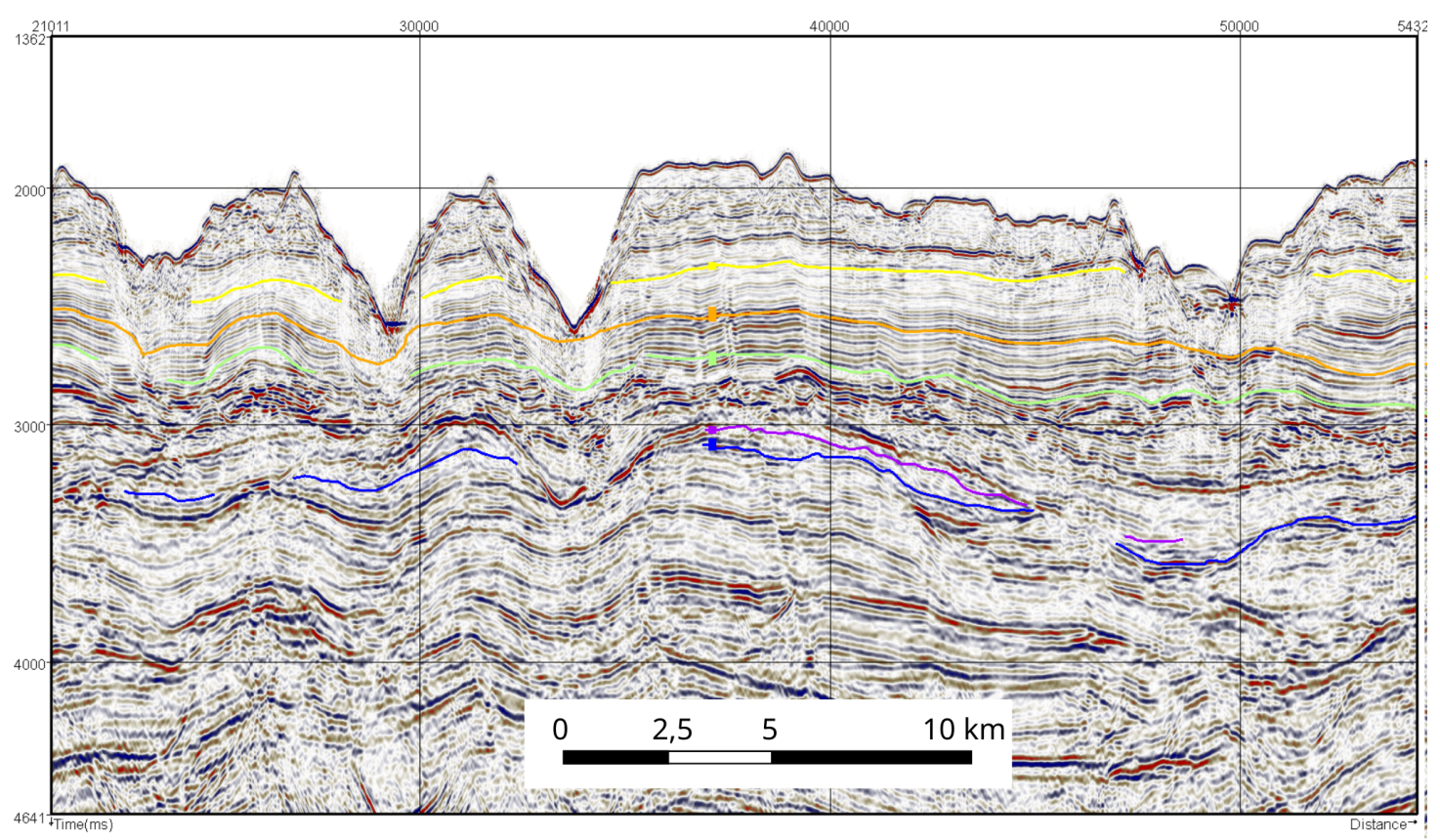

Figura 30: Detalhe da porção superior da linha 0231-MUNDAU-16A.0231-1158.MIG-FIN.7, indicando a presença de cânions no talude. Exagero vertical de 12 vezes

A presença de cânions desta dimensão no talude das bacias de Barreirinhas e do Ceará é pouco documentada, ainda que existam registros mais a leste, na Bacia Potiguar (RN) apresentados em trabalhos como os de Vital et al. (2010a) e Vital et al. (2010b). Não obstante, assim como na plataforma do Rio Grande do Norte, a distribuição de sedimentos através de canais também aparece nas duas bacias estudadas neste trabalho. 
Vital et al. (2010a) destacam ainda que a formação destes cânions está relacionada com períodos de nível do mar mais baixo, principalmente durante eventos glaciais mais extremos no Quaternário. Considerando as baixas profundidades da plataforma continental destas duas bacias, é de se esperar que estes canais tiveram também grande importância na distribuição de sedimentos a regiões mais profundas durante períodos em que o nível relativo médio do mar esteve mais elevado.

\subsubsection{Bacias menores separadas por altos}

As bacias sedimentares da MEB possuem descontinuidades devido à presença de diversos montes submarinos na região. A Bacia do Ceará, como visto anteriormente, é dividida em sub-bacias com características geomorfológicas distintas (Condé et al., 2007). A linha LEPLAC-502 (Fig. 31) é um bom exemplo, já que passa por dois montes submarinos interrompendo a sequência dos horizontes sísmicos, mesmo que não relacionados diretamente a estas sub-bacias.

Este é apenas um exemplo, mas esta mesma característica foi identificada em outras regiões da área de estudo, na Bacia de Barreirinhas, como nas linhas LEPLAC507 e LEPLAC-508 (Figs. 87 e 89, nos Apêndices), ou na Bacia do Ceará, nas linhas LEPLAC-501 e LEPLAC-503 (Figs. 73 e 77, nos Apêndices).

Todas estas variações topográficas refletem diretamente a influência destes altos na distribuição e deposição dos sedimentos na MEB e, ainda que presente nas duas bacias estudadas, na Bacia do Ceará esta influência é maior para o Cenozoico, como será visto adiante.

\subsubsection{Espessuras influenciadas por montes submarinos}

Uma das características mais marcantes identificadas na região proximal da Bacia do Ceará, junto ao sopé continental, é uma clara diferença nas espessuras quando comparados os lados SE e NO dos montes submarinos relacionados à Cordilheira Norte Brasileira. 


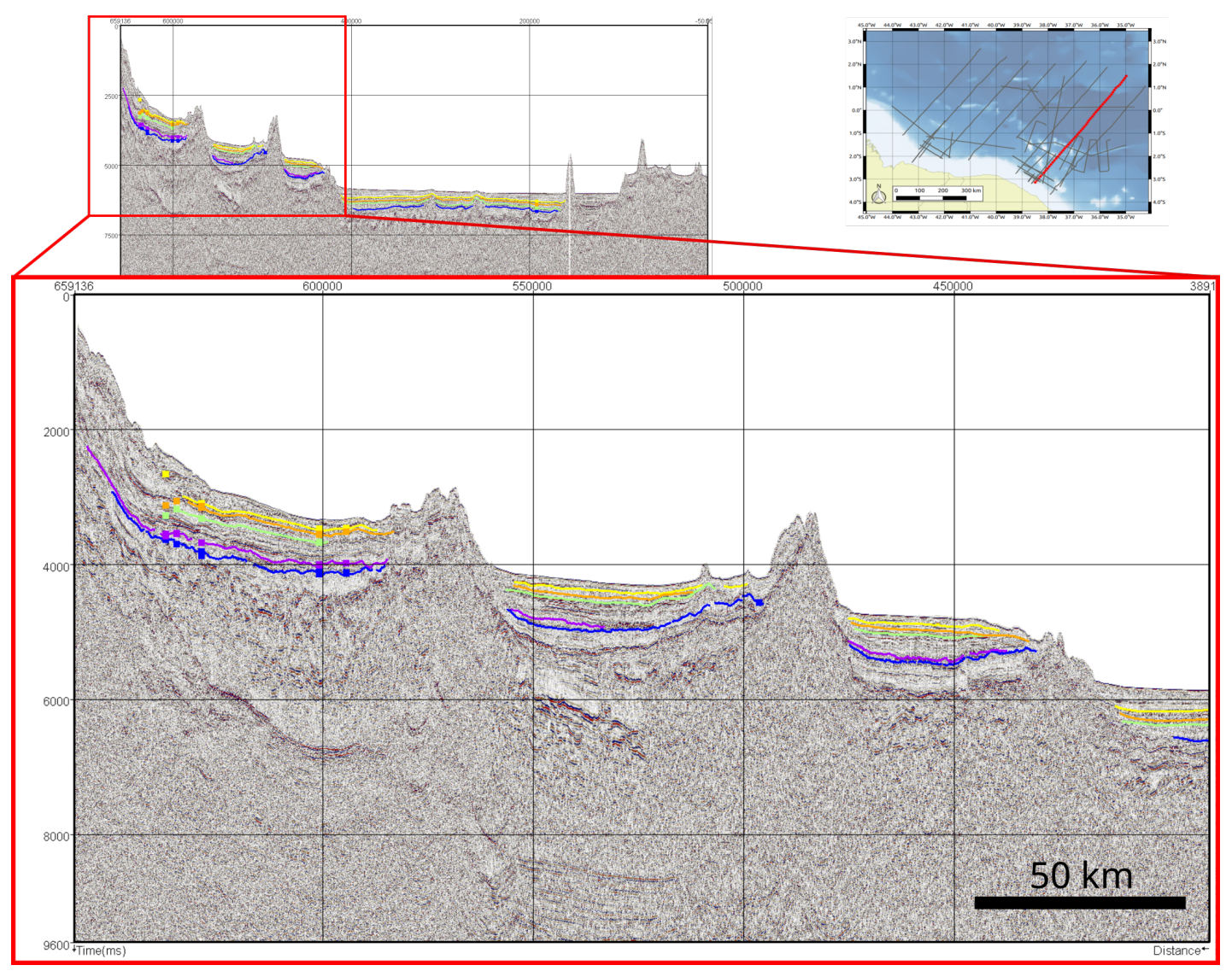

Figura 31: Detalhe da linha LEPLAC-502, mostrando (abaixo) a visão ampliada de bacias menores na Bacia do Ceará e, acima, o mapa de localização da seção sísmica. Exagero vertical de 27 vezes.

A linha sísmica 0231-MUNDAU-16A-SEGMENTO-0231-1170-FIN8 (Fig. 32), obtida na direção strike, indica uma nítida diferença nas profundidades dos horizontes sísmicos interpretados. Esta diferença está diretamente relacionada com a espessura total da coluna sedimentar dos dois lados do monte submarino presente na porção central da seção. Esta mesma diferença na espessura do pacote sedimentar cenozóico será vista mais adiante, quando calculadas as espessuras das UC.

\subsubsection{Estruturas internas identificadas na sísmica}

As estruturas internas identificadas nas seções sísmicas contribuem para o entendimento de alguns processos sedimentares e tectônicos. Nas áreas mais distantes da plataforma continental, onde predomina a deposição autóctone/pelágica, os refletores sísmicos adquirem um caráter plano-paralelo. Este tipo de reflexão é esperado e está presente nas duas bacias estudadas. Entretanto, quando se aproxima do talude e sopé continentais, bem 


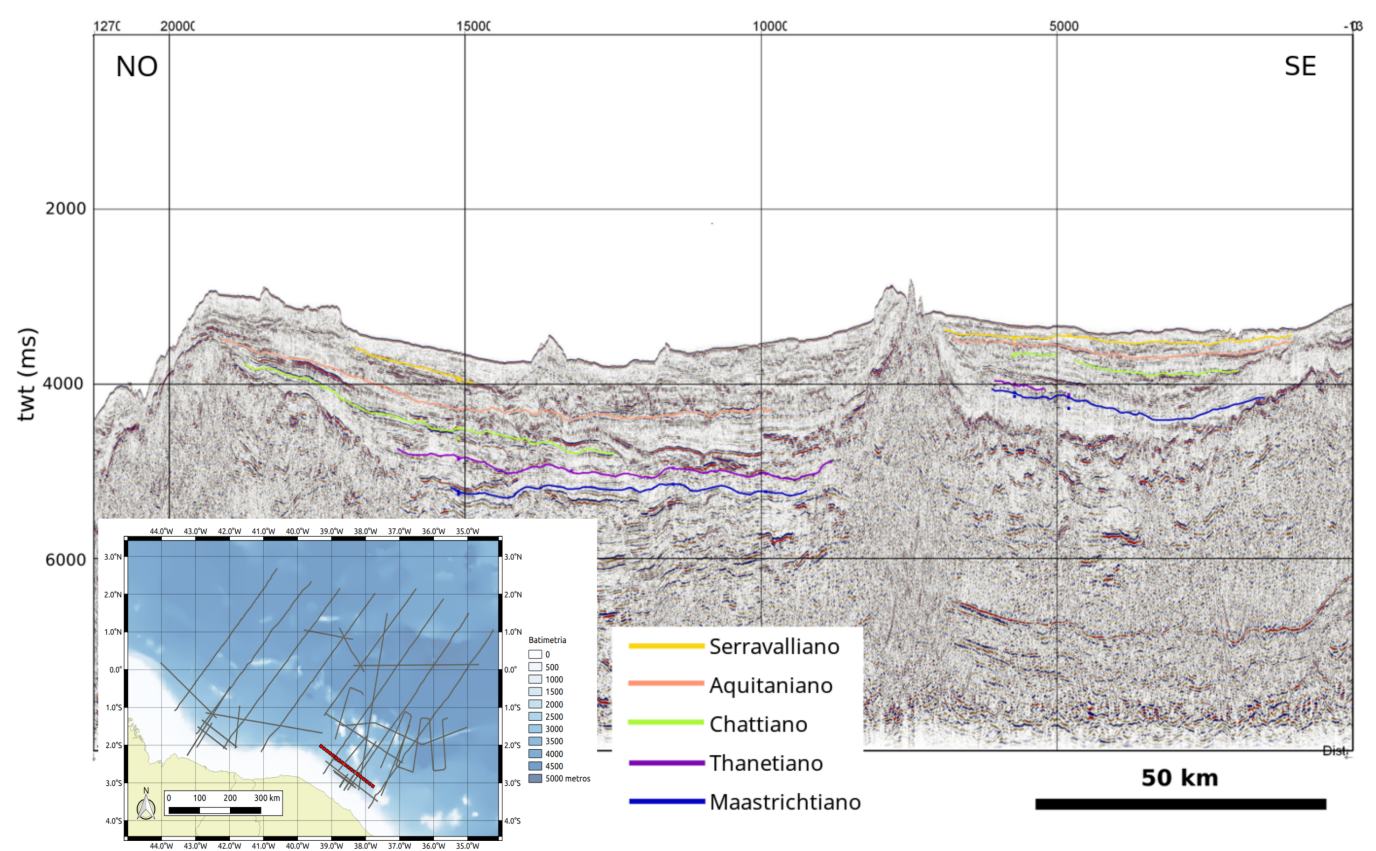

Figura 32: Linha sísmica 0231-MUNDAU-16A-SEGMENTO-0231-1170-FIN8, indicando uma diferença de mais de 1 segundo na profundidades dos horizontes quando comparadas as poções mais a SE e mais a NO da Bacia do Ceará. Exagero vertical de 27 vezes.

como dos montes submarinos presentes na área, diferentes tipos de sismofácies podem ser encontradas.

Na Bacia de Barreirinhas, por exemplo, em sua porção mais recente - marcada pelo horizontes sísmicos H4 e H5 - identificou-se a presença terminações em onlap dos horizontes H5 (amarelo), H4 (laranja) e H3 (verde) (Fig. 33) em direção a uma antiga superfície deposicional, pertencente possivelmente ao Paleógeno.

A linha LEPLAC-502 possui $655 \mathrm{~km}$ e é um exemplo de como as sismofácies se alteram com o distanciamento da plataforma e talude continental. A partir da morfologia dos horizontes sísmicos interpretados nesta linha (Fig. 34), é possível ver a variação nas sismofácies desde as áreas mais próximas ao continente (SO) até as áreas mais distantes (NE).

Outros tipos de sismofácies encontrados ao longo das seções sísmicas estão relacionados às proximidades dos montes submarinos. Não é o escopo deste trabalho discutir as idades destes montes (como fizeram Jovane et al. (2016), por exemplo), mas observase que existem padrões diferentes quando se comparam alguns deles. Em alguns casos, como os do Platô do Ceará, (linha 501, na Figura 73, nos Apêndices), observam-se refletores sísmicos plano-paralelos no topo do platô, indicando que o soerguimento do monte 


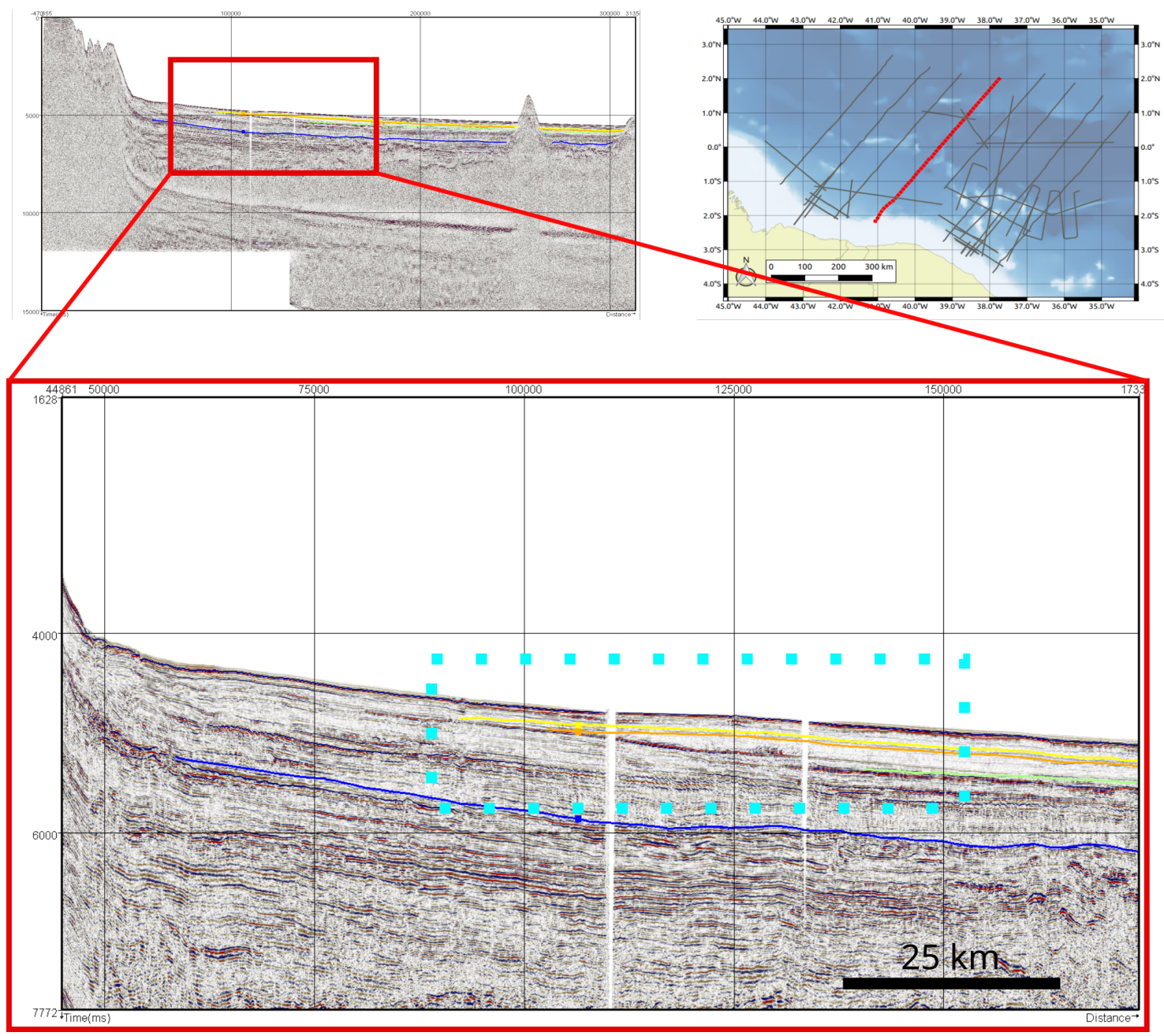

Figura 33: Trecho da seção sísmica da linha LEPLAC-505, mostrando os horizontes H3, H4 e H5 (em destaque no retângulo pontilhado em verde) terminando em onlap contra uma antiga superfície deposicional. Exagero vertical de 17 vezes.

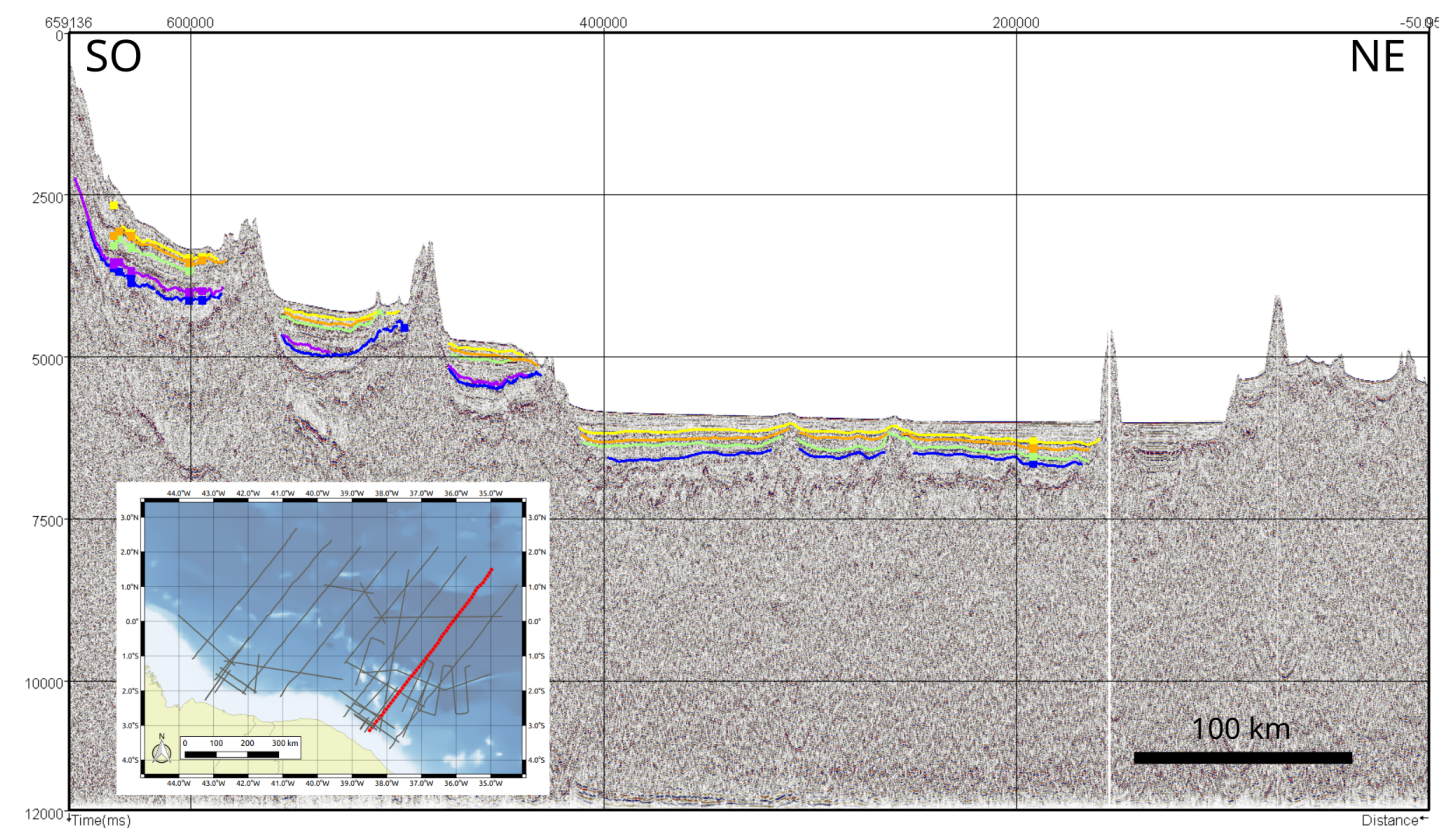

Figura 34: Seção sísmica completa da linha LEPLAC-502, mostrando as diferentes sismofácies ao longo dos 655 km da linha. Exagero vertical de 40 vezes. 
deve ter ocorrido previamente à deposição. Em outros casos, como nos montes submarinos da linha LEPLAC-513 (Fig. 81, nos Apêndices), refletores ascendentes nas bases dos montes indicam maior probabilidade de que seu soerguimento tenha se dados após a deposição.

\subsection{Conversão tempo $x$ profundidade}

A conversão dos dados sísmicos de tempo para profundidades foi realizada com as velocidades de propagação calculadas conforme descrito na Seção 5.6. Os valores de velocidade intervalar foram calculados para cada Unidade Cronoestratigráfica definida (Tabela 5).

Tabela 5: Valores de velocidade de propagação do som aplicados para a conversão tempo x profundidades nos dados sísmicos, definidos para cada unidade cronoestratigráfica.

\begin{tabular}{c|c|c}
\hline \hline Unidade Cronoestratigráfica & Horizonte & Velocidade $\left(\mathbf{m . s} \mathbf{~}^{-1}\right)$ \\
\hline \hline UC1 & H1 a H2 & 2530,07 \\
\hline UC2 & H2 a H3 & 2653,52 \\
\hline UC3 & H3 a H4 & 2201,25 \\
\hline UC4 & H4 a H5 & 1982,60 \\
\hline UC5 & H5 ao leito marinho & 1932,48 \\
\hline Coluna d'água & Leito à superfície do mar & 1500,00 \\
\hline \hline
\end{tabular}




\subsection{Horizonte H1}

O horizonte $\mathrm{H} 1$ corresponde ao topo do Maastrichtiano (66,00 Ma), marcando a base do Paleoceno. H1 foi o horizonte mapeado de forma mais contínua dadas as suas características sísmicas (amplitude e similaridade, principalmente) (Fig. 35).

H1 atinge profundidades superiores a 4500 metros logo após o final do talude na Bacia do Ceará. Nota-se também as diferenças nas profundidades entre as regiões a leste e a oeste dos montes submarinos. Enquanto a leste as profundidades ficam entre 800 e 1000 metros, a oeste elas ultrapassam 2000 metros.

$\mathrm{Na}$ área interpretada da Bacia de Barreirinhas, H1 apresenta profundidades menores, da ordem de 1400 a 1600 metros.

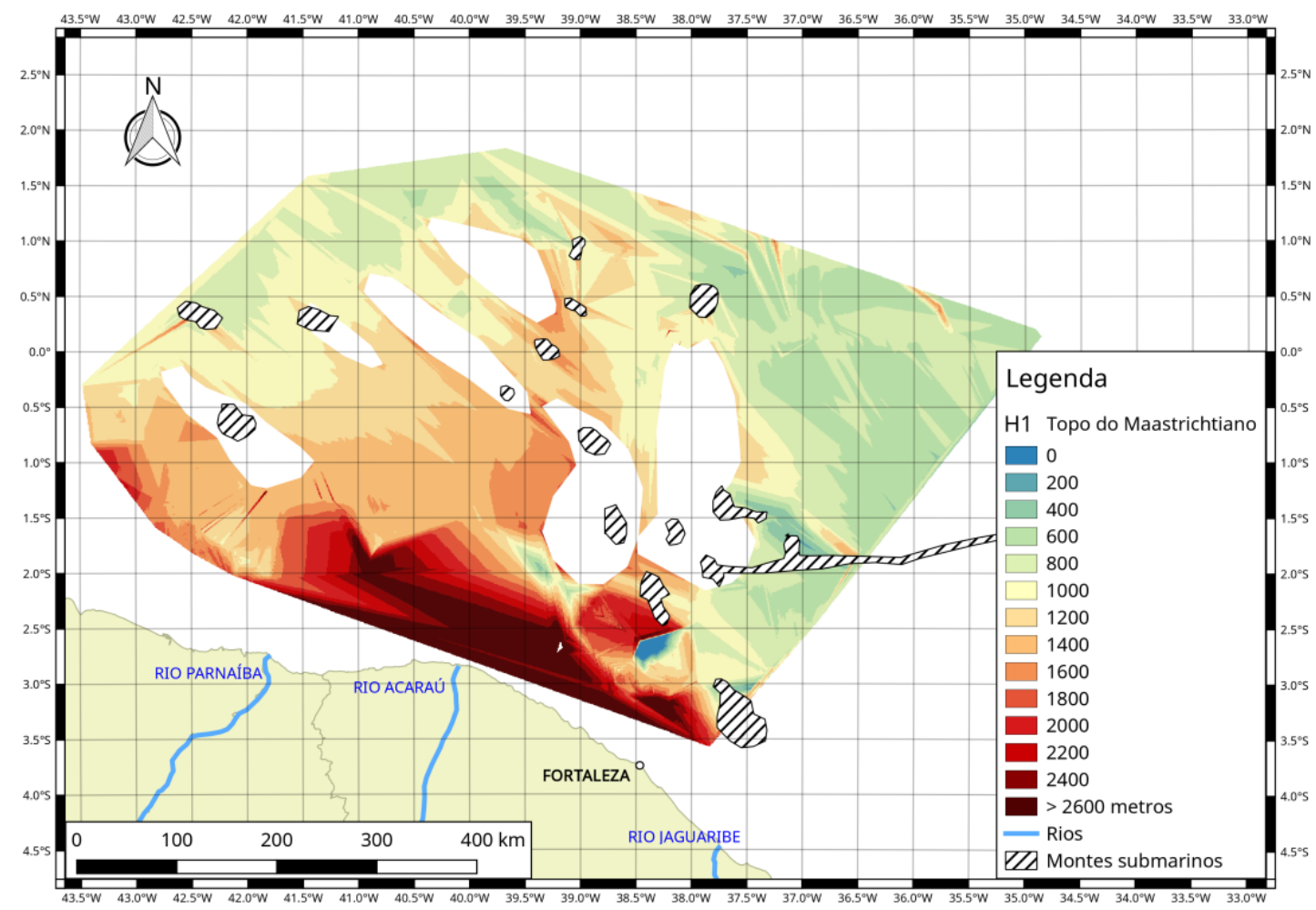

Figura 35: Mapa de espessuras do horizonte H1. Coordenadas geográficas, datum WGS84. As áreas em branco sofreram influência dos montes submarinos e foram removidas. 


\subsection{Horizonte $\mathrm{H} 2$}

O horizonte $\mathrm{H} 2$ corresponde ao topo do Thanetiano (56,00 Ma), foi mapeado em uma região bastante limitada (Fig. 36). Esta limitação foi decorrente das próprias características sísmicas e morfológicas do horizonte, que dificultaram a identificação de sua continuidade.

A principal característica identificada é o aumento da profundidade a oeste dos montes submarinos. Enquanto a leste dos montes as profundidades ficam entre 500 e 700 metros, a oeste elas atingem mais de 1600 metros.

Dada a limitação em área interpolada de H2, é impossível apontar quaisquer outras tendências morfológicas do horizonte na área de estudo.

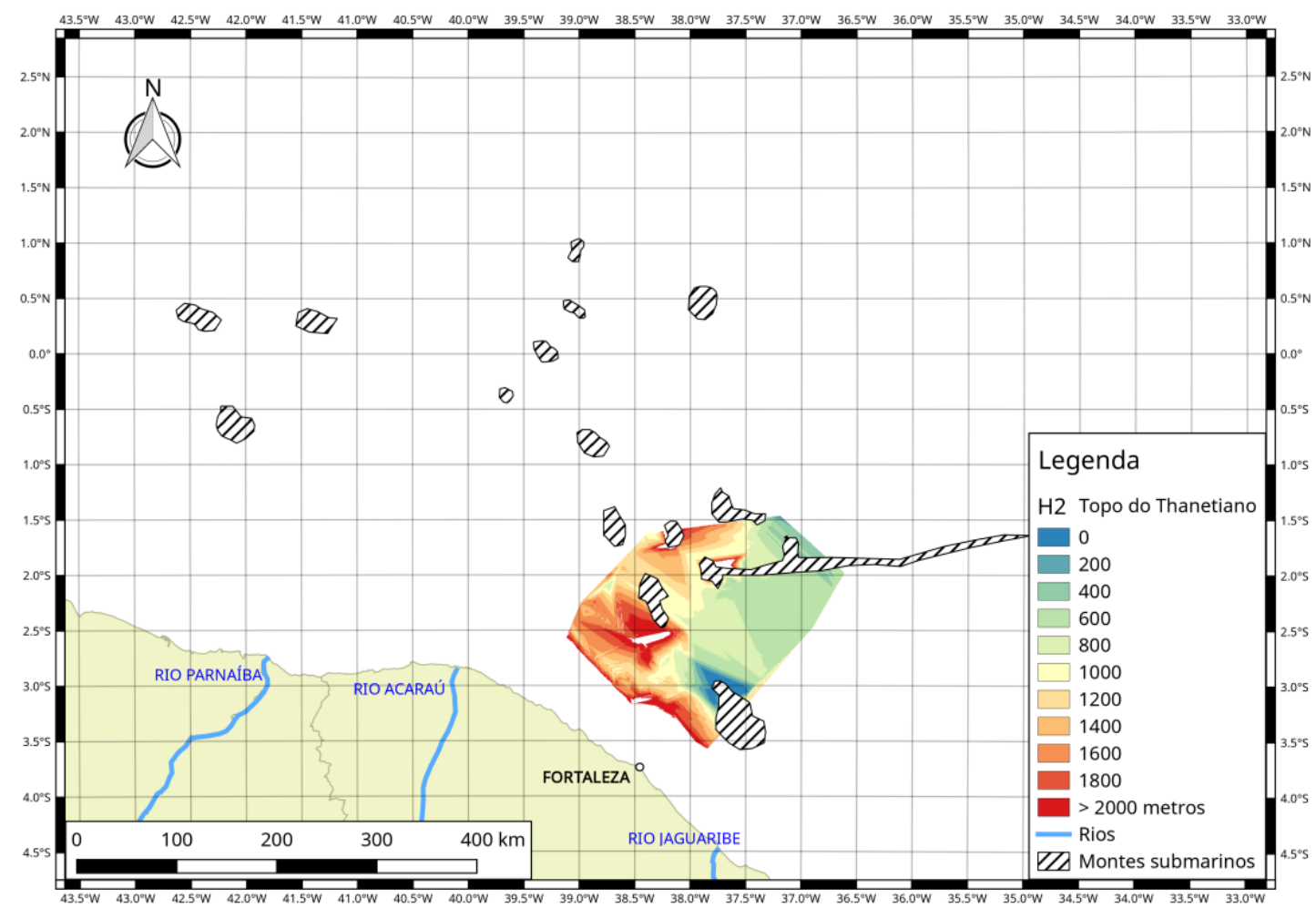

Figura 36: Mapa de espessuras do horizonte H2. Coordenadas geográficas, datum WGS84. As áreas em branco sofreram influência dos montes submarinos e foram removidas. 


\subsection{Horizonte $\mathrm{H3}$}

O horizonte H3 corresponde à superfície erosiva da base do Chattiano (27,82 Ma) e segue a morfologia do fundo (Fig. 37). Para o mapeamento de H3, houve problemas relacionados aos montes submarinos e elevações do embasamento acústico que impossibilitaram o mapeamento contínuo em algumas linhas sísmicas.

H3 apresenta um aprofundamento na região a oeste dos montes submarinos da Bacia do Ceará, com profundidades atingindo até 1400 metros. No restante da região, as profundidades médias do horizontes ficam entre 500 e 700 metros.

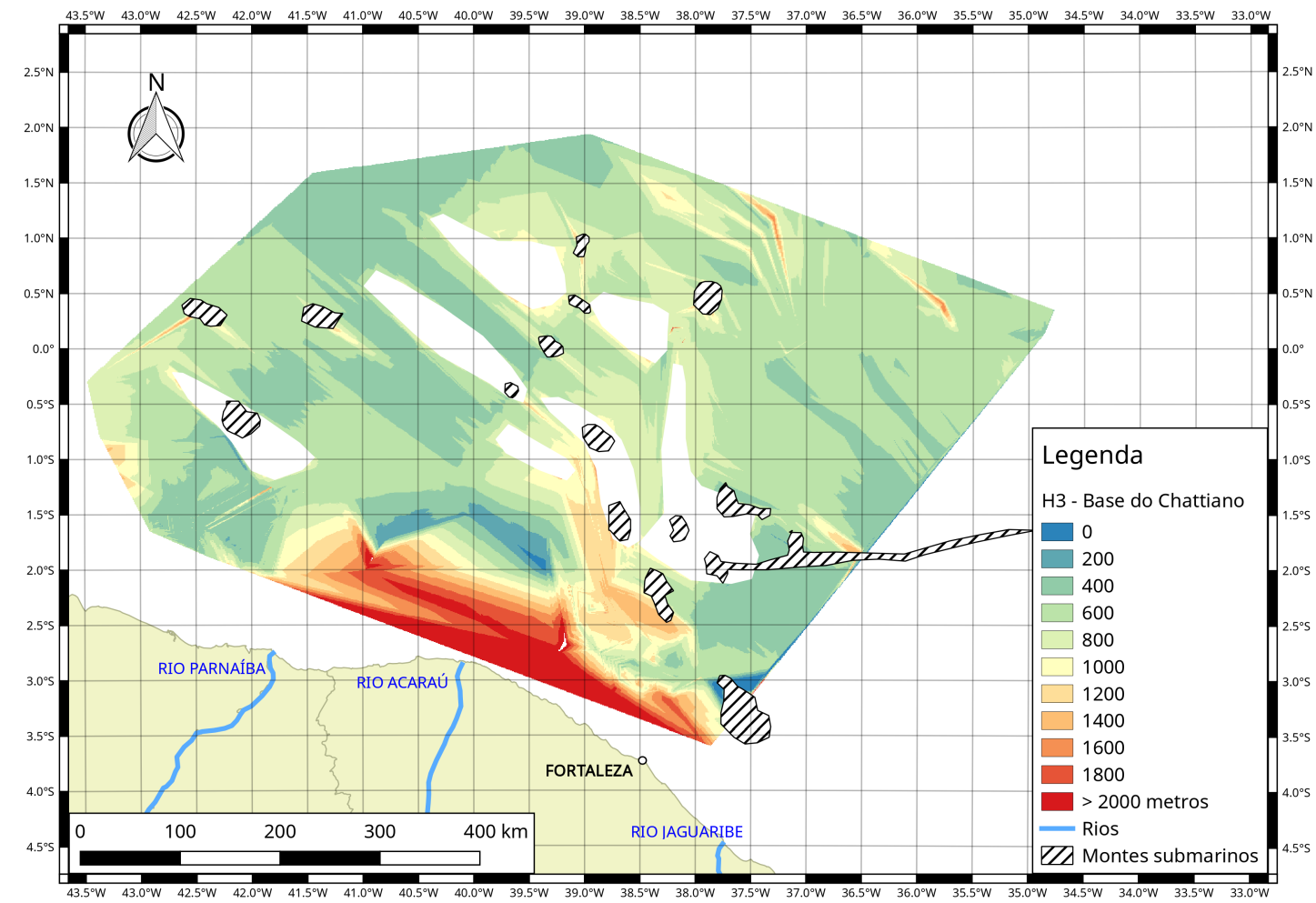

Figura 37: Mapa de espessuras do horizonte H3. Coordenadas geográficas, datum WGS84. As áreas em branco sofreram influência dos montes submarinos e foram removidas. 


\subsection{Horizonte $\mathrm{H} 4$}

O horizonte H4 corresponde ao topo do Aquitaniano (20,44 Ma) e possui distribuição bastante semelhante a H3 (Fig. 38), porém com profundidades médias entre 400 e 550 metros. H4 também foi bem mapeado na maior parte das linhas sísmicas (Fig. 29), possibilitando sua interpolação ao longo da área de estudo.

H4 também possui certa concordância com a batimetria, estando mais profundo na região da plataforma continental. H4 apresenta profundidades diferentes quando se comparam as imediações dos montes submarinos da região a sudeste da Bacia do Ceará. A oeste destes montes, há um aprofundamento deste horizonte, o que pode estar relacionado à irregularidade da bacia.

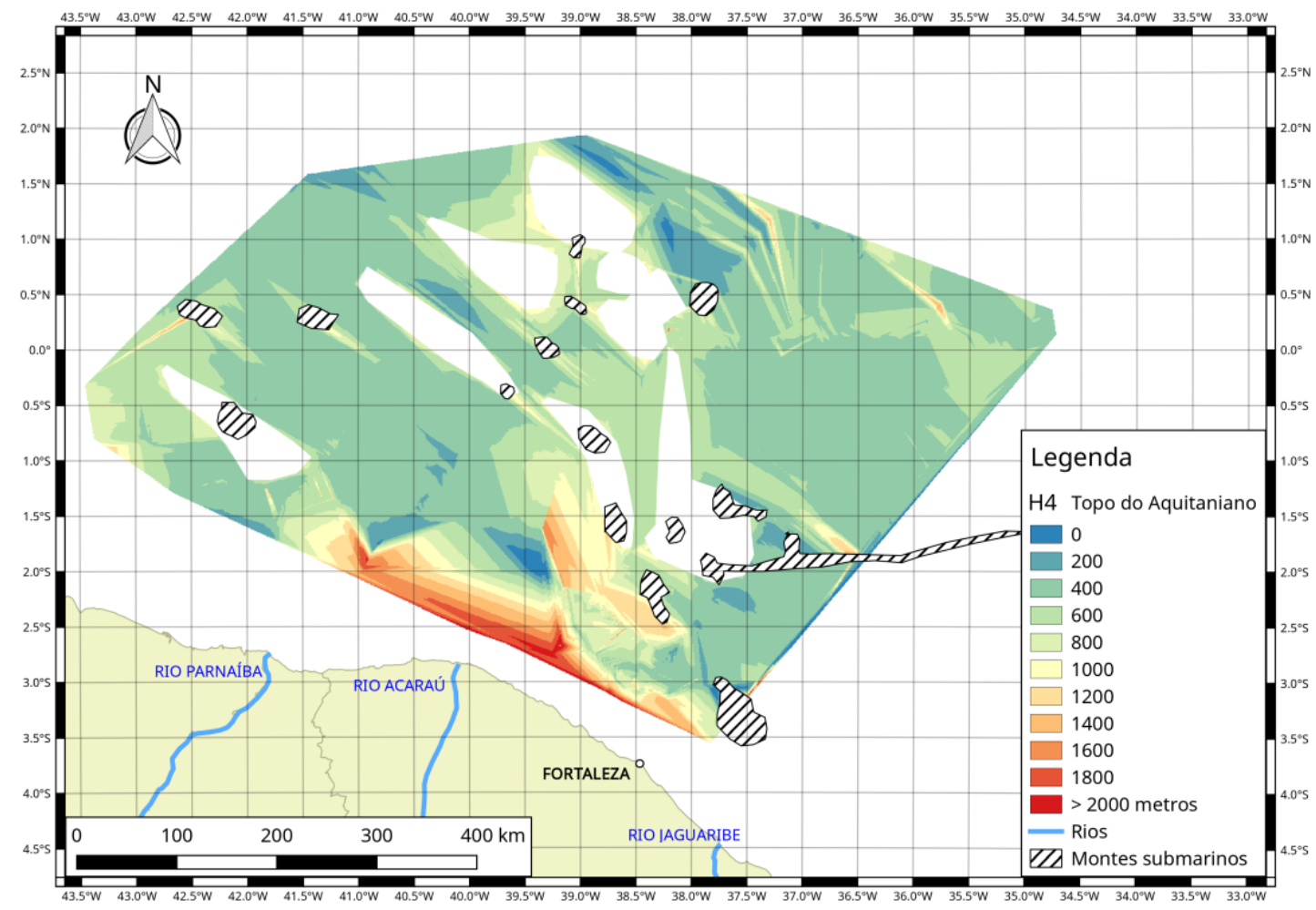

Figura 38: Mapa de espessuras do horizonte H4. Coordenadas geográficas, datum WGS84. As áreas em branco sofreram influência dos montes submarinos e foram removidas. 


\subsection{Horizonte H5}

O horizonte H5 corresponde ao topo do Serravalliano (11,63 Ma) (Fig. 39), e apresenta morfologia bastante semelhante à batimetria da área, com profundidades médias entre 200 e 400 metros.

Este horizonte não foi identificado nos montes submarinos (Fig. 29) e, por este motivo, não foi interpolado nestas áreas. Entretanto, na região do Platô do Ceará ele foi bem mapeado, indicando que a origem e idade deste platô é diferente dos demais montes submarinos da região (Jovane et al., 2016).

Notam-se também diferenças de cerca de 300 ou 400 metros nas profundidades de H5 nas imediações do Platô do Ceará e demais montes submarinos da porção sudeste da bacia do Ceará, o que pode indicar alguma influência destas elevações na sedimentação local.

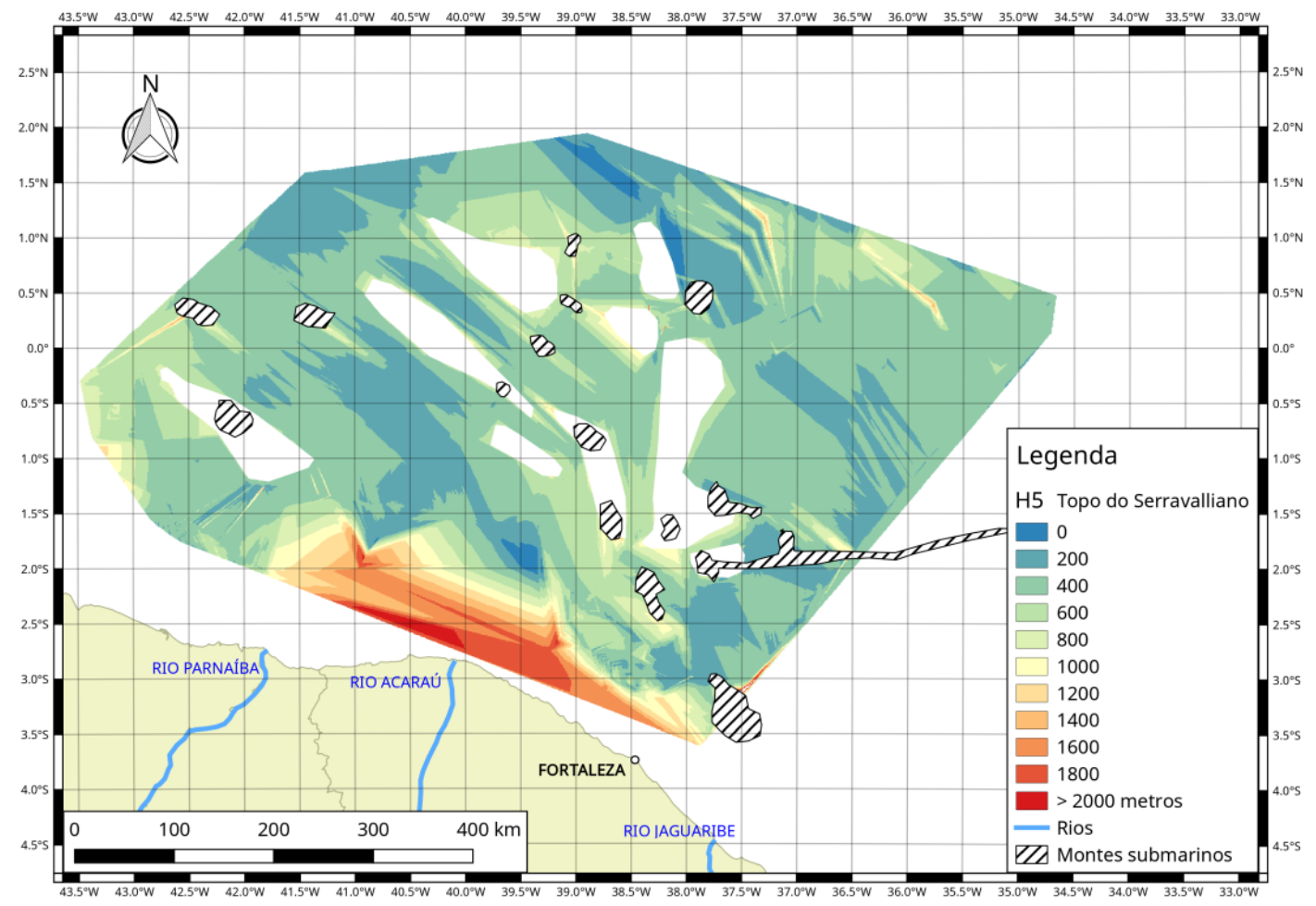

Figura 39: Mapa de espessuras do horizonte H5. Coordenadas geográficas, datum WGS84. As áreas em branco sofreram influência dos montes submarinos e foram removidas. 


\subsection{Batimetria}

A partir do mapa batimétrico da região (Fig. 40), é possível identificar as principais feições do fundo marinho, como: a plataforma continental (áreas em tons vermelho e laranja); o talude (áreas em tons de amarelo e verde); e a planície abissal (áreas em tons de azul). Além disso, é possível também identificar os montes submarinos relacionados com a Zona de Fraturas Romanche (ZFR), bem como o Platô do Ceará.

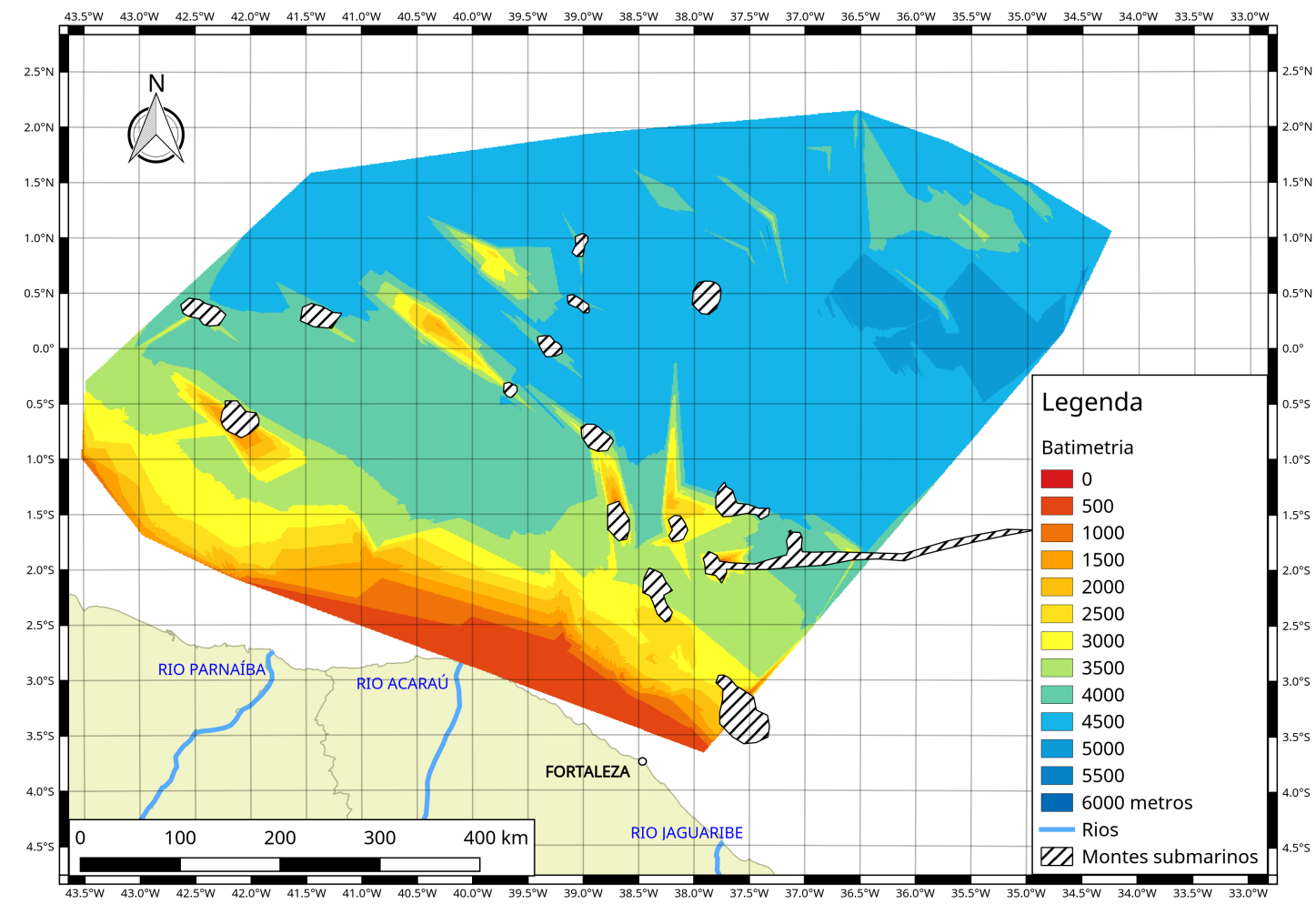

Figura 40: Mapa batimétrico das bacias de Ceará e Barreirinhas, MEB. Coordenadas geográficas, Datum WGS84.

Os dados batimétricos mostram que existe uma clara relação entre os montes submarinos na Bacia do Ceará e o alinhamento da ZFR. Além disso, fica clara a diferença na quantidade de elevações deste tipo quando se comparam as duas bacias sedimentares. Observa-se também que a quebra da plataforma continental segue a linha de costa, gerando um contorno de fundo que parece ter influência direta na sedimentação junto aos montes submarinos da Bacia do Ceará. As áreas em que foram identificados estes montes e onde foi possível mapear apenas o horizonte referente à batimetria também podem ser observadas (Fig. 40). 


\subsection{Unidade Cronoestratigráfica 1 - Paleoceno}

A primeira UC definida (da base para o topo) está limitada em sua base por H1, que corresponde à Discordância Interna do Maastrichtiano Superior (DIMS) (Condé et al., 2007), e em seu topo por H2, definindo assim o Paleoceno. Na Bacia do Ceará, a UC1 corresponde à Fm. Ubarana, composta predominantemente por siltitos e folhelhos (Fig. 6). Em seu topo se iniciam as Fm. Tibau (arenitos) e Guamaré (calcarenitos).

A sismofácies predominante na Bacia do Ceará (Fig. 41) para a UC1 é a de reflexões plano-paralelas em águas profundas, acompanhando a morfologia de H1. Em águas rasas, estas reflexões tornam-se mais subparalelas ou onduladas.

Na Bacia de Barreirinhas, esta UC corresponde ao Grupo Humberto de Campos, com as Fm. Areinhas, Ilha de Santana e Travosas (Fig. 7). Nesta bacia, seu limite superior teria correlação direta com uma rápida descida do nível do mar e a formação de uma superfície erosiva (Trosdtorf Junior et al., 2007). Entretanto, como não foi possível mapear H2 na Bacia de Barreirinhas, não foi também possível definir o limite superior desta UC.

Litologicamente, na porção proximal há predominância das frentes deltaicas da Fm. Areinhas e feições relacionadas a tectônica do período. Na Bacia de Barreirinhas, a sismofácies predominante em águas profundas é a de reflexões plano-paralelas, que acompanham a morfologia do horizontes $\mathrm{H} 1$ e, em águas rasas, as reflexões adquirem um caráter subparalelo.

\subsection{Unidade Cronoestratigráfica 2 - Eoceno}

A UC2 foi definida entre os horizontes $\mathrm{H} 2$ e H3, compreendendo assim boa parte do Eoceno e o Rupeliano do Oligoceno. Na Bacia do Ceará, esta UC representa um estado de mar alto, com deposição de finos da Fm. Ubarana em águas profundas, os arenitos e calcarenitos das formações Tibau e Guamaré em águas rasas. 
A sismofácies predominante desta UC é semelhante à da UC1 (Fig. 41), com reflexões plano-paralelas e subparalelas, de altas amplitudes. Ao contrário de H1, porém, H2 se mostrou bastaste descontínuo na Bacia do Ceará, já que está provavelmente relacionado à Discordância do Oligoceno Superior (DOS), um importante evento erosivo marcante em toda a bacia (Condé et al., 2007).

$\mathrm{Na}$ Bacia de Barreirinhas não foi possível mapear H2 e, portanto, também não foi possível definir esta UC.

\subsection{Unidade Cronoestratigráfica 3 - Oligoceno/Mioceno}

A UC3 foi delimitada entre os horizontes H3 - base do Chattiano e H4 - topo do Aquitaniano, definindo assim o Oligoceno Superior e o Mioceno Inferior. Na Bacia do Ceará, esta UC se inicia logo após o evento regressivo do Rupeliano. Litologicamente, assim como a UC2, ela também é composta de sedimentos finos da Fm. Ubarana em águas profundas, os arenitos e calcarenitos das formações Tibau e Guamaré em águas rasas.

Ainda na Bacia do Ceará, a sismofácies predominante é de refletores planoparalelos e subparalelos (Fig. 41), assim como na UC2, porém, com menores amplitudes.

Na Bacia de Barreirinhas, a UC se inicia em um estado de mar baixo, após a regressão do Rupeliano, com uma transgressão e o início da deposição dos carbonatos da Fm. Pirabas. Nesta bacia, destaca-se a presença de terminações em onlap tanto nos refletores internos da UC quanto em seu topo (H4) (Fig. 33).

\subsection{Unidade Cronoestratigráfica 4 - Mioceno Inferior/Médio}

A UC4 corresponde à primeira metade do Mioceno, tendo sua base no Mioceno Inferior (H4) e estando limitada superiormente por uma importante discordância erosiva no topo do Serravalliano (H5). 
Na Bacia do Ceará, continua a deposição de finos da Fm. Ubarana em águas profundas, bem como da deposição progradante das formações Tibau e Guamaré. As sismofácies predominantes continuam sendo de reflexões plano-paralelas a subparalelas (Fig. 41), com amplitudes ligeiramente maiores que na UC3.

Na Bacia de Barreirinhas, a UC4 também tem seu topo bem definido pela discordância do Mioceno Médio, que é muito bem definida em toda a Margem Equatorial (Trosdtorf Junior et al., 2007). Ela conta com um evento regressivo, seguido por uma transgressão com um novo afogamento da plataforma e continuação das plataformas carbonáticas da Fm. Pirabas. Nesta bacia, os horizontes H4 e H5 apresentam terminações em onlap contra a superfície anterior (Fig. 33).

\subsection{Unidade Cronoestratigráfica 5 - Mioceno Médio até presente}

A UC5 tem como base o horizonte H5, correspondente à última grande discordância erosiva, tanto na Bacia de Barreirinhas quanto na Bacia do Ceará (Condé et al., 2007; Trosdtorf Junior et al., 2007), no final do Serravalliano. A unidade corresponde a todo o período entre o Mioceno Médio e a superfície atual do nível do mar. Na Bacia do Ceará, estão presentes ainda as formações Ubarana, Guamaré e Tibau, e também a Fm. Barreiras, com arenitos tanto na parte emersa quanto imersa da bacia.

As sismofácies predominante na UC5 é de refletores plano-paralelos de amplitude média (Fig. 41). Entretanto, há refletores de maior amplitude, possivelmente relacionados a eventos e marcadores do Plioceno e Pleistoceno.

Na Bacia de Barreirinhas, a UC5 é formada principalmente pelos carbonatos da Fm. Pirabas e com uma pequena participação da Fm. Barreiras. Em águas rasas, as sismofácies são de menor amplitude, quando comparadas com aquelas das águas mais fundas, em decorrência da diferença na composição sedimentar. Nesta bacia, o horizonte H5 apresenta terminações em onlap contra a superfície anterior, assim como outros refletores internos da UC. 


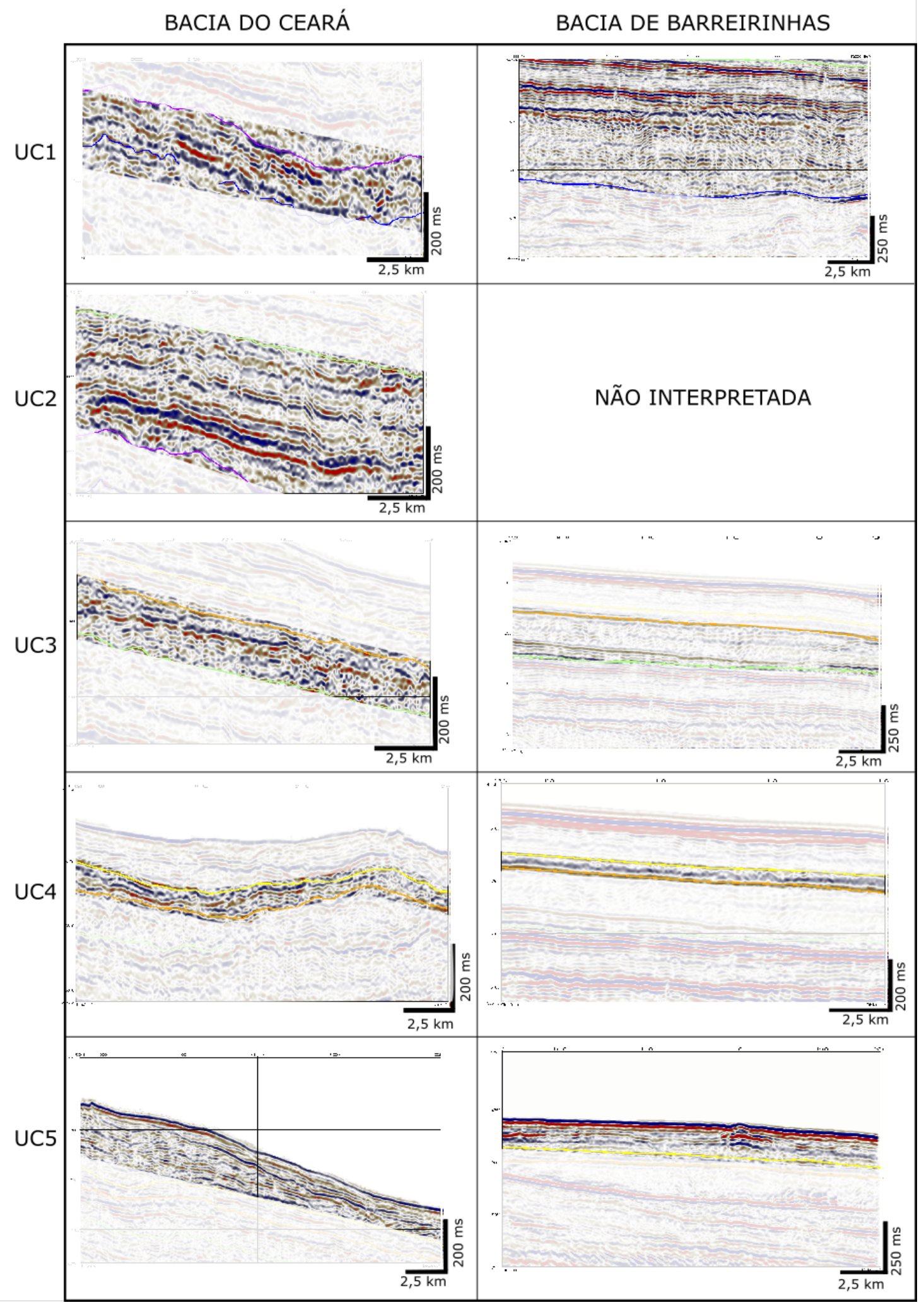

Figura 41: Exemplo das sismofácies presentes em cada uma das unidades cronoestratigráficas nas duas bacias sedimentares. 


\subsection{Divisão em fases}

Os mapas de espessuras são importantes ferramentas para o estudo de bacias sedimentares, principalmente quando calculados para sequências sucessivas (Brookfield, 2008). Com mapas deste tipo, é possível compreender alterações na distribuição da sedimentação na bacia ao longo do tempo.

As unidades cronoestratigráficas definidas no início desta seção de resultados correspondem às Épocas da classificação estratigráfica da ICS - International Commision of Stratigraphy (Cohen et al., 2017). Elas foram ainda agrupadas em duas fases, a fim de se melhor compreender o papel das variações climáticas e oceanográficas ao longo do Cenozoico nas bacias do Ceará e de Barreirinhas (Fig. 42):

- Fase 1 (F1): Da UC1 à UC3, correspondendo ao Paleógeno.

- Fase 2 (F2): Da UC3 ao leito marinho, passando pela UC4 e UC5, correspondendo ao Neógeno e Quaternário.

Na Bacia do Ceará, toda a sedimentação cenozóica se desenvolveu em um ambiente marinho regressivo, com o nível relativo médio do mar baixando desde o Eoceno Médio, com a deposição dos sistemas progradantes das Formações Tibau (siliciclásticos) e Guamaré (carbonatos).

Na Bacia de Barreirinhas, entretanto, Paleógeno e Neógeno são distintos. Até a discordância do Chattiano (horizonte H3), a sedimentação na bacia se dá em um ambiente regressivo, assim como na Bacia do Ceará. Em Barreirinhas, há três discordâncias importantes nesse período: no Paleoceno (base do Thanetiano), no Eoceno Médio (base do Bartoniano) e no Oligoceno (base do Chattiano), sendo que esta última foi interpretada nos dados como o horizonte $\mathrm{H} 3$.

Estas discordâncias marcam eventos erosivos de rápidas descidas do nível do mar, com o avanço do sistema deposicional para as regiões mais profundas da bacia. No início do Neógeno, entretanto, a natureza da deposição passou para transgressiva, levando o ambiente deposicional até a plataforma continental. Registros desta transgressão ficam evidentes com as terminações em onlap em UC4 e UC5, identificadas nas seções sísmicas das linhas LEPLAC-505 e LEPLAC-506 (Fig. 33 e figuras 83 e 85, nos Apêndices). 


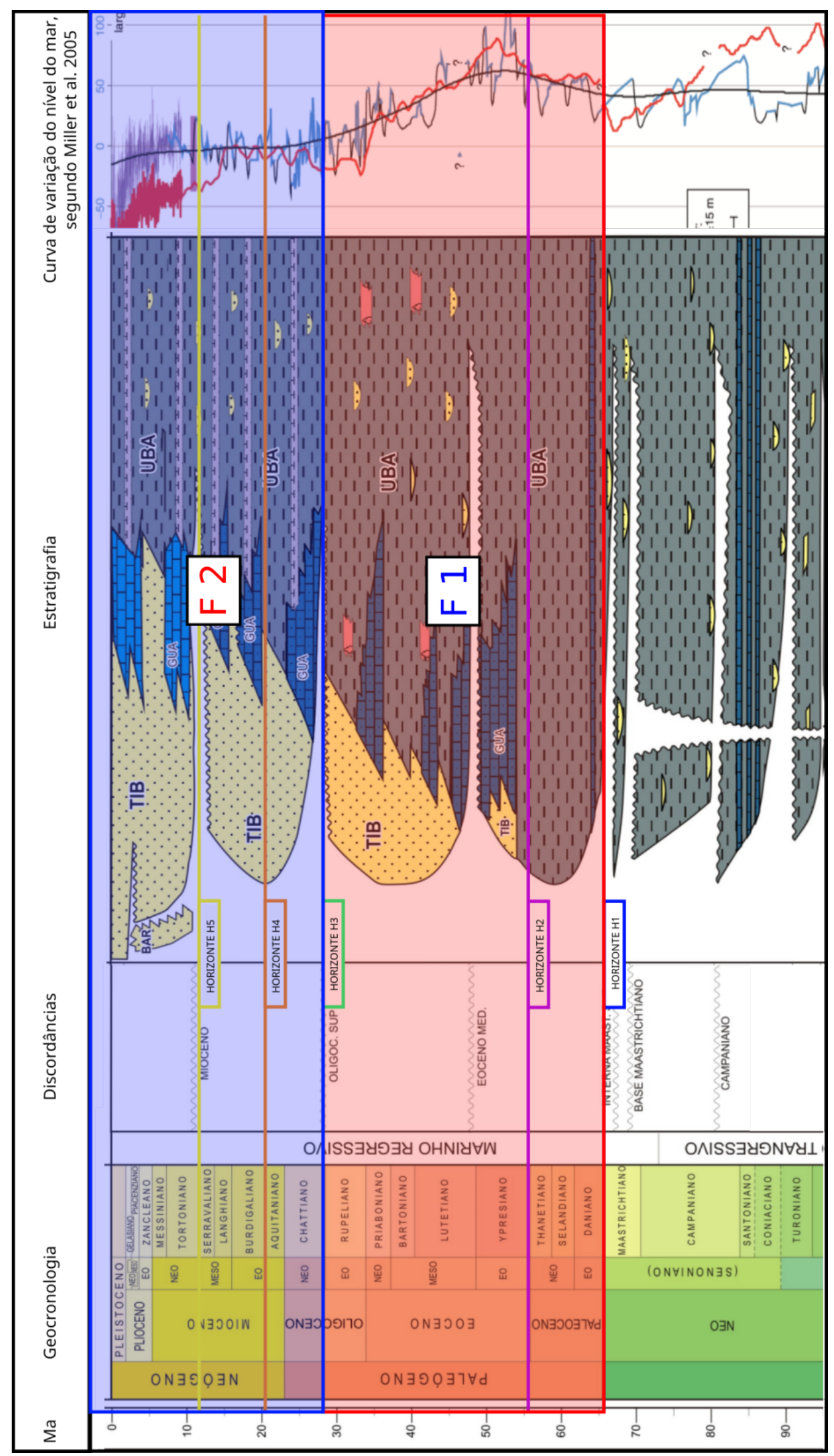

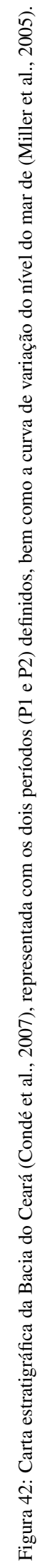


No Neógeno de Barreirinhas há ainda duas importantes discordâncias erosivas: uma no topo do Burdigaliano e outra no topo do Serravalliano (interpretado nos dados como o horizonte H5). Estas discordâncias marcam eventos de descidas momentâneas do nível do mar, mas com o subsequente afogamento da bacia, em ambos os casos, e avanço das plataformas carbonáticas da Fm. Pirabas para a plataforma continental.

\subsection{Espessuras do Paleógeno e do Neógeno}

Após a divisão dos períodos, foram calculadas as espessuras para cada um deles, apresentadas em mapas de distribuição em mesma escala, para favorecer a comparação entre eles (Figs. 43 e 44). É fundamental notar que as regiões próximas aos montes submarinos sofrem importante prejuízo na qualidade dos dados, dificultando a interpretação dos horizontes sísmicos mais rasos. Isso significa que nas proximidades dos montes, os valores de espessuras - e, consequentemente, os valores de taxas de sedimentação - não são confiáveis e, por este motivo, foram removidos dos mapas interpolados (Áreas não consideradas, nas Figs. 43, 44, 45, 46 e 47).

Durante o Paleógeno, observa-se nítida diferença de espessuras quando se comparam as áreas mais profundas de Barreirinhas e Ceará. Enquanto na Bacia do Ceará as espessuras em águas profundas ficam entre menos de 200 e 400 metros, na Bacia de Barreirinhas atingem valores maiores, passando de 800 metros. Em torno de $1,5^{\circ} \mathrm{S}$, notam-se maiores espessuras, nas latitudes aproximadas da cadeia de montes submarinos da Cordilheira Norte Brasileira.

Quando se observam as espessuras no Neógeno, porém, é importante destacar os problemas oriundos da interpolação de linhas sísmicas com grandes espaçamentos, como as utilizadas neste trabalho. Nas regiões mais profundas, acima do Equador, a presença de montes submarinos interrompeu a continuidade do horizonte H3 (base da UC3 e de P2). Assim, para o cálculo das espessuras em relação ao leito marinho (que considera as elevações dos montes), estas áreas foram removidas, para que não fossem geradas incorreções na interpolação (Áreas não consideradas, na Fig. 44). Desconsiderandose estas regiões, observa-se que as espessuras para o Neógeno apresentam valores mais homogêneos em águas profundas, variando entre 450 e 600 metros, com algum sinal de acúmulo junto aos montes submarinos relacionados à Cordilheira Norte Brasileira. 


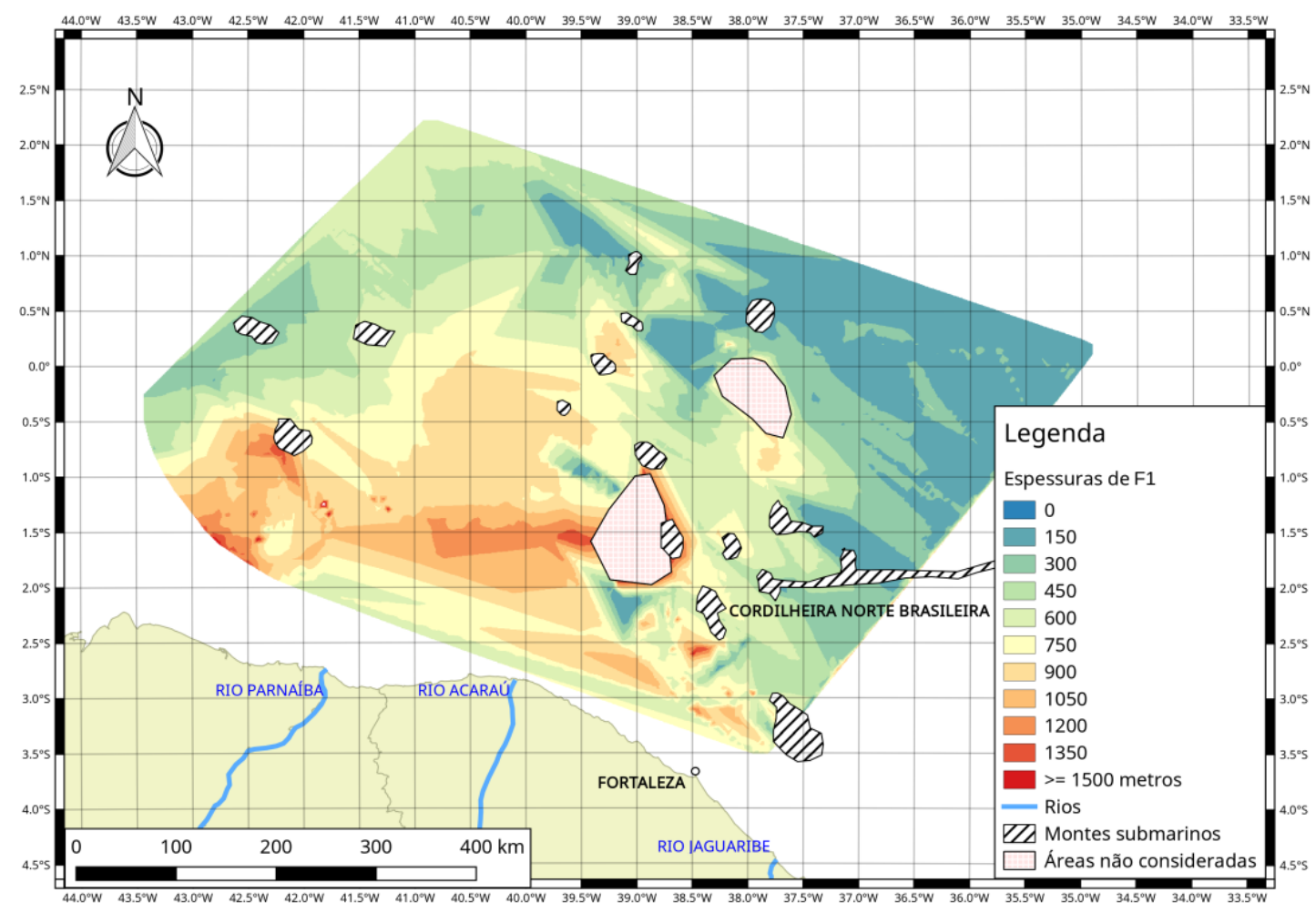

Figura 43: Mapa de espessuras do Paleógeno. Coordenadas geográficas, datum WGS84.

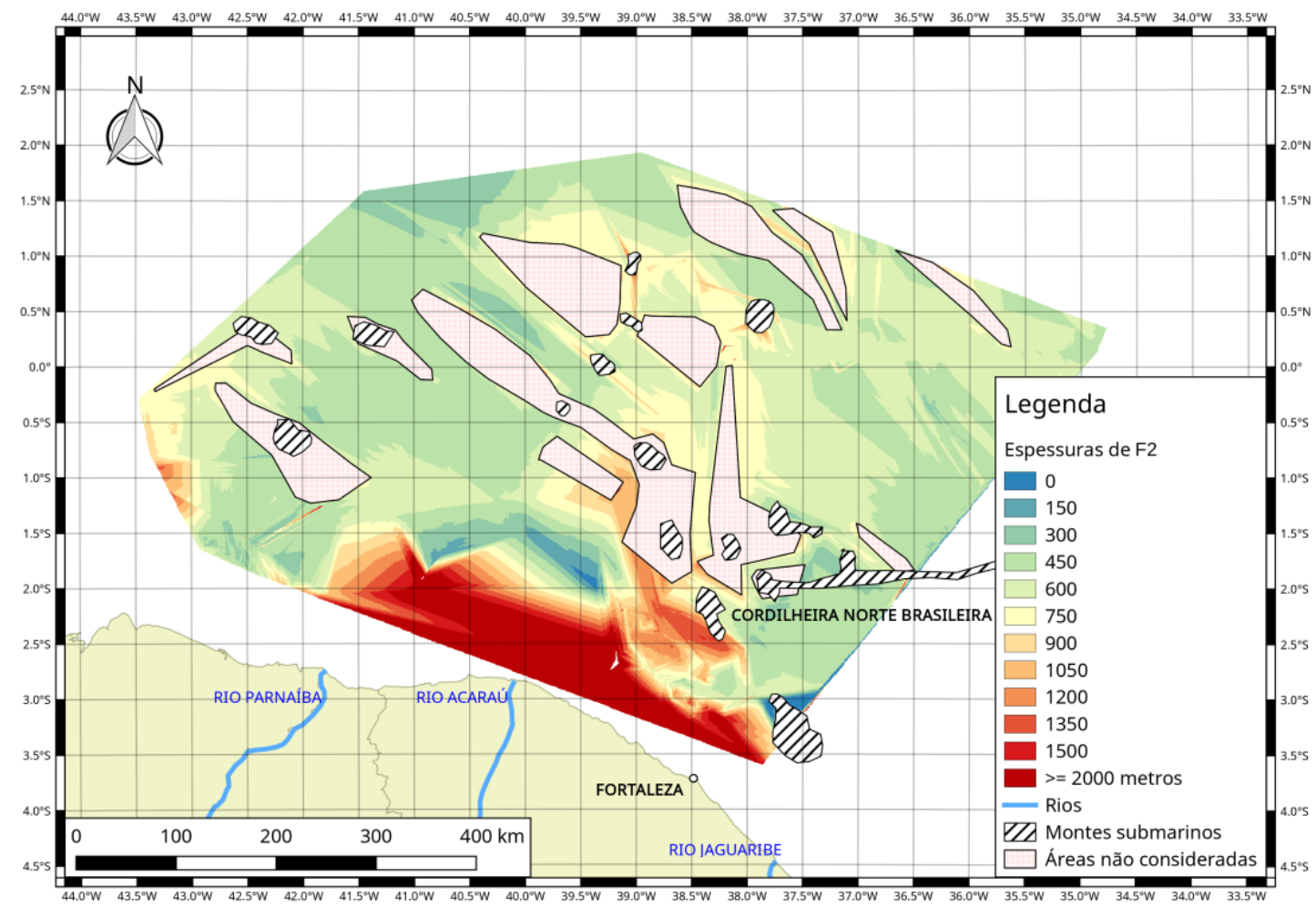

Figura 44: Mapa de espessuras do Neógeno e Quaternário. Coordenadas geográficas, datum WGS84. 
O mapa de espessuras para todo o Cenozoico (Fig. 45) é também apresentado com a mesma escala dos outros dois mapas de espessuras. Ele foi calculado pela diferença entre as profundidades do leito marinho e do horizonte $\mathrm{H} 1$, que representa a base do Paleoceno. Nele, nota-se que maiores espessuras - com colunas sedimentares de mais de 2 mil metros - são encontradas nas regiões mais próximas à costa do estado do Ceará.

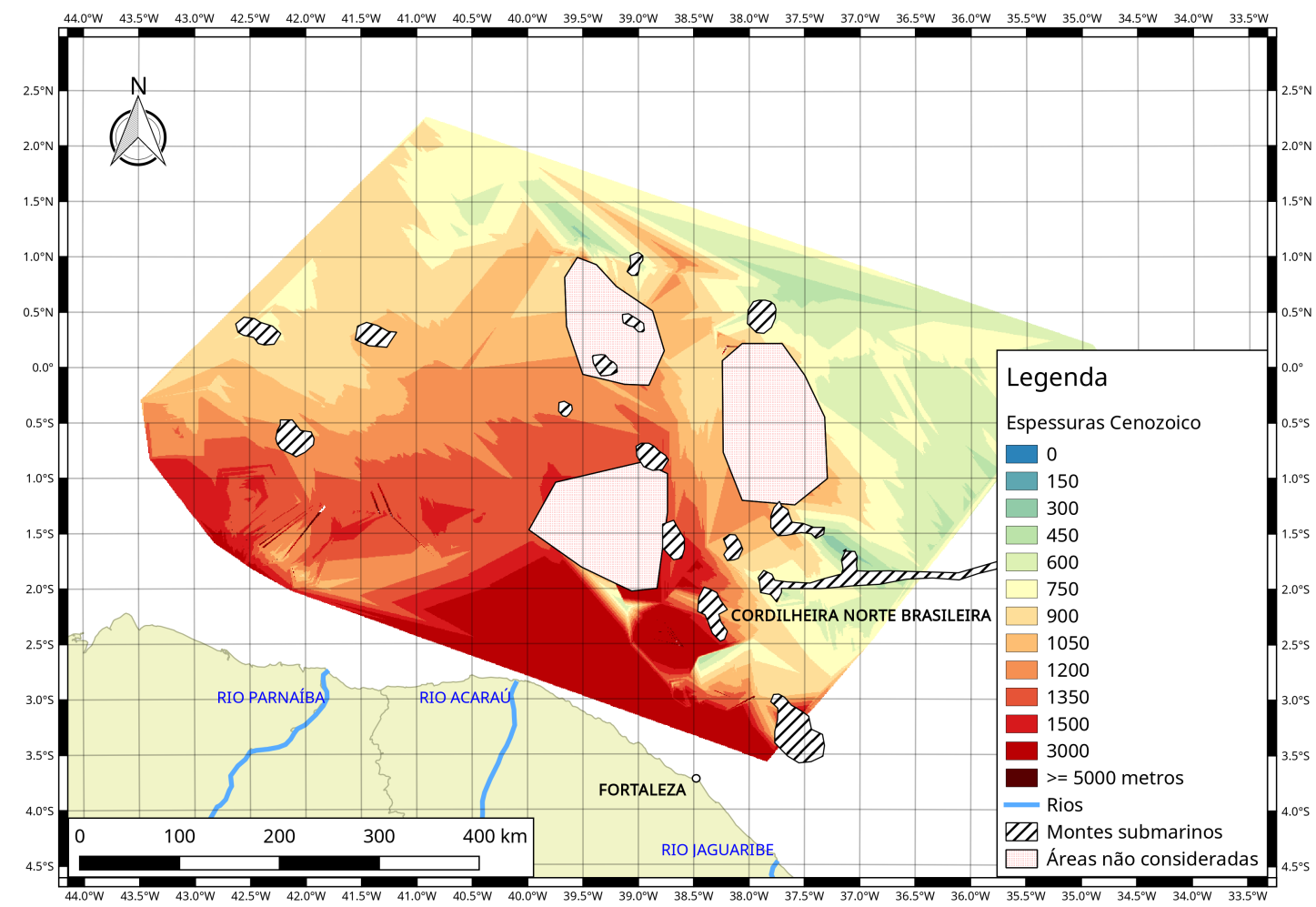

Figura 45: Mapa de espessuras para todo o Cenozoico. Coordenadas geográficas, datum WGS84.

Há importantes diferenças entre as espessuras na Bacia do Ceará e de Barreirinhas. A plataforma continental e os montes submarinos dividem duas áreas com espessuras características diferentes: a leste de $39,0{ }^{\circ} \mathrm{W}$, aproximadamente, as espessuras totais ficam entre 400 e 800 metros; a oeste desta longitude, as espessuras são sempre superiores a 1000 metros, atingindo até mesmo valores maiores que 1600 metros.

Os montes submarinos da Bacia do Ceará parecem ter influência sobre o acúmulo de sedimentos do período, com espessuras muito menores a leste quando comparadas àquelas a oeste. Pelas mesmas razões descritas anteriormente, também para as espessuras totais para o Cenozoico, algumas das áreas não foram consideradas. 


\subsection{Taxas de sedimentação para o Paleógeno e Neógeno}

Observa-se uma mudança significativa tanto nos valores quanto em sua distribuição ao longo das duas bacias, quando se comparam as taxas de sedimentação para o Paleógeno e para o Neógeno + Quaternário (Figs. 46 e 47, respectivamente). Durante o Paleógeno, as taxas de sedimentação não ultrapassam 4,0 cm/mil anos, ficando predominantemente entre 0,5 e 3,5 cm/mil anos, com exceção às áreas próximas aos montes submarinos da Cordilheira Norte Brasileira, e também a região mais rasa da Bacia de Barreirinhas. Por outro lado, durante o Neógeno e o Quaternário, os valores nas proximidades da plataforma continental ultrapassam $6,0 \mathrm{~cm} / \mathrm{mil}$ anos, podendo chegar a 9,0 $\mathrm{cm} / \mathrm{mil}$ anos. Na planície abissal, os valores ficam sempre entre 1,0 e 3,5 cm/mil anos.

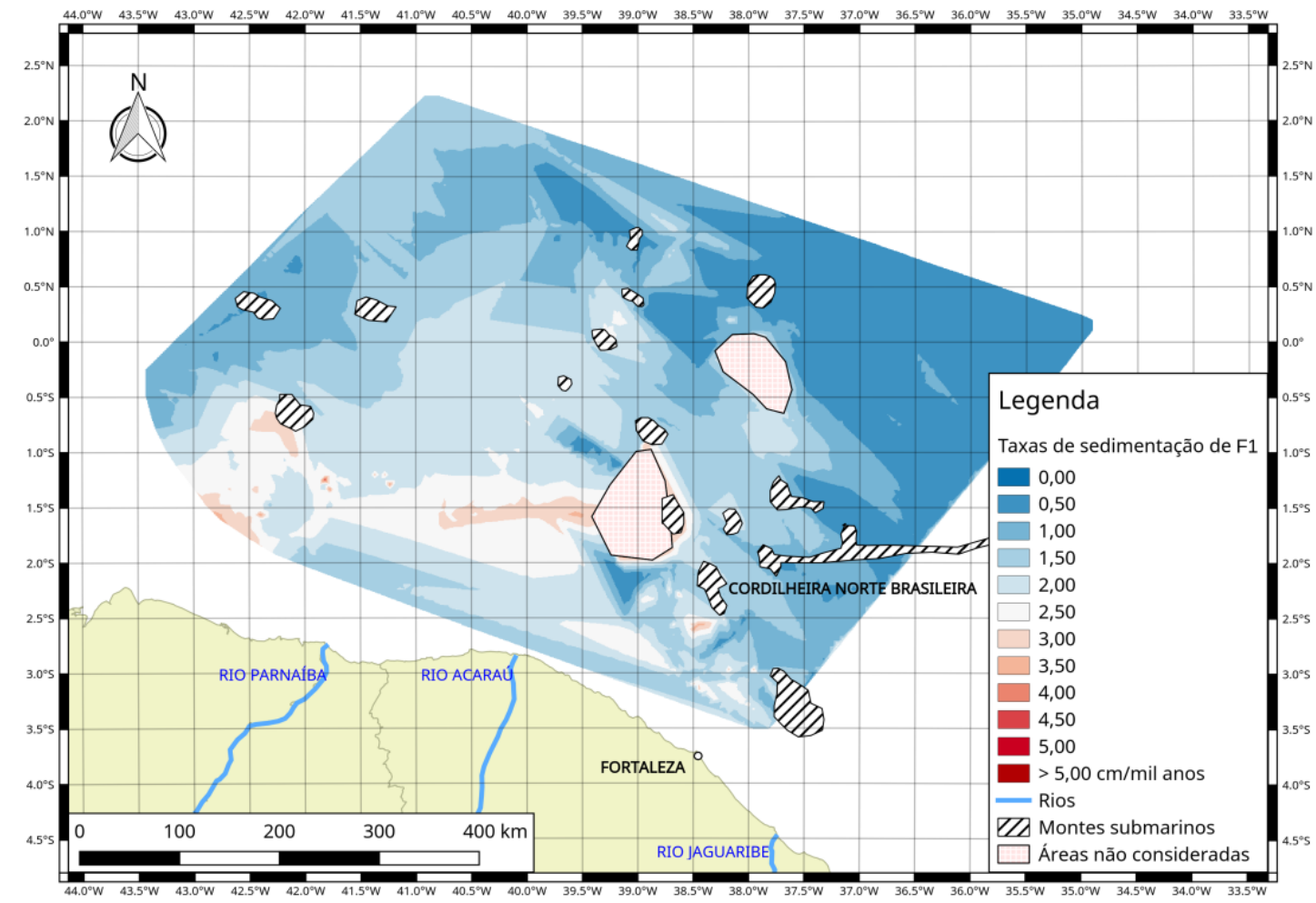

Figura 46: Mapa de distribuição das taxas de sedimentação para o Paleógeno, em cm/mil anos. Coordenadas geográficas, datum WGS84. 


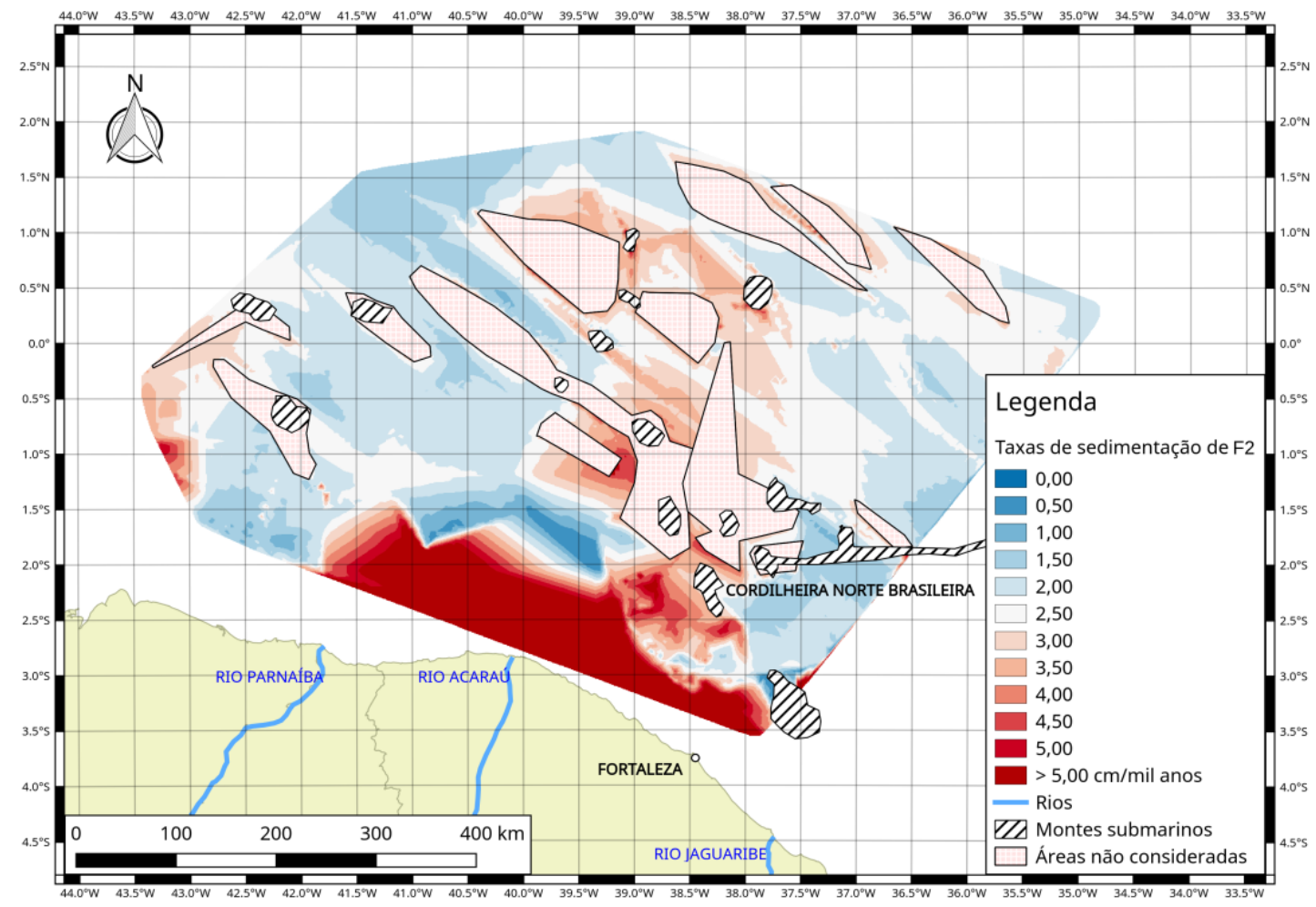

Figura 47: Mapa de distribuição das taxas de sedimentação para o Neógeno, cm/mil anos. Coordenadas geográficas, datum WGS84. 


\section{Discussão}

Para o estudo do preenchimento sedimentar das bacias de Barreirinhas e do Ceará é fundamental que se entenda como as condições oceanográficas podem ter mudado durante o tempo. Dentre essas condições, três principais fatores precisam ser considerados para a compreensão da evolução de qualquer bacia sedimentar: (1) o aporte sedimentar; (2) as variações relativas do nível do mar; e (3) os movimentos de subsidência e soerguimento nas bacias.

Em relação à subsidência e soerguimento, mesmo que se reconheça a importância da tectônica na geração ou diminuição de espaço de acomodação para os sedimentos nas bacias, neste trabalho, tal ação não é considerada. Enquanto a componente sedimentar está relacionada ao aporte de sedimentos continentais e a produção de sedimentos autóctones, e suas variações no tempo, a componente climática considera as mudanças nos padrões de vento, chuva, circulação oceânica de superfície e de fundo, bem como as variações do nível do mar decorrentes do aumento de volume de água nos oceanos. Quanto a estas variações climáticas, serão consideradas apenas aquelas de baixa frequência, como o resfriamento geral do planeta após o Cretáceo, por exemplo, sem considerar as variações de alta frequência do Quaternário.

As pequenas bacias de drenagens dos rios com foz na MEB, quando comparadas a rios de outras bacias hidrológicas, possuem regimes fortemente influenciados por variações climáticas. Aquino da Silva et al. (2015) mostraram como o Delta do Rio Parnaíba passou por modificações morfológicas e hidrodinâmicas ao longo do tempo por conta de variações climáticas. Já Arz et al. (1999) mostram como períodos de maior umidade no Holoceno no continente estão relacionados diretamente com maior aporte de sedimentos para a Bacia do Ceará.

Estudos da influência das variações climáticas na MEB ainda são poucos e concentrados no Quaternário. Entretanto, como a margem equatorial não passou por mudanças significativas em sua posição latitudinal durante o Cenozoico, pode-se supor que estas mesmas condições possam ter ocorrido também ao longo dos últimos 66 milhões de anos.

Outro fator importante a se considerar no estudo da sedimentação nas bacias da MEB, é a curta extensão da plataforma continental na região equatorial da margem 
brasileira - desconsiderando a Bacia da Foz do Amazonas. As bacias do Ceará e de Barreirinhas possuem extensão média de 50 e $70 \mathrm{~km}$, respectivamente, fazendo com que o espaço de acomodação dos sedimentos seja pequeno (quando comparado a outras bacias, como as da margem sudeste do Brasil). Assim, os sedimentos atingem o talude e sopé continental mais facilmente e as variações do nível relativo do mar se tornam ainda mais importantes no espaço total disponível para a sedimentação.

Outra característica importante da plataforma continental na MEB é sua declividade pouco acentuada, o que faz com que ela tenha menores profundidades por uma extensão maior da plataforma até chegar ao talude. Estas menores profundidades a expõem totalmente em períodos de nível do mar mais baixo e também coloca praticamente toda sua extensão dentro da zona fótica, propiciando condições para a formação de plataformas carbonáticas. Na Bacia de Barreirinhas, a sedimentação carbonática é especialmente importante, com a Fm. Ilha de Santana no Paleógeno e a Fm. Pirabas no Neógeno (Fig. 7).

Finalmente, uma terceira característica importante da MEB é a presença de diversos montes submarinos, que ajudam a definir uma morfologia irregular para as bacias - especialmente a do Ceará -, morfologia esta que tem influência direta na distribuição e deposição dos sedimentos.

\subsection{Sedimentação}

O Cenozoico apresenta uma característica bastante marcante nas bacias de Barreirinhas e do Ceará: uma diferença notável nas espessuras quando se comparam as regiões a leste e a oeste dos montes submarinos da Cordilheira Norte Brasileira (Fig. 45). Enquanto a leste dos montes submarinos os valores ficam entre 600 e 750 metros, a oeste eles passam de 1000 metros em praticamente toda a área de estudo, ultrapassando os 3000 metros na plataforma continental.

\subsubsection{Sedimentação no Paleógeno}

Os mapas de espessuras separados para os períodos Paleógeno e Neógeno são também ferramenta essencial para a interpretação da sedimentação. A partir deles, por 
exemplo, é possível observar locais de concentração da sedimentação e inferir a distribuição dos sedimentos nas bacias sedimentares.

Ao se observar as espessuras dos dois períodos, é possível identificar diferenças importantes que estão relacionadas diretamente com a história deposicional das bacias. Durante o Paleógeno (Fig. 43), nota-se uma nítida diferença nas espessuras quando comparadas as porções leste e oeste das bacias de Barreirinhas e do Ceará. Tomando-se como base os montes submarinos centrados na longitude $38,5^{\circ} \mathrm{W}$, as espessuras a leste possuem valores médios entre 150 e 300 metros. Por outro lado, a oeste dos montes submarinos, as espessuras aumentam para valores entre 450 e 600 metros em águas profundas.

Aproximando-se das águas mais rasas e da plataforma continental, as espessuras do Paleógeno assumem valores maiores, indicando uma maior concentração da deposição na região mais central da área de estudo, com espessuras entre 900 e 1300 metros. De fato, as taxas de sedimentação nesta região central (Fig. 46) mostram valores de até 3,5 cm/mil anos. Outra característica interessante de se notar é que o acúmulo de sedimentos nesta região parece ter relação direta com a presença dos montes submarinos. Estas feições morfológicas agiriam como um anteparo ao transporte de sedimentos para sudeste em águas profundas.

\subsubsection{Sedimentação no Neógeno}

No Neógeno, a sedimentação se concentrou mais na plataforma, quando comparada à sedimentação em águas profundas (Fig. 47). Enquanto os valores ao longo da maior parte da área de estudo ficam em torno de 1,5 a 2,0 cm/mil anos, na plataforma estes valores ultrapassam os 5,0 cm/mil anos. Além disso, assim como no Paleógeno, parece ser também importante o efeito da presença dos montes submarinos na sedimentação no Neógeno, com taxas maiores em suas proximidades.

As altas taxas de sedimentação na plataforma levaram ao desenvolvimento de colunas sedimentares de grande espessura, com mais de 1500 metros (Fig. 44). Mesmo assim, o padrão de maiores espessuras a oeste dos montes submarinos da Cordilheira Norte Brasileira não parece se manter no Neógeno e no Quaternário. Pelo contrário, ao 
longo da área estudo, observa-se uma maior homogeneidade nos valores de espessura nestas regiões quando comparados ao Paleógeno. Ainda assim, os valores médios das espessuras no Neógeno são maiores que no Paleógeno, o que também fica claro ao se observar as taxas de sedimentação para os dois períodos.

\subsection{Paleocirculação}

O preenchimento sedimentar das bacias de Barreirinhas e do Ceará deve ser estudado considerando-se também o efeito da circulação das correntes superficiais e de fundo no transporte dos sedimentos. Como a história deposicional das duas bacias está relacionada diretamente com a abertura do Atlântico Equatorial e, consequentemente, com o estabelecimento gradual das correntes e massas d'águas atuais, é fundamental que se compreenda este processo.

A sedimentação atual na MEB sofre influência direta de dois tipos principais de circulação: a de superfície e médias profundidades, com a CNB; e a de fundo, com a CCOP. Compreender quando ambas passaram a atuar na MEB é essencial para a construção da história deposicional de suas bacias sedimentares (Fig. 48).

A CNB é hoje a principal corrente superficial no norte do Brasil, sendo responsável por transportar parte dos sedimentos oriundos do Rio Amazonas para as margens das Guianas. Por razões climáticas, porém, ela passou a atuar de forma mais efetiva a partir do Mioceno (cerca de $20 \mathrm{Ma}$ ) (Barron e Peterson, 1991), e atua no transporte de águas mais quentes ao Atlântico Norte e Mar do Caribe.

A retroflexão da CNB também tem papel importante no equilíbrio climático, já que acontece de forma sazonal, com maior intensidade durante o verão austral (Johns et al., 1990). A mudança de direção da corrente por períodos mais prolongados tem impacto importante no clima do planeta, já que interfere no balanço de calor entre os dois hemisférios (Wilson et al., 2011). Rühlemann et al. (2001) identificaram que o enfraquecimento da Corrente do Golfo durante o Último Máximo Glacial foi concomitante com uma retroflexão contínua da CNB, enquanto Wilson et al. (2011) relacionam períodos 


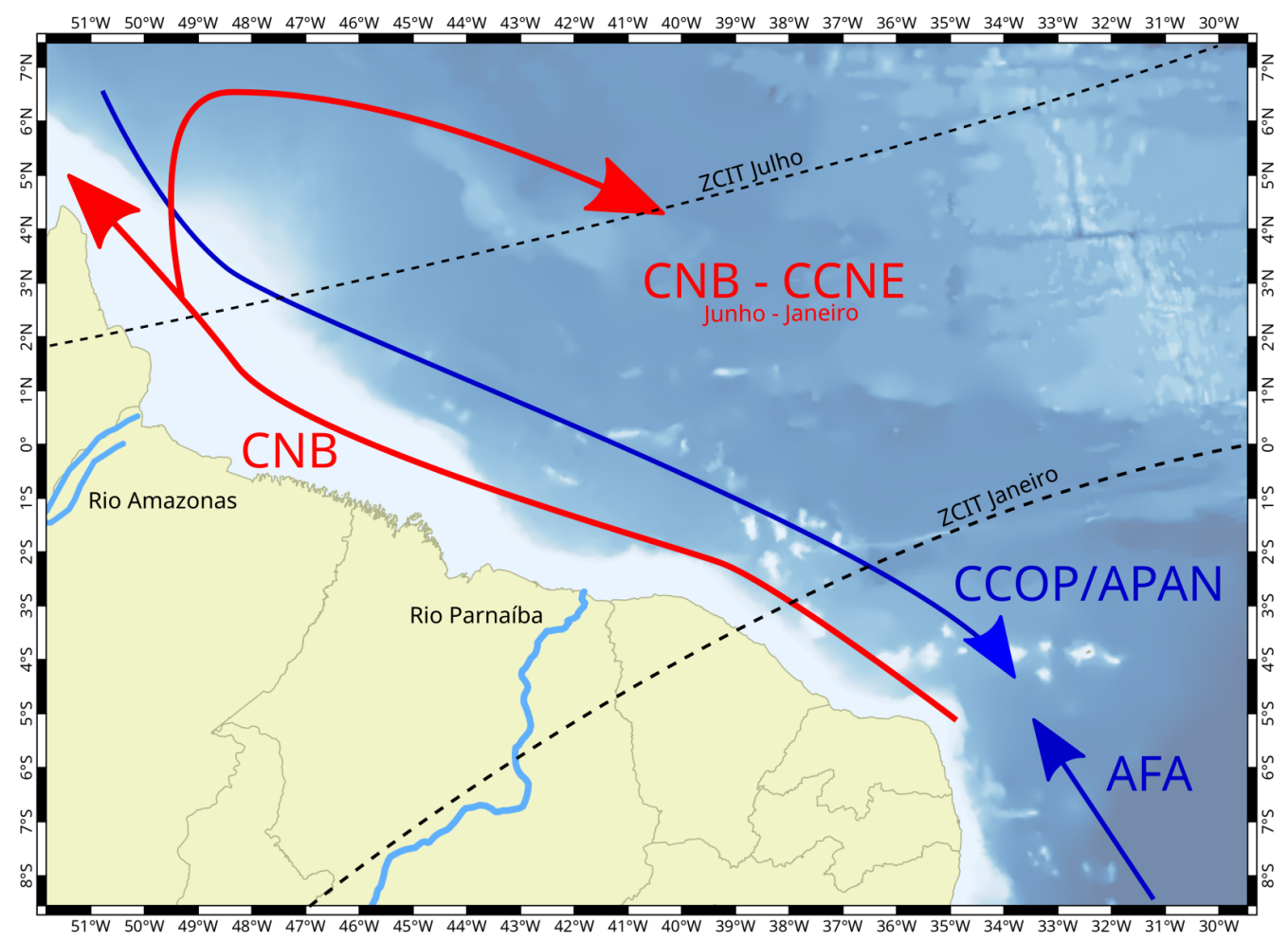

Figura 48: Principais correntes atuando na MEB atualmente, com informações de Rühlemann et al. (2001). Siglas: CNB = Corrente Norte do Brasil; AFA = Água de Fundo Antártica; APAN = Água Profunda do Atlântico Norte; CCOP = Corrente de Contorno Oeste Profunda; ZCIT = Zona de Convergência Intertropical.

mais longos de retroflexão da CNB com climas mais frios. Além de seu papel na distribuição do calor, a retroflexão também afeta a distribuição dos sedimentos. Durante os meses em que ela é máxima, entre agosto e outubro, até $70 \%$ dos sedimentos do Rio Amazonas são transportados para leste (Rühlemann et al., 2001).

A circulação termohalina é dependente das condições climáticas da atmosfera e dos oceanos e, portanto, é de se esperar que as condições atuais não sejam as mesmas daquelas do Paleógeno. Uenzelmann-Neben et al. (2017) consideraram que a circulação no Atlântico Sul do Paleógeno seria uma continuação daquela do Cretáceo, com uma AMOC muito mais rasa e menos intensa. De acordo com os mesmos autores, a AMOC só se tornaria mais intensa e próxima dos níveis de hoje no Mioceno Médio, a partir do Serravalliano. Katz et al. (2011) determinam a importância do estabelecimento da Corrente Circumpolar Antártica (CCA) no estabelecimento de um oceano com múltiplas camada a partir do Oligoceno Superior e até os dias de hoje. Os mesmos autores ainda atribuem à CCA a possibilidade do início da incursão da APAN até o Atlântico Sul através da CCOP. 
O estabelecimento de correntes de fundo no Atlântico Equatorial ainda é fonte de estudos, mas é praticamente consenso que apenas após o Oligoceno, com o resfriamento do planeta, é que se iniciou uma subsidência de massas d'água mais efetiva no Atlântico Norte (Uenzelmann-Neben, 2002; Via e Thomas, 2006; Katz et al., 2011). Durante o Mioceno, a atuação da circulação de fundo ainda era pouco intensa, principalmente porque o Istmo do Panamá ainda estava aberto, permitindo a intrusão da Água Superficial do Pacífico até o Atlântico Norte e Sul (Uenzelmann-Neben et al., 2017). Após seu fechamento, a Água Profunda do Atlântico Norte passou a atuar de forma bem mais efetiva através da CCOP (Uenzelmann-Neben et al., 2017).

O fechamento da comunicação entre o Pacífico e o Atlântico no Istmo do Panamá, conhecida como Central American Seaway (CAS), é considerado por muitos como evento do início do Plioceno (Uenzelmann-Neben et al., 2017). Entretanto, Montes et al. (2015) trabalharam com informações geocronológicas e de proveniência de sedimentos dos Andes e posicionaram este fechamento um tanto antes, no meio do Mioceno.

O resultado das simulações de Uenzelmann-Neben et al. (2017) (Fig, 49), que mostram o início do desenvolvimento de uma APAN mais efetiva na passagem do Mioceno para o Plioceno, seguida por seu estado atual de chegada a altas latitudes no Holoceno. Na simulação para o Eoceno Inferior, nota-se que a Água Superior do Pacífico (ASP) percorre toda a costa brasileira até a latitude de $45^{\circ} \mathrm{S}$, onde diverge para leste forçada pela Água Intermediária Antártica.

A ASP teve uma atuação importante na distribuição dos sedimentos ao longo da MEB, em um momento em que não haviam outras correntes importantes atuando de forma efetiva na região. Por se tratar de uma corrente superficial, sua ação no transporte de sedimentos para sudeste se dava apenas nas camadas superiores do oceano, de maneira consistente até o Mioceno Médio, quando se iniciou o processo de fechamento da CAS. 

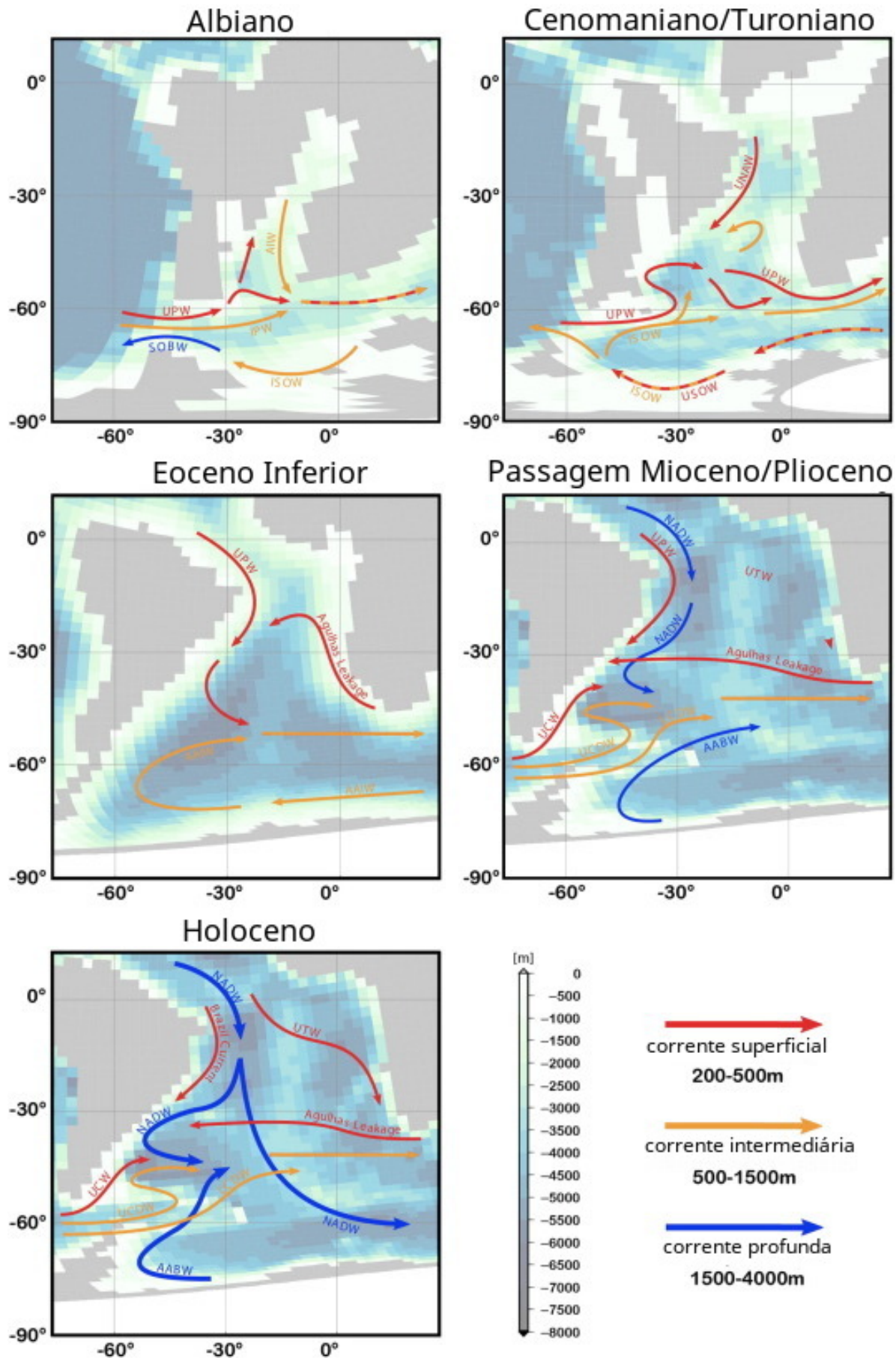

corrente superficial 200-500m

corrente intermediária 500-1500m

corrente profunda $1500-4000 \mathrm{~m}$

Figura 49: Paleocirculação no Oceano Atlântico, desde o Albiano. Adaptado de Uenzelmann-Neben et al. (2017). As siglas das massas d'água, em inglês: AAIW = Água Intermediária Antártica, AABW = Água de Fundo Antártica, AIW = Água Intermediária do Atlântico, IPW = Água Intermediária do Pacífico, LCDW = Água Profunda Circumpolar Inferior, NADW = Água Profunda do Atlântico Norte, SOBW = Água de Fundo do Oceano Sul, SOIW = Água Intermediária do Oceano Sul, UCDW = Água Profunda Circumpolar Superior, UCW = Água Circumpolar Superior, UPW = Água Superior do Pacífico, UNAW = Água Superior do Atlântico Norte, USOW = Água Superior do Oceano Sul, UTW = Água Tropical Superior. 
Durante o Paleógeno, quando ainda não havia se desenvolvido uma circulação nem de superfície nem de fundo, há uma dispersão muito maior dos sedimentos pela duas bacias sedimentares (Fig. 43). Tanto em Barreirinhas quando em Ceará, a sedimentação alcança latitudes menores, chegando a valores de cerca de $2,0 \mathrm{~cm} / \mathrm{mil}$ anos e espessuras de 900 metros na latitude zero.

Nesta situação de inexistência efetiva da CNB ou da CCOP, a atuação da ASP superficial é importante devido a sua possível atuação na distribuição dos sedimentos nas bacias de Barreirinhas e do Ceará. No Paleógeno, há uma clara concentração dos sedimentos a oeste da Cordilheira Norte Brasileira (Fig. 43), indicando que a remobilização dos sedimentos que chegavam à plataforma e talude continentais seria feita por esta corrente com direção sudeste. Desta forma, os montes submarinos agiriam como um anteparo aos sedimentos, proporcionando maior acúmulo de sedimentos nesta região. De fato, Martins e Coutinho (1981) comentam que a Cordilheira Norte Brasileira aprisionava os sedimentos na MEB pelo menos até o Mioceno Inferior.

\subsubsection{O papel da Cordilheira Norte Brasileira}

Além das correntes atuando na distribuição dos sedimentos de fundo nas bacias de Barreirinhas e do Ceará, é fundamental que se entenda o papel dos montes submarinos relacionados à Cordilheira Norte Brasileira no controle da deposição. A quase inexistência de trabalhos sobre a sedimentação em mar profundo na MEB dificulta comparações mais assertivas, entretanto, assim como os registros sísmicos apontam neste estudo, Martins e Coutinho (1981) também indicam o papel dos montes submarinos da MEB como anteparo à sedimentação pelo menos até o Mioceno Inferior.

Neste trabalho, observando-se os mapas de espessuras para o Paleógeno e o Neógeno (Figs. 43 e 44, respectivamente), nota-se claramente que a oeste dos montes submarinos (ou a oeste de $38,5^{\circ} \mathrm{W}$ ) há maiores valores de espessuras. É importante destacar ainda que durante o Paleógeno este acúmulo de material se prolonga até águas bastante profundas, perto do Equador. No Neógeno e no Quaternário, por outro lado, o acúmulo se concentra nas proximidades dos montes submarinos. 
O resultado de um modelo de velocidades para a isóbata de 1900 metros, calculado por Dengler et al. (2004) (Fig. 50), mostra que o "caminho preferencial" para a CCOP se dá a norte dos montes submarinos, "caminho" este representado pelos maiores vetores de velocidade. Considerando este estado atual de circulação de fundo na MEB, as menores velocidades a sul da Cordilheira Norte Brasileira explicam as maiores taxas de sedimentação nesta região no Neógeno (Fig. 47).

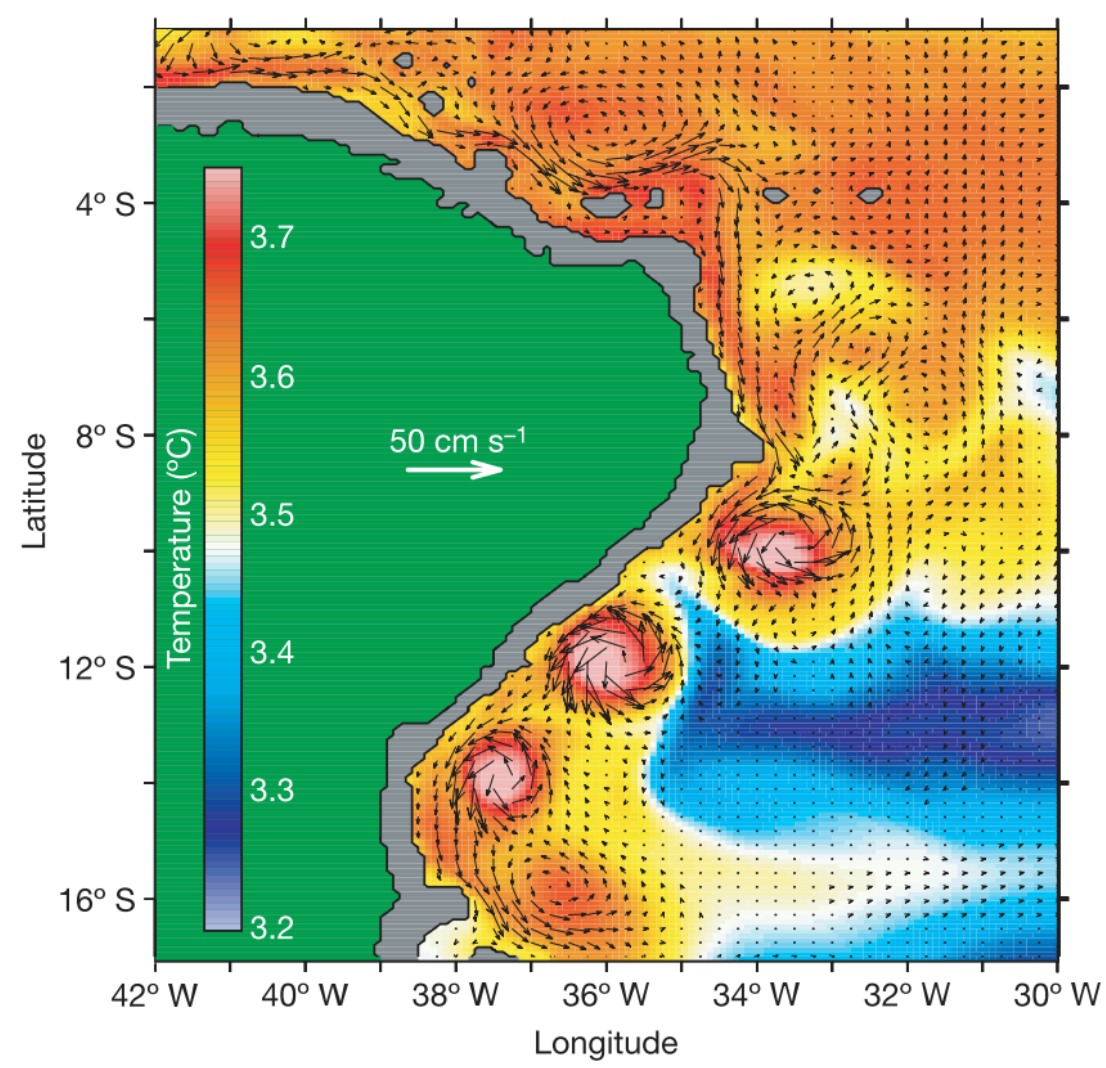

Figura 50: Resultados do modelo de velocidades ao longo da costa brasileira obtido por Dengler et al. (2004), na isóbata de 1900 metros.

A idade de formação dos montes submarinos da MEB também deve ser levada em consideração durante essa análise. Entretanto, com exceção do trabalho de Jovane et al. (2016), que tenta estimar a idade do Platô do Ceará com base em dados sísmicos, há poucos trabalhos deste tipo para os demais montes da cordilheira. Nos registros sísmicos das linhas do LEPLAC, podem ser encontrados alguns indícios das idades de alguns destes montes submarinos.

O monte cruzado pela linha LEPLAC-503 (Fig. 77, nos Apêndices), mostra o horizonte H3 (Base do Chattiano) ascendente junto a ele. Isso indica que sua deposição foi prévia ou concomitante ao soerguimento, colocando a idade do monte subma- 
rino na segunda metade do Oligoceno. O mesmo não ocorre, porém, nos montes da linha LEPLAC-502 (Fig. 75, nos Apêndices), cujos horizontes interpretados não possuem mesma terminação ascendente junto a eles.

A linha LEPLAC-513 (Fig. 81, nos Apêndices) mostra três destes montes submarinos. Naquele do extremo leste, observa-se que uma forte reflexão inferior ao horizonte H1 (Topo do Maastrichtiano) tem terminação ascendente junto ao monte submarino, colocando sua formação anterior ao início do Paleoceno. No monte do extremo oeste (o mesmo cortado pela linha LEPLAC-503), por outro lado, o soerguimento parece estar novamente no Oligoceno Médio.

A resolução dos registros sísmicos não possibilita uma análise mais completa sobre estas idades - e nem é este o escopo deste trabalho. Porém, conhecer a idade de soerguimento destes montes submarinos é de extrema importância para a reconstrução paleoceanográfica em trabalhos futuros.

\subsection{Paleoclima, paleoceanografia e taxas de sedimentação}

O clima na Terra desde o Cretáceo mudou significativamente, trazendo consequências para a circulação atmosférica e para a oceânica, bem como para a formação de geleiras e a maior diferença entre os climas equatorial e polar. No Mesocretáceo, a diferença de temperaturas da superfície do mar entre os polos e o Equador chegava a $50^{\circ} \mathrm{C}$, enquanto atualmente esta diferença fica entre 25 e $30^{\circ} \mathrm{C}$ (Hay, 2011).

No Cenozoico este quadro passou a se inverter e o mundo começou a passar um resfriamento, com diminuição das temperaturas médias, diminuição do nível relativo médio do mar, isolamento térmico da Antártica e formação de calotas de gelo (Zachos et al., 2008; Katz et al., 2008; Edgar et al., 2010). Estes processos culminaram, a longo prazo, no estabelecimento da circulação termohalina, no início do efeito de albedo no planeta, principalmente nas regiões polares, e na geração do atual clima, com diferenças marcantes bem estabelecidas entre os climas equatorial e polar (Hay, 2011).

A evolução climática ao longo do Cenozoico (Fig. 51), baseada no trabalho de Zachos et al. (2008), mostra claramente o decréscimo dos valores de $\delta^{18} \mathrm{O}$ e destaca-se 
a idade de início do formação da calota polar Antártica no final do Eoceno e também os ótimos climáticos existentes no Eoceno e Mioceno.

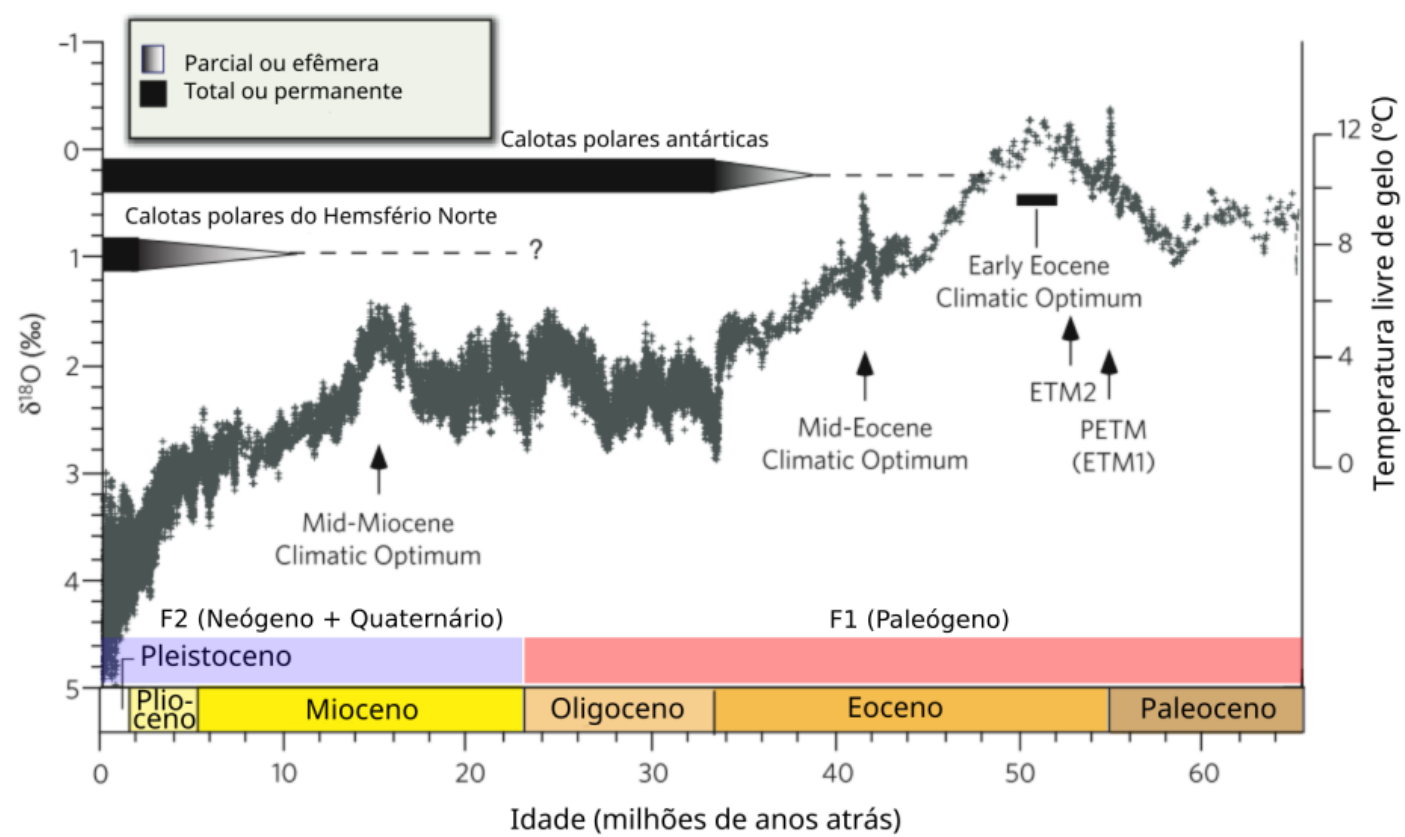

Figura 51: Valores de $\delta^{18} \mathrm{O}$ desde o Paleoceno, adaptado de Zachos et al. (2008); a escala de temperaturas livre de gelo vale apenas para o período em que não havia calotas polares, cuja formação na Antártica (por volta de 35 milhões de anos) também está representada; estão indicados também os ótimos climáticos ao longo do Cenozoico e o início da formação de geleiras no Hemisfério Norte.

\subsubsection{Paleoclima e sedimentação no Paleógeno}

A divisão proposta neste trabalho para o Cenozoico nas Bacias de Barreirinhas e do Ceará em duas fases, permite que se possa definir climas bastante distintos para o Paleógeno e para o Neógeno. Durante Paleógeno, o planeta passou por um intenso resfriamento, mesmo que ainda não o bastante para a formação de gelo polar (Fig. 51). Nesse período, o clima era muito mais equilibrado entre Equador, trópicos e regiões polares, fazendo com que quaisquer alterações no clima fossem muito mais lentas (Peizhen et al., 2001).

Entre o Paleoceno e o Oligoceno, o continente sul-americano e o Atlântico Sul encontravam-se sob o clima mais quente, mais úmido e mais equilibrado, herdado do Cretáceo. Este maior equilíbrio climático, aliado à baixa circulação descrita anteriormente, favoreceram um acúmulo mais distribuído dos sedimentos nas duas bacias estudadas aqui. 
A erosão nos continentes - e, consequentemente, o aporte de sedimentos para as bacias oceânicas - está relacionada a dois fatores principais: (1) as variações climáticas e (2) eventos de soerguimento de massas continentais (Harris e Mix, 2002), que fornecem a energia de agentes erosivos e maior disponibilidade de rochas. Peizhen et al. (2001) sugerem que as rápidas mudanças climáticas, principalmente aquelas regionais, são muito mais importantes para o maior acúmulo de sedimentos nas bacias. Os autores consideram que durante mudanças mais velozes do clima, os sedimentos possuem menos tempo para remobilização, e acabam se concentrando nas bacias sedimentares. O acúmulo de sedimentos nas Bacias de Barreirinhas e do Ceará no Paleógeno corroboram com esta hipótese, já que ele é muito mais bem distribuída ao longo da plataforma, talude e planície abissal quando comparada ao período subsequente.

O clima quente e úmido do Paleógeno favorece a erosão, já que aumenta o intemperismo químico. Mesmo com uma carga menor de sedimentos para as bacias, evidenciada pelas menores taxas de sedimentação, durante o Paleógeno foi acumulada grande quantidade de sedimentos (Fig. 43), principalmente devido à maior duração do período. Em um Atlântico Equatorial mais restrito e de menor circulação, mesmo com taxas de sedimentação mais baixas (Fig. 46) foi possível a geração de colunas sedimentares de até 1000 metros de espessura.

Quando se estuda a paleoclimatologia do Eoceno, não se pode deixar de considerar os efeitos do Ótimo Climático do Eoceno Inferior (EECO, na sigla em inglês) e do Ótimo Climático do Eoceno Médio (MECO, na sigla em inglês). Durante estes dois momentos, a tendência de resfriamento do clima foi interrompida por um rápido aquecimento e retorno às condições climáticas cretáceas (Zachos et al., 2008) (Fig. 51). Entretanto, a resolução dos registros sísmicos analisados neste trabalho impedem quaisquer considerações sobre o efeitos destes dois momentos na sedimentação da MEB.

Durante a transição do Oligoceno para o Mioceno, um outro evento climático importante se desenvolveu, colocando o planeta momentaneamente em um estágio interglacial (Miller et al., 1991). Durante este evento, em diversas partes do planeta foram identificados aumentos na razão $\delta^{18} \mathrm{O}$ que, por sua vez, foram correlacionados com aumento da erosão nos continentes e também aumento no sequestro de carbono nos oceanos (Stewart et al., 2017). Este evento possui correlações em diversas partes do planeta com 
variações eustáticas (Haq et al., 1987; Miller et al., 1991) e tem relação direta com a superfície erosiva do Oligoceno (Figs. 7 e 6), bastante marcante nas duas bacias estudadas. A subsequente subida do nível do mar é registrada principalmente na Bacia de Barreirinhas, pela presença das terminações em onlaps dos horizontes H4 e H5 (Fig. 33).

\subsubsection{Paleoclima e sedimentação no Neógeno e Quaternário}

Após o final do Oligoceno, já com as calotas polares antárticas estabelecidas, e com clima mais seco, passa a haver maior variação climática, com eventos de maiores frequências, principalmente no Pleistoceno. O nível do mar mais baixo e condições mais secas no continente resultam em menor erosão, mas, por outro lado, com o aporte continental atingindo regiões mais distais da plataforma e o talude (Fig. 47). De fato, Hay et al. (1988) sugerem que as maiores taxas de sedimentação no Neógeno são esperadas principalmente nos últimos 5 milhões de anos, quando houve um aumento global da sedimentação terrígena nos oceanos. Estes mesmos autores destacam o papel importante das geleiras na erosão dos continentes e, consequentemente, na disponibilização de sedimentos terrígenos para as bacias oceânicas.

No norte da América do Sul, não houve qualquer papel de geleiras na erosão ou sedimentação de terrígenos. Sendo assim, torna-se mais importante o efeito das alterações climáticas nas variações da sedimentação na MEB (Peizhen et al., 2001). O acúmulo de sedimentos na plataforma e talude de Barreirinhas e Ceará durante o Neógeno e Quaternário mostram um aumento nas taxas de sedimentação nesta região durante este período, reforçando a constatação de Hay et al. (1988) sobre as maiores taxas de terrígenos nos últimos 5 milhões de anos.

A importância das variações climáticas na sedimentação da MEB foi também constatada por Harris e Mix (2002). Os autores utilizaram sedimentos de um testemunho na Elevação do Ceará para comparar possíveis efeitos da tectônica e do clima nas variações de sedimentos terrígenos na região. Segundo os autores, a principal forçante para estas variações no Plioceno e Pleistoceno para a Bacia da Foz do Amazonas é realmente o clima. 
Mesmo considerando o predomínio dos efeitos do clima, não se pode deixar de relacionar o imenso aporte continental que começou a chegar à região da MEB no Mioceno. O estabelecimento do Rio Amazonas como um rio transcontinental durante este período aumentou, por exemplo, o aporte sedimentar para as bacias de Barreirinhas e Pará-Maranhão (Krueger et al., 2012; Hoorn et al., 2017), aporte este que foi inclusive capaz de interromper a sedimentação carbonática na Bacia da Foz do Amazonas (Figueiredo et al., 2009). O aumento das taxas de sedimentação nas porções mais a oeste durante o Neógeno (Fig. 47) tem influência direta do recém estabelecido aporte sedimentar, bem como com o estabelecimento da circulação de fundo (CCOP) e de superfície (CNB) na região.

As variações na sedimentação de siliciclásticos e carbonáticos nas Bacias do Ceará e Barreirinhas estão também relacionadas com as variações no aporte continental oriundo dos outros rios menores que deságuam na MEB. As condições atuais destes rios de baixo aporte sedimentar podem ter sido diferentes ao longo do tempo, assim como Figueiredo et al. (2009) já propuseram ter acontecido com o próprio Rio Amazonas ao longo do Mioceno.

Do Mioceno em diante, a AMOC já estava estabelecida e seus efeitos no clima devem ser considerados também nas bacias de Barreirinhas e do Ceará. Eventos de menor duração e maior frequência são mais bem estudados - no Quaternário, principalmente - por conta dos registros sedimentares. Entretanto, é de se supor que antes disso, e com menor variação, eventos de resfriamento do clima no Hemisfério Norte também ocorreram. Estes eventos, diminuem a intensidade da AMOC e fortalecem os ventos de $\mathrm{NE}$, causando o deslocamento da ZCIT mais a sul. Este descolamento gera mais chuvas no continente, influenciando na sedimentação e na salinidade, por exemplo (Wang et al., 2004; Santos et al., 2014).

A migração da ZCIT ao longo do tempo influencia não somente a pluviosidade no continente, mas também as formações vegetais e, consequentemente, a resistência do solo à erosão (Wang et al., 2004). Como a relação entre posição da ZCIT e a AMOC são retroalimentadas, autores como Arz et al. (1998) e Nace et al. (2014), por exemplo, destacam a direta relação entre a diminuição do transporte da CNB para norte (parte 
integrante da AMOC), as temperaturas superficiais do mar no Atlântico Norte e o aumento de precipitação no Nordeste do Brasil.

Durante o Oligoceno e o Mioceno, pelo menos três importantes transgressões marinhas estão presentes nos registros estratigráficos das bacias do Ceará (Fig. 6) e de Barreirinhas (Fig. 7). Estes avanços do nível do mar geraram a Discordância do Oligoceno Superior, que marca a separação entre o Paleógeno e o Neógeno, além de outras duas discordâncias erosivas no Mioceno Inferior e Médio, durante o Neógeno, que na Bacia de Barreirinhas estão relacionadas a Fm. Pirabas (Trosdtorf Junior et al., 2007). Todas elas puderam ser identificadas nos registros sísmicos na Bacia de Barreirinhas, na forma de onlaps em UC3, UC4 e UC5. (Fig. 33), assim como haviam sido em seções expostas no continente (Rossetti et al., 2013).

As três regressões anteriores a estas transgressões diminuíram localmente o nível do mar, levando a deposição para regiões mais próximas do talude e do sopé na bacia, o que pode explicar as taxas de sedimentação ligeiramente mais altas por volta de $1,25^{\circ} \mathrm{S}$ e $41^{\circ} \mathrm{W}$ e também no extremo oeste da região no Neógeno (Fig. 47).

Assim como aqueles ocorridos no Eoceno, durante o Mioceno também houve um evento climático importante, o Ótimo Climático do Mioceno Médio (MMCO, na sigla em inglês) (Fig. 51). O MMCO representa uma alteração muito significativa nas condições climáticas do Neógeno, cujas temperaturas médias vinham diminuindo desde o Oligoceno. Durante este ótimo climático, o planeta atingiu temperaturas tão quentes quanto aquelas do Eoceno Médio (Flower e Kennett, 1994), provocando importantes alterações na circulação oceânica, clima dos continentes e sedimentação nas bacias marinhas.

Durante esta época, a circulação da MEB já era muito próxima do que é hoje, e um evento deste tipo pode ter influenciado significativamente a sedimentação em Barreirinhas e Ceará. Um maior aquecimento das águas polares, como aqueles ocorridos nos ótimos climáticos do Eoceno, afetariam a circulação termohalina, a AMOC e o regime de chuvas no continente sul-americano.

Zhang et al. (2011) e Chiessi et al. (2014) relacionaram maiores valores de temperatura da superfície do Atlântico Equatorial a uma intensidade reduzida da AMOC no 
Quaternário, assim como intensidade reduzida da CNB. Sendo assim, durante o MMCO, é esperado este mesmo enfraquecimento da CNB e, consequentemente, no transporte para noroeste dos sedimentos da MEB. Esta diminuição temporária - já que ela volta a níveis atuais após o novo resfriamento do planeta - do transporte da CNB, atrelado ao maior aporte sedimentar gerado pelo aumento da pluviosidade, pode ter causado um aumento também temporário das taxas de sedimentação na plataforma continental de Barreirinhas e Ceará durante o MMCO.

As maiores espessuras e taxas de sedimentação na Bacia de Barreirinhas no Neógeno podem ter relação ainda com a deposição de sedimentos autóctones e o início da formação das plataformas carbonáticas, justamente durante o MMCO, quando as condições climáticas e oceanográficas fornecem melhores condições a elas. 


\section{Conclusões}

A Margem Equatorial Brasileira é uma margem do tipo passiva e está posicionada há pelo menos 100 milhões de anos na região equatorial, em latitudes praticamente constantes. Estas duas características proporcionam às bacias que a compõem a possibilidade de serem fontes de registros paleoclimáticos e paleoceanográficos de grande importância científica para o estudo do continente sul-americano e do Atlântico Equatorial.

Estudar e melhor compreender como se deu o preenchimento sedimentar de uma região como esta é uma ferramenta de grande valia para o estudo do paleoclima e a da paleoceanografia da região. Por esta razão, o principal resultado deste trabalho foi propor um modelo deposicional para as duas bacias sedimentares centrais da MEB, baseando-se em uma análise sismoestratigráfica e contribuindo para a evolução dos estudos na margem. Este modelo considerou forçantes climáticas e oceanográficas como contribuintes para o aporte, redistribuição e deposição de sedimentos na plataforma, talude e planície abissal das Bacias de Barreirinhas e do Ceará.

A hipótese científica na qual se baseou este trabalho é a de que a sedimentação cenozoica na MEB possui duas fases bastante distintas:

- Fase 1. Se desenvolveu desde o final do Cretáceo e durante o Paleógeno, com um clima ainda quente e úmido, e uma circulação de superfície e fundo restritas, que não permitiam a remobilização dos sedimentos.

- Fase 2. Quando ocorre o estabelecimento da CNB e a CCOP em níveis perto dos atuais, atuando na remobilização dos sedimentos e erosão de depósitos de águas profundas. Além disso, nesta terceira fase é possível também identificar os efeitos das variações climáticas na atuação das correntes oceânicas, no aporte sedimentar e, consequentemente, no padrão deposicional.

Neste contexto, as Bacias de Barreirinhas e do Ceará foram de fundamental importância para a compreensão da evolução paleoceanográfica da região, principalmente 
devido à sua localização central na MEB, próximo a inúmeros montes submarinos a leste e a um grande aporte continental (Rio Amazonas, após o Mioceno) a oeste. Além disso, o grau de preservação da coluna sedimentar nestas duas bacias é bastante grande, com colunas de mais de $1 \mathrm{~km}$ de espessura, que permitiram o mapeamento de marcadores cronoestratigráficos até o Paleoceno.

Os registros sísmicos utilizados neste trabalho foram cedidos pela Marinha do Brasil e pela Agência Nacional do Petróleo, tratando-se de dados da indústria e também do projeto LEPLAC para levantamentos e estudos na plataforma continental brasileira. $\mathrm{O}$ conjunto de dados serviu como ferramenta essencial para os resultados aqui apresentados.

Foram identificados 5 horizontes sísmicos que, após a amarração com os dados do poço CES-112, foram classificados como marcadores cronoestratigráficos para cinco idades do Cenozoico: H1, marcando o topo do Maastrichtiano; H2, marcando o topo do Thanetiano; H3, marcando a base do Chattiano; H4, marcando o topo do Aquitaniano; e H5, marcando o topo do Serravalliano.

A partir destes marcadores, foram definidas cinco unidades cronoestratigráficas (UC), representando: Paleoceno (UC1), Eoceno e Oligoceno Inferior (UC2), Oligoceno Superior e Mioceno Inferior (UC3), Mioceno Inferior (UC4) e Mioceno Médio até o presente (UC5). Dadas as características dos períodos estudados, as UC foram agrupadas e divididas em duas fases: F1 - Paleógeno (UC1 e UC2) e F2 - Neógeno e Quaternário (UC3, UC4 e UC5).

Para o estudo das duas fases, foram analisados os mapas de espessuras para ambas, relacionando as feições e características encontradas com a história paleoclimática e paleoceanográfica da MEB. Durante o Paleógeno, o planeta vinha de um clima de altas temperaturas, alta concentração de $\mathrm{CO}_{2}$ na atmosfera e, no caso do Atlântico Sul e Equatorial, circulação de fundo muito restrita. No Neógeno, e em direção ao Quaternário, o resfriamento do planeta se acelerou, e a maior abertura do Atlântico, aliada às novas características climáticas, permitiu o estabelecimento da circulação termohalina e o início do desenvolvimento da AMOC.

Os dados analisados neste trabalho permitem concluir que a circulação de fundo na MEB passou a existir de forma mais atuante apenas no Neógeno. Antes disso, no 
Paleógeno, observa-se nos dados de espessura e taxa de sedimentação, que há pouca redistribuição dos sedimentos, que se acumulam a norte da plataforma continental. Ainda no Paleógeno, com o Istmo do Panamá aberto, a Água Superior do Pacífico percorria toda a MEB até o Atlântico Sul, transportando parte dos sedimentos para E-SE. Parte destes sedimentos ficaram aprisionados junto à Cordilheira Norte Brasileira e outros montes submarinos da região.

No final do Paleógeno, a transição Oligoceno-Mioceno ficou marcada nas bacias sedimentares do Ceará e de Barreirinhas por uma importante superfície erosiva. Esta transição, que marca um evento interglacial com registros de descida do nível do mar em diversas áreas do planeta, é seguida por uma nova transgressão marinha, marcada pelas terminações em onlap dos horizontes sísmicos H4 e H5, durante o Mioceno.

Com a continuação do resfriamento do planeta e das águas oceânicas, no Neógeno passa a se desenvolver a circulação termohalina, com a formação de massas d'água e correntes de fundo na Antártica e no Atlântico Norte. A APAN passa a chegar até MEB e o Atlântico Sul através da CCOP, que começa a atuar na redistribuição dos sedimentos em águas de média e grande profundidades. Por sua direção E-SE, parte dos sedimentos remobilizados e transportados por ela ainda ficam aprisionados nos montes submarinos.

Durante o Neógeno, o nível do mar continua em diminuição, quando comparado ao Paleógeno, ainda que existam variações de alta frequência, principalmente no Quaternário. Com a circulação de fundo e de superfície estabelecidas, a deposição dos sedimentos nas bacias de Barreirinhas e do Ceará passa a se concentrar em maiores taxas na plataforma e talude.

No Mioceno, a carga de sedimentos do Rio Amazonas passa a chegar na MEB, e parte desta carga pode também ter atingido as bacias estudadas, principalmente pelo transporte de fundo. Este fato é corroborado pelas maiores taxas de sedimentação na região mais a oeste de Barreirinhas. Ainda nesta região, as transgressões do Mioceno ficaram marcadas em onlaps nos registros sísmicos. As regressões anteriores a cada uma destas três grandes transgressões podem também ser responsáveis pelas maiores taxas de sedimentação na parte oeste de Barreirinhas. 
Períodos de ótimos climáticos durante o Eoceno (EECO e MECO, por exemplo), não puderam ser identificados nos dados sísmicos, principalmente por conta de sua resolução. Por outro lado, durante o MMCO, o enfraquecimento da AMOC levou à diminuição da intensidade da CNB, diminuindo assim o transporte de sedimentos para NO. Esta diminuição, atrelada ao maior aporte sedimentar por conta do aumento da pluviosidade no continente sul-americano, pode também ter contribuído para as maiores espessuras e taxas de sedimentação na porção oeste da Bacia de Barreirinhas. Ainda nesta bacia, a deposição autóctone e a formação de plataformas carbonáticas parecem ter relação com o MMCO e as maiores taxas de sedimentação e espessuras da bacia no Neógeno.

Os quatro objetivos propostos neste trabalho foram atingidos, com a descrição da evolução sedimentar em dois períodos distintos para as duas bacias; a compreensão do papel da Cordilheira Norte Brasileira e outros montes submarinos como anteparo ao transporte de sedimentos; a relação entre os horizontes sísmicos H3, H4 e H5 com eventos climáticos e tectônicos do Mioceno; e, finalmente, com a descrição detalhada do papel das correntes de superfície e de fundo no transporte e deposição dos sedimentos. 


\section{Referências}

Allen, P. A. e J. R. Allen (1991), Basin Analysis: Principles and Applications. Wiley.

Almeida, F. F. M. (1967), Origem e evolução da plataforma brasileira. DNPM.

Almeida, F. F. M., B. B. de Brito Neves, e C. D. R. Carneiro (2000), “The origin and evolution of the south american platform." Earth-Science Reviews, 50, 77-111.

Almeida, F. F. M. de, Y. Hasui, B. B. de Brito Neves, e R. A. Fuck (1977), "Províncias estruturais brasileiras.” Simpósio de Geologia do Nordeste, 8, 363-391.

Almeida, N. M., H. Vital, e M. P. Gomes (2015), "Morphology of submarine canyons along the continental margin of the potiguar basin, ne brazil." Marine and Petroleum Geology, 68, 307-324.

Alves, D. P. V. (2012), A evolução sedimentar do Canal de São Sebastião, no litoral norte do estado de São Paulo, estudada a partir de uma abordagem sismoestratigráfica. Diss. de mestrado, Universidade de São Paulo.

Aquino da Silva, A. G., K. Stattegger, K. Schwarzer, H. Vital, e B. Heise (2015), “The Influence of Climatic Variations on River Delta Hydrodynamics and Morphodynamics in the Parnaíba Delta, Brazil.” Journal of Coastal Research, 314, 930-940.

Arai, M. (2014), "Aptian/albian (early cretaceous) paleogeography of the south atlantic: a paleontological perspective.” Brazilian Journal of Geology, 44, 339-350.

Armstrong, H. A. e M. B. Allen (2011), "Shifts in the intertropical convergence zone, Himalayan exhumation, and late Cenozoic climate." Geology, 39, 11-14.

Arz, H. W., J. Pätzold, e G. Wefer (1999), "Climatic changes during the last deglaciation recorded in sediment cores from the northeastern brazilian continental margin." GeoMarine Letters, 19, 209-218.

Arz, H. W., J. Pätzold, e G. Wefer (1998), “Correlated millennial-scale changes in surface hydrography and terrigenous sediment yield inferred from last-glacial marine deposits off northeastern brazil." Quaternary Research, 50, 157-166. 
Azevedo, R. L. (2016), "Morfoestrutura e dispersão sedimentar na bacia oceânica ao largo da bacia pará-maranhão, através da interpretação de perfis de sísmica multicanal.” $R e$ vista Brasileira de Geomorfologia, 15, 273-289.

Barron, E. J. e W. H. Peterson (1991), "The Cenozoic ocean circulation based on ocean General Circulation Model results.” Palaeogeography, Palaeoclimatology, Palaeoeco$\log y, 83,1-28$.

Behling, H. e M. L. da Costa (2001), "Holocene vegetational and coastal environmental changes from the lago crispim record in northeastern pará state, eastern amazonia." Review of Palaeobotany and Palynology, 114, 145-155.

Beltrami, C. V., L. E. M. Alves, e F. J. Feijo (1994), “Bacia do ceará.” Boletim de Geociências da PETROBRAS, 8, 117-125.

Bonatti, E., M. Ligi, A. M. Borsetti, L. Gasperini, A. Negri, e R. Sartori (1996), "Lower Cretaceous deposits trapped near the equatorial Mid-Atlantic Ridge." Nature, 380, $518-520$.

Brookfield, M. E. (2008), Principles of Stratigraphy. Wiley.

Castro, D. L., F. H. R. Bezerra, M. O. L. Sousa, e R. A. Fuck (2012), "Influence of neoproterozoic tectonic fabric on the origin of the potiguar basin, northeastern brazil and its links with west africa based on gravity and magnetic data." Journal of Geodynamics, 54, 29-42.

Chang, H. K., R. O. Kowsmann, e A. M. F. Figueiredo (1988), "New concepts on the development of east brazilian marginal basins." Episodes, 11, 194-202.

Chang, P., L. Ji, e H. Li (1997), "A decadal climate variation in the tropical atlantic ocean from thermodynamic air-sea interactions." Nature, 385, 516-518.

Chiessi, C. M., S. Mulitza, J. Groeneveld, J. B. Silva, M. .C Campos, e M. H. C. Gurgel (2014), "Variability of the brazil current during the late holocene." Palaeogeography, Palaeoclimatology, Palaeoecology, 415, 8-36.

Chopra, S. e K. J. Marfurt (2007), Seismic attributes for prospect identification and reservoir characterization, volume 11. Society of Exploration Geophysicists Tulsa, Oklahoma. 
Cohen, K., S. Finney, P. Gibbard, e J. Fan (2017), "The ics international chronostratigraphic chart.” Episodes, 36, 199-204.

Colinvaux, P. A., P. E. Oliveira, J. E. Moreno, M. C. Miller, e M. B. Bush (1996), “A long pollen record from lowland amazonia: forest and cooling in glacial times." Science, $274,85$.

Condé, V.C, C. C. Lana, O. C. Pessoa Neto, E. H. Roesner, J. M. Morais Neto, e D. C. Dutra (2007), "Bacia do ceará." Boletim de Geociências da PETROBRAS, 15, 347355.

Cunha, A. A. S. e E. A. M. Koutsoukos (1998), "Calcareous nannofossils and planktic foraminifers in the upper Aptian of the Sergipe Basin, northeastern Brazil: palaeoecological inferences.” Palaeogeography, Palaeoclimatology, Palaeoecology, 142, 175184.

Dengler, M., F. A. Schott, C. Eden, P. Brandt, J. Fischer, e R. J. Zantopp (2004), “Break-up of the atlantic deep western boundary current into eddies at 8 s." Nature, 432, 1018 1020.

Dingle, R. V. (1999), "Walvis Ridge barrier: its influence on palaeoenvironments and source rock generation deduced from ostracod distributions in the early South Atlantic Ocean." Geological Society, 153, 293-302.

Edgar, K. M., P. A. Wilson, P. F. Sexton, S. J. Gibbs, A. P. Roberts, e R. D. Norris (2010), "New biostratigraphic, magnetostratigraphic and isotopic insights into the middle eocene climatic optimum in low latitudes." Palaeogeography, Palaeoclimatology, Palaeoecology, 297, 670-682.

Figueiredo, J., C. Hoorn, P. Van der Ven, e E. Soares (2009), "Late miocene onset of the amazon river and the amazon deep-sea fan: Evidence from the foz do amazonas basin." Geology, 37, 619-622.

Flower, B. P. e J. P. Kennett (1994), “The middle Miocene climatic transition: East Antarctic ice sheet development, deep ocean circulation and global carbon cycling." Palaeogeography, Palaeoclimatology, Palaeoecology, 108, 537-555. 
Garreaud, R. D., M. Vuille, R. Compagnucci, e J. Marengo (2009), "Present-day South American climate." Palaeogeography, Palaeoclimatology, Palaeoecology, 281, 180195.

Gomes, M. P., H. Vital, K. Stattegger, e K. Schwarzer (2016), "Bedrock control on the assu incised valley morphology and sedimentation in the brazilian equatorial shelf." International Journal of Sediment Research.

Haq, B. U., J. Hardenbol, e P. R. Vail (1987), “Chronology of fluctuating sea levels since the triassic." Science, 235, 1156-1167.

Harris, S. E. e A. C. Mix (2002), "Climate and tectonic influence on continental erosion of tropical Southe America, 0-13Ma." Geology, 30, 447-450.

Hastenrath, S. e J. Merle (1987), "Annual cycle of subsurface thermal structure in the tropical atlantic ocean." Journal of Physical Oceanography, 17, 1518-1538.

Hay, W. W. (2011), “Can humans force a return to a 'Cretaceous' climate?” Sedimentary Geology, 235, 5-16.

Hay, W. W., J. L. Sloan, e C. N. Wold (1988), "Mass age distribution and composition of sediments on the ocean-floor and the global rate of sediment subduction." Journal of Geophysical Research - Solid Earth And Planets, 93, 14933-14940.

Hayes, D. e M. Ewing (1970), "North brazilian ridge and adjacent continental margin." Am. Assoc. Petroleum Geologists Bull., 54, 2120-2150.

Hoorn, C., G. R. Bogotá, M. Romero-Baez, E. I. Lammertsma, S. G. A. Flantua, E. L. Dantas, E. Dino, S. A. do Carmo, e F. Chemale (2017), "The amazon at sea: Onset and stages of the amazon river from a marine record, with special reference to neogene plant turnover in the drainage basin." Global and Planetary Change, 153, 51-65.

Houtz, R. E., W. J. Ludwig, J. D. Milliman, e J. A. Grow (1977), "Structure of the northern Brazilian continental margin.” Bulletin of the Geological Society of America, 88, 711719.

Jenkyns, H. C. (2010), “Geochemistry of oceanic anoxic events.” Geochemistry, Geophysics, Geosystems, 11. 
Johns, W. E., D. M. Fratantoni, e R. J. Zantopp (1993), “Deep western boundary current variability off northeastern brazil." Deep Sea Research Part I: Oceanographic Research Papers, 40, 293-310.

Johns, W. E., T. N. Lee, R. C. Beardsley, J. Candela, R. Limeburner, e B. Castro (1998), “Annual cycle and variability of the north brazil current.” Journal of Physical Oceanography, 28, 103-128.

Johns, W. E., T. N. Lee, F. A. Schott, R. J. Zantopp, e R. H. Evans (1990), “The North Brazil Current Retrofiection: Seasonal Structure and Eddy Variability Seasonal.” Journal of Geophysical Research, 95, 22,103-22,120.

Jovane, L., R. Coccioni, A. Marsili, e G. Acton (2009), “The late eocene greenhouseicehouse transition: Observations from the massignano global stratotype section and point (gssp).” Geological Society of America Special Papers, 452, 149-168.

Jovane, L., J. Figueiredo, D. P. V. Alves, D. Iacopini, M. Giorgioni, P. Vannuchi, D. S. Moura, F. H. Bezerra, H. Vital, I. Rios, e E. Molina (2016), "Sismostratigraphy of the ceará plateau: clues to decipher the cenozoic evolution of brazilian equatorial margin.” Frontiers in Earth Science.

Katz, M. E., B. S. Cramer, J. R. Toggweiler, G. Esmay, C. Liu, K. G. Miller, Y. Rosenthal, B. S. Wade, e J. D. Wright (2011), "Impact of Antarctic Circumpolar Current Development on Late Paleogene Ocean Structure.” Science, 332, 1076-1079.

Katz, M. E., K. G. Miller, J. D. Wright, B. S. Wade, J. V. Browning, B. S. Cramer, e Y. Rosenthal (2008), "Stepwise transition from the eocene greenhouse to the oligocene icehouse." Nature Geoscience, 1, 329-334.

Knoppers, B., W. Ekau, e A. G. Figueiredo (1999), “The coast and shelf of east and northeast brazil and material transport." Geo-Marine Letters, 19, 171-178.

Knutz, P. C. (2008), “Palaeoceanographic Significance of Contourite Drifts.” In Developments in Sedimentology: Contourites (M. Rebesco e A. Camerlenghi, eds.), volume 60, capitulo 24, 511-535, Elsevier B.V. 
Kominz, M. A. (1984), Inter regional Unconformities and Hydrocarbon Accumulation, capitulo Oceanic ridge volumes and sea-level change-an error analysis, 109-127. AAPG Special Volumes.

Kominz, M. A., K. G. Miller, e J. V. Browning (1998), "Long-term and short-term global cenozoic sea-level estimates." Geology, 26, 311-314.

Krauspenhar, P. M., M. A. Carvalho, G. Fauth, e C. C. Lana (2014), “Albian palynostratigraphy of odp leg 207 (holes 1257a, 1258c and 1260b), demerara rise, equatorial atlantic." Revue de micropaléontologie, 57, 1-13.

Krueger, A., M. Murphy, E. Gilbert, e K. Burke (2012), "Deposition and deformation in the deepwater sediment of the offshore barreirinhas basin, brazil." Geosphere, GES00805-1.

Martins, L. R. e P. N. Coutinho (1981), “The brazilian continental margin.” Earth-Science Reviews, 17, 87-107.

Maslin, M. A. e S. J. Burns (2000), "Reconstruction of the amazon basin effective moisture availability over the past 14,000 years." Science, 290, 2285-2287.

Matos, R. M. D. (1987), "Sistema de riftes cretáceos do ne brasileiro." Seminário de Tectônica da PETROBRAS, 1, 125-159.

Matos, R. M. D. (1992), “The northeast brazilian rift system.” Tectonics, 11, 766-791.

Matos, R. M. D. (2000), “Tectonic evolution of the equatorial south atlantic.” Atlantic rifts and continental margins, 331-354.

Melo, A., I. A. Cavalcanti, e P. Souza (2009), Zona de Convergência Intertropical., capitulo 2, 25-41. Oficina do Texto.

Miller, K. G., M. A. Kominz, J. V. Browning, J. D. Wright, G. S. Mountain, M. E. Katz, P. J. Sugarman, B. S. Cramer, N. Christie-Blick, e S. F. Pekar (2005), “The phanerozoic record of global sea-level change." Science, 310, 1293-1298.

Miller, Kenneth G., James D. Wright, e Richard G. Fairbanks (1991), "Unlocking the Ice House: Oligocene-Miocene oxygen isotopes, eustasy, and margin erosion." Journal of Geophysical Research: Solid Earth, 96, 6829-6848. 
Mitchum, R. M., P. R. Vail, e J. B. Sangree (1977), "Seismic stratigraphy and global changes of sea level: Part 6. stratigraphic interpretation of seismic reflection patterns in depositional sequences: Section 2. application of seismic reflection configuration to stratigraphic interpretation."

Mizusaki, A. M. P., A. Thomaz-Filho, E. J. Milanic, e P. Césero (2002), "Mesozoic and Cenozoic igneous activity and its tectonic control in northeastern Brazil." Journal of South American Earth Sciences, 15, 183-198.

Mohriak, W. U. (2003), "Bacias sedimentares da margem continental brasileira." Geologia, tectônica e recursos minerais do Brasil, Cap. 3, 87-165.

Montes, C., A. Cardona, C. Jaramillo, A. Pardo, J. C. Silva, V. Valencia, C. Ayala, L. C. Pérez-Angel, L. A. Rodriguez-Parra, V. Ramirez, e H. Niño (2015), "Middle Miocene closure of the Central American Seaway." Science, 348, 226-229.

Morais Neto, J., O. Neto, C. Lana, e P. Zalán (2003), "Bacias sedimentares brasileiras: Bacia do cear/'a." 57.

Nace, T. E., P. A. Baker, G. S. Dwyer, C. G. Silva, C. A. Rigsby, S. J. Burns, L. Giosan, B. Otto-Bliesner, Z. Liu, e J. Zhu (2014), “The role of north brazil current transport in the paleoclimate of the brazilian nordeste margin and paleoceanography of the western tropical atlantic during the late quaternary." Palaeogeography, Palaeoclimatology, Palaeoecology, 415, 3-13.

Naish, T. e P. J. J. Kamp (1997), “Sequence stratigraphy of sixth-order (41 ky) pliocenepleistocene cyclothems, wanganui basin, new zealand: a case for the regressive systems tract." Geological Society of America Bulletin, 109, 978-999.

Payton, C. E. et al. (1977), Seismic stratigraphy: applications to hydrocarbon exploration, volume 26. American Association of Petroleum Geologists Tulsa, OK.

Peizhen, Z., P. Molnar, e W. R. Downs (2001), "Increased sedimentation rates and grain sizes 2-4 Myr ago due to the influence of climate change on erosion rates." Nature, 410 , 891-897. 
Pessenda, L. C. R., R. Boulet, R. Aravena, V. Rosolen, S. E. M. Gouveia, A. S. Ribeiro, e M. Lamotte (2001), "Origin and dynamics of soil organic matter and vegetation changes during the holocene in a forest-savanna transition zone, brazilian amazon region.” The Holocene, 11, 250-254.

Pessoa Neto, O. C., U. M. Soares, J. G. F. Silva, H. J. Roesner, C. P. Florencio, e C. A. V. Souza (2007), "Bacia potiguar." Boletim de Geociências da PETROBRAS, 15, 357369.

Philander, S. G. (2001), Atlantic Ocean equatorial currents, volume 188. Academic Press.

Posamentier, H. W. (1988), Sea Level change - an integrated approach, capitulo Eustatic controls on clastic deposition II—sequence and systems tract models. Special Publications of SEPM.

Posamentier, H. W. e G. P. Allen (1999), Siliciclastic sequence stratigraphy: concepts and applications, volume 7. SEPM (Society for Sedimentary Geology) Tulsa.

Rebesco, M. (2005), “Contourites.” In Encyclopedia of Geology (R.C. Selley, L.R.M. Cocks, e I.R. Plimer, eds.), 513-527, Elsevier.

Rebesco, M., F. J. Hernandez-Molina, D. Van Rooij, e A. Wahlin (2014), “Contourites and associated sediments controlled by deep-water circulation processes: State-of-theart and future considerations." Marine Geology, 352, 111-154.

Rebesco, M. e D. Stow (2001), "Seismic expression of contourites and related deposits: A preface." Marine Geophysical Researches, 22, 303-308.

Ribeiro, H. J. P. S. (2001), Estratigrafia de sequências: fundamentos e aplicações. São Leopoldo, Editora UNISINOS.

Rosa, R., A. Luiz, M. C. Schinelli, et al. (1985), "Deconvolution tests with deep water experimental data from campos basin, brazil.” In 1985 SEG Annual Meeting, Society of Exploration Geophysicists.

Rossetti, D. F., F. H. R. Bezerra, e J. M. L. Dominguez (2013), "Late oligocene-miocene transgressions along the equatorial and eastern margins of brazil." Earth-Science Reviews, 123, 87-112. 
Rühlemann, C., B. Dickmann, S. Mulitza, e M. Frank (2001), "Late Quaternary changes of western equatorial Atlantic surface.” Paleoceanography, 16, 293-305.

Russell, J. M. e T. C. Johnson (2005), "Late Holocene climate change in the North Atlantic and equatorial Africa: Millennial-scale ITCZ migration." Geophysical Research Letters, 32, 1-4.

Santos, T. P., A. L. Belem, C. F. Barbosa, T. Dokken, e A. L. S. Albuquerque (2014), "Paleoceanographic reconstruction of the western equatorial atlantic during the last 40kyr." Palaeogeography, Palaeoclimatology, Palaeoecology, 415, 14-20.

Schlanger, S. O. e H. C. Jenkins (1976), “Cretaceous Oceanic Anoxic Events: Causes and consequences." Geologie en Mijnbouw, 55, 179-184.

Schott, F. A., M. Dengler, R. J. Zantopp, L. Stramma, J. Fischer, e P. Brandt (2005), “The Shallow and Deep Western Boundary Circulation of the South Atlantic at $5^{\circ}-11^{\circ}$ S." Journal of Physical Oceanography, 35, 2031-2053.

Scotese, C. R. e J. Golonka (1997), Paleogeographic atlas. PALEOMAP Project, University of Texas at Arlington.

Silveira, I. C. A. da, L. B. Miranda, e W. S. Brown (1994), "On the origins of the north brazil current." Journal of Geophysical Research, 99, 22-501.

Souza, J. M. de (1999), “Mar territorial, zona econômica exclusiva ou plataforma continental?" Revista Brasileira de Geofísica, 17, 79-82.

Steckler, M. S. e A. B. Watts (1978), "Subsidence of the Atlantic-type continental margin off New York." Earth and Planetary Science Letters, 41, 1-13.

Stewart, Joseph A., Rachael H. James, Pallavi Anand, e Paul A. Wilson (2017), "Silicate Weathering and Carbon Cycle Controls on the Oligocene-Miocene Transition Glaciation.” Paleoceanography, 32, 1070-1085.

Szczygielski, A., K. Stattegger, K. Schwarzer, A. G. A. da Silva, H. Vital, e J. Koenig (2015), "Evolution of the Parnaíba Delta (NE Brazil) during the late Holocene." GeoMarine Letters, 35, 105-117. 
Trosdtorf Junior, I., P.V Zalán, J. J. P. Figueiredo, e E. F. Soares (2007), “Bacia de barreirinhas." Boletim de Geociências da PETROBRAS, 15, 331-339.

Turcq, B., A. L. S. Albuquerque, R. C. Cordeiro, A. Sifeddine, F. F. L. Simões Filho, A. G. Souza, J. J. Abrão, F. B. L. Oliveira, A. O. Silva, e J. Capitâneo (2002), “Accumulation of organic carbon in five brazilian lakes during the holocene." Sedimentary Geology, $148,319-342$.

Uenzelmann-Neben, G. (2002), "Seismic characteristics of sediment drifts: An example from the Agulhas Plateau, southwest Indian Ocean.” Marine Geophysical Researches, $22,323-343$.

Uenzelmann-Neben, G., T. Weber, J. Grützner, e M. Thomas (2017), “Transition from the Cretaceous ocean to Cenozoic circulation in the western South Atlantic - A twofold reconstruction." 716, 225-240.

Vail, P. R. (1987), Atlas of seismic stratigraphy, capitulo Seismic stratigraphy interpretation using sequence stratigraphy: Part 1: Seismic stratigraphy interpretation procedure. AAPG Special Volumes.

Vail, P R, R M Mitchum, e S Thompson (1977), Seismic stratigraphy - Application to hydrocarbon exploration. Memoir 26, volume Part 3, capitulo Seismic Stratigraphy and Global Change of Sea Level, Part 3: Relative changes of sea level from coastal onlap, 63-81.

Van Sickel, W. A., M. A. Kominz, K. G. Miller, e J. V. Browning (2004), "Late cretaceous and cenozoic sea-level estimates: backstripping analysis of borehole data, onshore new jersey." Basin Research, 16, 451-465.

Via, R. K. e D. J. Thomas (2006), "Evolution of Atlantic thermohaline circulation: Early Oligocene onset of deep-water production in the North Atlantic." Geology, 34, 441444.

Vital, H., V. E. Amaro, e I. C. M. da Silveira (2006), "Coastal erosion on the rio grande do norte state (northeastern brazil): Causes and factors versus effects and associated processes." Journal of Coastal Research, 1306-1309. 
Vital, H., S. F. L. Furtado, e M. P. Gomes (2010a), "Response of the apodi-mossoró estuary-incised valley system (ne brazil) to sea-level fluctuations." Brazilian journal of Oceanography, 58, 13-24.

Vital, H., M. P. Gomes, W. F. Tabosa, E. P. Frazão, C. L. A. Santos, P. Júnior, e J. Saraiva (2010b), "Characterization of the brazilian continental shelf adjacent to rio grande do norte state, ne brazil." Brazilian Journal of Oceanography, 58, 43-54.

Wagner, T. (2002), "Late cretaceous to early quaternary organic sedimentation in the eastern equatorial atlantic.” Palaeogeography, Palaeoclimatology, Palaeoecology, 179, $113-147$.

Wang, X., A. S. Auler, R. L. Edwards, H. Cheng, P. S Cristalli, P. L. Smart, D. A. Richards, e C. Shen (2004), "Wet periods in northeastern Brazil over the past $210 \mathrm{kyr}$ linked to distant climate anomalies." Nature, 432, 2767-2769.

Weissert, H. e E. Erba (2004), "Volcanism, co2 and palaeoclimate: a late jurassic-early cretaceous carbon and oxygen isotope record." Journal of the Geological Society, 161, $695-702$.

Wilson, Katy E., Mark A. Maslin, e Stephen J. Burns (2011), “Evidence for a prolonged retroflection of the North Brazil Current during glacial stages." Palaeogeography, Palaeoclimatology, Palaeoecology, 301, 86-96.

Zachos, J. C., G. R. Dickens, e R. E. Zeebe (2008), "An early cenozoic perspective on greenhouse warming and carbon-cycle dynamics." Nature, 451, 279-283.

Zalán, P. V. (2005), "End members of gravitational fold and thrust belts (gftbs) in the deep waters of brazil." An AAPG Seismic Atlas: AAPG Studies in Geology, 53, 147-156.

Zalán, P. V. (2011), "Fault-related folding in the deep waters of the equatorial margin of brazil.” In Thrust fault-related folding (K McClay, J Shaw, e J Suppe, eds.), 335-355, AAPG Special Volumes.

Zhang, D., R. Msadek, M. J. McPhaden, e T. Delworth (2011), "Multidecadal variability of the North Brazil Current and its connection to the Atlantic meridional overturning circulation.” Journal of Geophysical Research, 116, C04012. 
Zhang, Y., C. M. Chiessi, S. Mulitza, M. Zabel, R. I. F. Trindade, M. H. B. M. Hollanda, E. L. Dantas, A. Govin, R. Tiedemann, e G. Gerold Wefer (2015), “Origin of increased terrigenous supply to the ne south american continental margin during heinrich stadial 1 and the younger dryas." Earth and Planetary Science Letters, 432, 493-500. 


\section{Apêndices}

Nesta seção estão apresentadas as principais e mais relevantes linhas sísmicas utilizadas no trabalho. 


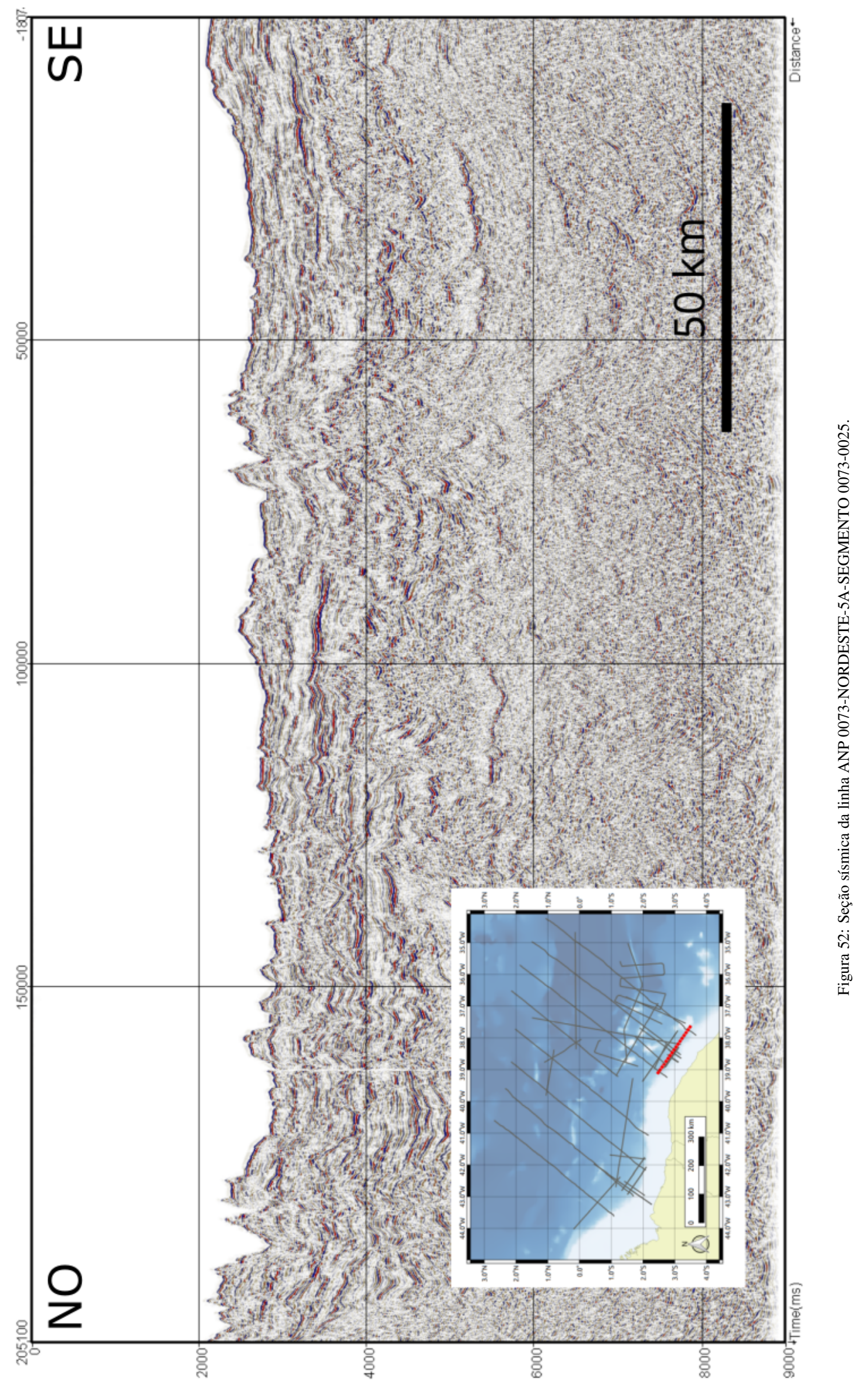




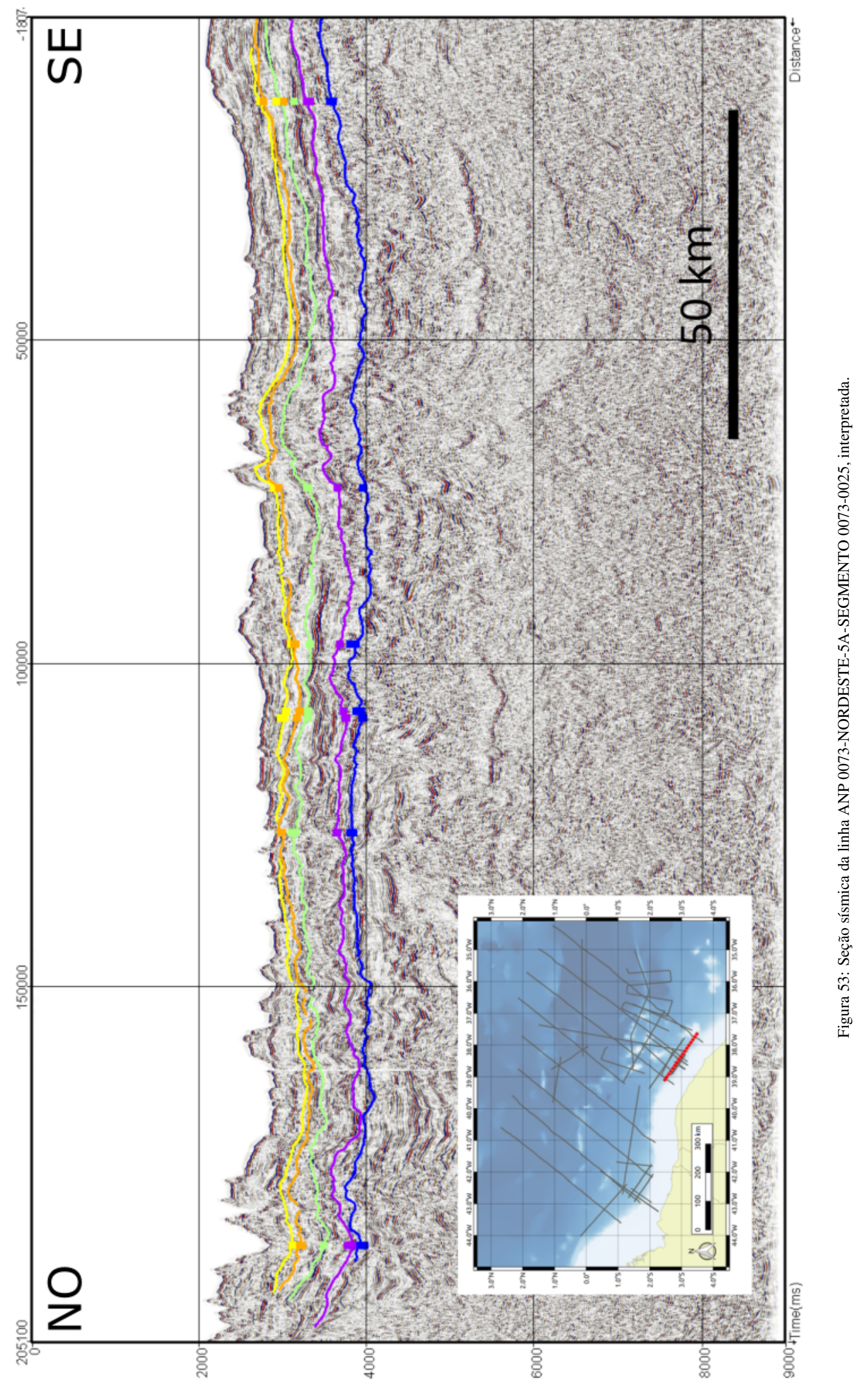




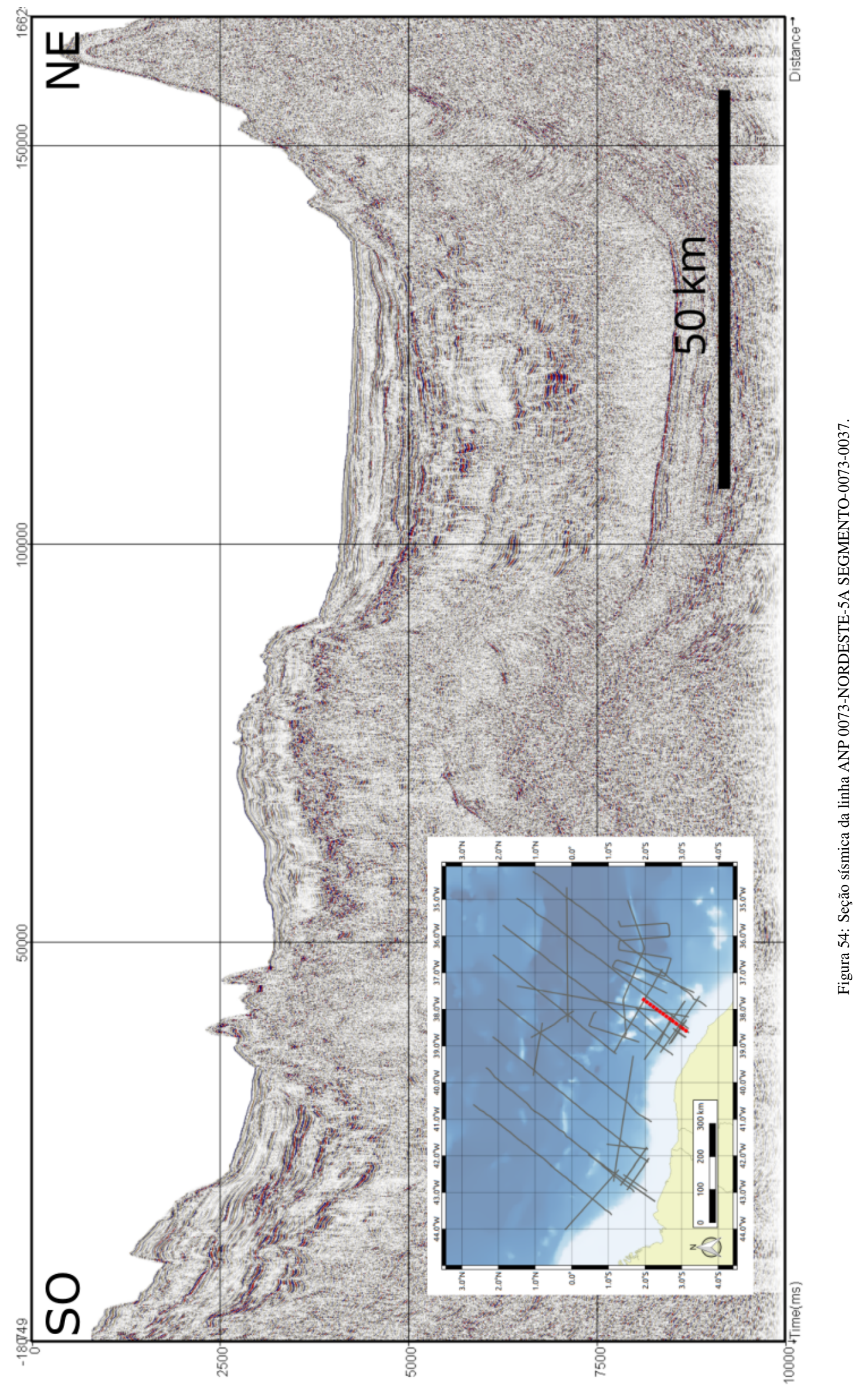




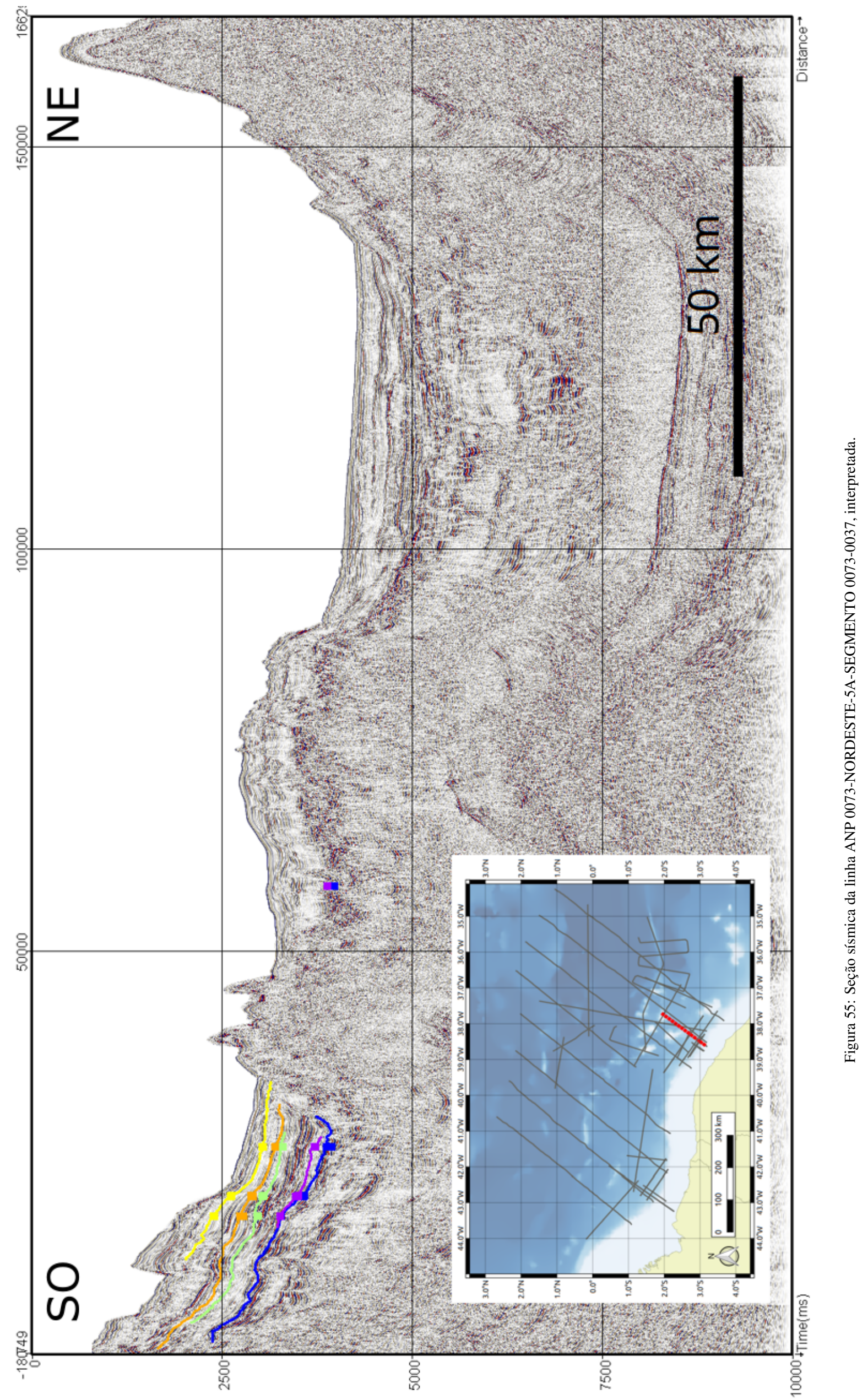




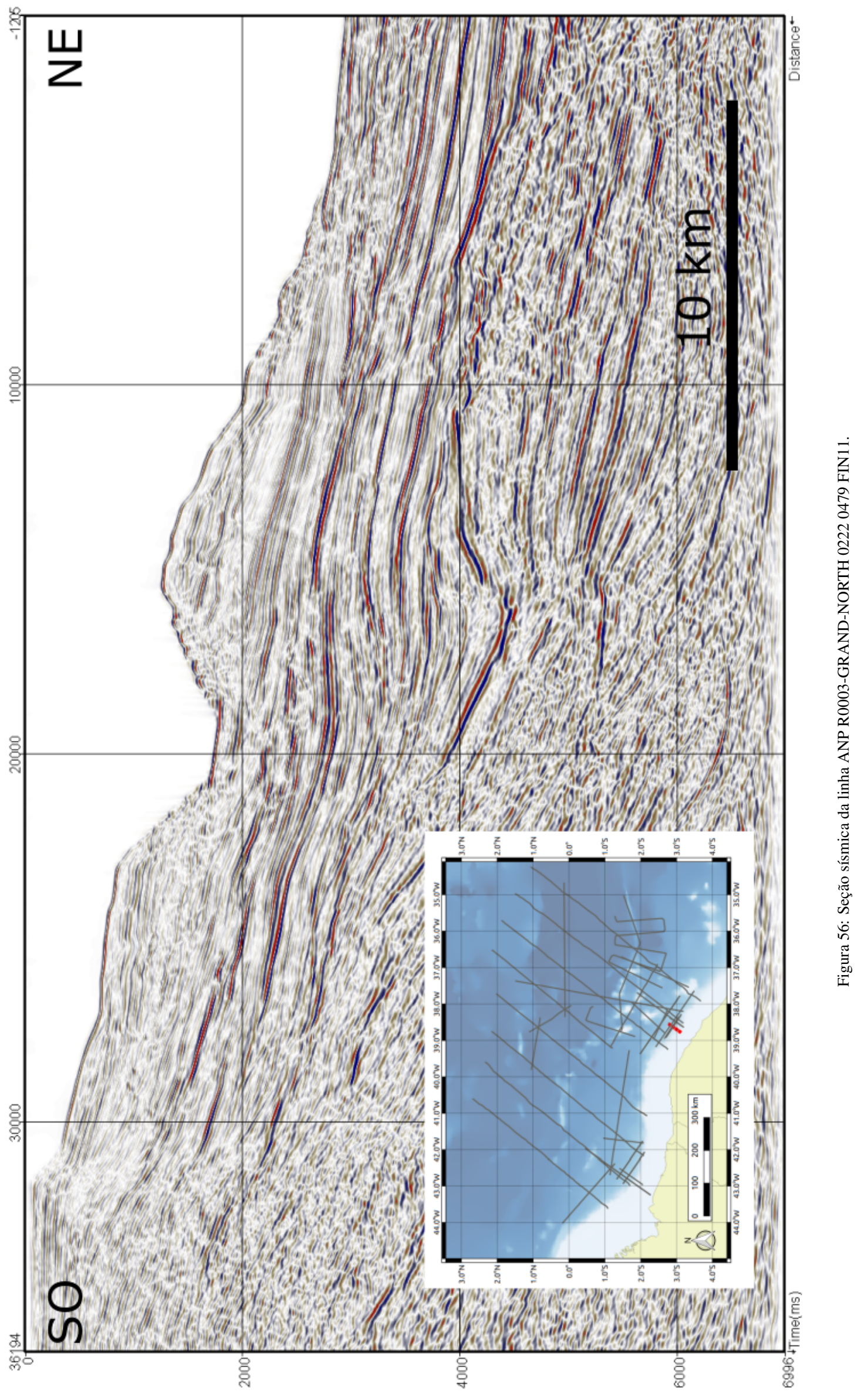




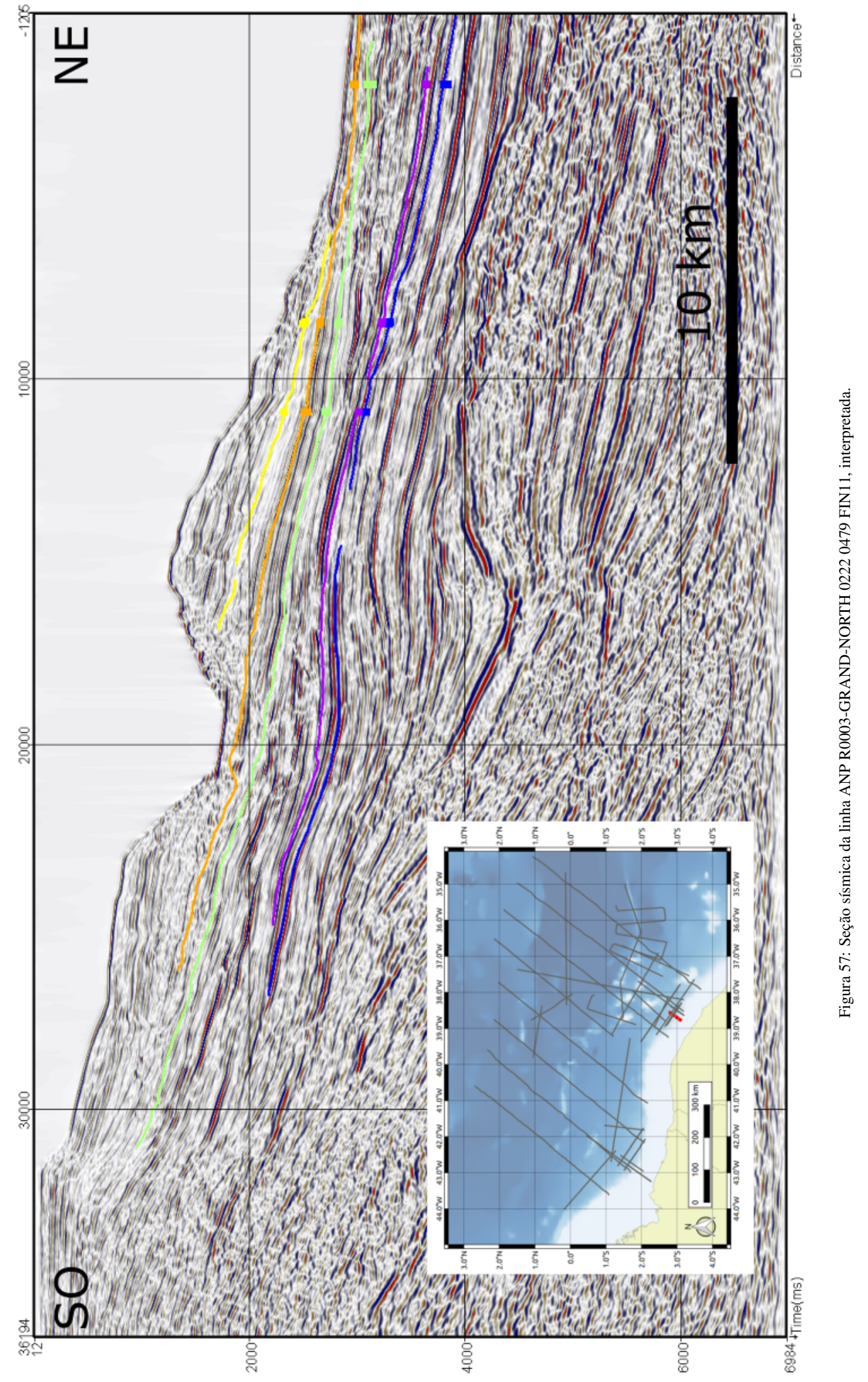




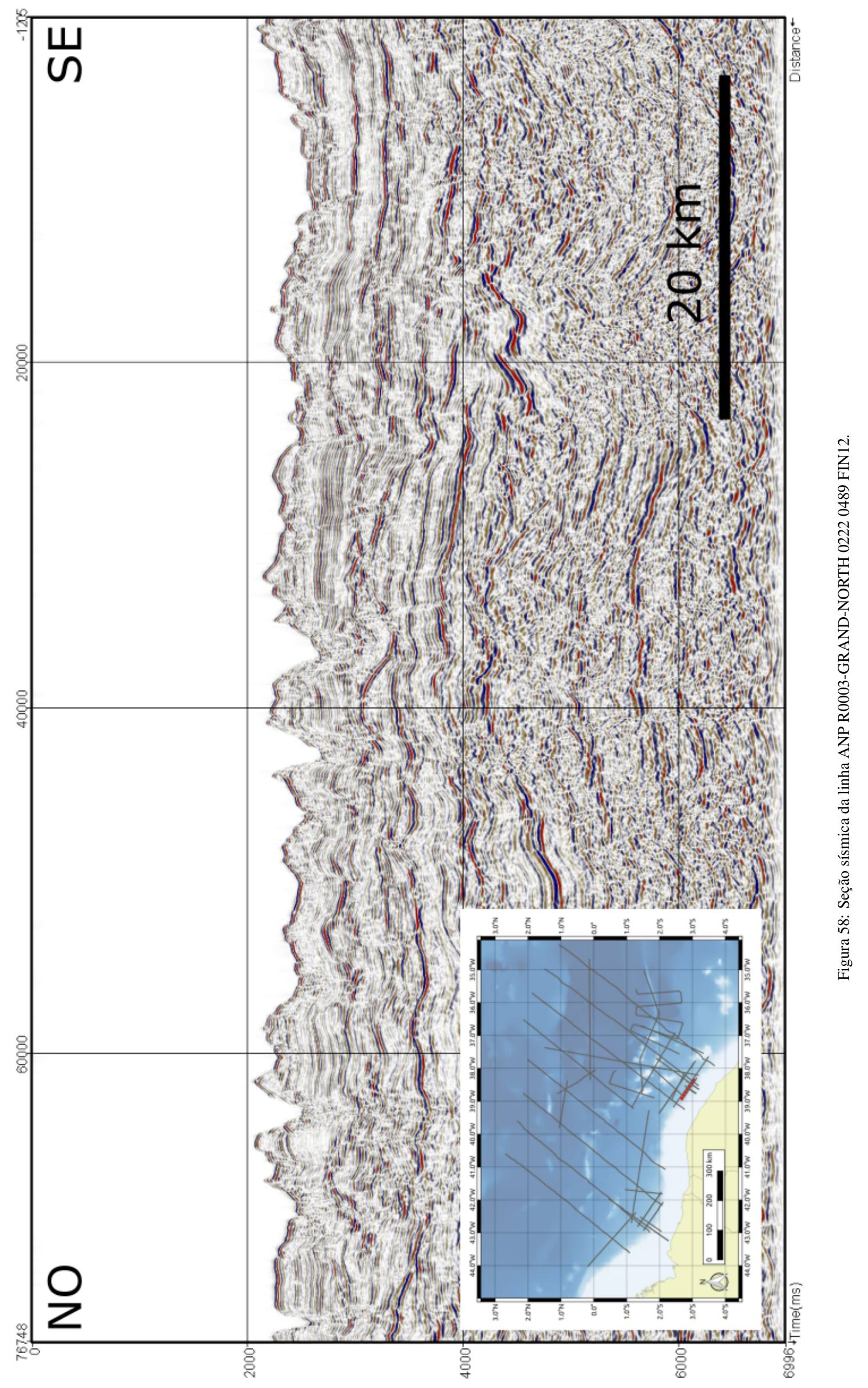




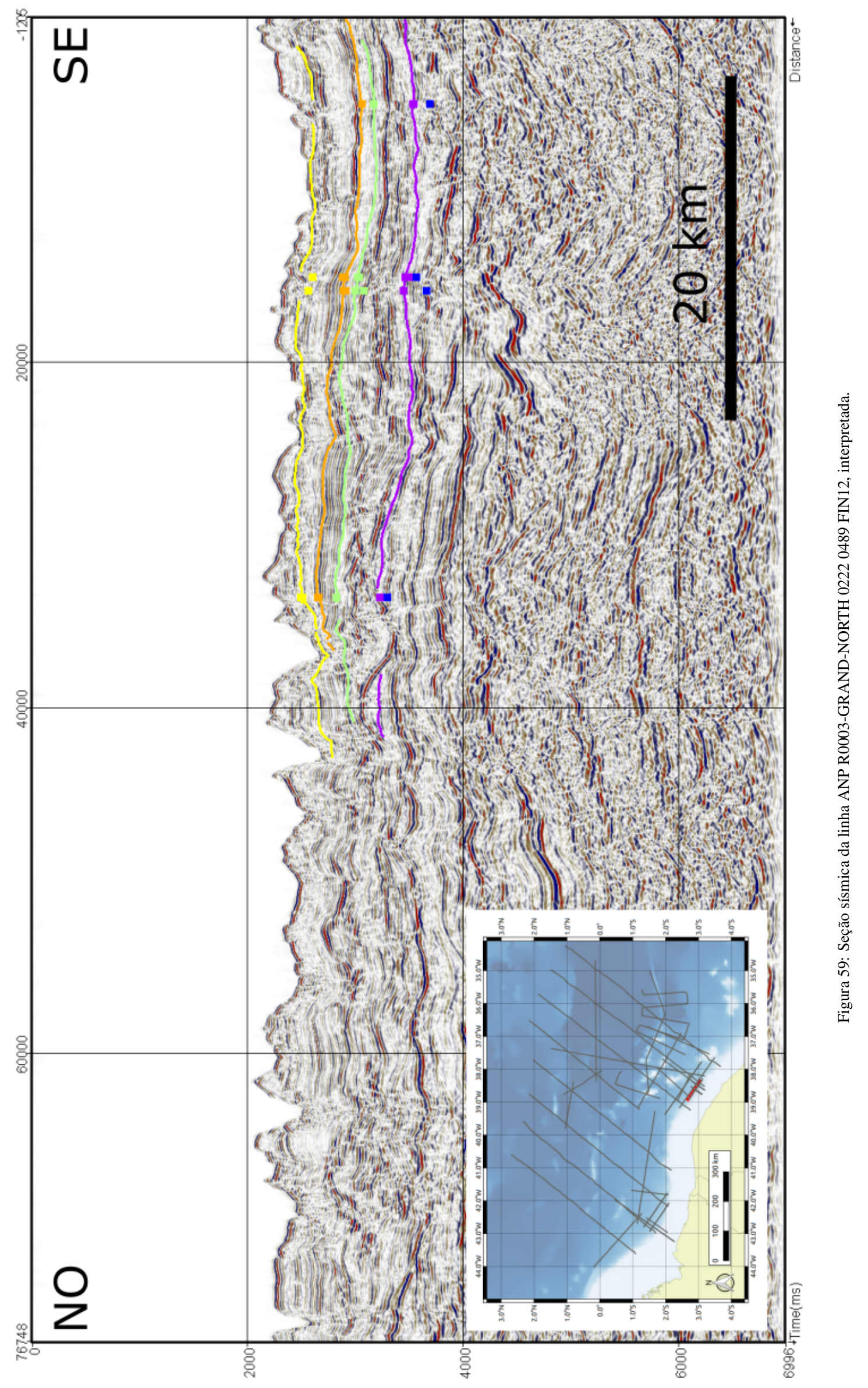




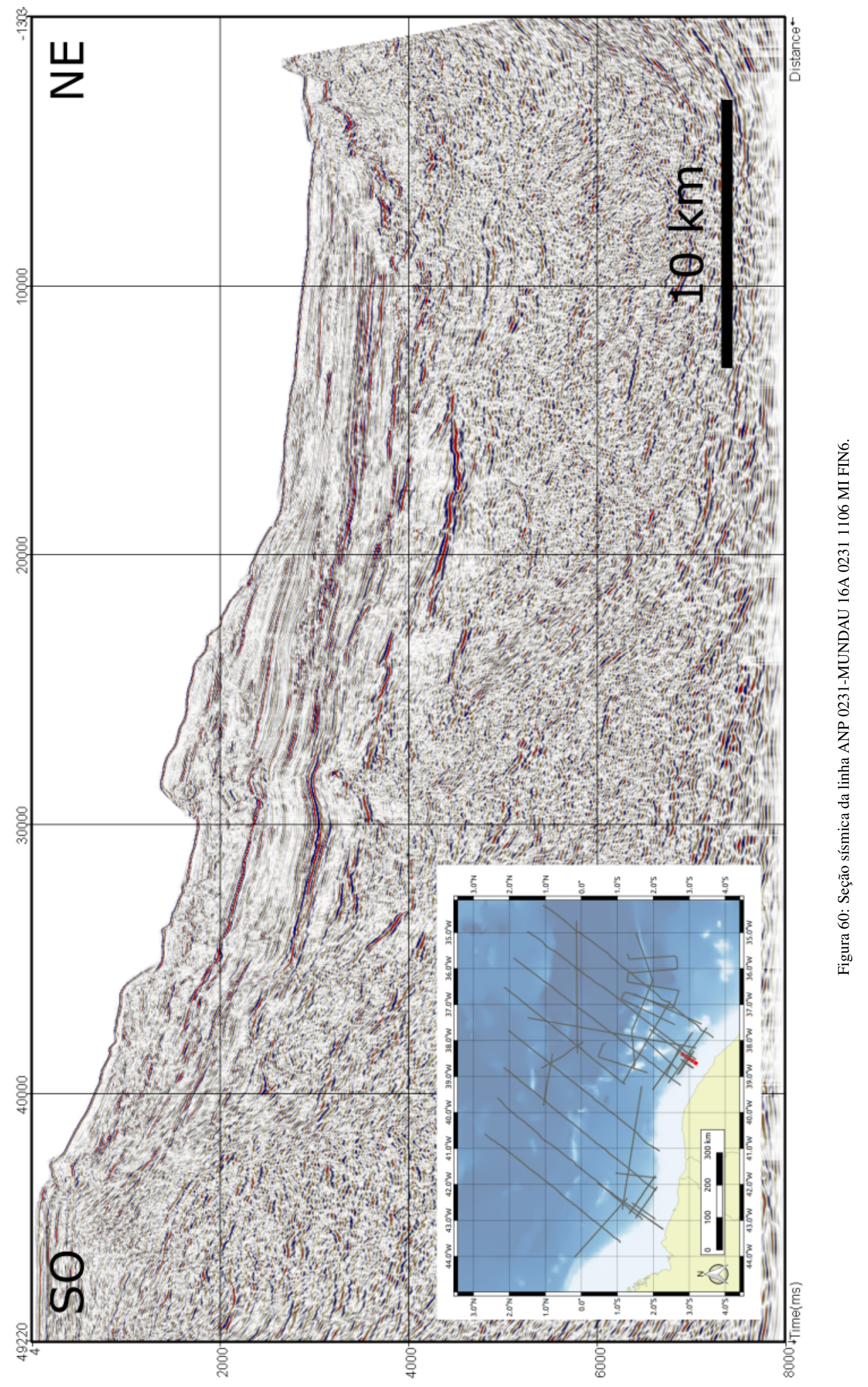




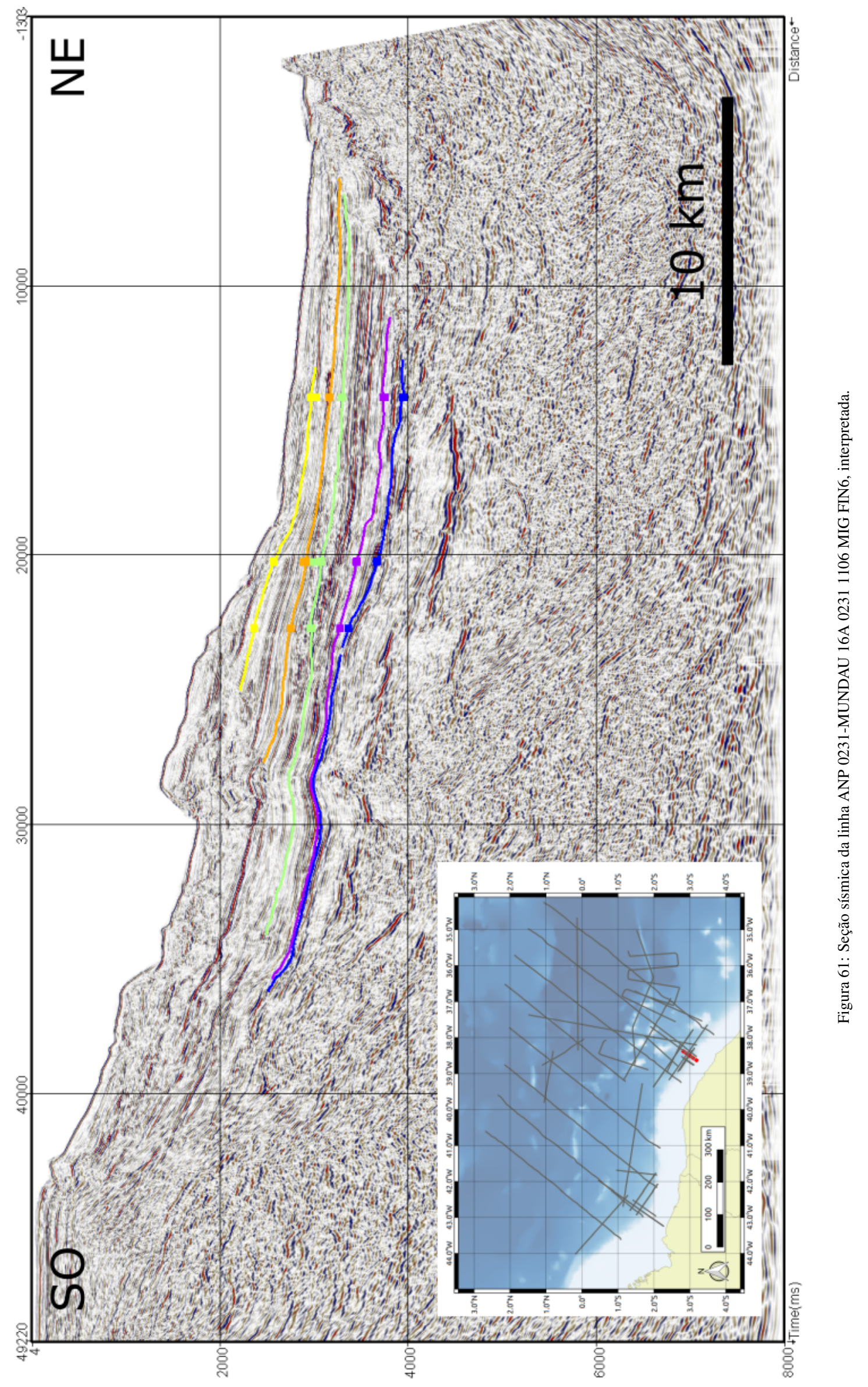




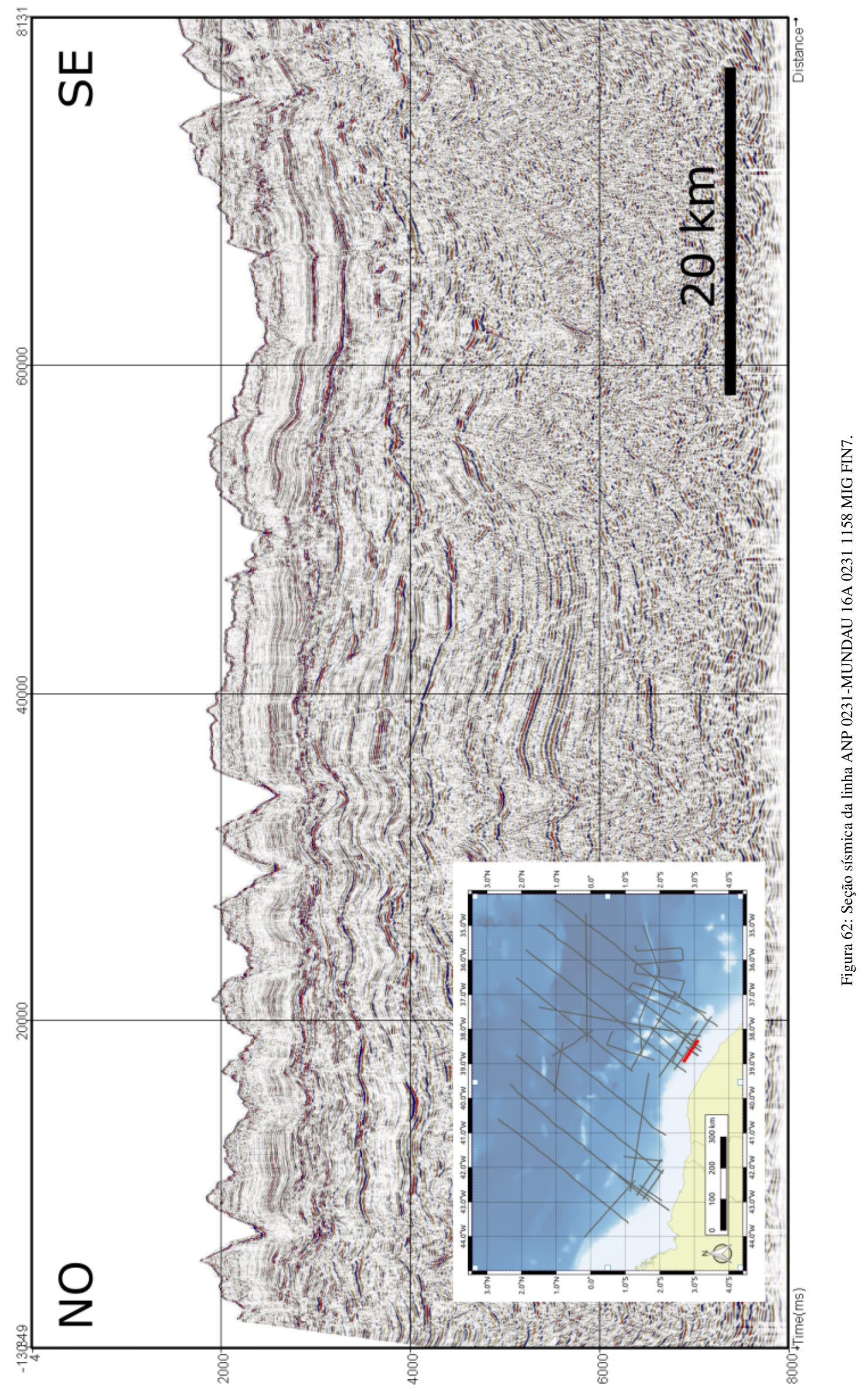




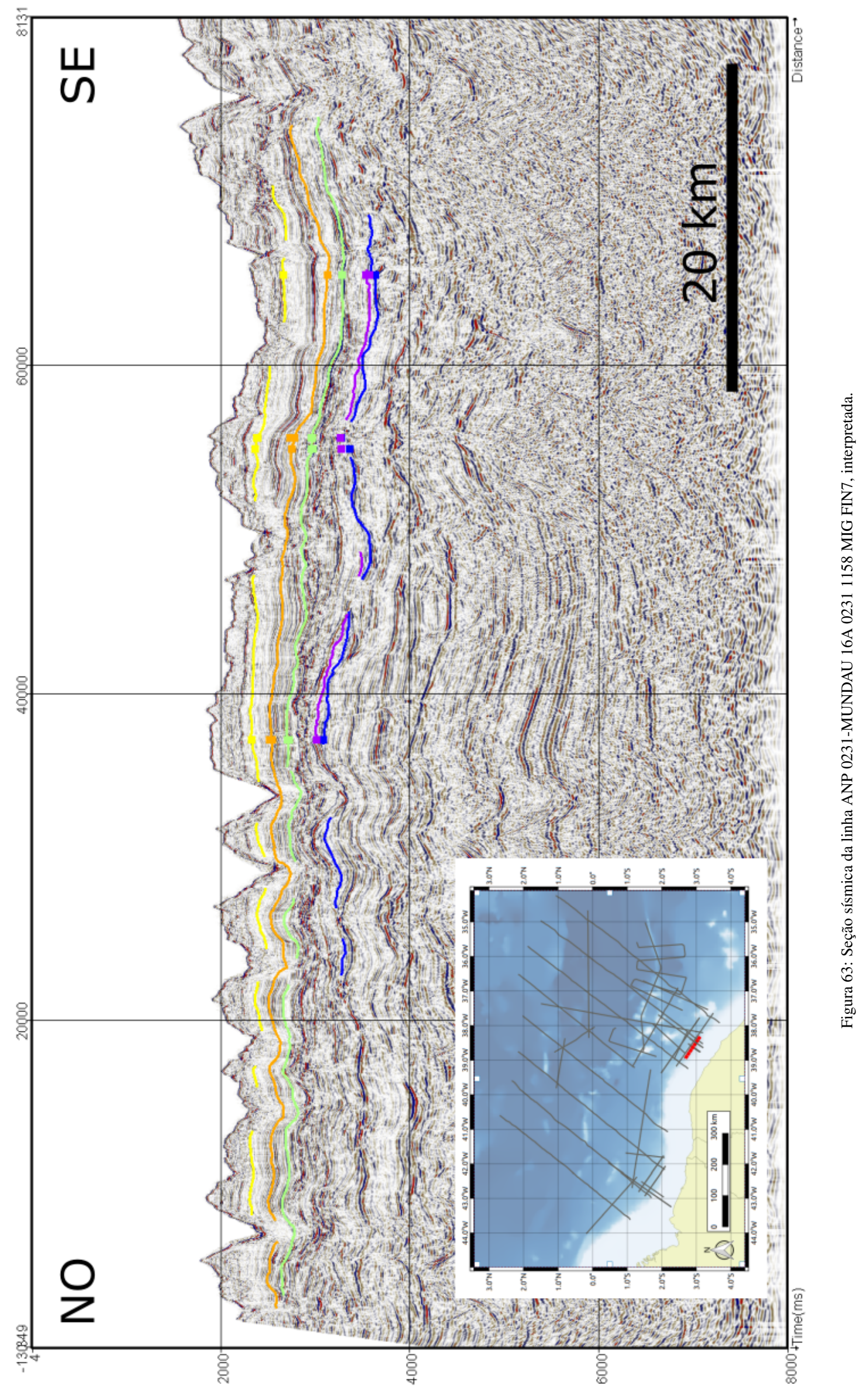




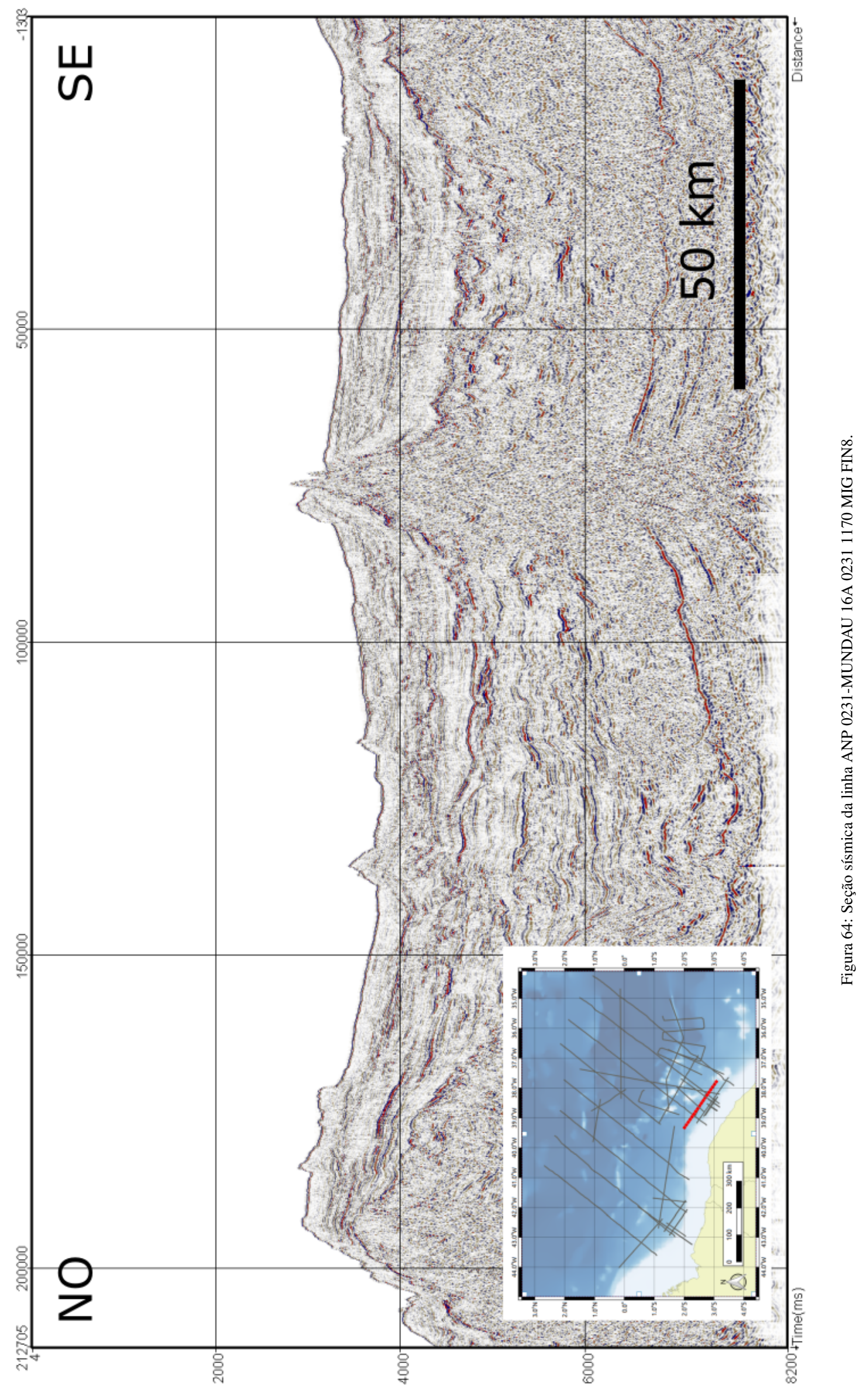




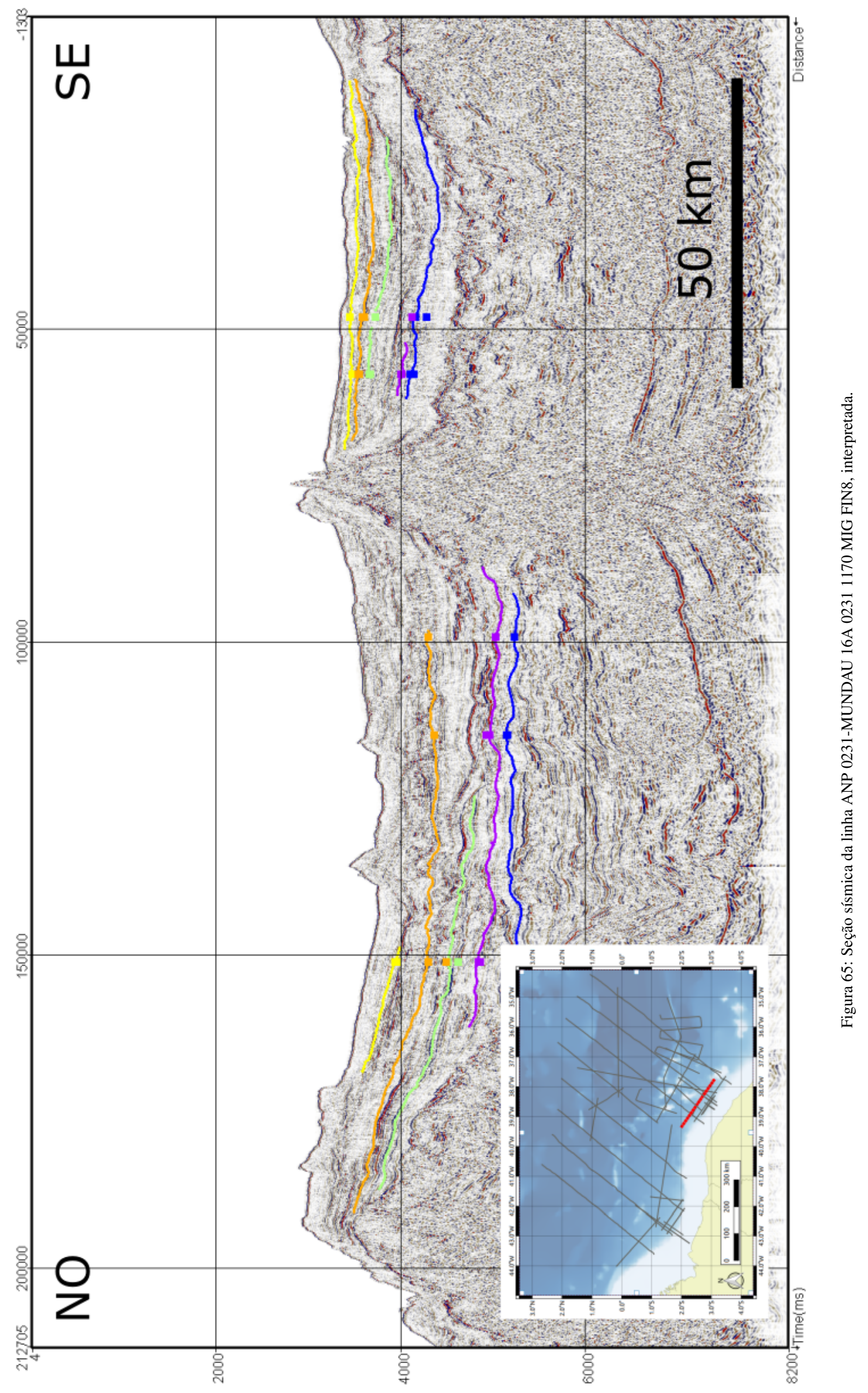




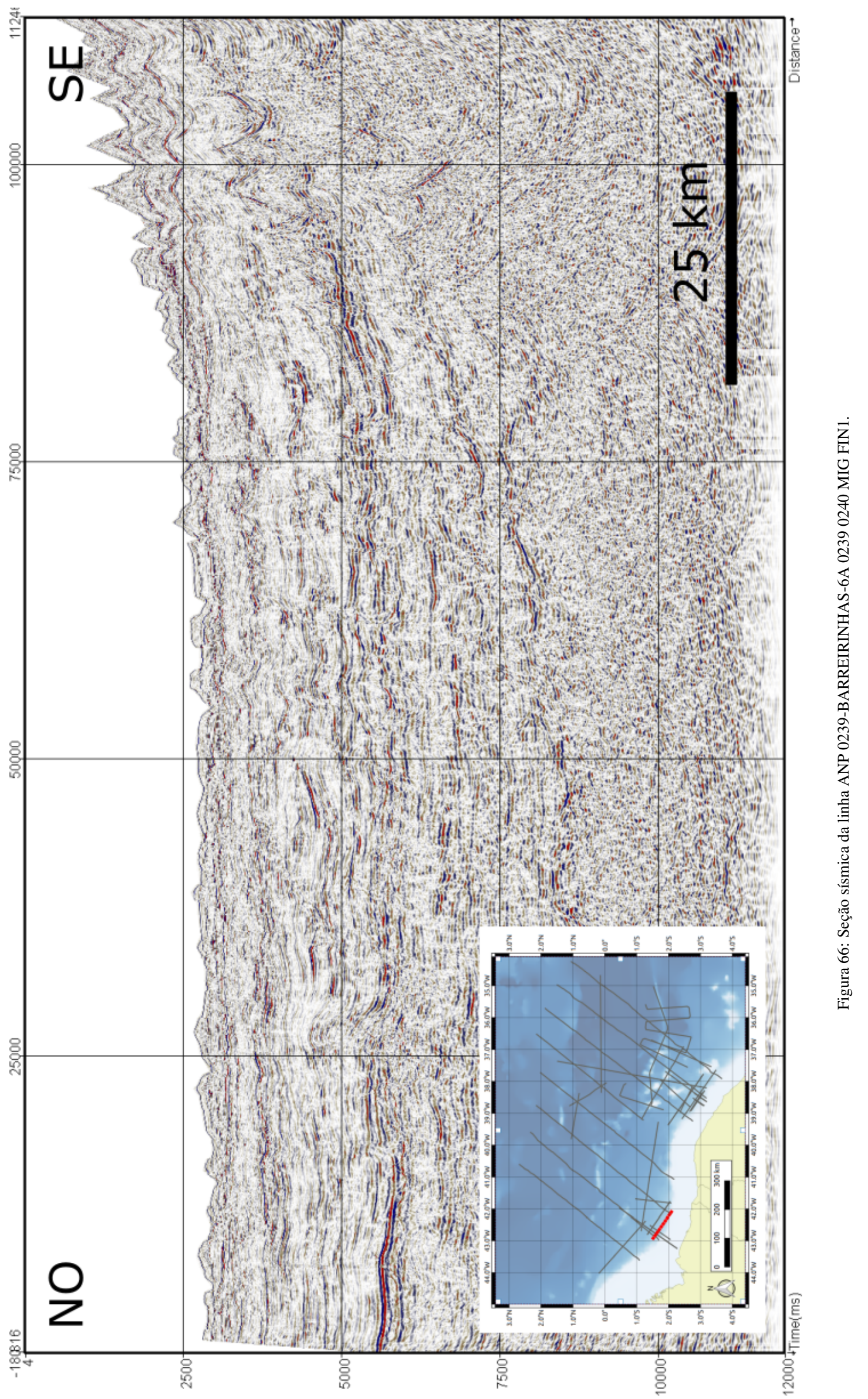




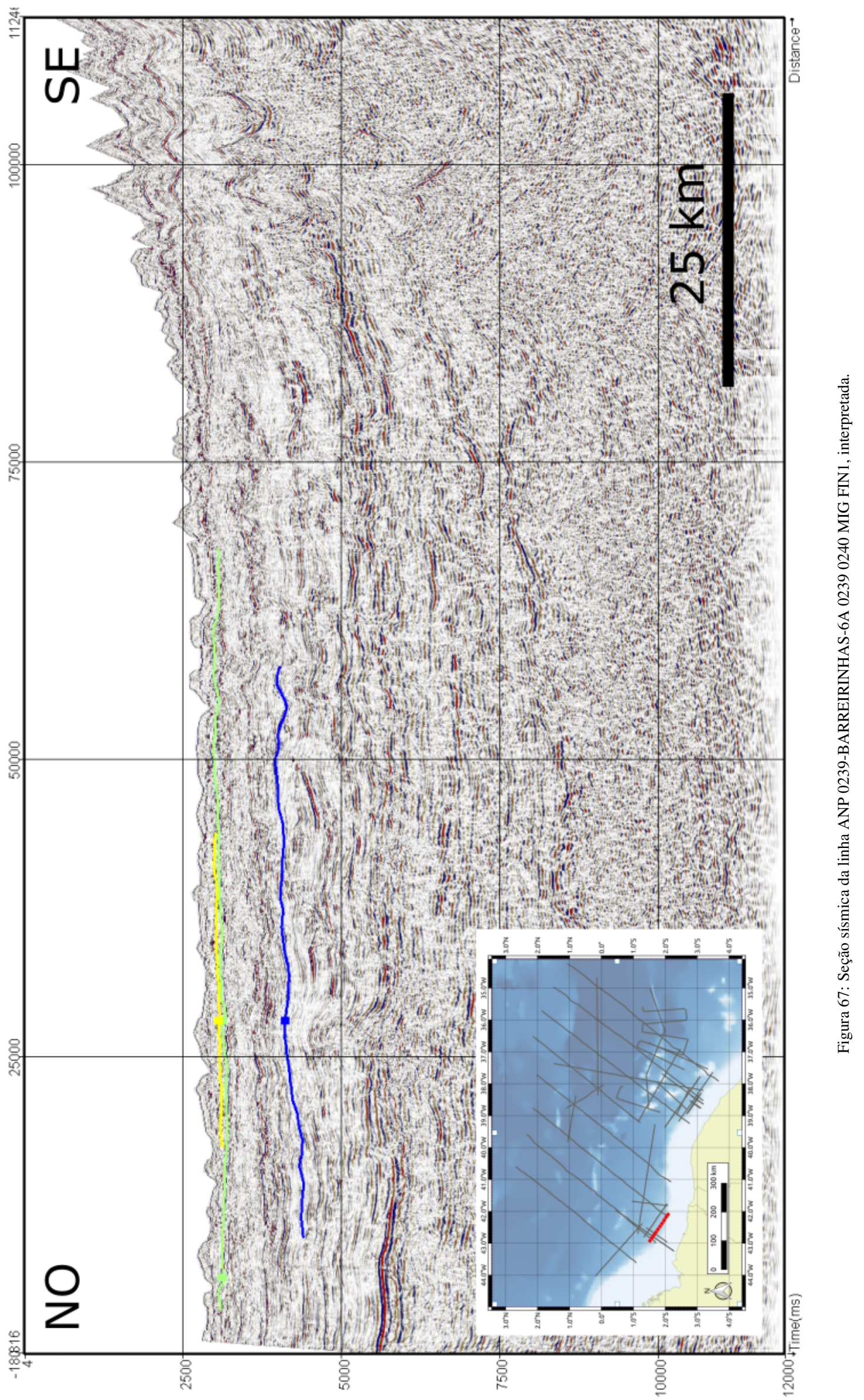




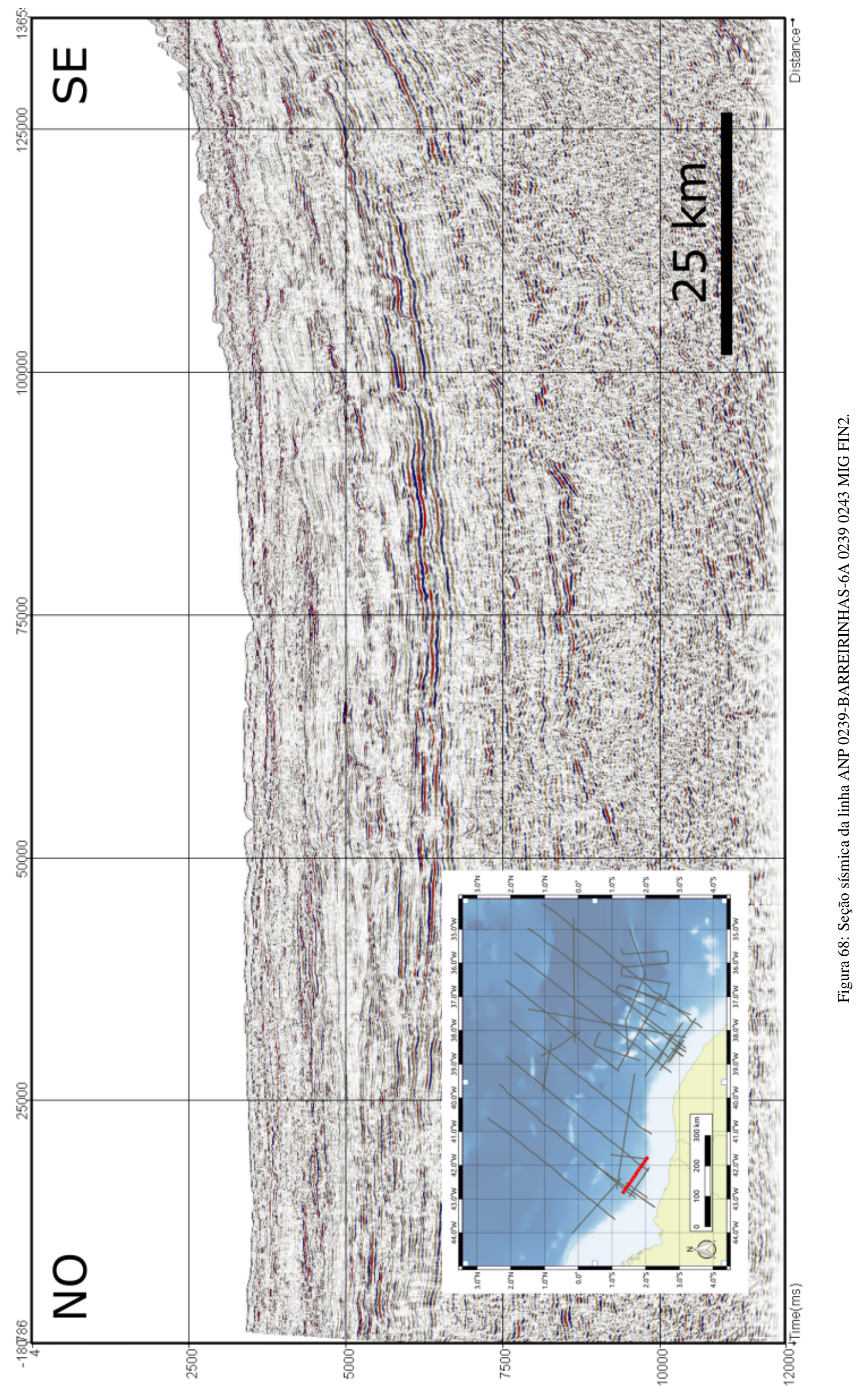




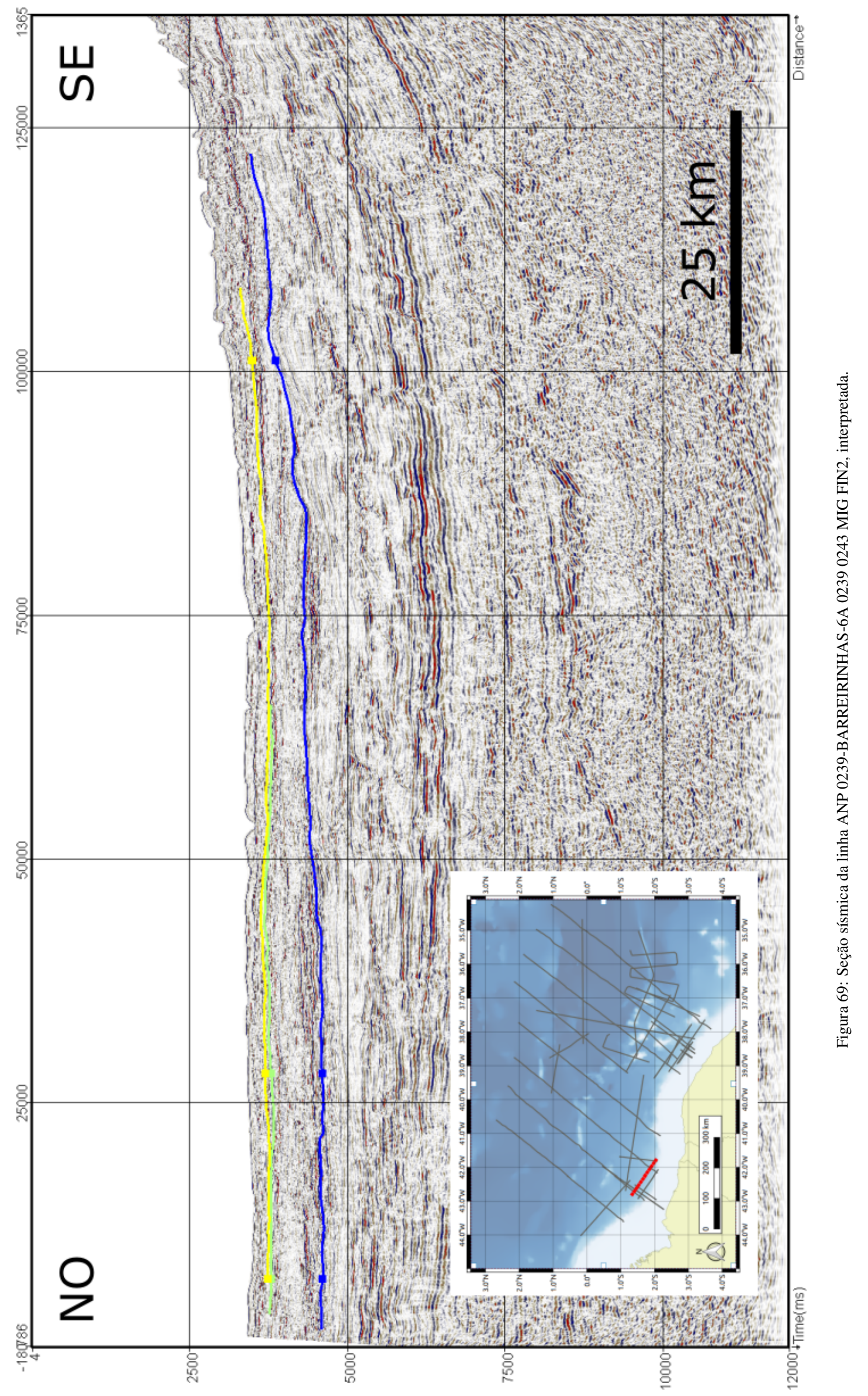




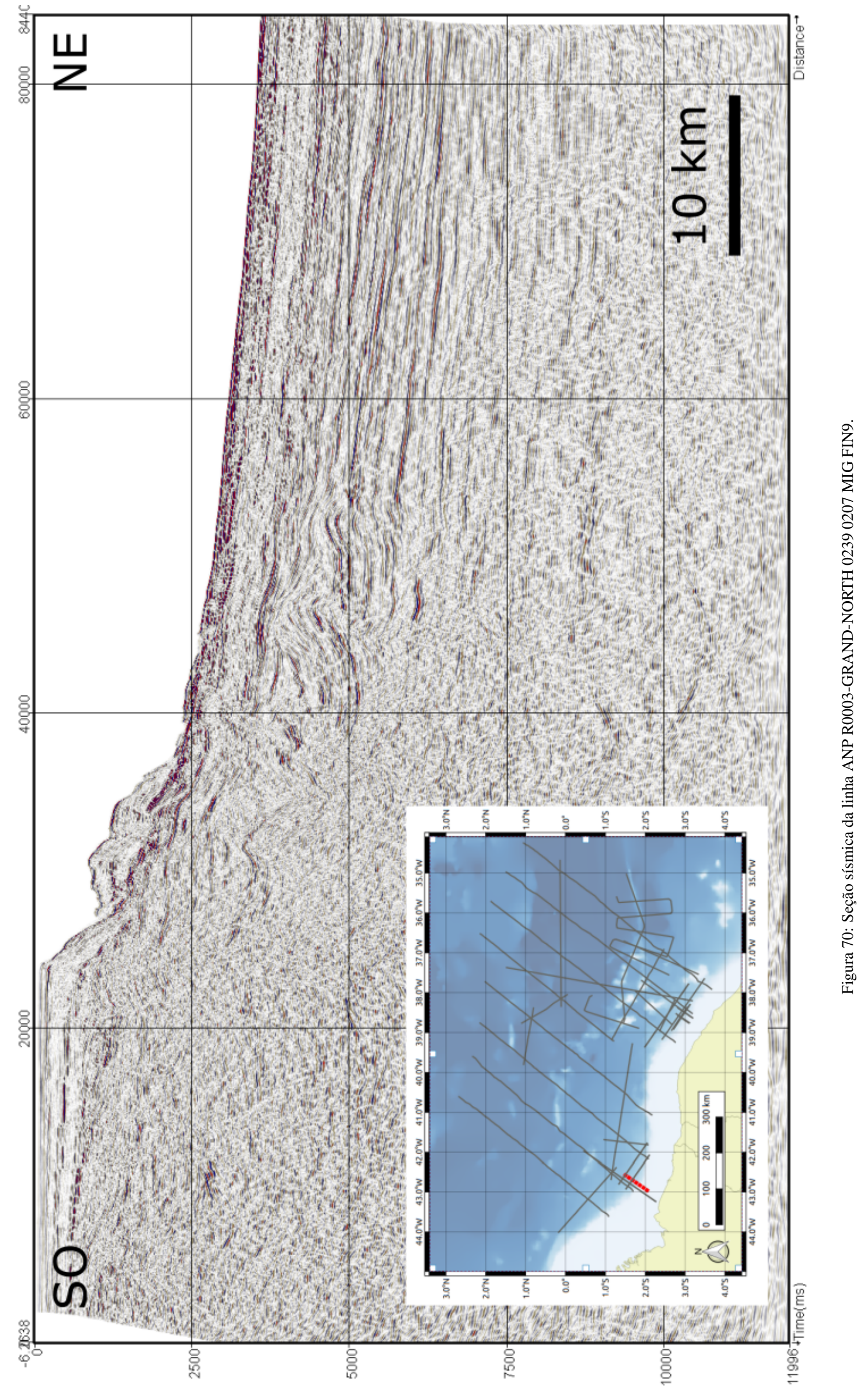




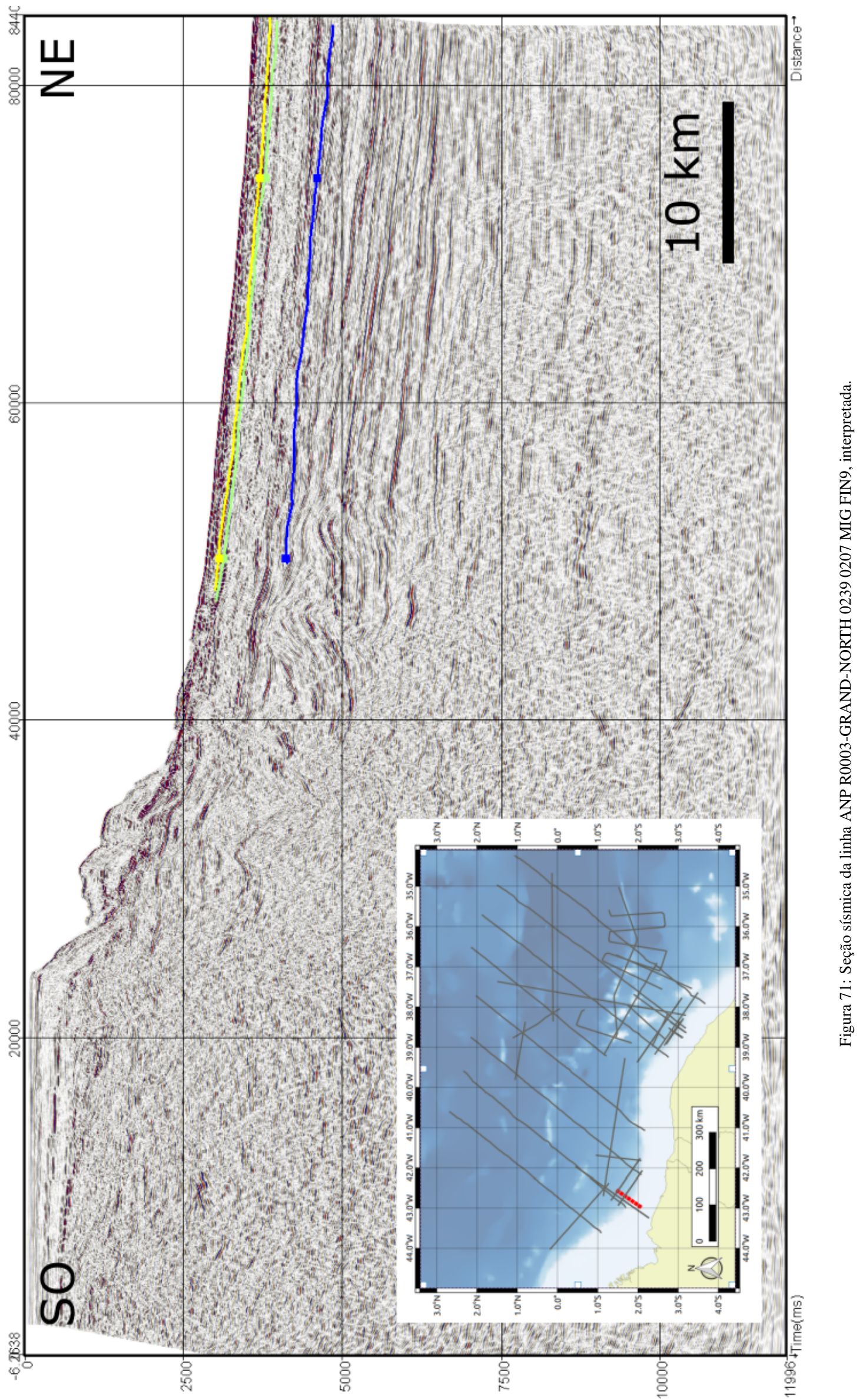




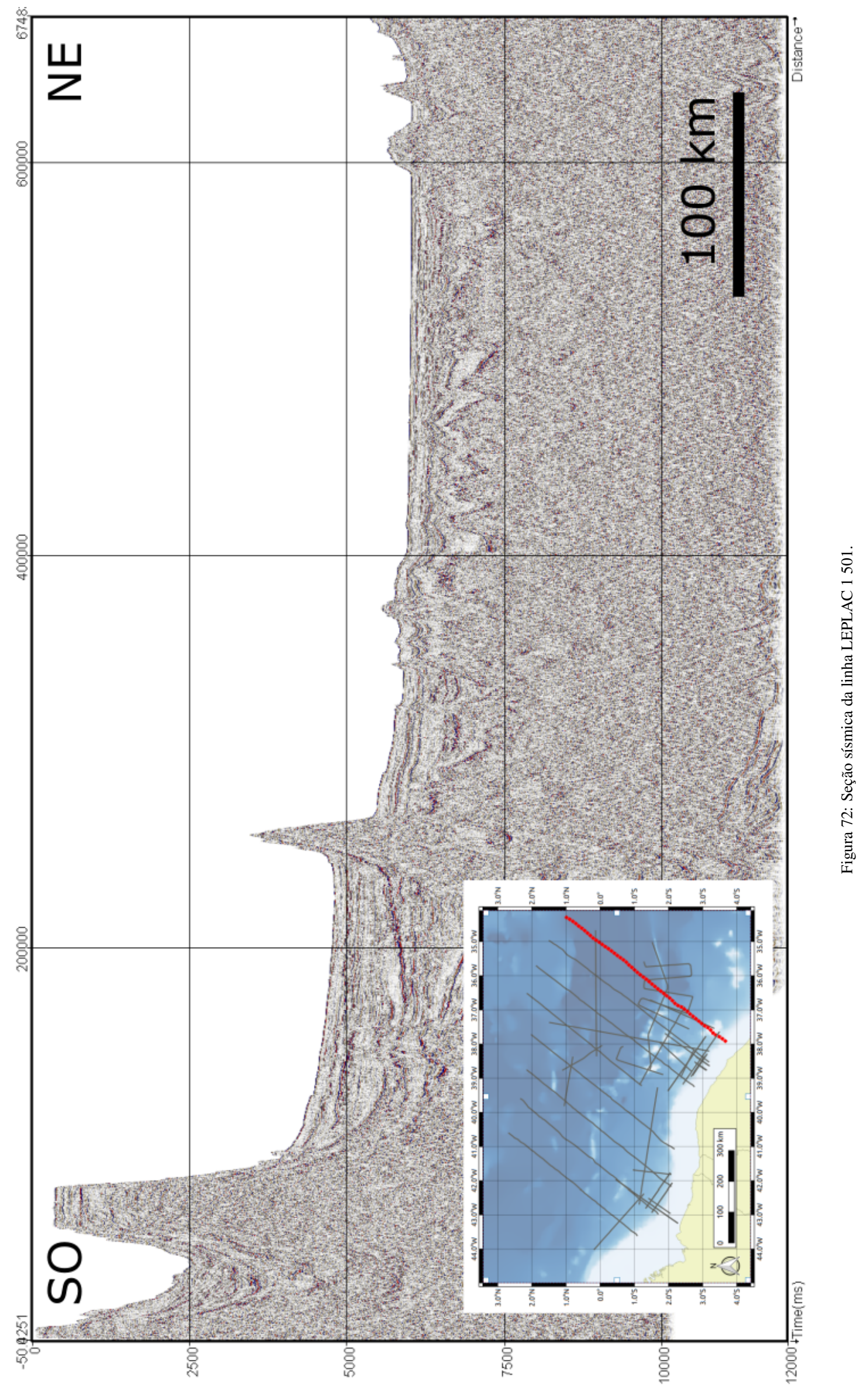




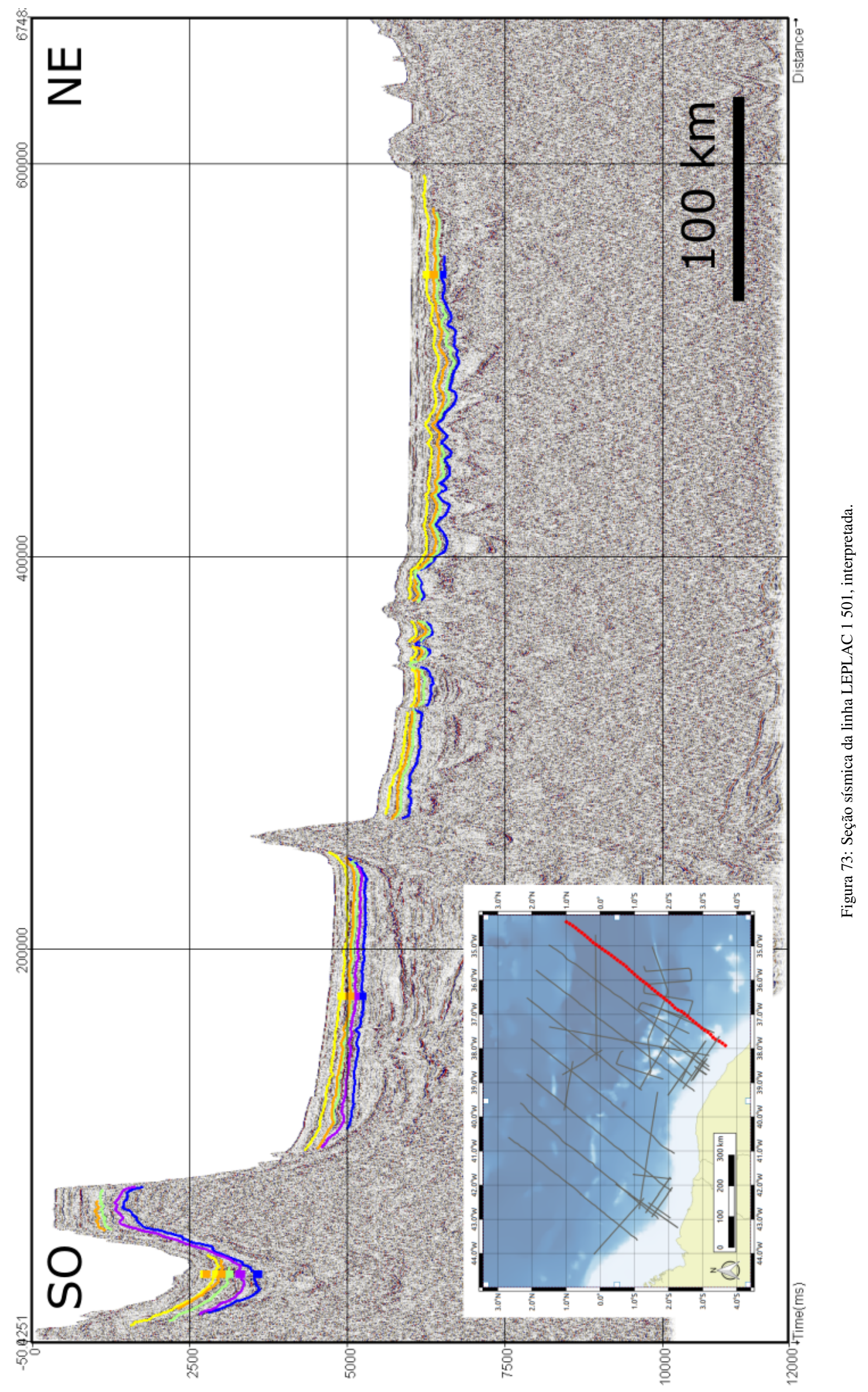




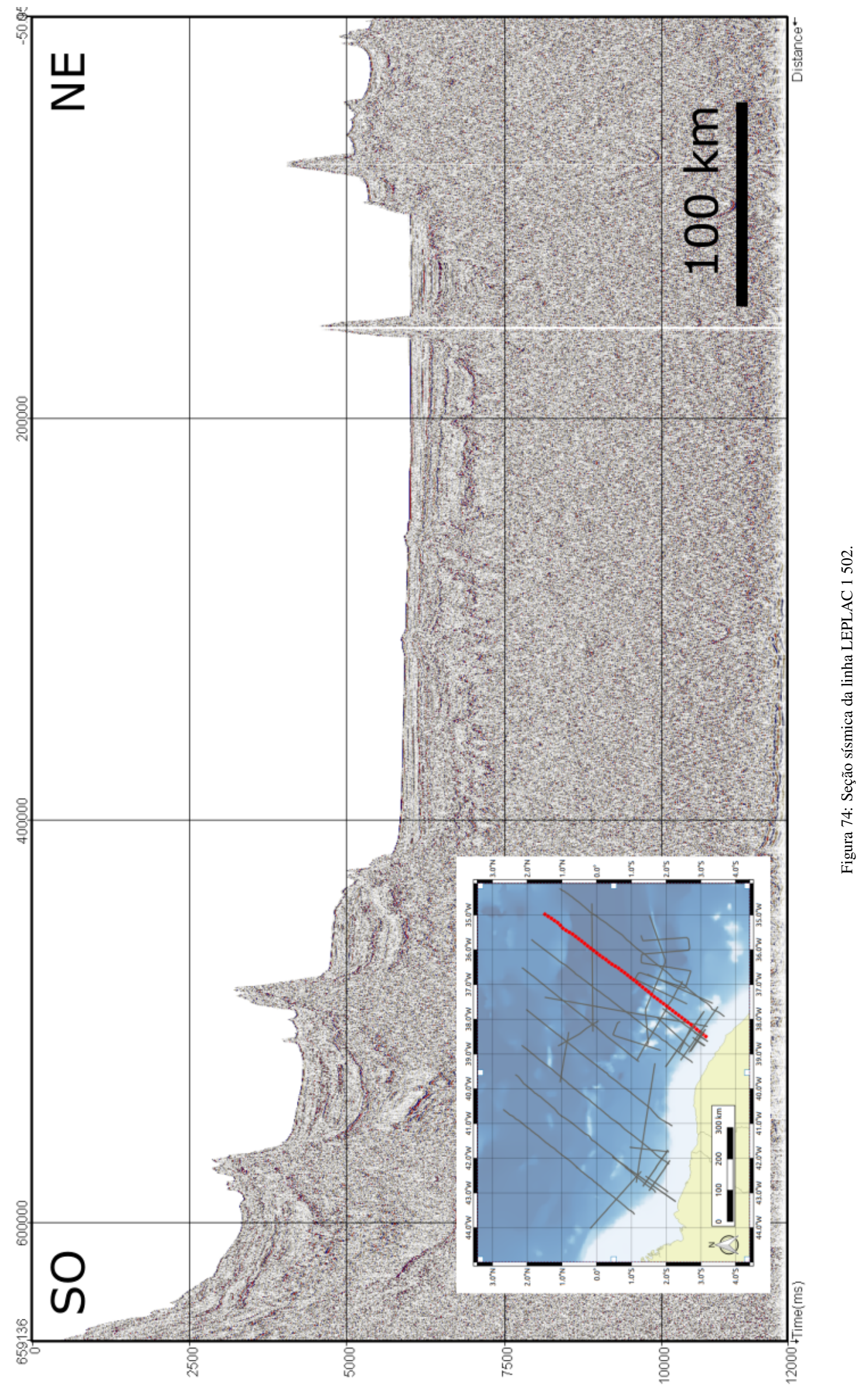




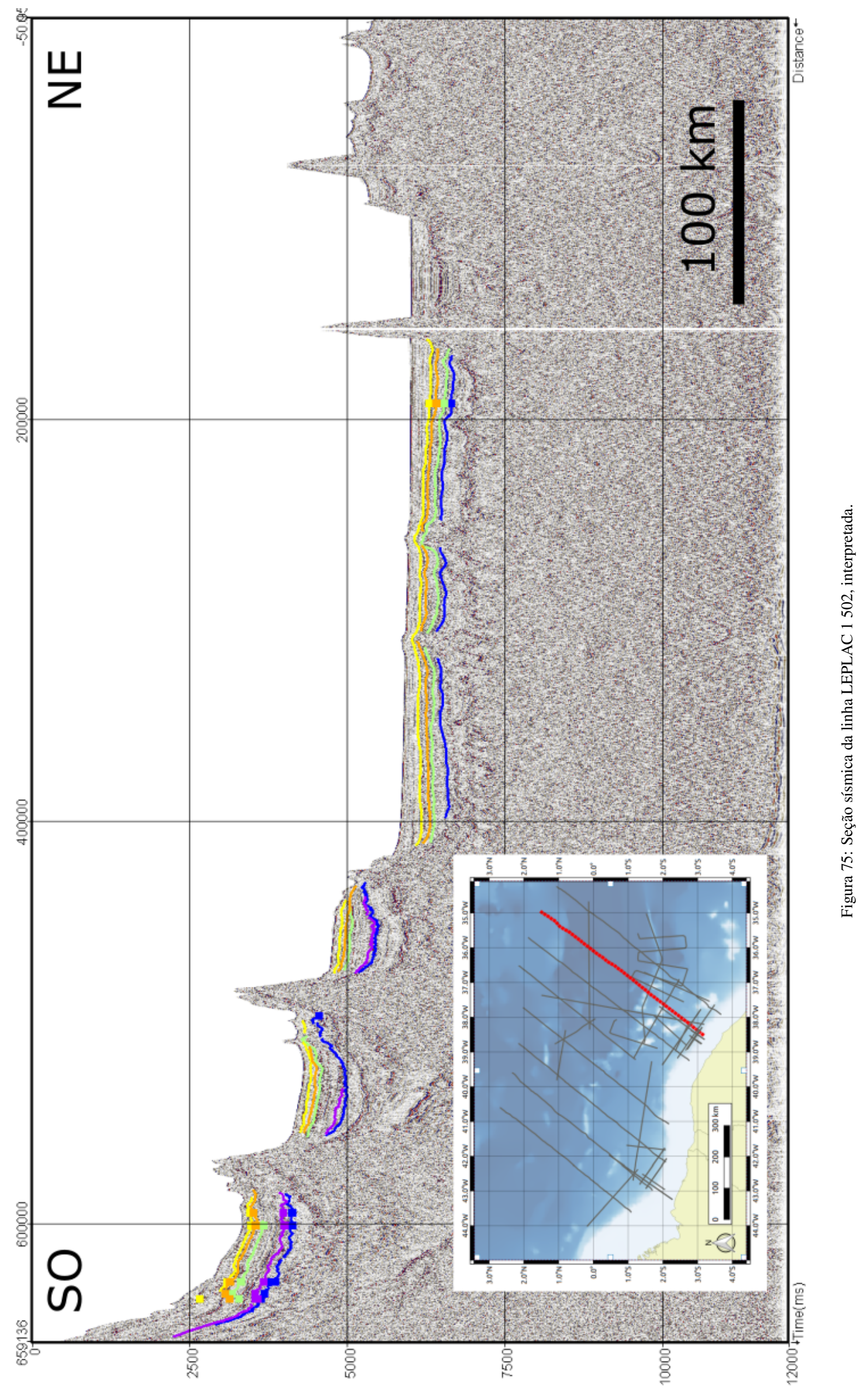




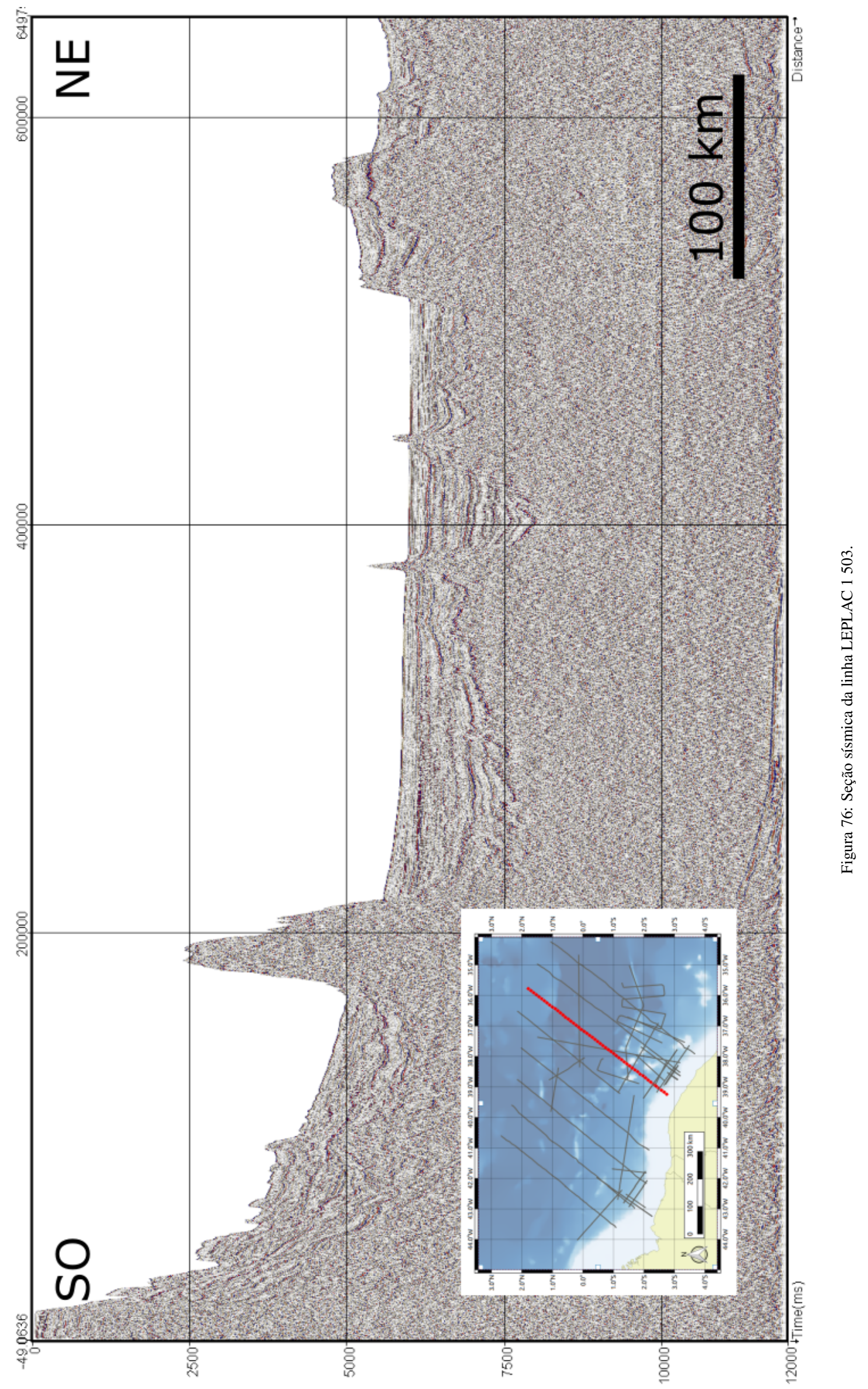




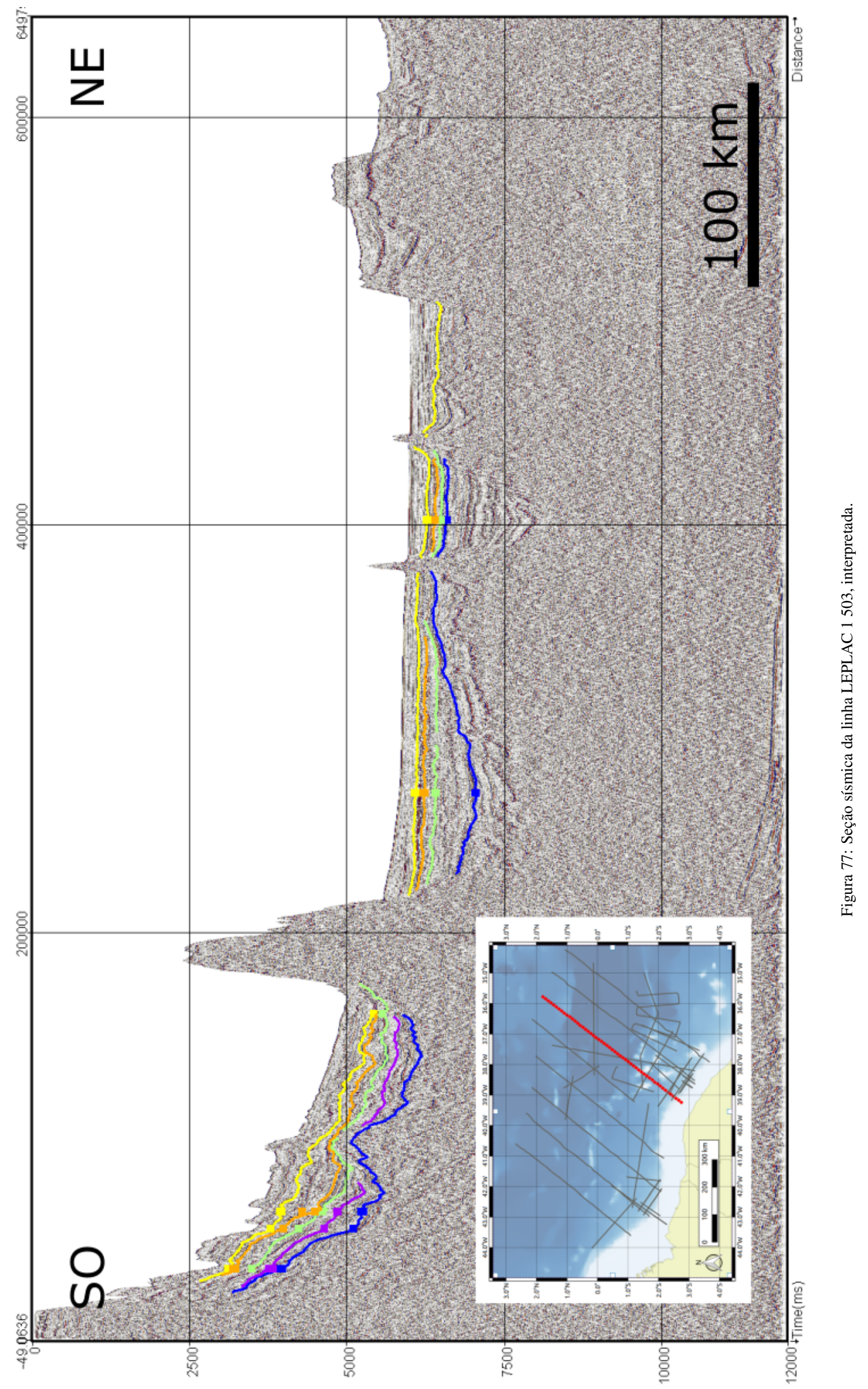




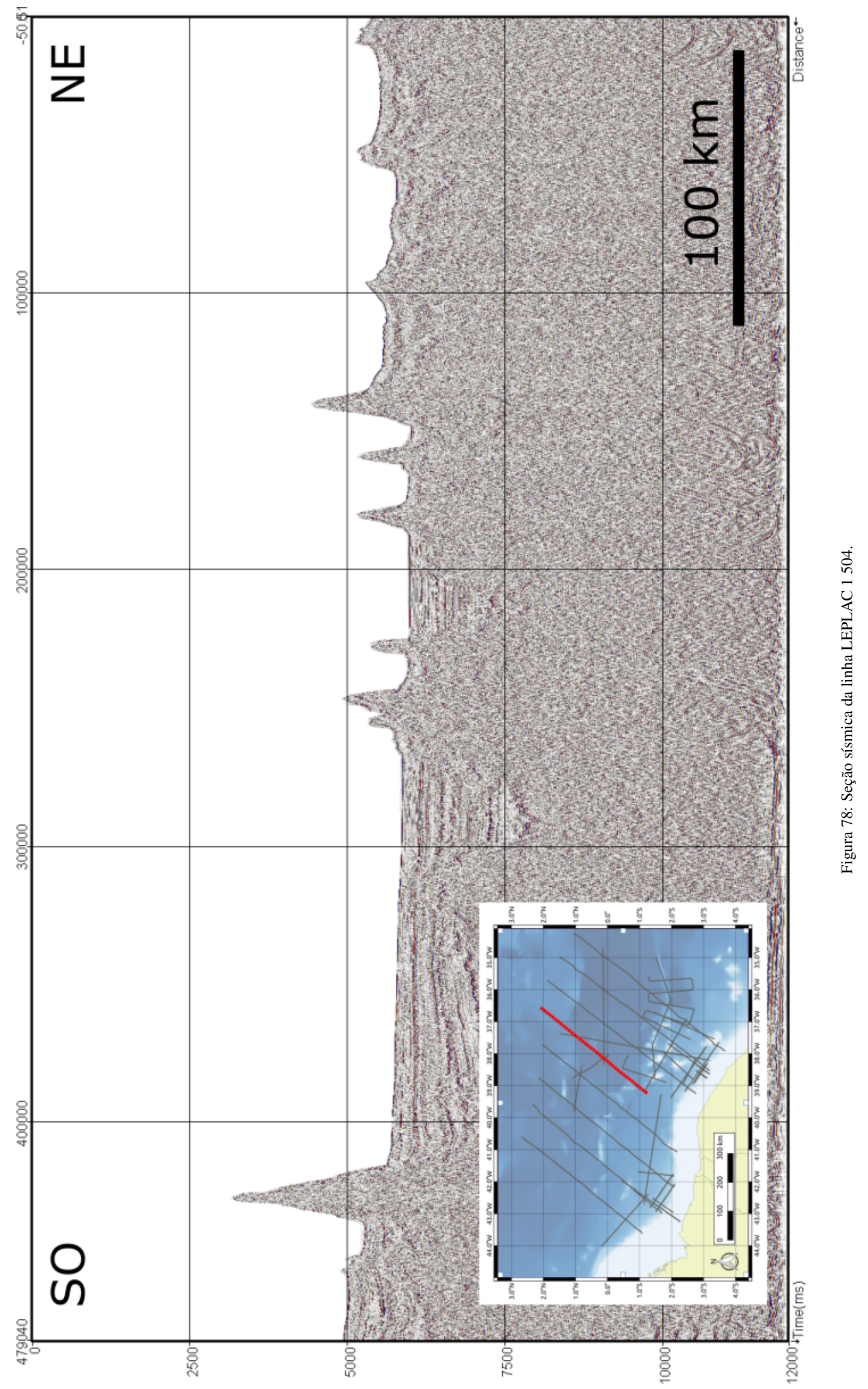




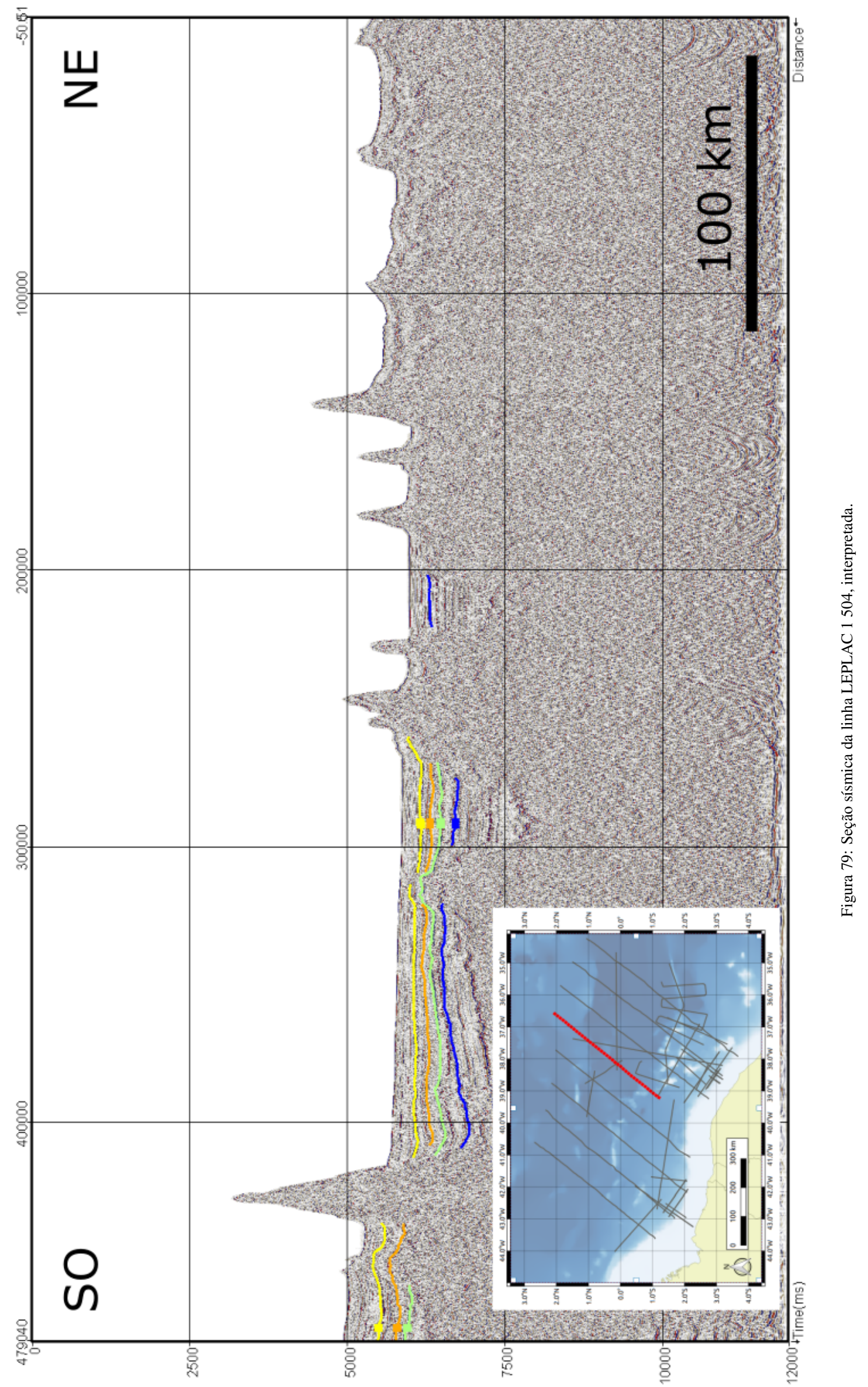




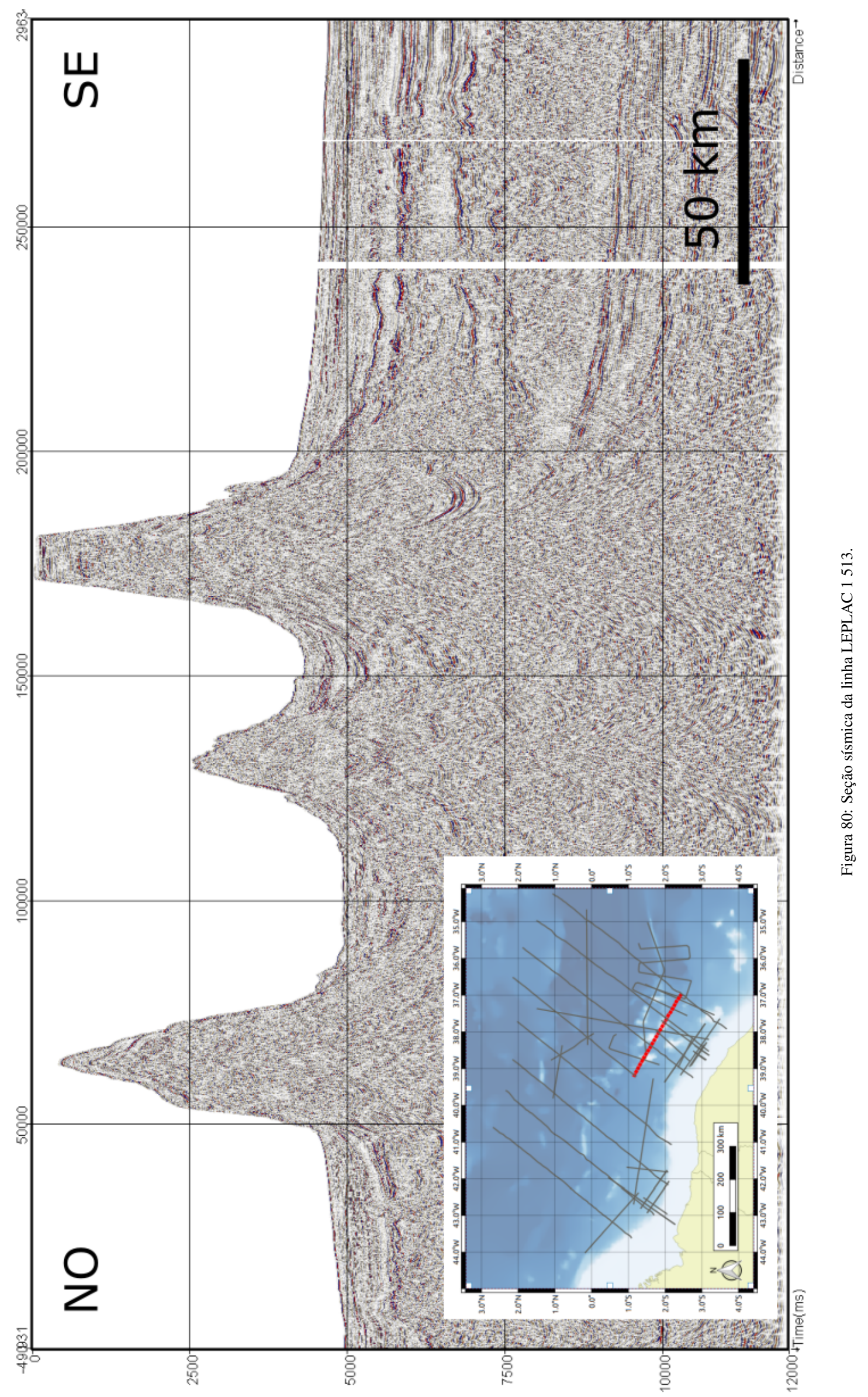




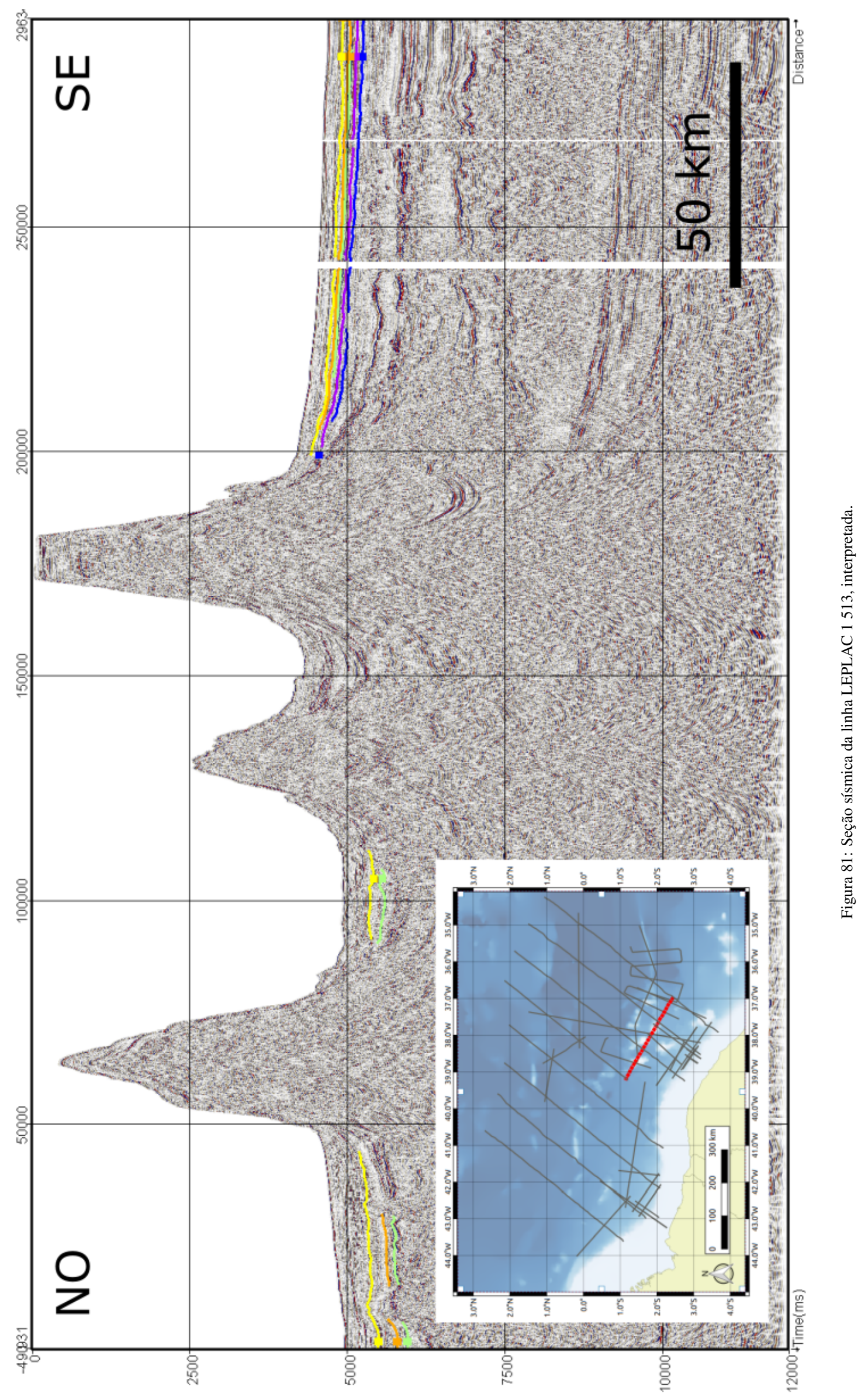




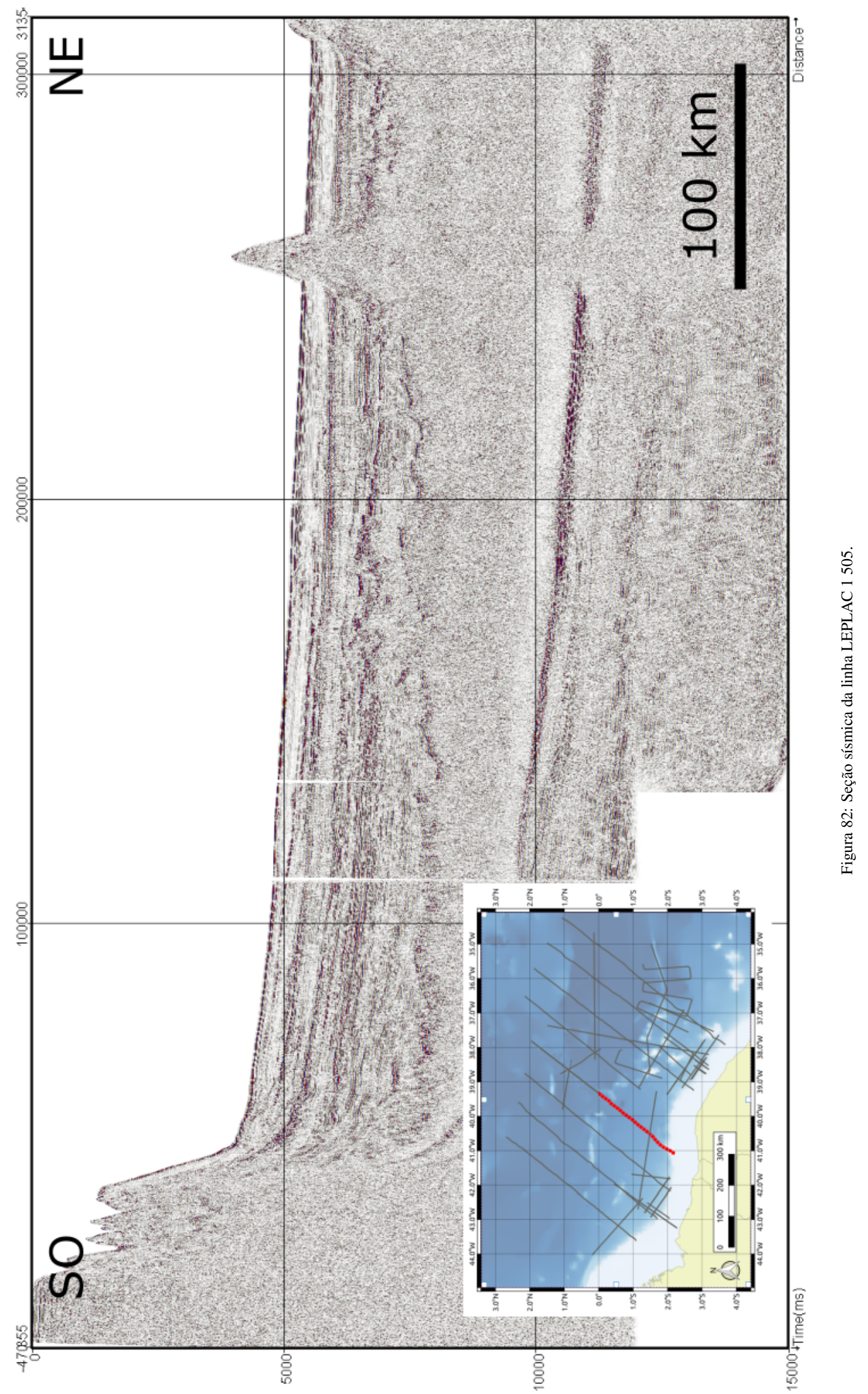




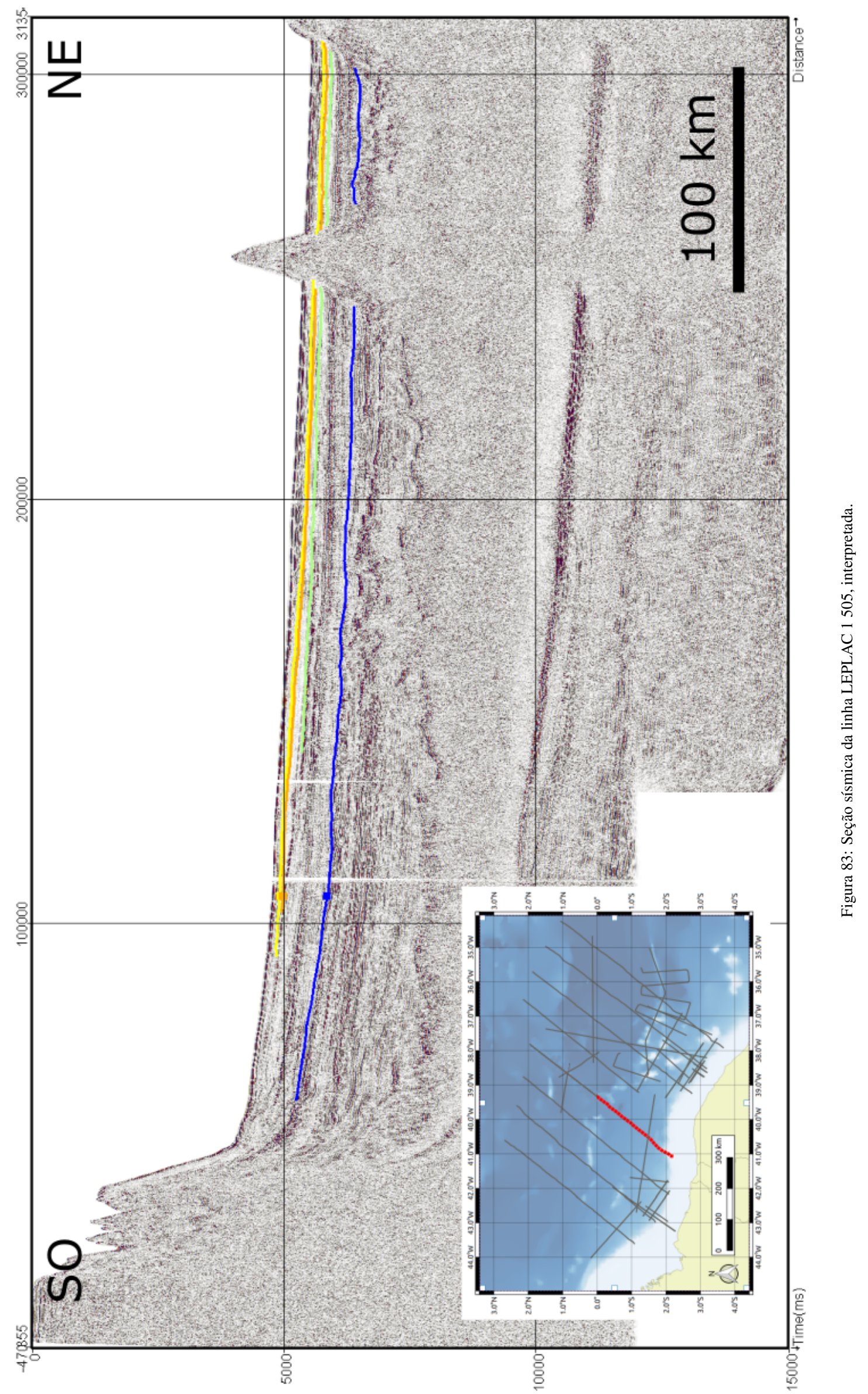




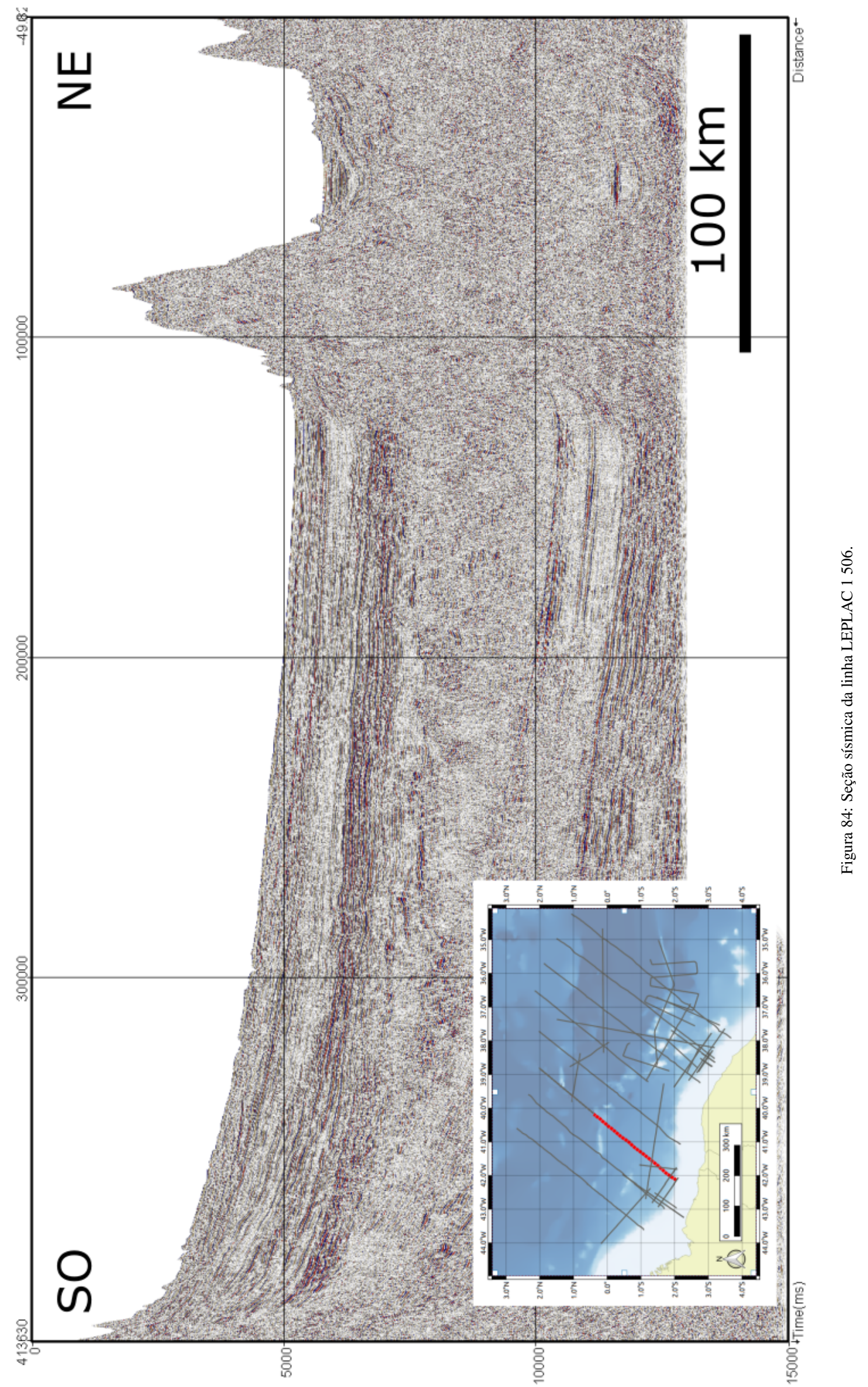




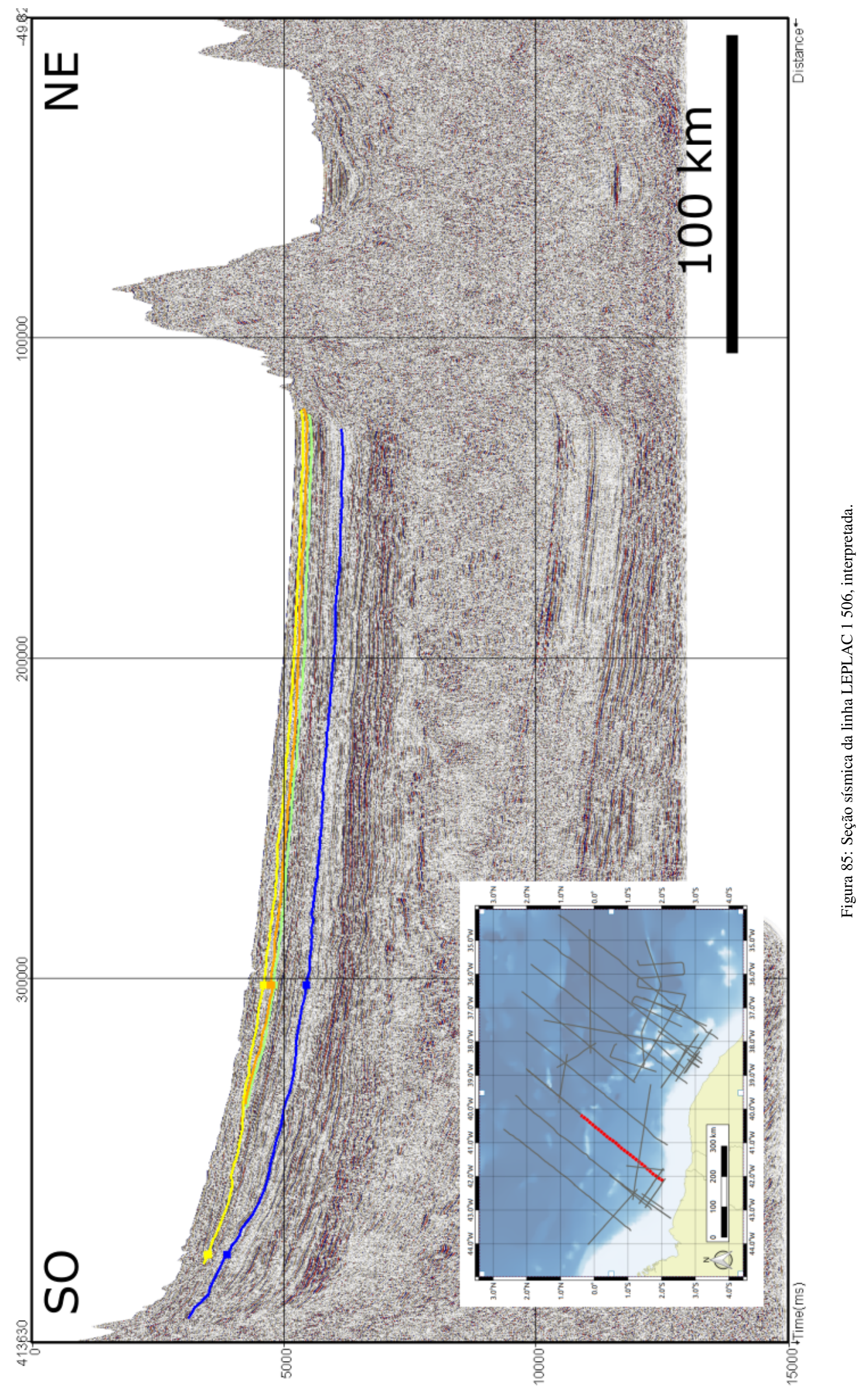




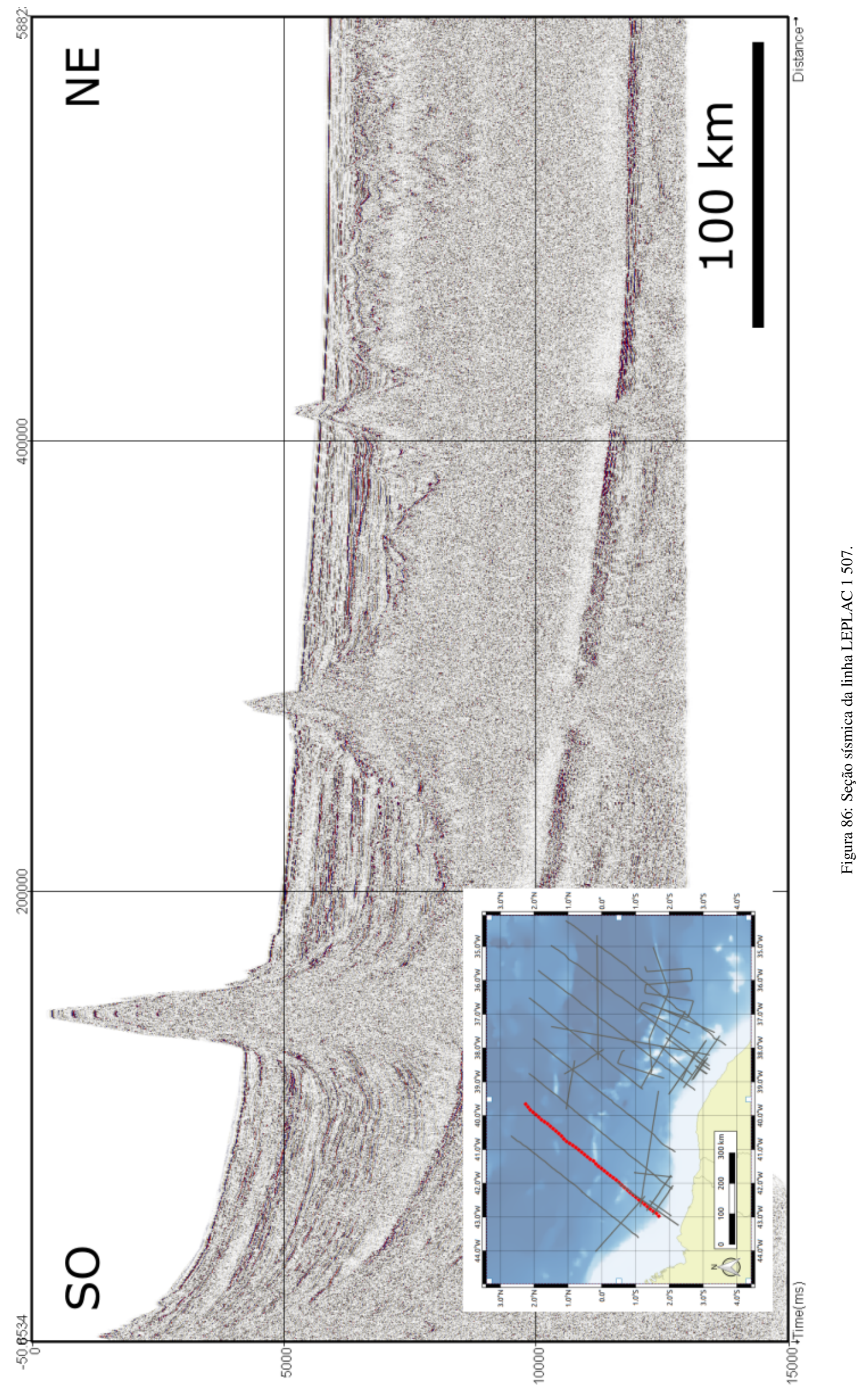




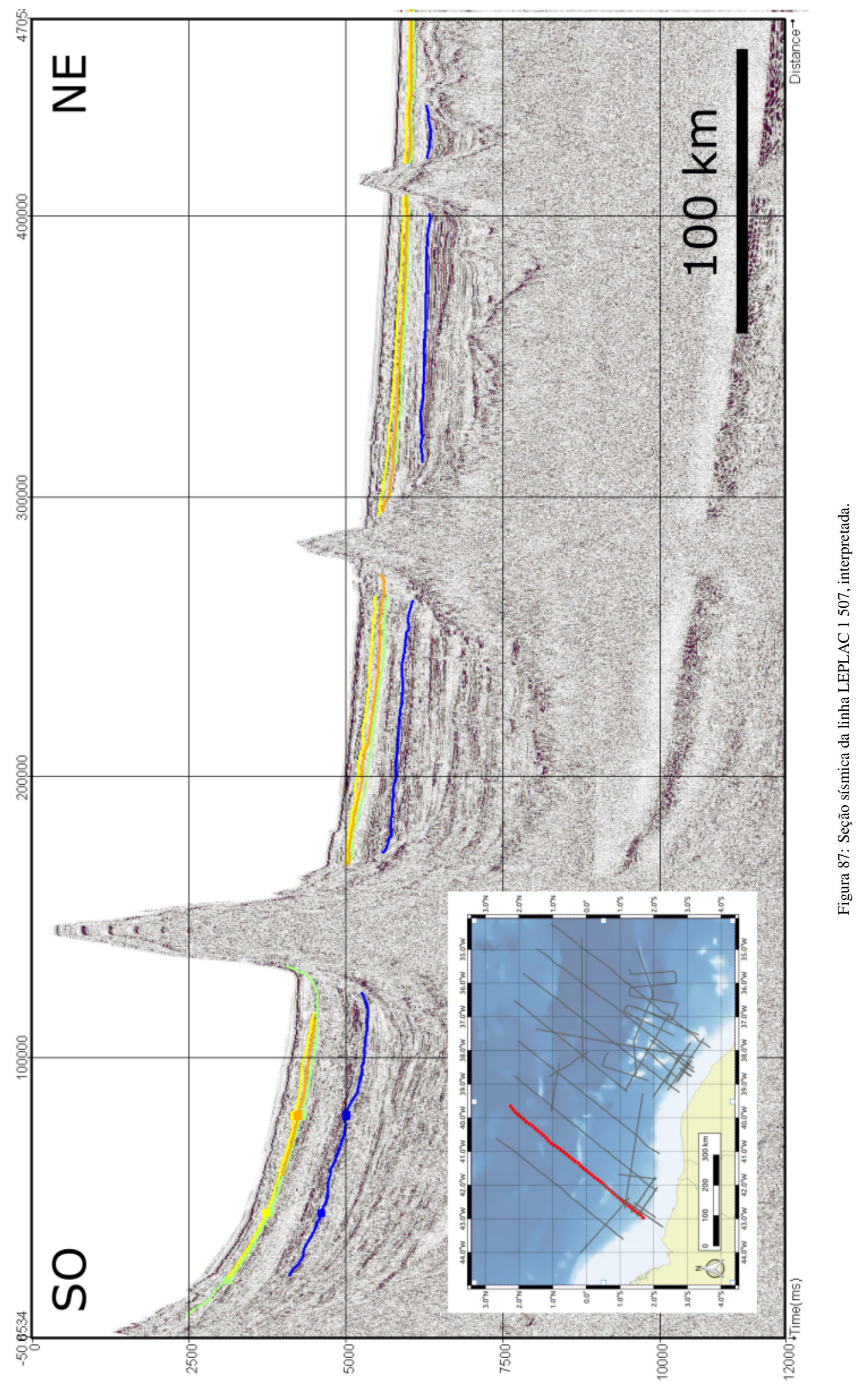




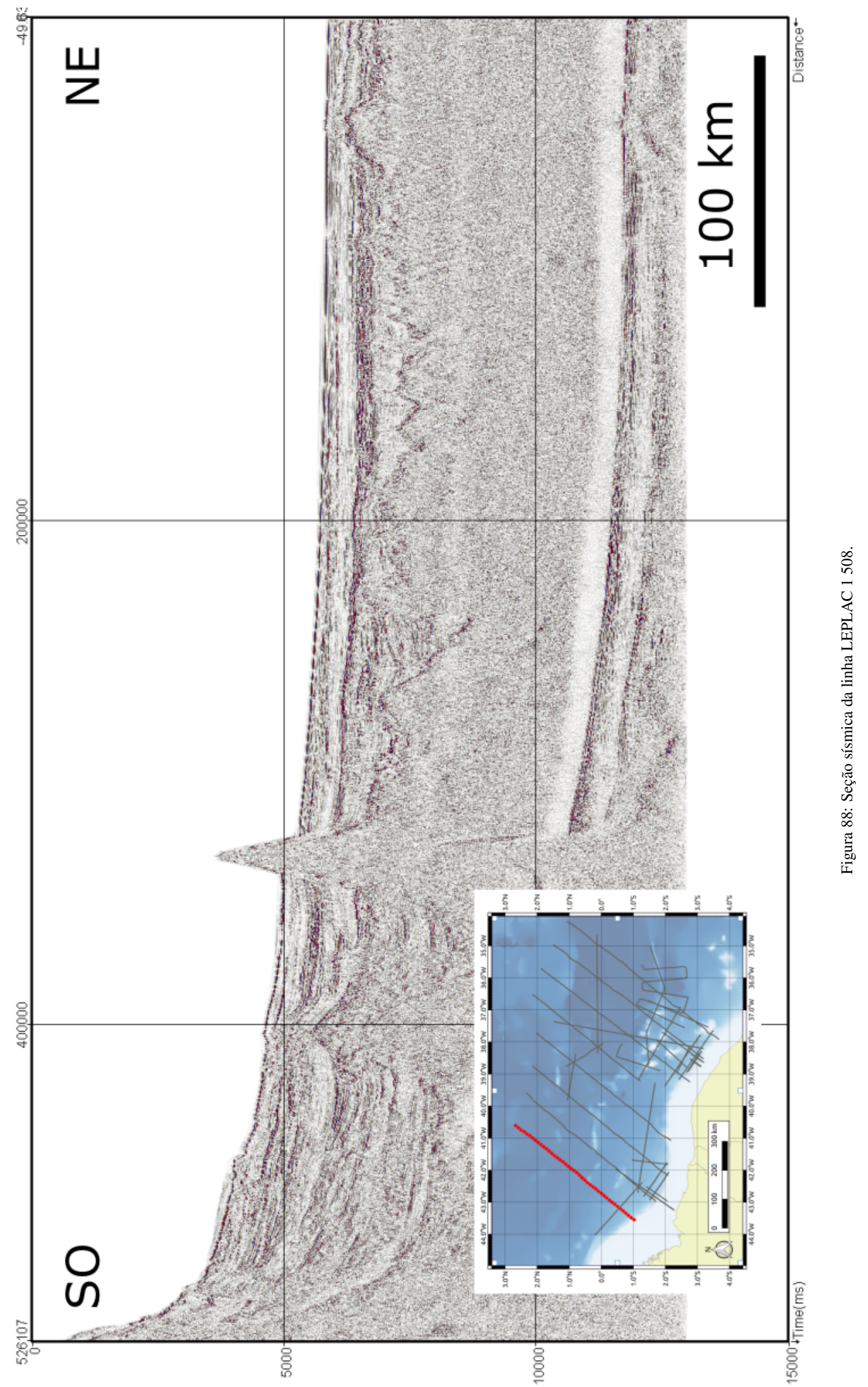




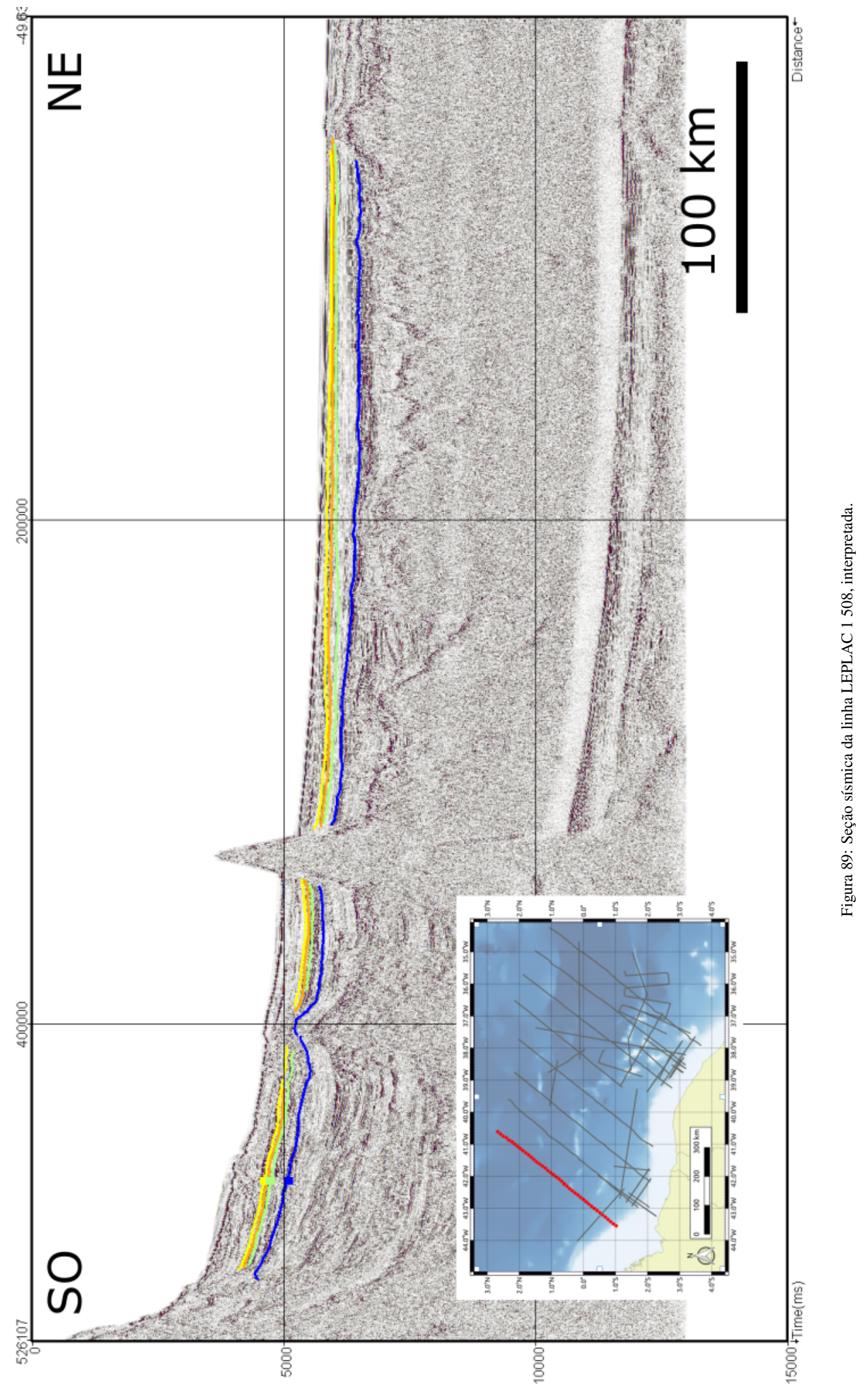




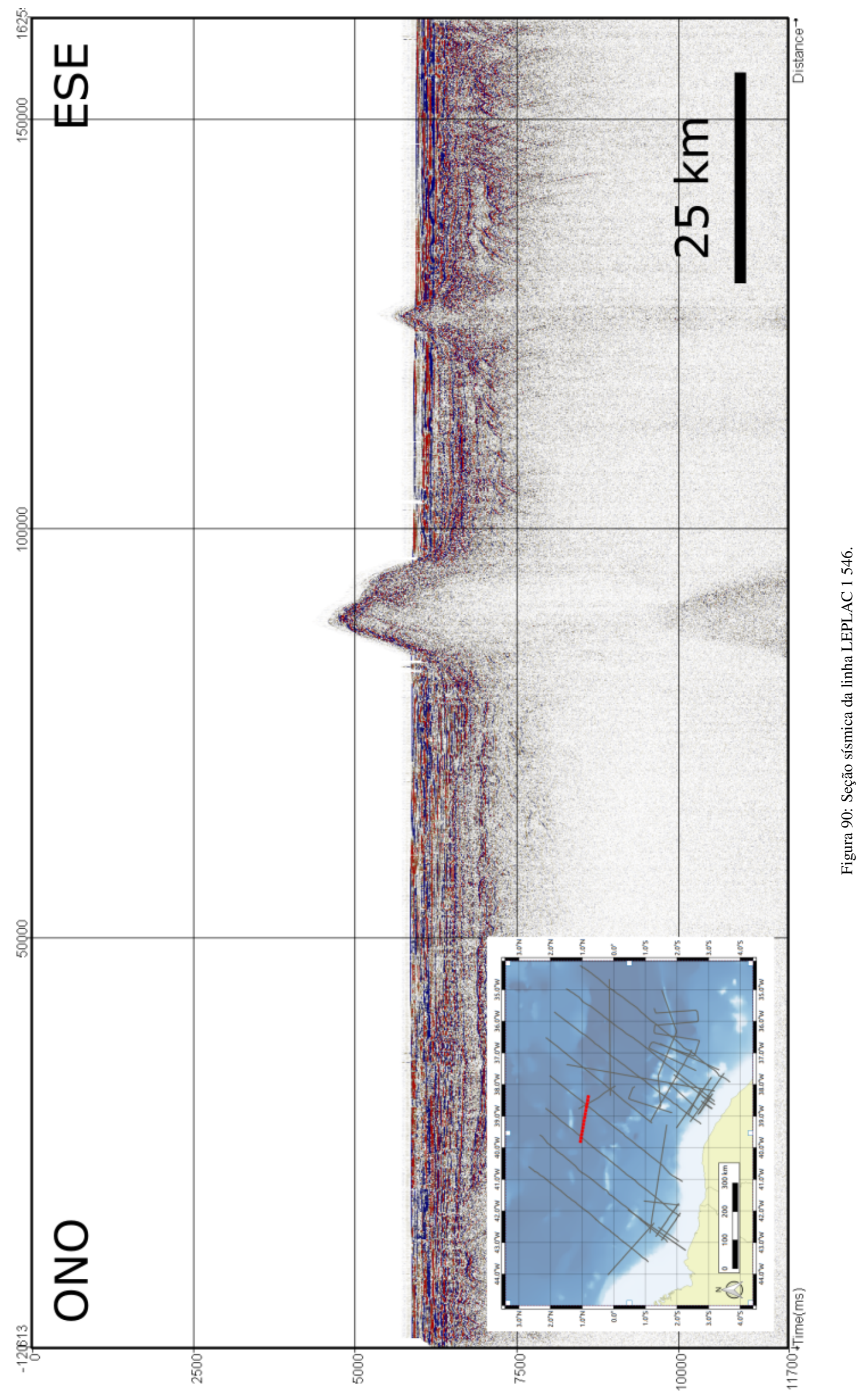




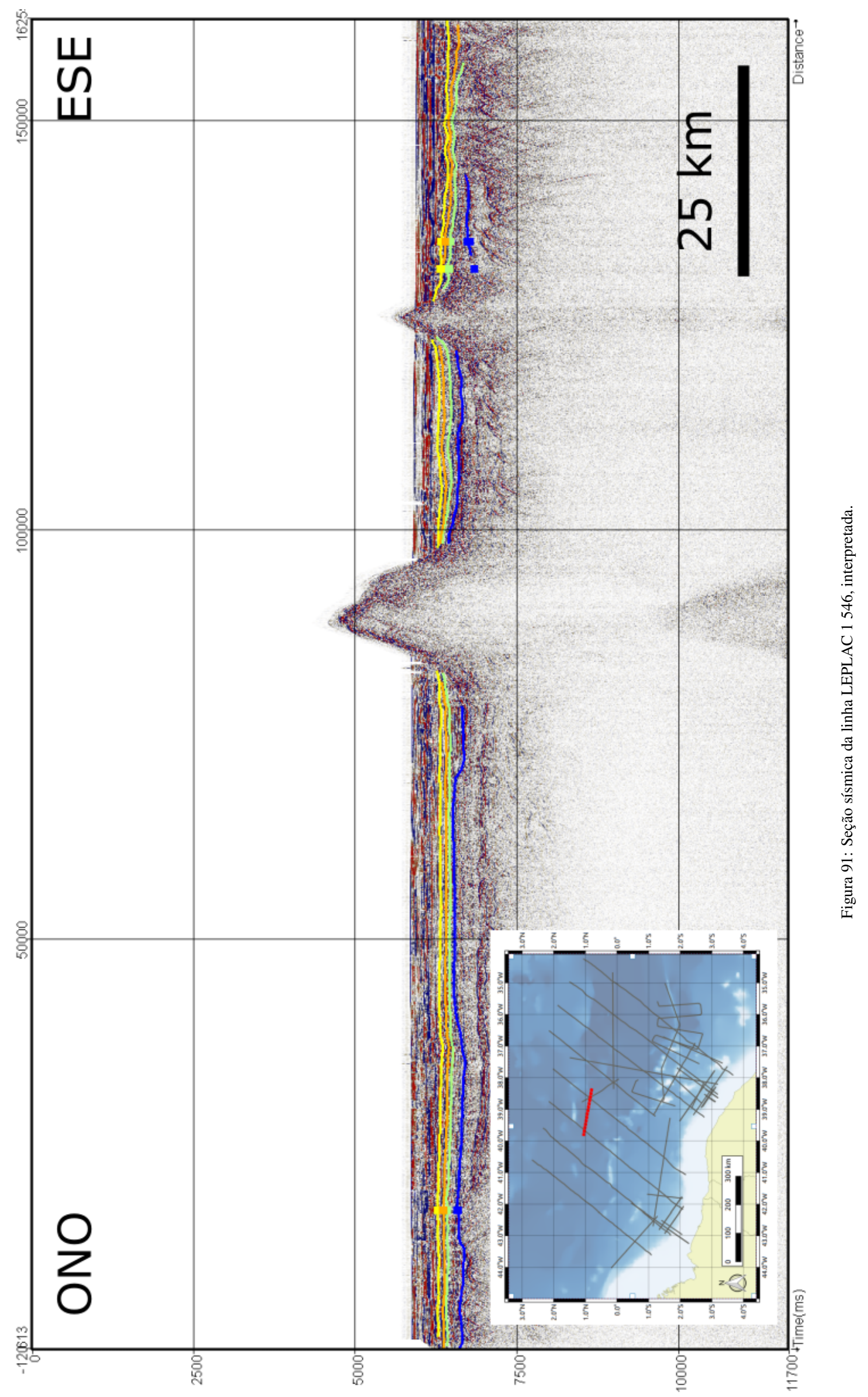




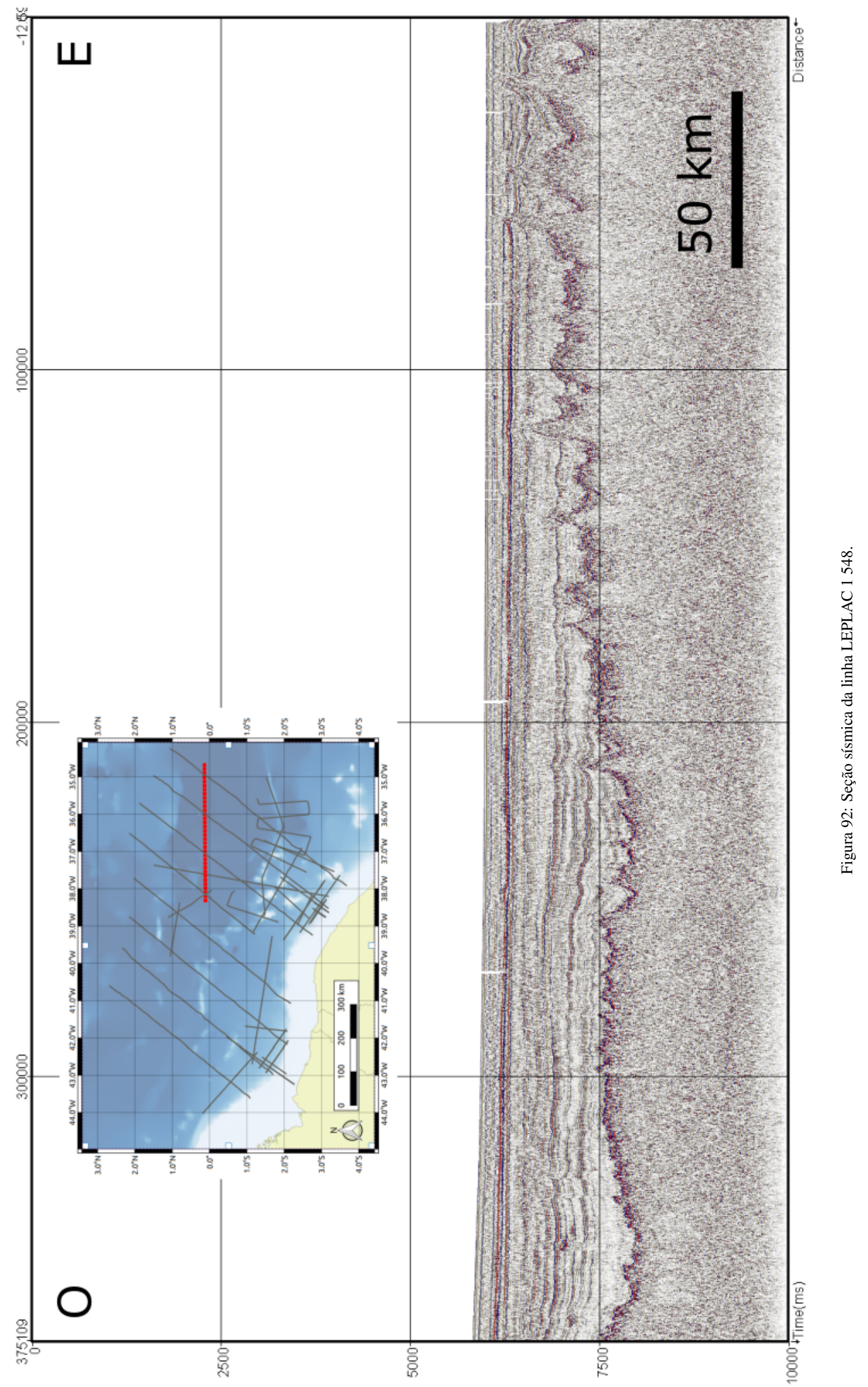




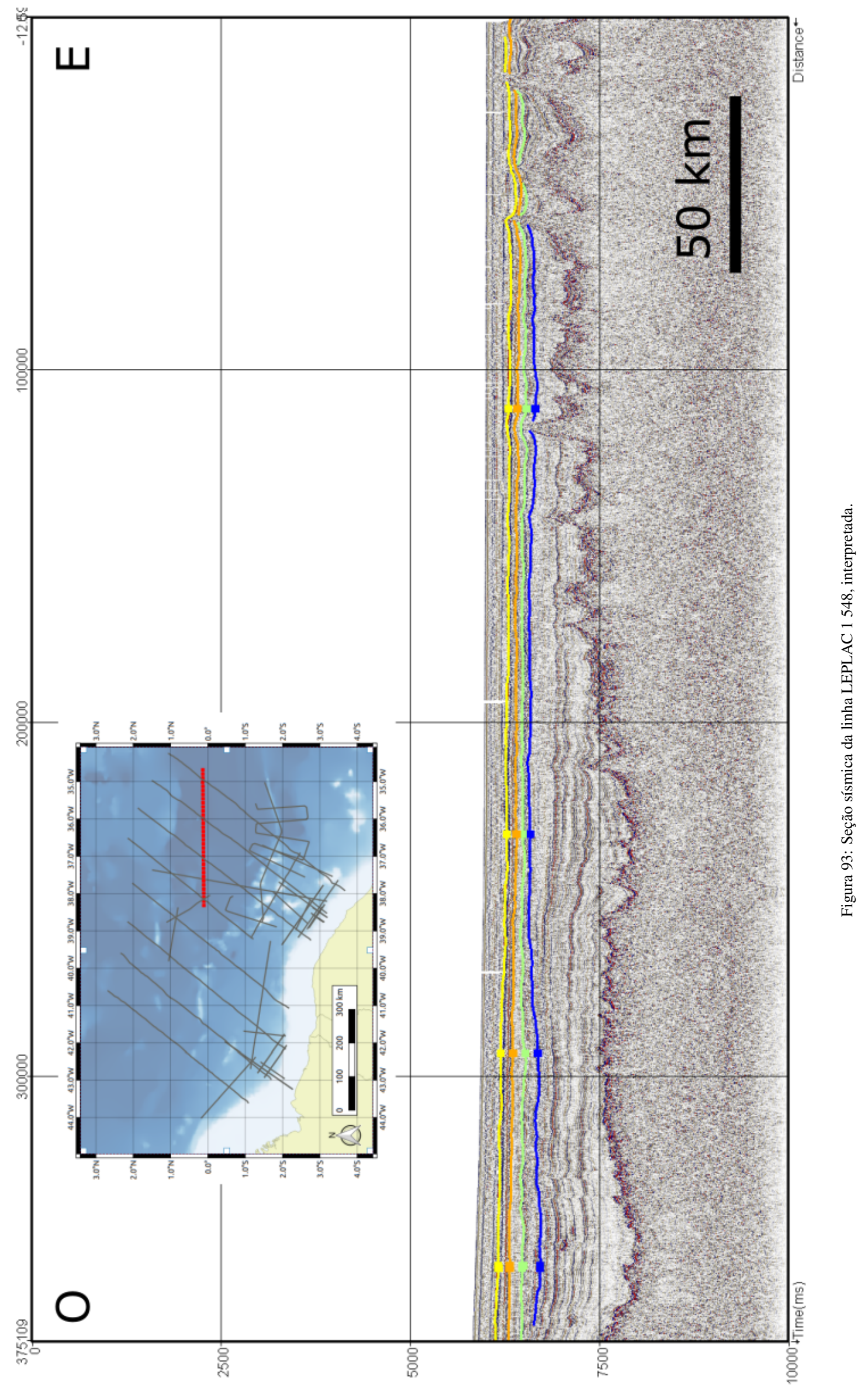




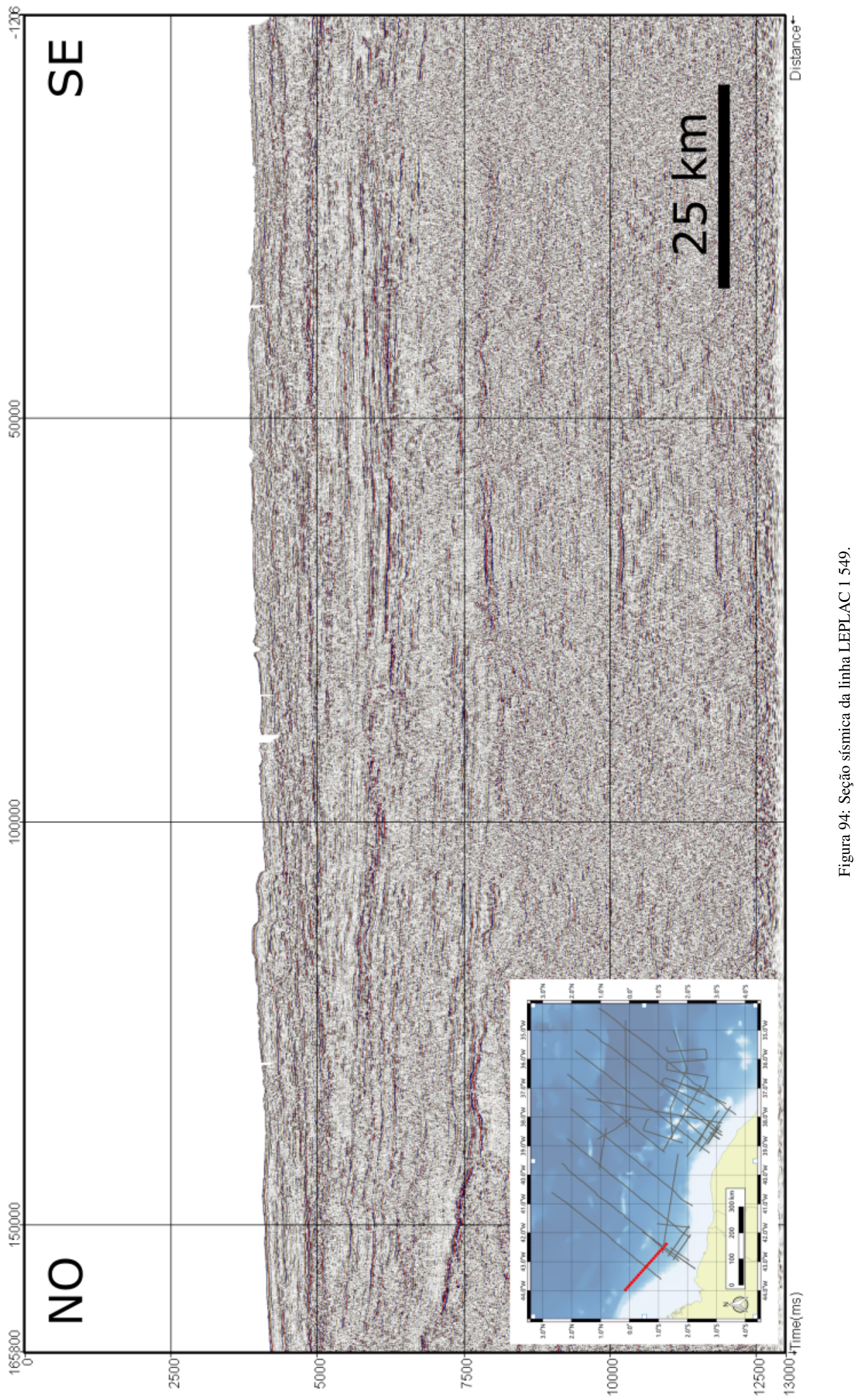




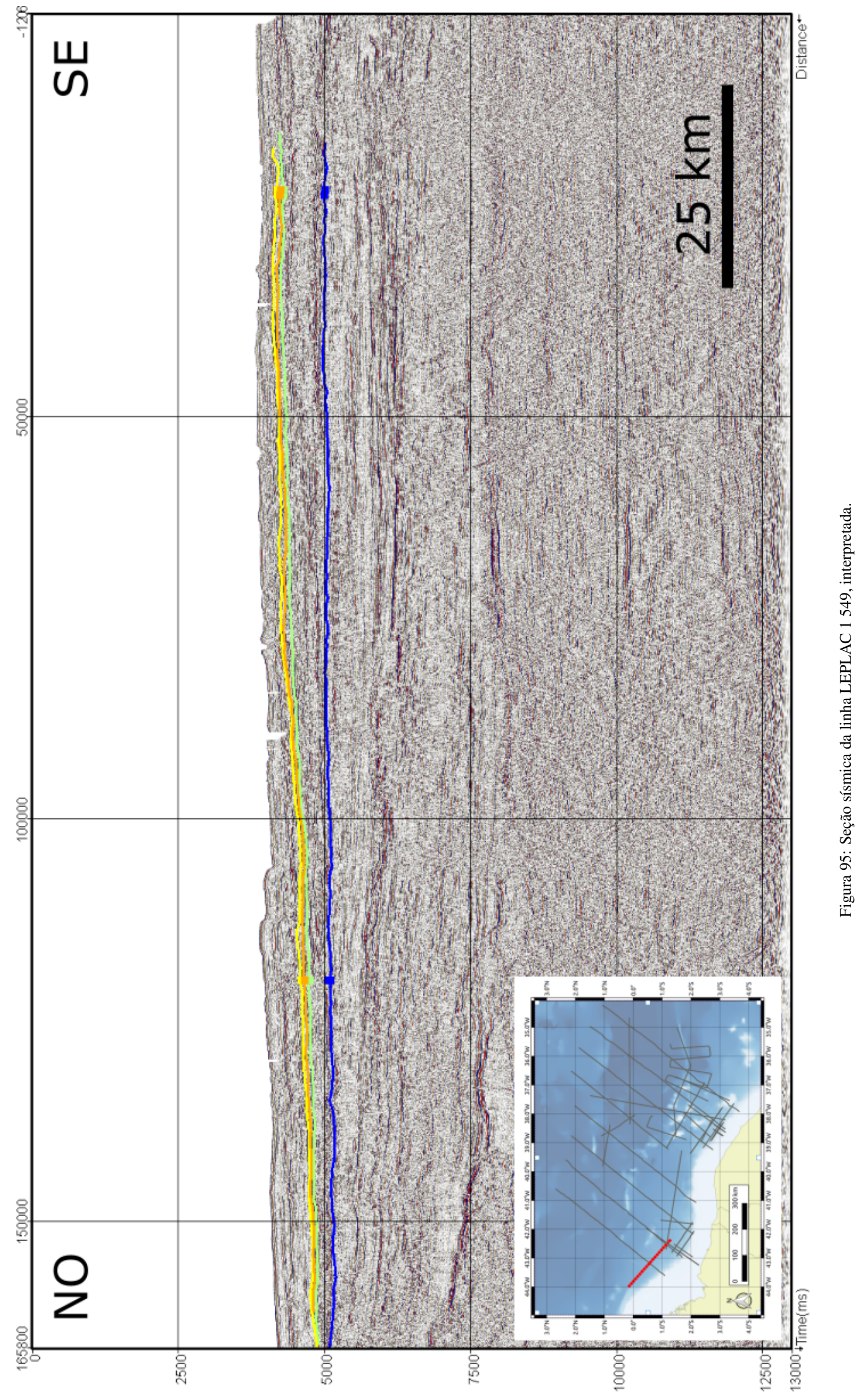




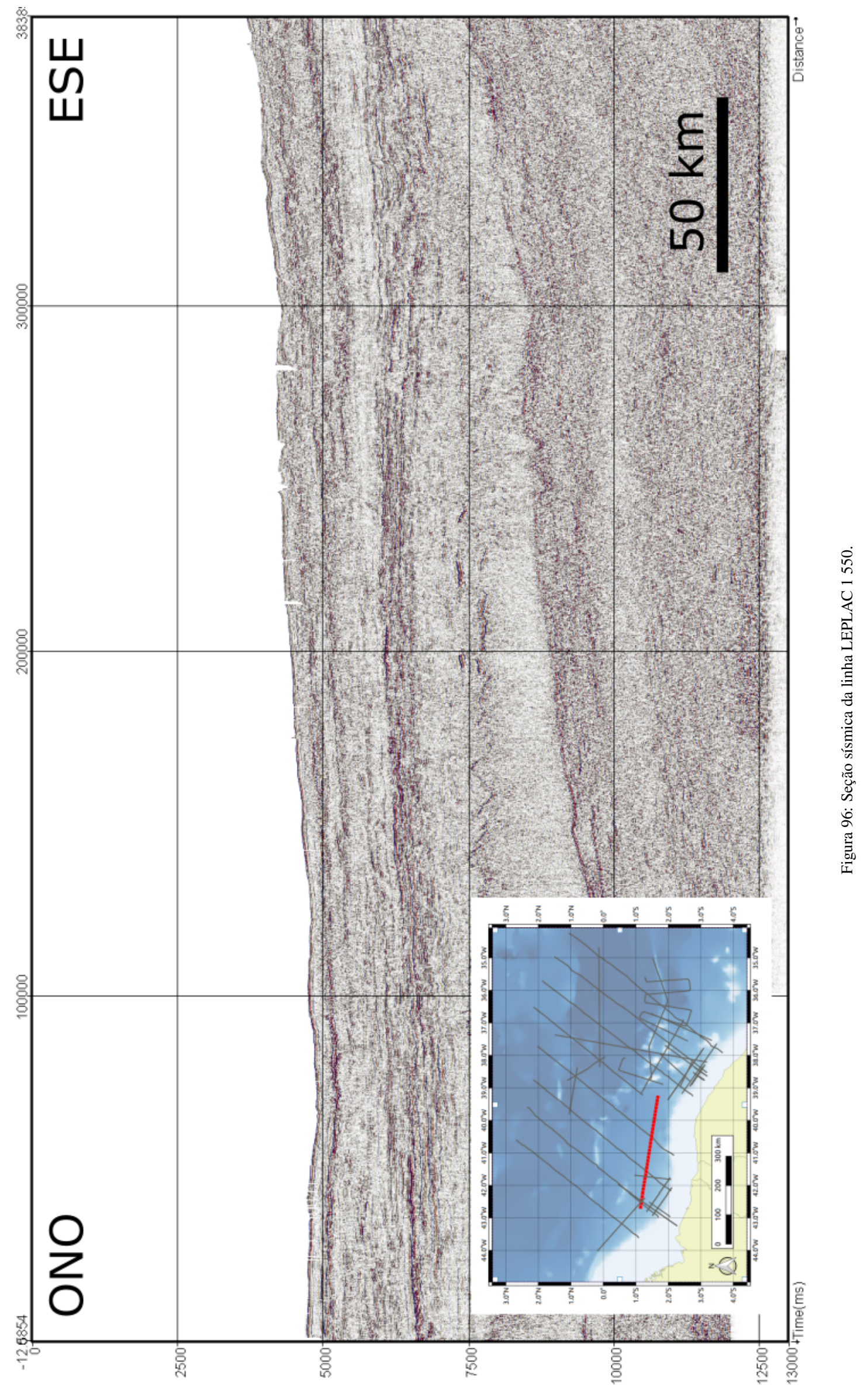




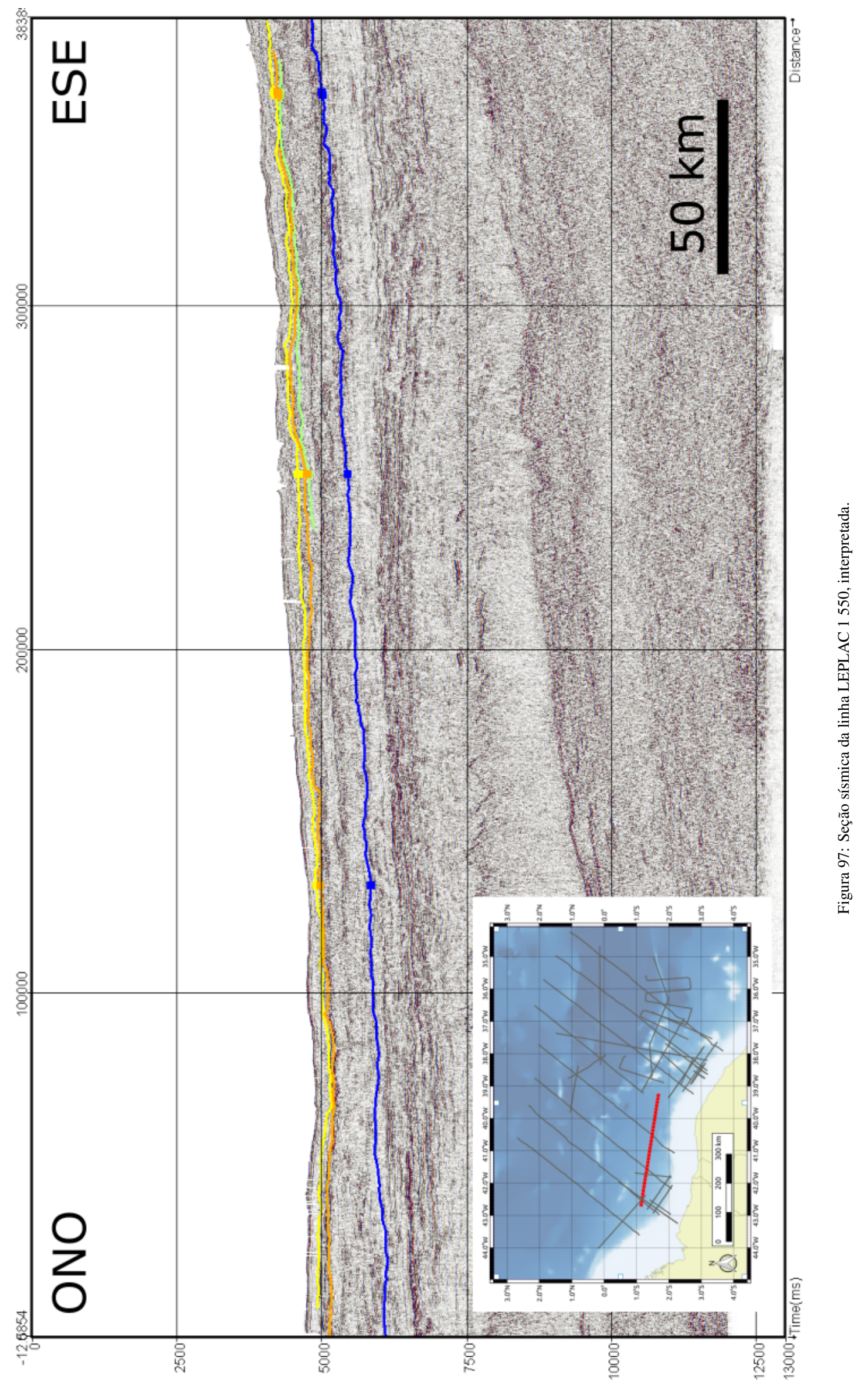




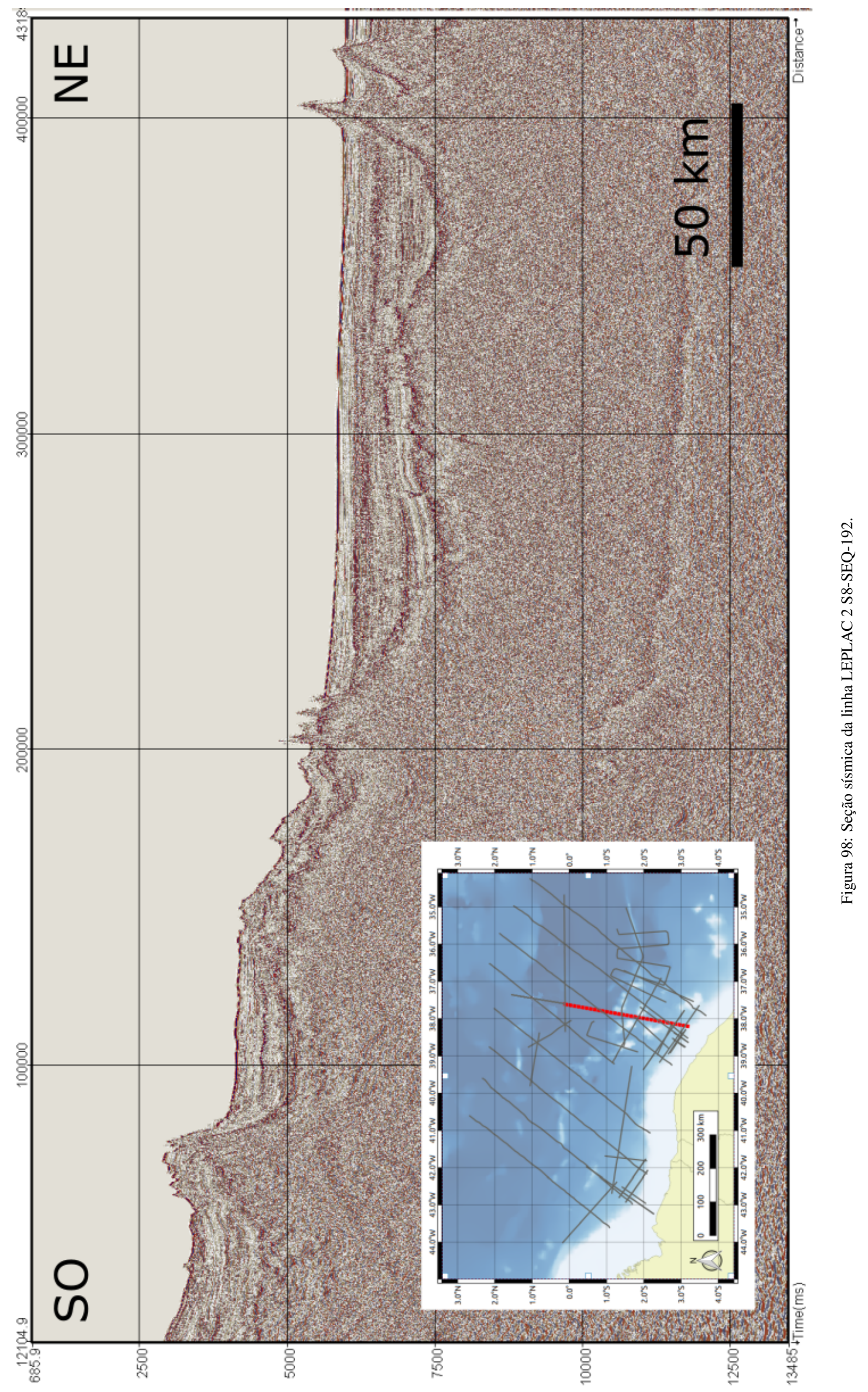




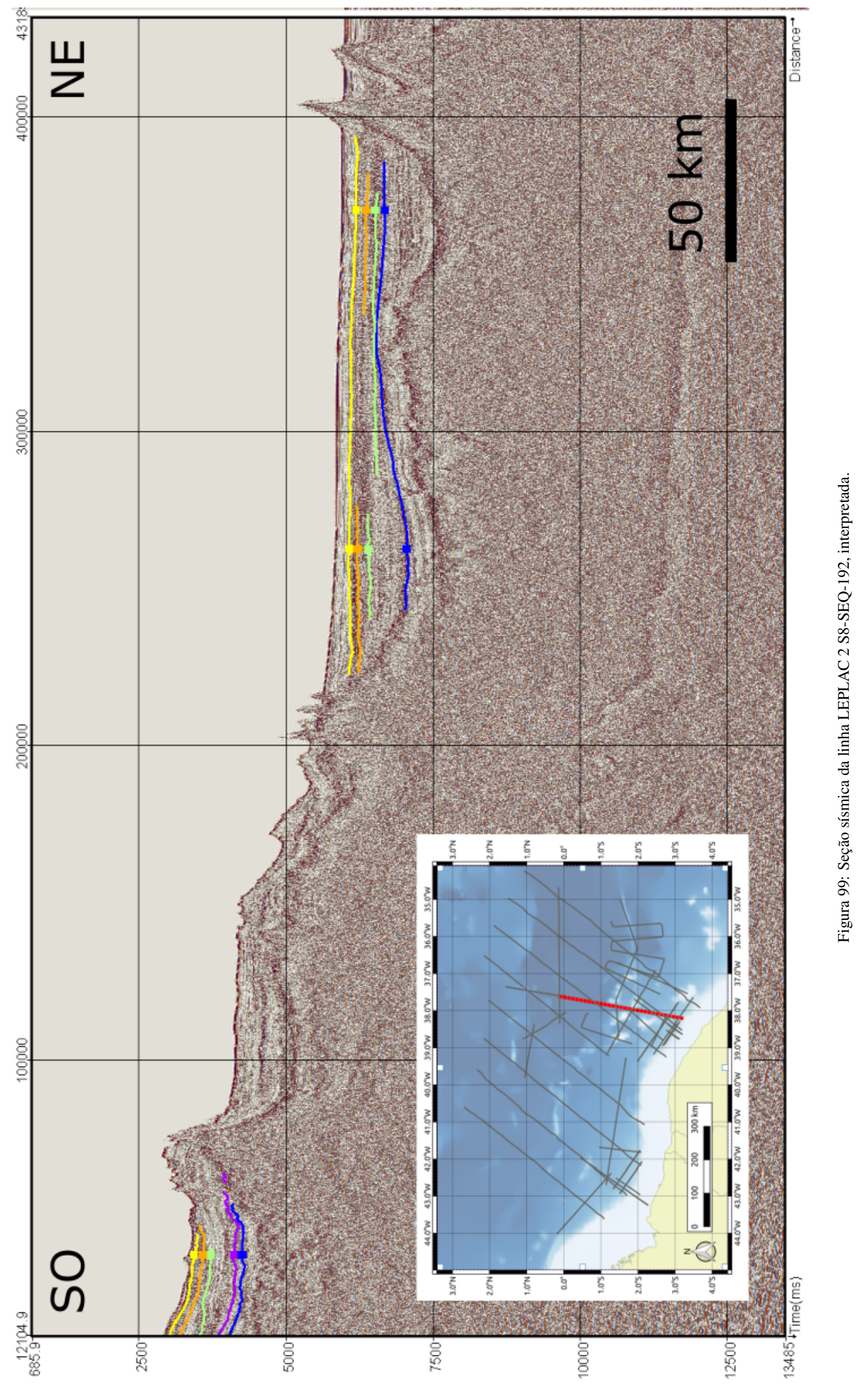

